\title{
RELIABILITY ANALYSIS OF TRUCK ESCAPE RAMP DESIGN
}

\author{
by \\ Kaitlyn Ann Greto, BASc, EIT \\ Bachelor of Applied Science, University of Toronto, 2015 \\ Toronto, Ontario, Canada
}

\author{
A Major Research Project \\ presented to Ryerson University \\ In partial fulfillment of the \\ requirements for the degree of \\ Master of Engineering \\ In the Program of \\ Civil Engineering
}

Toronto, Ontario, Canada, 2016

CKaitlyn Ann Greto 2016 


\section{Author's Declaration for Electronic Submission of a MRP}

I hereby declare that I am the sole author of this MRP. This is a true copy of the MRP, including any required final revisions.

I authorize Ryerson University to lend this MRP to other institutions or individuals for the purpose of scholarly research.

I further authorize Ryerson University to reproduce this MRP by photocopying or by other means, in total or in part, at the request of other institutions or individuals for the purpose of scholarly research.

I understand that my MRP may be made electronically available to the public. 


\section{Abstract}

Truck Escape Ramp Analysis

Master of Engineering, 2016

Kaitlyn Ann Greto

Yeates School of Graduate Studies, Civil Engineering

Ryerson University

The truck escape ramp design presented by the Transportation Association of Canada is based on deterministic values of the design variables which include the required stopping distance, design speed, rolling resistance, and grade. Currently, a reliability analysis of the design of truck escape ramps does not exist. This report presents two methods used to analyze the reliability of truck escape ramp design; the first order second moment reliability method and the advanced first order second moment reliability method. These methods do not rely on deterministic values rather the mean and variance (moments) of each random variable's probability distribution. Each reliability method was used to analyze truck escape ramps with one grade and two grades, for a total of four cases. The results of each case are provided and discussed along with an application to two existing truck escape ramps. The results show that the advanced first order second moment reliability method ensures more accurate results as well as a larger safety margin in comparison to the first order second moment method due to the nature of the methodology itself which considers design points. 


\section{Acknowledgements}

I would first and foremost like to thank my supervisor, Dr. Said Easa, for allowing me to work under his supervision and believing in my academic ability while providing the funding, guidance, and advice necessary to complete my major research project. I would like to thank Dr. Ali Mekky for taking the time to review my paper and provide positive feedback. I would also like to thank my family for their unending support and encouragement throughout my education and professional career. Without these participants, this accomplishment would not have been possible. 


\section{Table of Contents}

AUTHOR'S DECLARATION FOR ELECTRONIC SUBMISSION OF A MRP ...............................................II

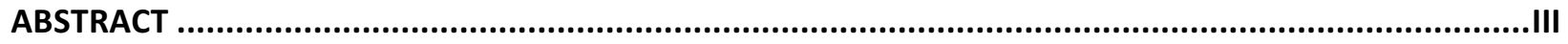

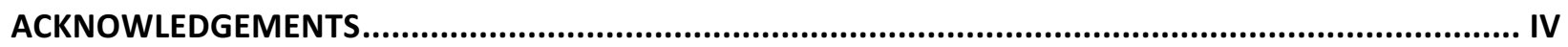

LIST OF TABLES

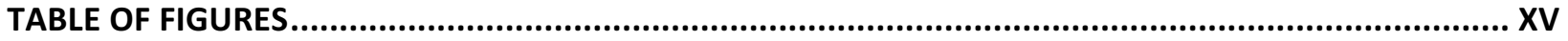

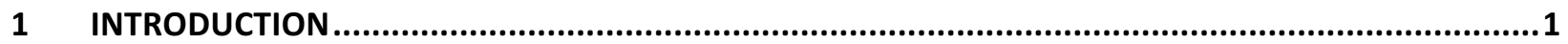

2 LITERATURE REVIEW - TRUCK ESCAPE RAMPS \& DESIGN …...................................................5

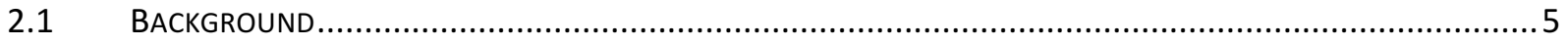

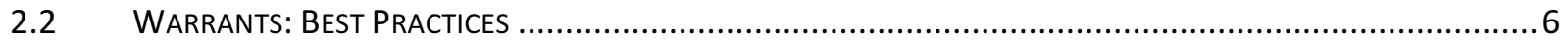

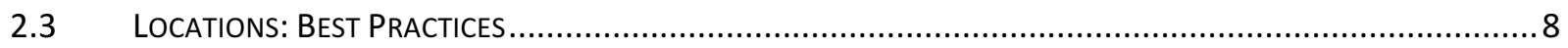

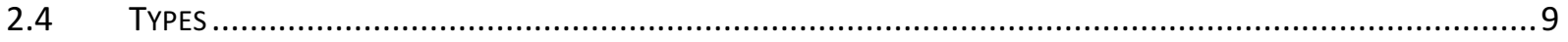

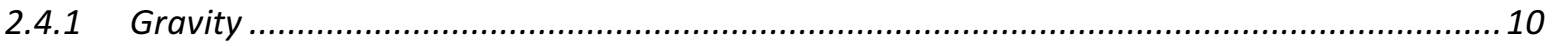

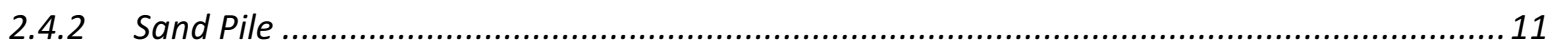

2.4.3 Arrestor Bed - Horizontal Grade, Descending Grade, Ascending Grade.............................11

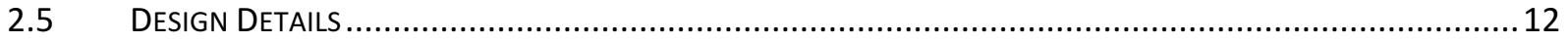

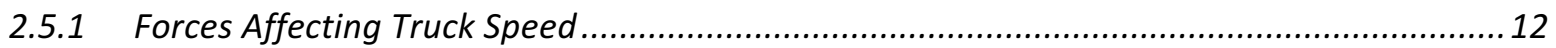

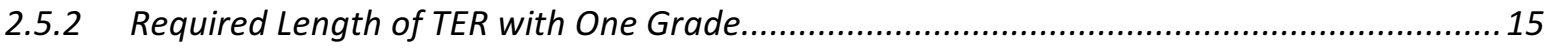

2.5.3 Required Length of TER with More Than One Grade .................................................... 16

2.5.4 If the Required Length of TER is Not Feasible .................................................................... 17

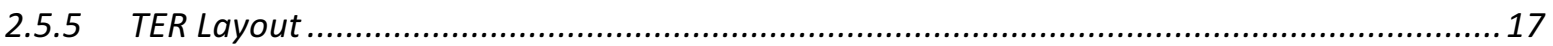

2.5.6 TER Arrestor Bed Details \& Design Elements ............................................................. 19

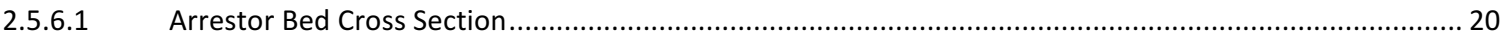

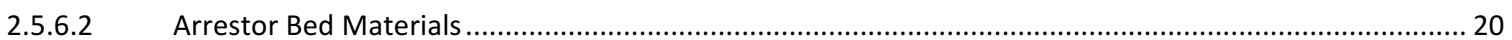




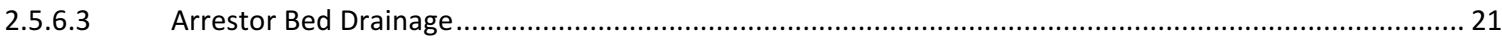

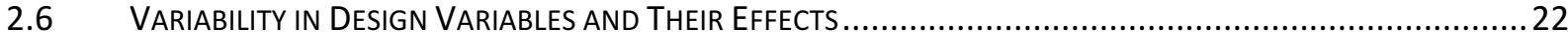

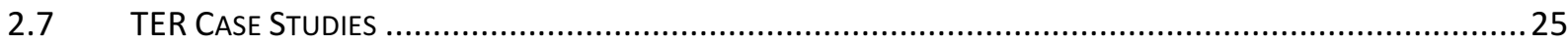

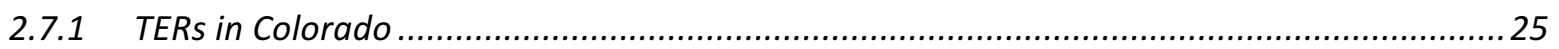

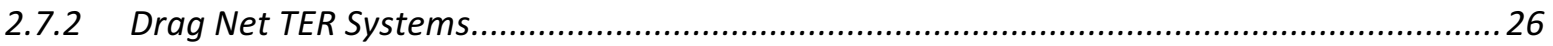

3 LITERATURE REVIEW - RELIABILITY MODELS ...........................................................30

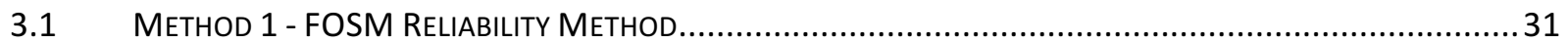

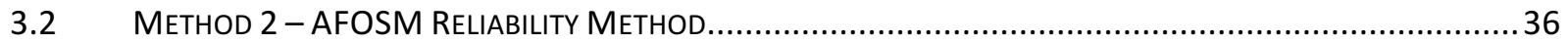

4 DEVELOPMENT OF RELIABILITY MODELS FOR TERS.....................................................

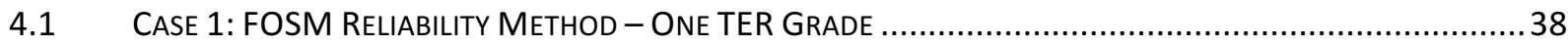

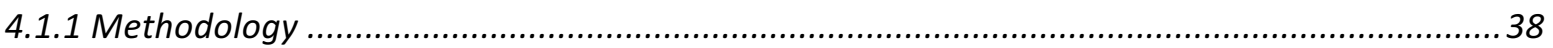

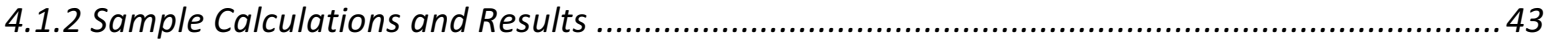

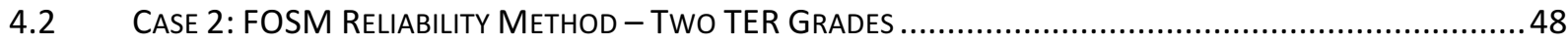

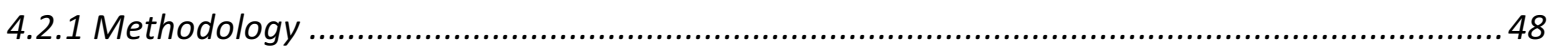

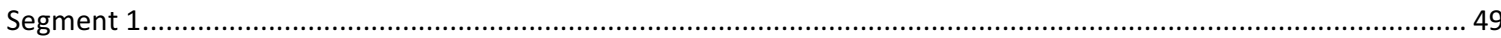

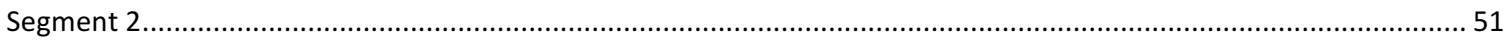

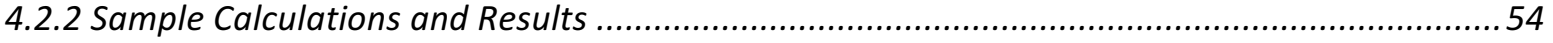

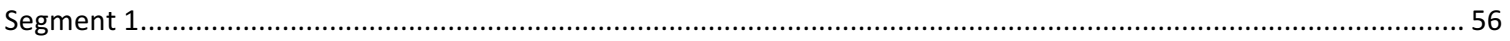

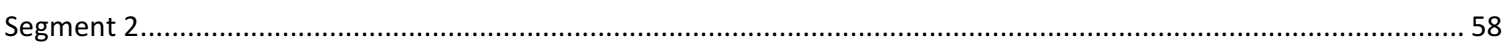

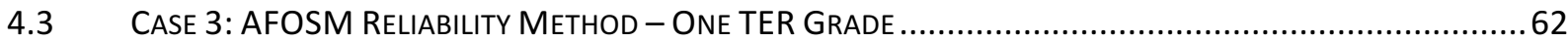

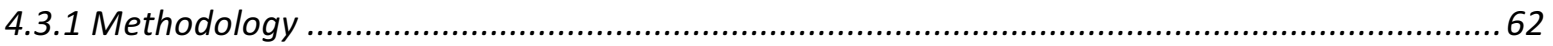

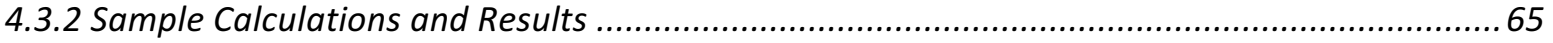

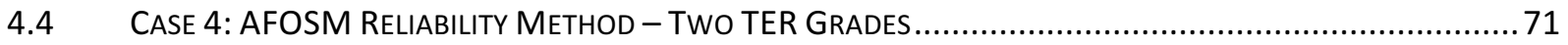

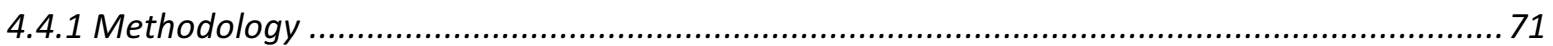

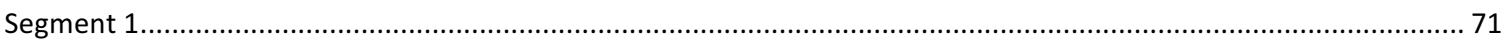


Segment 2 .

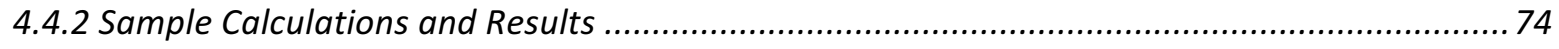

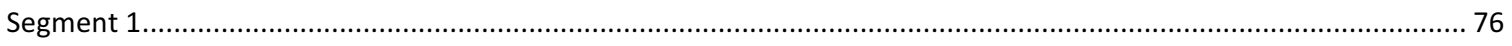

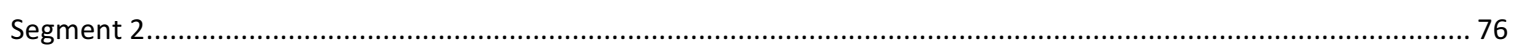

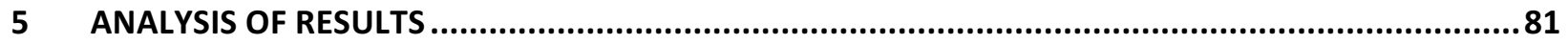

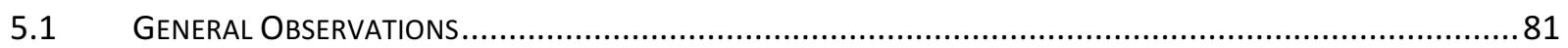

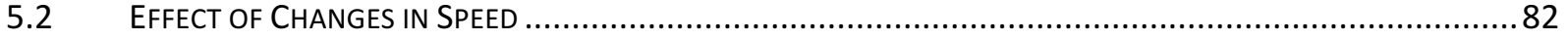

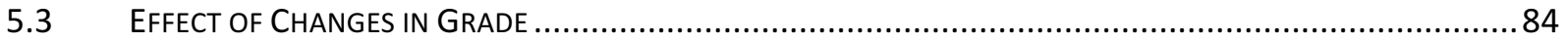

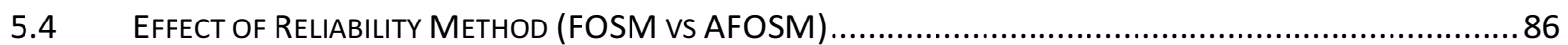

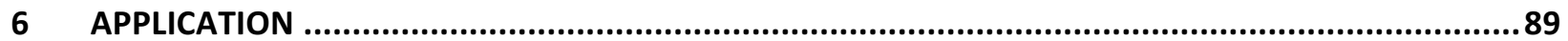

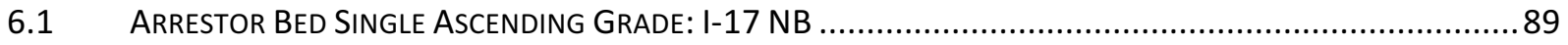

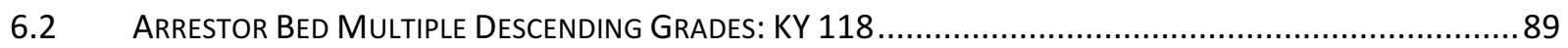

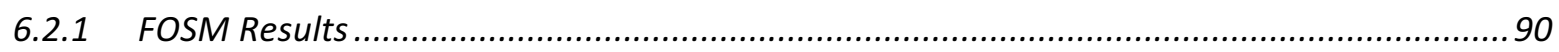

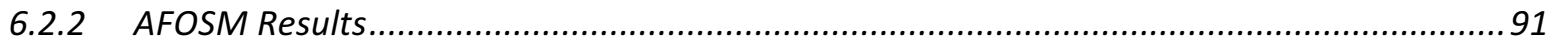

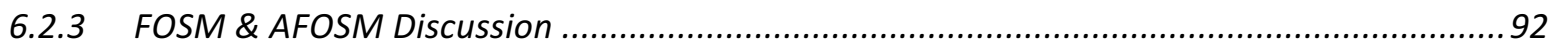

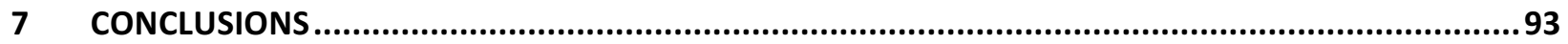

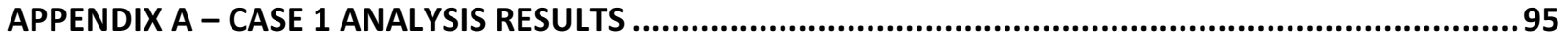

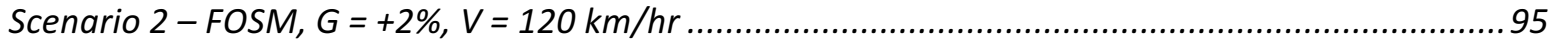

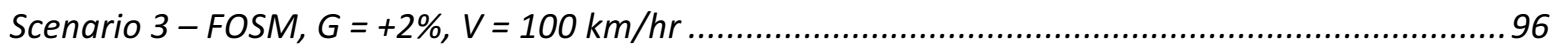

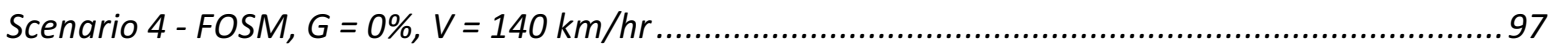

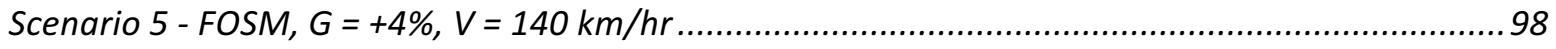

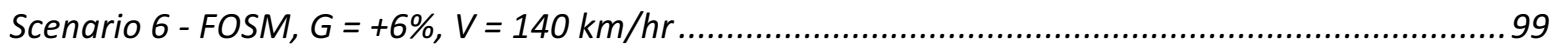

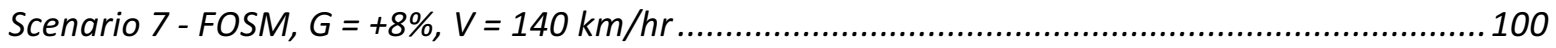

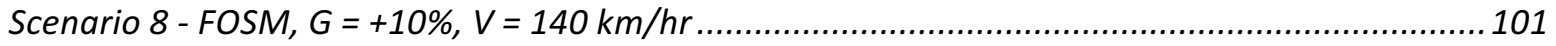


Scenario 9 - FOSM, G $=-2 \%, V=140 \mathrm{~km} / \mathrm{hr}$ 102

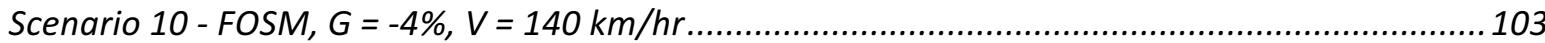

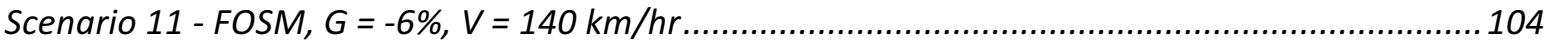

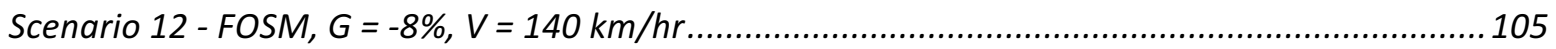

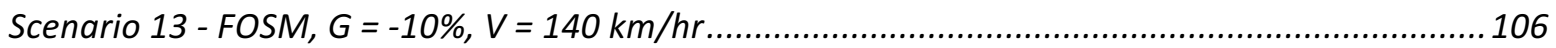

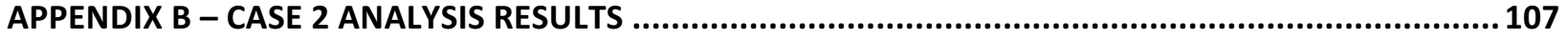

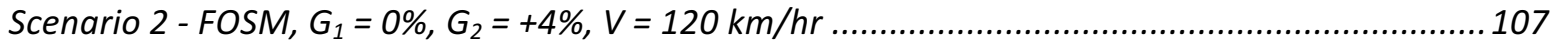

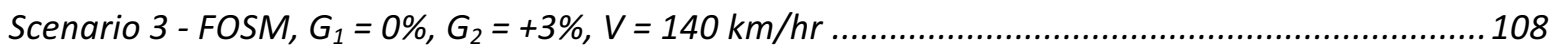

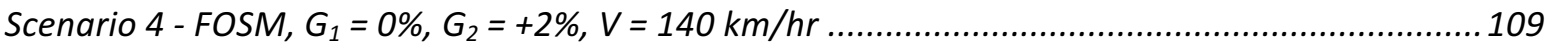

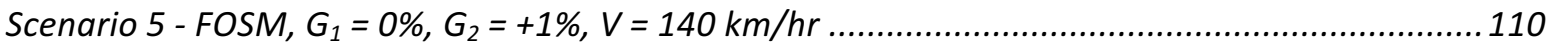

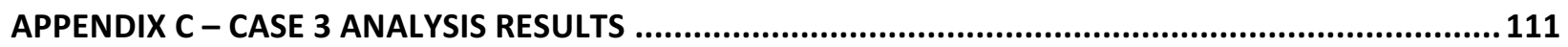

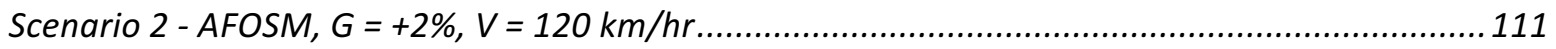

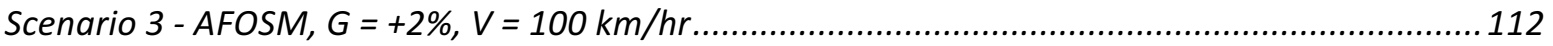

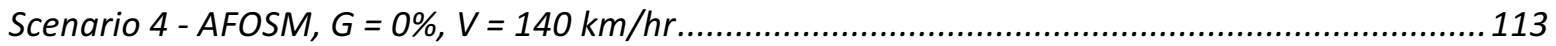

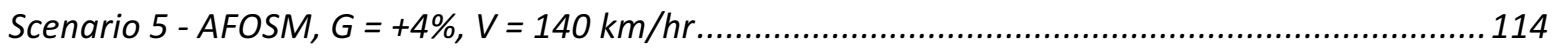

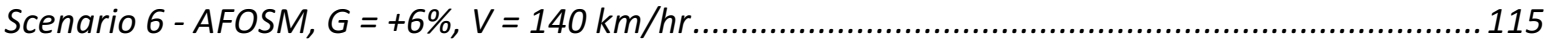

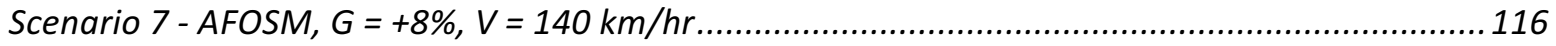

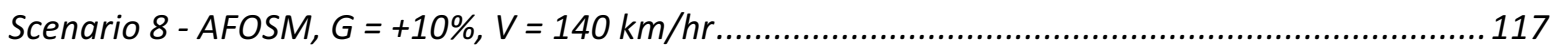

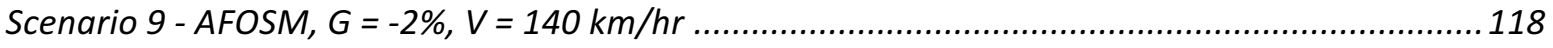

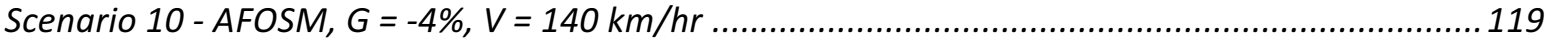

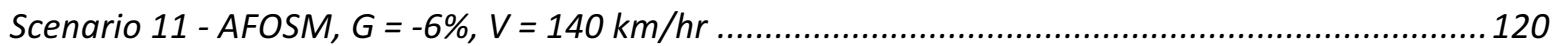

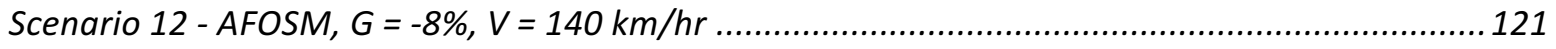

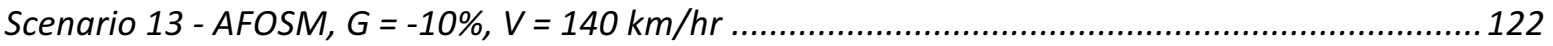

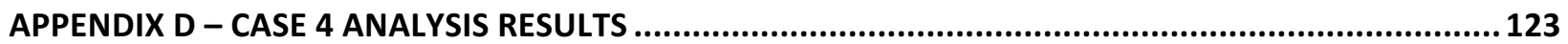


Scenario 2 - AFOSM, $G_{1}=0 \%, G_{2}=+4 \%, V=120 \mathrm{~km} / \mathrm{hr}$.....

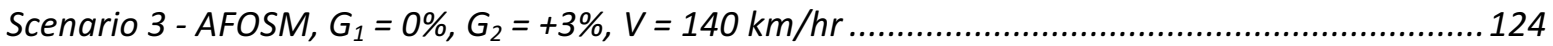

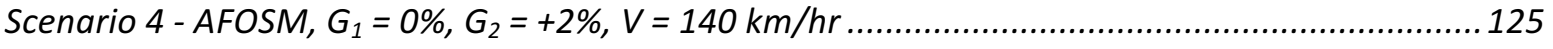

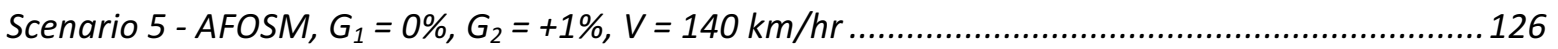

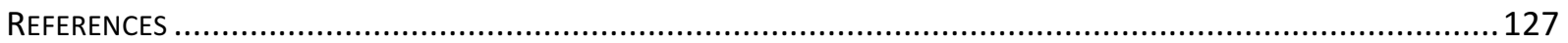




\section{List of Tables}

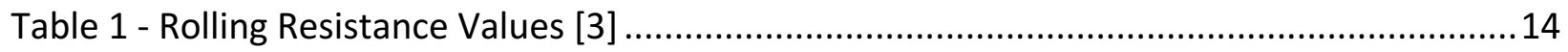

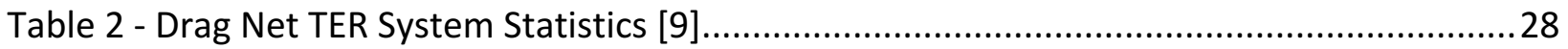

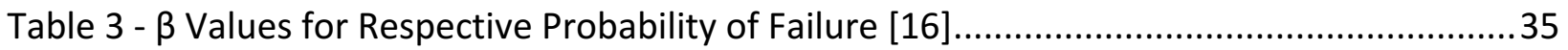

Table 4 - $\beta$ Values for Respective Probability of Failure [16] ............................................... 42

Table 5 - Selected Mean Values for Each Random Variable .................................................44

Table 6 - Calculated Standard Deviation for each Random Variable at Varying CV Values.........45

Table 7-Calculated Variance of SM and Standard Deviation of SM at Varying CV Values .........46

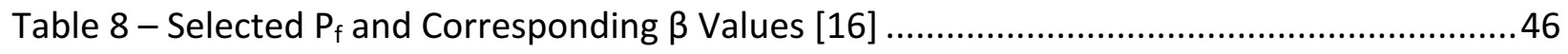

Table $9-\mathrm{L}_{\text {supply }}$ Values at Corresponding $\mathrm{P}_{\mathrm{f}}$ and CV Values..............................................47

Table 10 - Selected Mean Values for Each Random Variable ................................................56

Table 11 - Calculated Standard Deviation for each Random Variable at Varying CV Values.......56

Table 12 - Calculated Variance of $\mathrm{V}_{2}$ and Standard Deviation of $\mathrm{V}_{2}$ at Varying CV Values ..........57

Table 13 - Selected Mean Values for Each Random Variable .............................................58

Table 14 - Calculated Standard Deviation for each Random Variable at Varying CV Values.......59

Table 15 - Calculated Variance of SM and Standard Deviation of SM at Varying CV Values.......60 
Table 16 - Selected $P_{f}$ and Corresponding $\beta$ Values $[16]$

Table $17-L_{\text {supply }}$ Values at Corresponding $P_{f}$ and CV Values......

Table 18 - $\beta$ Values for Respective Probability of Failure [16] 65

Table 19 - Selected Mean Values for Each Random Variable .67

Table 20 - Calculated Standard Deviation for each Random Variable at Varying CV Values.......67

Table 21 - Case 3 Iterations for Estimated $\mathrm{L}_{\text {supply }}=350 \mathrm{~m}$

Table 22 - $\beta$ Values for Respective Probability of Failure [16] 69

Table 23 - Case 3 Iterations for Estimated $L_{\text {supply }}$ Using Excel Solver 70

Table $24-L_{\text {supply }}$ Values at Corresponding $\mathrm{P}_{\mathrm{f}}$ and $\mathrm{CV}$ Values 70

Table 25 - Calculated Variance of $\mathrm{V}_{2}$ and Standard Deviation of $\mathrm{V}_{2}$ at Varying CV Values 76

Table 26 - Selected Mean Values for Each Random Variable .76

Table 27 - Calculated Standard Deviation for each Random Variable at Varying CV Values.......77

Table 28 - Case 4 Iterations for Estimated $L_{\text {supply }}=300 \mathrm{~m}$ 79

Table 29 - $\beta$ Values for Respective Probability of Failure [16] 79

Table 30 - Case 3 Iterations for Estimated $L_{\text {supply }}$ Using Excel Solver........ 79

Table $31-L_{\text {supply }}$ Values at Corresponding $P_{f}$ and CV Values..... 80 
Table $32-L_{\text {supply }}$ Values at Corresponding $P_{f}$ and CV Values

Table 33 - $L_{\text {supply }}$ Values at Corresponding $P_{f}$ and CV Values

Table $34-L_{\text {supply }}$ Values at Corresponding $P_{f}$ and CV Values 95

Table $35-L_{\text {supply }}$ Values at Corresponding $P_{f}$ and CV Values .96

Table $36-L_{\text {supply }}$ Values at Corresponding $P_{f}$ and CV Values .97

Table $37-L_{\text {supply }}$ Values at Corresponding $P_{f}$ and CV Values........ 98

Table $38-L_{\text {supply }}$ Values at Corresponding $P_{f}$ and CV Values .99

Table $39-L_{\text {supply }}$ Values at Corresponding $P_{f}$ and CV Values 100

Table $40-L_{\text {supply }}$ Values at Corresponding $P_{f}$ and CV Values 101

Table $41-L_{\text {supply }}$ Values at Corresponding $P_{f}$ and CV Values. 102

Table $42-L_{\text {supply }}$ Values at Corresponding $P_{f}$ and CV Values........ 103

Table $43-L_{\text {supply }}$ Values at Corresponding $P_{f}$ and CV Values .104

Table $44-L_{\text {supply }}$ Values at Corresponding $P_{f}$ and CV Values 105

Table $45-L_{\text {supply }}$ Values at Corresponding $P_{f}$ and CV Values 106

Table $46-L_{\text {supply }}$ Values at Corresponding $P_{f}$ and CV Values......... .107

Table $47-L_{\text {supply }}$ Values at Corresponding $P_{f}$ and CV Values 108 
Table $48-L_{\text {supply }}$ Values at Corresponding $P_{f}$ and CV Values 109

Table $49-L_{\text {supply }}$ Values at Corresponding $P_{f}$ and CV Values 110

Table $50-L_{\text {supply }}$ Values at Corresponding $P_{f}$ and CV Values

Table $51-L_{\text {supply }}$ Values at Corresponding $P_{f}$ and CV Values

Table $52-L_{\text {supply }}$ Values at Corresponding $P_{f}$ and CV Values

Table 53 - $L_{\text {supply }}$ Values at Corresponding $P_{f}$ and CV Values

Table $54-L_{\text {supply }}$ Values at Corresponding $P_{f}$ and CV Values .115

Table $55-L_{\text {supply }}$ Values at Corresponding $P_{f}$ and CV Values

Table $56-L_{\text {supply }}$ Values at Corresponding $P_{f}$ and CV Values

Table $57-L_{\text {supply }}$ Values at Corresponding $P_{f}$ and CV Values

Table $58-L_{\text {supply }}$ Values at Corresponding $P_{f}$ and CV Values 119

Table $59-L_{\text {supply }}$ Values at Corresponding $P_{f}$ and CV Values

Table $60-L_{\text {supply }}$ Values at Corresponding $P_{f}$ and CV Values

Table 61 - $L_{\text {supply }}$ Values at Corresponding $P_{f}$ and CV Values 122

Table $62-L_{\text {supply }}$ Values at Corresponding $P_{f}$ and CV Values.........

Table $63-L_{\text {supply }}$ Values at Corresponding $P_{f}$ and CV Values 124 
Table $64-L_{\text {supply }}$ Values at Corresponding $P_{f}$ and CV Values............................................ 125

Table $65-L_{\text {supply }}$ Values at Corresponding $P_{f}$ and CV Values...........................................126 


\section{Table of Figures}

Figure 1 - Truck Escape Ramp Located on US Route 44 Westbound in Avon, Connecticut (Credit: Connecticut Department of Transportation) [2] 5

Figure 2 - Truck Escape Ramp Used by Runaway Truck (Credit: Transportation Research Board) [4] 6

Figure 3 - Basic Truck Escape Ramp Design Categories (Reproduced with the express written authority of the Transportation Association of Canada (TAC). Excerpted from the TAC publication: Geometric Design Guide for Canadian Roads (1999)) [3].... 10

Figure 4 - Tractive Resistance Forces as Illustrated on a Truck in Motion (Reproduced with the express written authority of the Transportation Association of Canada (TAC). Excerpted from the TAC publication: Geometric Design Guide for Canadian Roads (1999)) [3].....

Figure 5 - Visual of TER with One Positive Grade, $G_{i}$ 15

Figure 6 - Visual of TER with Two Positive Grades, $G_{i}$ and $G_{i+1}$ 17

Figure 7 - Typical TER Layout (Reproduced with the express written authority of the Transportation Association of Canada (TAC). Excerpted from the TAC publication: Geometric Design Guide for Canadian Roads (1999)) [3] 17

Figure 8 - TER Should Leave Through Roadway at the Smallest Angle Possible (Credit: Transportation Research Board) [4] 18 
Figure 9 - Example of TER Which Can Accommodate More than One Runaway Vehicle (Credit: Transportation Research Board) [4]. 19

Figure 10 - Typical TER Cross Section (Reproduced with the express written authority of the Transportation Association of Canada (TAC). Excerpted from the TAC publication: Geometric Design Guide for Canadian Roads (1999)) [3] 20

Figure 11 - Runaway Truck Entering TER (Credit: ADOT) [7] 22

Figure 12 - Runaway Truck Displacing Arrestor Bed Aggregate (Credit: ADOT) [7] ..... .22

Figure 13 - Ranges of Maximum Runaway Vehicle Stopping Distances at Four Arrestor Bed TER Locations Tested in Arizona (Credit: ADOT) [7] 24

Figure 14 - Visual of Drag Net TER Design (Credit: WYDOT) [9]. 27

Figure 15 - Visual of Runaway Truck Using Drag Net TER Design (Credit: WYDOT) [9] 27

Figure 16 - Ontario's Highway 11 Drag Net TER (Credit: MTO) [6]. 29

Figure 17 - TER Length Failure Region .34

Figure 18 - Reliability Index and Probability of Failure [13] 34

Figure 19 - FOSM Visual Representation of $L_{\text {supply }}$ for a TER using $G=+2 \%, V=140 \mathrm{~km} / \mathrm{hr}$, and $R$ $=0.25 \mathrm{~kg} / \mathrm{kgGVM}$ 48

Figure 20 - Visual of TER Split into Segment 1 and Segment 2. 48 
Figure 21 - FOSM Visual Representation of $L_{\text {supply }}$ for a TER using $G_{1}=0 \%, G_{2}=+4 \%, V=140$ $\mathrm{km} / \mathrm{hr}$, and $\mathrm{R}=0.25 \mathrm{~kg} / \mathrm{kgGVM}$ 61

Figure 22 - AFOSM Visual Representation of $L_{\text {supply }}$ for a TER using $G=+2 \%, V=140 \mathrm{~km} / \mathrm{hr}$, and $\mathrm{R}=0.25 \mathrm{~kg} / \mathrm{kgGVM}$ 71

Figure 23 - AFOSM Visual Representation of $L_{\text {supply }}$ for a TER using $G_{1}=0 \%, G_{2}=+4 \%, V=140$ $\mathrm{km} / \mathrm{hr}$, and $\mathrm{R}=0.25 \mathrm{~kg} / \mathrm{kgGVM}$ 80

Figure 24 - Effect of Varying Vehicle Speed on TER $L_{\text {supply }}$ (using $G_{1}=+2 \%, R=0.25 \mathrm{~kg} / \mathrm{kgGVM}$ ) 83

Figure 25 - Effect of Varying Grade on TER $L_{\text {supply }}$ (using V $=140 \mathrm{~km} / \mathrm{hr}, \mathrm{R}=0.25 \mathrm{~kg} / \mathrm{kgGVM}$ ) ....85

Figure 26 - Effect of Varying Reliability Method on TER $L_{\text {supply }}$ for One TER Grade (using Case 1 FOSM Reliability Method vs Case 3 AFOSM Reliability Method; G = +2\%, V = $140 \mathrm{~km} / \mathrm{hr}, \mathrm{R}=$ $0.25 \mathrm{~kg} / \mathrm{kgGVM})$ 87

Figure 27 - Effect of Varying Reliability Method on TER $L_{\text {supply }}$ for Two TER Grades (using Case 2 FOSM Reliability Method vs Case 4 AFOSM Reliability Method; $\mathrm{G}_{1}=0 \%, \mathrm{G}_{2}=+4 \%, \mathrm{~V}=140$ $\mathrm{km} / \mathrm{hr}, \mathrm{R}=0.25 \mathrm{~kg} / \mathrm{kgGVM})$ 88

Figure 28 - Visual Representation of $L_{\text {supply }}$ for a TER using $G_{1}=-8 \%, G_{2}=-4 \%, V=140 \mathrm{~km} / \mathrm{hr}$, and $\mathrm{R}=0.25 \mathrm{~kg} / \mathrm{kgGVM}$ 91

Figure 29 - Visual Representation of $L_{\text {supply }}$ for a TER using $G_{1}=-8 \%, G_{2}=-4 \%, V=140 \mathrm{~km} / \mathrm{hr}$, and $\mathrm{R}=0.25 \mathrm{~kg} / \mathrm{kgGVM}$ 92 
Figure 30 - FOSM Visual Representation of $L_{\text {supply }}$ for a TER using $G=+2 \%, V=120 \mathrm{~km} / \mathrm{hr}$, and R $=0.25 \mathrm{~kg} / \mathrm{kgGVM}$

Figure 31 - FOSM Visual Representation of $L_{\text {supply }}$ for a TER using $G=+2 \%, V=100 \mathrm{~km} / \mathrm{hr}$, and $R$ $=0.25 \mathrm{~kg} / \mathrm{kgGVM}$ 96

Figure 32 - FOSM Visual Representation of $L_{\text {supply }}$ for a TER using $G=0 \%, V=140 \mathrm{~km} / \mathrm{hr}$, and $R=$ $0.25 \mathrm{~kg} / \mathrm{kgGVM}$ 97

Figure 33 - FOSM Visual Representation of $L_{\text {supply }}$ for a TER using $G=+4 \%, V=140 \mathrm{~km} / \mathrm{hr}$, and $R$ $=0.25 \mathrm{~kg} / \mathrm{kgGVM}$ 98

Figure 34 - FOSM Visual Representation of $L_{\text {supply }}$ for a TER using $G=+6 \%, V=140 \mathrm{~km} / \mathrm{hr}$, and R $=0.25 \mathrm{~kg} / \mathrm{kgGVM}$ 99

Figure 35 - FOSM Visual Representation of $L_{\text {supply }}$ for a TER using $G=+8 \%, V=140 \mathrm{~km} / \mathrm{hr}$, and R $=0.25 \mathrm{~kg} / \mathrm{kgGVM}$ 100

Figure 36 - FOSM Visual Representation of $L_{\text {supply }}$ for a TER using $G=+10 \%, V=140 \mathrm{~km} / \mathrm{hr}$, and R $=0.25 \mathrm{~kg} / \mathrm{kgGVM}$ 101

Figure 37 - FOSM Visual Representation of $L_{\text {supply }}$ for a TER using $G=-2 \%, V=140 \mathrm{~km} / \mathrm{hr}$, and $R=$ $0.25 \mathrm{~kg} / \mathrm{kgGVM}$ 102

Figure 38 - FOSM Visual Representation of $L_{\text {supply }}$ for a TER using $G=-4 \%, V=140 \mathrm{~km} / \mathrm{hr}$, and $R=$ $0.25 \mathrm{~kg} / \mathrm{kgGVM}$ 103

xviii 
Figure 39 - FOSM Visual Representation of $L_{\text {supply }}$ for a TER using $G=-6 \%, V=140 \mathrm{~km} / \mathrm{hr}$, and $R=$ $0.25 \mathrm{~kg} / \mathrm{kgGVM}$ 104

Figure 40 - FOSM Visual Representation of $L_{\text {supply }}$ for a TER using $G=-8 \%, V=140 \mathrm{~km} / \mathrm{hr}$, and $R=$ $0.25 \mathrm{~kg} / \mathrm{kgGVM}$ 105

Figure 41 - FOSM Visual Representation of $L_{\text {supply }}$ for a TER using $G=-10 \%, V=140 \mathrm{~km} / \mathrm{hr}$, and $R$ $=0.25 \mathrm{~kg} / \mathrm{kgGVM}$ 106

Figure 42 - FOSM Visual Representation of $L_{\text {supply }}$ for a TER using $G_{1}=0 \%, G_{2}=+4 \%, V=120$ $\mathrm{km} / \mathrm{hr}$, and $\mathrm{R}=0.25 \mathrm{~kg} / \mathrm{kgGVM}$ 107

Figure 43 - FOSM Visual Representation of $L_{\text {supply }}$ for a TER using $G_{1}=0 \%, G_{2}=+3 \%, V=140$ $\mathrm{km} / \mathrm{hr}$, and $\mathrm{R}=0.25 \mathrm{~kg} / \mathrm{kgGVM}$ 108

Figure 44 - FOSM Visual Representation of $L_{\text {supply }}$ for a TER using $G_{1}=0 \%, G_{2}=+2 \%, V=140$ $\mathrm{km} / \mathrm{hr}$, and $\mathrm{R}=0.25 \mathrm{~kg} / \mathrm{kgGVM}$ 109

Figure 45 - FOSM Visual Representation of $L_{\text {supply }}$ for a TER using $G_{1}=0 \%, G_{2}=+1 \%, V=140$ $\mathrm{km} / \mathrm{hr}$, and $\mathrm{R}=0.25 \mathrm{~kg} / \mathrm{kgGVM}$ 110

Figure 46 - AFOSM Visual Representation of $L_{\text {supply }}$ for a TER using $G=+2 \%, V=120 \mathrm{~km} / \mathrm{hr}$, and $R$ $=0.25 \mathrm{~kg} / \mathrm{kgGVM}$

Figure 47 - AFOSM Visual Representation of $L_{\text {supply }}$ for a TER using $G=+2 \%, V=100 \mathrm{~km} / \mathrm{hr}$, and $R$ $=0.25 \mathrm{~kg} / \mathrm{kgGVM}$ 
Figure 48 - AFOSM Visual Representation of $L_{\text {supply }}$ for a TER using $G=0 \%, V=140 \mathrm{~km} / \mathrm{hr}$, and R $=0.25 \mathrm{~kg} / \mathrm{kgGVM}$

Figure 49 - AFOSM Visual Representation of $L_{\text {supply }}$ for a TER using $G=+4 \%, V=140 \mathrm{~km} / \mathrm{hr}$, and $R$ $=0.25 \mathrm{~kg} / \mathrm{kgGVM}$ 114

Figure 50 - AFOSM Visual Representation of $L_{\text {supply }}$ for a TER using $G=+6 \%, V=140 \mathrm{~km} / \mathrm{hr}$, and R $=0.25 \mathrm{~kg} / \mathrm{kgGVM}$ 115

Figure 51 - AFOSM Visual Representation of $L_{\text {supply }}$ for a TER using $G=+8 \%, V=140 \mathrm{~km} / \mathrm{hr}$, and R $=0.25 \mathrm{~kg} / \mathrm{kgGVM}$ 116

Figure 52 - AFOSM Visual Representation of $L_{\text {supply }}$ for a TER using $G=+10 \%, V=140 \mathrm{~km} / \mathrm{hr}$, and $\mathrm{R}=0.25 \mathrm{~kg} / \mathrm{kgGVM}$ 117

Figure 53 - AFOSM Visual Representation of $L_{\text {supply }}$ for a TER using $G=-2 \%, V=140 \mathrm{~km} / \mathrm{hr}$, and R $=0.25 \mathrm{~kg} / \mathrm{kgGVM}$ 118

Figure 54 - AFOSM Visual Representation of $L_{\text {supply }}$ for a TER using $G=-4 \%, V=140 \mathrm{~km} / \mathrm{hr}$, and R $=0.25 \mathrm{~kg} / \mathrm{kgGVM}$ 119

Figure 55 - AFOSM Visual Representation of $L_{\text {supply }}$ for a TER using $G=-6 \%, V=140 \mathrm{~km} / \mathrm{hr}$, and R $=0.25 \mathrm{~kg} / \mathrm{kgGVM}$ 120

Figure 56 - AFOSM Visual Representation of $L_{\text {supply }}$ for a TER using $G=-8 \%, V=140 \mathrm{~km} / \mathrm{hr}$, and R $=0.25 \mathrm{~kg} / \mathrm{kgGVM}$ 
Figure 57 - AFOSM Visual Representation of $L_{\text {supply }}$ for a TER using $G=-10 \%, V=140 \mathrm{~km} / \mathrm{hr}$, and $\mathrm{R}=0.25 \mathrm{~kg} / \mathrm{kgGVM}$ 122

Figure 58 - AFOSM Visual Representation of $L_{\text {supply }}$ for a TER using $G_{1}=0 \%, G_{2}=+4 \%, V=120$ $\mathrm{km} / \mathrm{hr}$, and $\mathrm{R}=0.25 \mathrm{~kg} / \mathrm{kgGVM}$. 123

Figure 59 - AFOSM Visual Representation of $L_{\text {supply }}$ for a TER using $G_{1}=0 \%, G_{2}=+3 \%, V=140$ $\mathrm{km} / \mathrm{hr}$, and $\mathrm{R}=0.25 \mathrm{~kg} / \mathrm{kgGVM}$ 124

Figure 60 - AFOSM Visual Representation of $L_{\text {supply }}$ for a TER using $G_{1}=0 \%, G_{2}=+2 \%, V=140$ $\mathrm{km} / \mathrm{hr}$, and $\mathrm{R}=0.25 \mathrm{~kg} / \mathrm{kgGVM}$. 125

Figure 61 - AFOSM Visual Representation of $L_{\text {supply }}$ for a TER using $G_{1}=0 \%, G_{2}=+1 \%, V=140$ $\mathrm{km} / \mathrm{hr}$, and $\mathrm{R}=0.25 \mathrm{~kg} / \mathrm{kgGVM}$ 126 


\section{Introduction}

A truck escape ramp is a type of auxiliary lane used in extreme circumstances and as a final resort by runaway vehicles that are out of control. Truck escape ramps are designed based on their capacity to stop a runaway vehicle and are implemented to increase roadway safety. The design of truck escape ramps depends on several factors including the speed the runaway vehicle enters the truck escape ramp, rolling resistance, and the truck escape ramp grade.

Current research does not contain a reliability analysis on the design of truck escape ramps. Therefore, the focus of this report is to develop a reliability model for various scenarios in order to establish a design that ensures safety and evades failure. In this report, two reliability methods are developed which examine and analyze various truck escape ramp designs. The methods include a first order second moment reliability method and an advanced first order second moment reliability method. These methods were selected as they are analytical methods and are simpler to use than other methods such as Monte Carlo simulation. The purpose of developing these methods is to limit the probability of failure of a truck escape ramp in order to enhance roadway safety.

These models were then applied to two existing truck escape ramps to assess the reliability of the design of the existing truck escape ramps. The results of the analysis are reported along with a brief discussion and comparison. 
A flow chart of tasks performed in this project is outlined below:

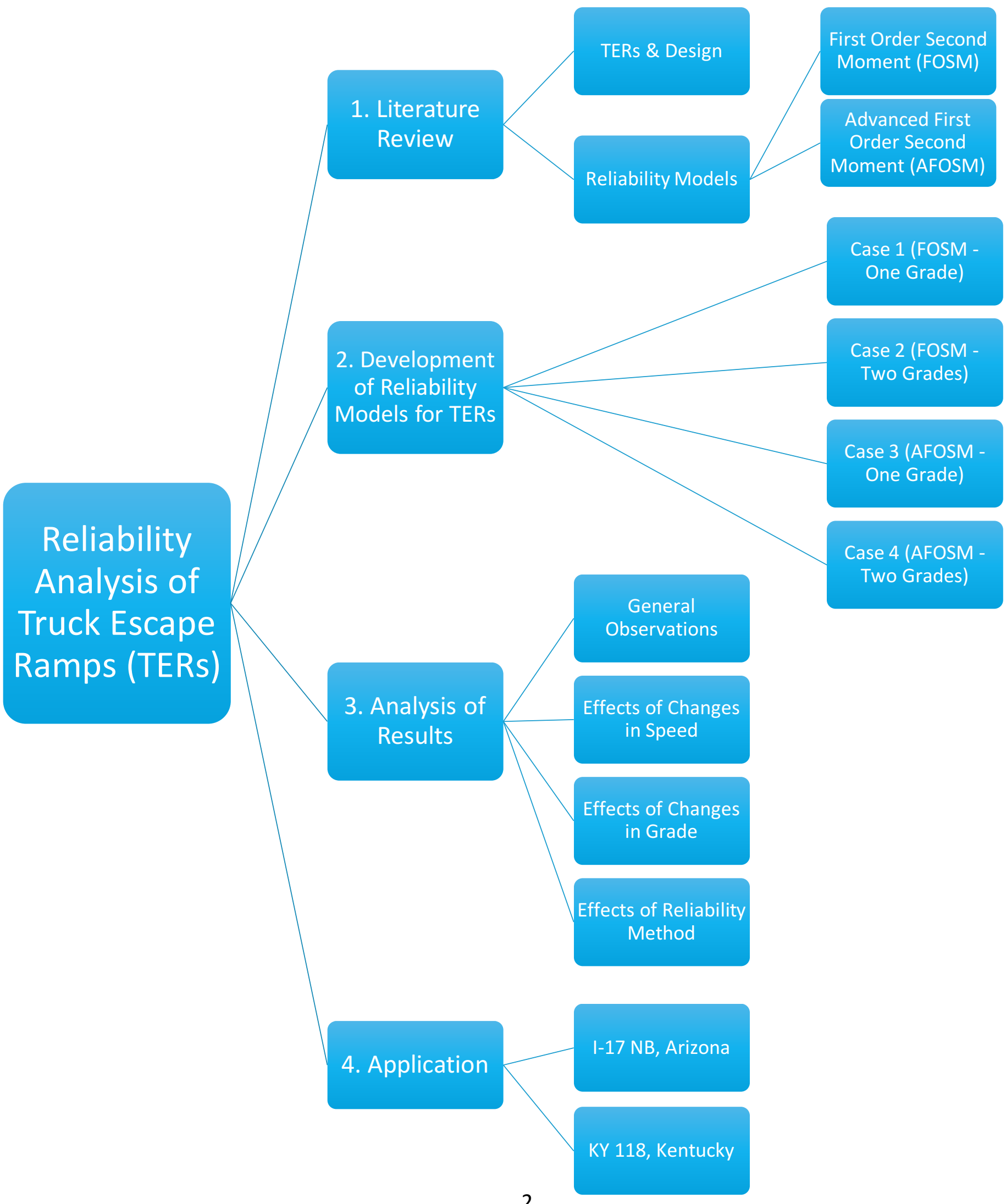


Chapter 1 - Introduction. This chapter provides a brief overview of the report.

Chapter 2 - Literature Review - Truck Escape Ramps \& Design. This chapter presents a brief overview of the function of truck escape ramps, best practices for the warrant and location of a new truck escape ramp, various truck escape ramp design details, technical design details, the effect variation of design variables has on truck escape ramps, and truck escape ramp case studies.

Chapter 3 - Literature Review - Reliability Models. This chapter presents an overview on the two reliability methods used to analyze the truck escape ramp design. These methods include the first order second moment (FOSM) reliability method and the advanced first order second moment (AFOSM) reliability method. A discussion on the use of these methods is discussed in this chapter.

Chapter 4 - Development of Reliability Models for Truck Escape Ramps. This chapter presents the development of each reliability method for the analysis of the design of truck escape ramps. Four cases are established for analysis; Case 1: FOSM reliability method for one grade, Case 2: FOSM reliability method for two grades, Case 3: AFOSM reliability method for one grade, and Case 4: AFOSM reliability method for two grades. The methodology behind the development of each method as well as sample calculations and results are provided in this chapter.

Chapter 5 - Analysis of Results. An analysis of the results obtained in Chapter 4 is presented. General observations of the results obtained in Case 1 through Case 4 are mentioned. Furthermore, the effect of changes in speed and changes in grade are discussed along with the effect the selected reliability method has on the length of the truck escape ramp. 
Chapter 6 - Application. This chapter presents an application of the FOSM and AFOSM models developed in this report. Each model was applied to the I-17 NB in Arizone and the KY 118 in Kentucky. The results are displayed in this chapter along with a brief discussion.

Chapter 7 - Conclusions. This chapter presents the final remarks regarding this project. 


\section{Literature Review - Truck Escape Ramps \& Design}

\subsection{Background}

A truck escape ramp (TER), otherwise known as a runaway truck ramp or emergency escape ramp, is a type of auxiliary lane implemented adjacent to roadways with a steep, sustained grade, to increase roadway safety and avoid potential fatal crashes [1].

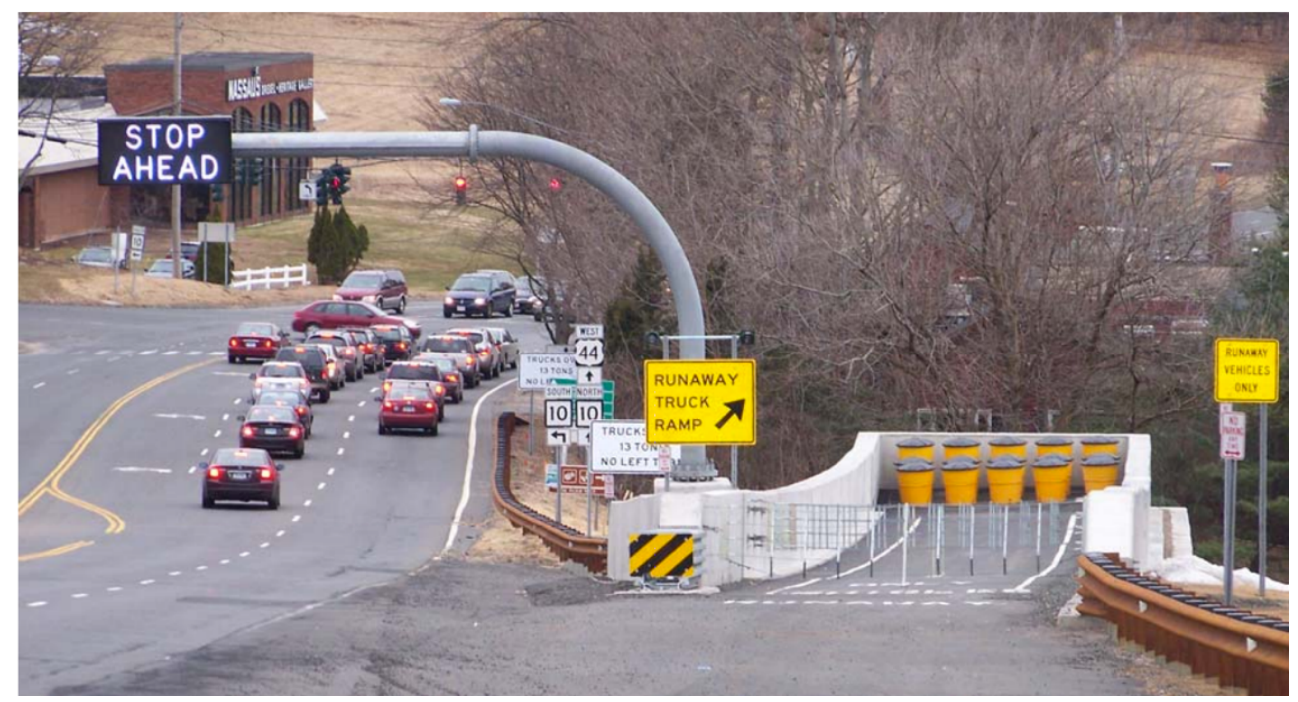

Figure 1 - Truck Escape Ramp Located on US Route 44 Westbound in Avon, Connecticut (Credit: Connecticut Department of Transportation) [2]

The name of the system comes from the purpose and function of the system which is to divert and stop runaway trucks, buses and/or other vehicles which are out of control due to reasons such as a failed brake system. It is in these cases where methods to slow down the runaway vehicle, such as shifting down gears or applying the brakes, are not sufficient to stop the uncontrollable vehicle. When a vehicle enters the TER system at high speeds, the great amount of energy is dissipated through rolling resistance and/or gravitational deceleration. Thus, the design of a TER is based on the type of surfacing material used, the speed of the runaway 
vehicle entering the TER, and the percent grade of the TER [3]. The implementation of TERs therefore results in lower vehicular damage and reduced collision injury.

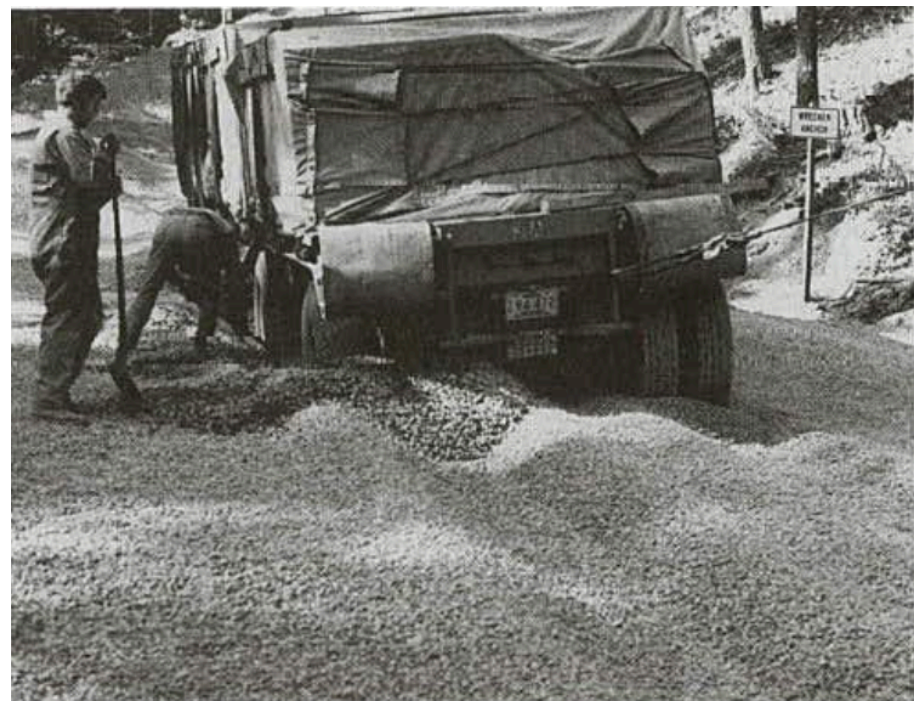

Figure 2 - Truck Escape Ramp Used by Runaway Truck (Credit: Transportation Research Board) [4]

\subsection{Warrants: Best Practices}

The principal demands for TERs are traffic safety, safe exit and stop of a runaway vehicle, and protection of residences or alternate activities operating along the highway or at the base of the roadway grade. According to the Transportation Association of Canada's Geometric Design Guide for Canadian Roads (TAC Guide), a uniformly accepted practice to warrant a TER or establish a TER location does not exist. Each individual scenario involves unique variables which require independent means of determining if a TER is warrantable and where the TER should be located. As a result, each location should be evaluated using a benefit cost analysis and engineering judgement with strong consideration for user safety [3].

While considering the above, TERs are typically warrantable where continuous steep downgrades exist in either rural or urban areas, or where short steep downgrades exist with a 
residential or urban area along the highway or at the base of the downgrade $[1,3]$. This can include mountainous regions, such as in the State of California, where small residential areas exist. It is these areas in which various factors such as increased truck weight, traffic volume, and speed result in an increased number of runaway vehicles [5]. Collision data, such as number of fatal crashes, in combination with terrain evaluation, can also bring attention to a specific location in need of a TER.

Another way to determine the need and specific location for a TER is using the Grade Severity Rating System which uses vehicle weight and a preset brake temperature limit, for example $260^{\circ} \mathrm{C}$, to determine a maximum safe descent speed. The TAC Guide defines a maximum safe descent speed as "that speed from which an emergency vehicle stop at the bottom of the grade will not generate brake temperatures above a pre-selected temperature limit" [3]. In scenarios where the brake temperature exceeds the preset limit, the system determines this scenario as brake failure, and a potential location where a TER can be implemented. Since this system only analyzes the roadway grade and not the horizontal alignment, it cannot be used alone and must be used in conjunction with other determining factors prior to rejecting the implementation of a TER.

Aside from the geometric design of a roadway, other factors must be considered when determining the need for a TER. For instance, many truck drivers are from out-of-area and are unfamiliar with maneuvering various terrain. For example, $65 \%$ of the total number of truck drivers within the State of California are out-of-state trucks whose drivers are not familiar with 
maneuvering through the mountainous terrain [5]. In this case driver unfamiliarity could initiate the need for TERs.

Another example is low truck maintenance in order to reduce company overhead costs [5]. This poses a serious threat to highway safety due to overloaded trucks, and as a result, failed brake systems.

It is these situations where TERs should be considered for implementation. These factors, amongst others, initiate the need for the design and implementation of TERs in order to maintain control of runaway vehicles and prevent serious, and potentially fatal, collisions. The implementation of TERs will thus increase the safety of all road users, truck drivers, and roadside properties.

\subsection{Locations: Best Practices}

Similar to TER warrants, specific criteria or guidelines for a singly defined TER location do not exist [3]. Although each scenario is unique, choosing an appropriate location is critical.

According to the TAC Guide, the main factors considered when determining the location of a TER include alignment and terrain. More specifically: grade, topography, horizontal alignment, location of collisions, length of grade, speed of the out-of-control vehicle(s), the condition at the bottom of the grade, distance below the summit, and the available space adjacent to the highway and the environmental impact [3]. 
Furthermore, some best practices when locating the TER include [3]:

1. Locate the TER such that it intercepts the largest number of runaway vehicles. This can be achieved by locating the TER at the bottom of the highway's grade, at intermediate points along the highway grade, or at a location where the runaway vehicle(s) may cause disastrous results. In this case, collision data is very important.

2. Locate the TER where "brake fade" may begin.

3. Locate the TER prior to specific accident-prone locations along the highway. For example, areas which cannot be safely navigated due a sharp vertical curve.

4. Locate the TER on a horizontal tangent or locations with very flat curvature.

5. Ideally, and in terms of driver expectation, locate the TER on the right side of the highway. In cases where this is not possible, locate the TER on the left side where there is a wide median.

If there is more than one warrantable location along the highway, and at the same downgrade, priorities can be determined for the appropriate selection of the location of the TER.

\subsection{Types}

Many types of TERs exist, however the three main basic categories of TERs are: gravel, sand pile, and arrestor bed [3]. The arrestor bed TER design can be further categorized as: horizontal grade, descending grade, and ascending grade [3]. These designs are shown in Figure 3. Alternate versions and new state of the art of TERs exist, such as the Dragnet Escape System implemented on Ontario's Highway 11, which uses additional elements to further improve the 
design of the TER, however, for the purpose of this project, only the aforementioned four types of basic TERs will be considered for the reliability analysis [6].
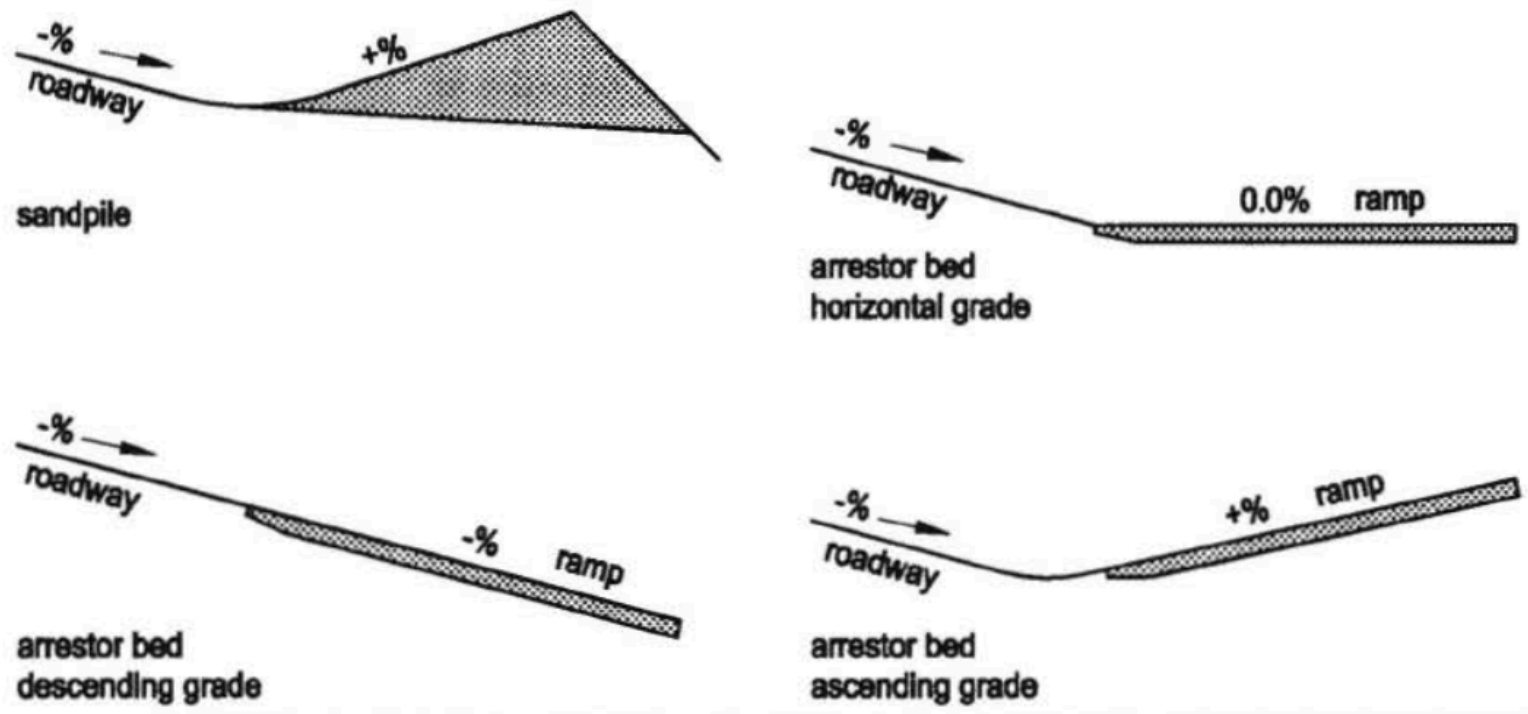

Figure 3 - Basic Truck Escape Ramp Design Categories (Reproduced with the express written authority of the Transportation Association of Canada (TAC). Excerpted from the TAC publication: Geometric Design Guide for Canadian Roads (1999)) [3]

\subsubsection{Gravity}

The most basic type of TER is the gravity TER, which consists of a paved surface which simply depends on gravity in combination with an ascending grade to slow down and stop the runaway truck [3]. Gravity TERs are typically adjacent existing roads or are created as an ascending grade parallel to the travelled way $[1,3]$. Since this type of TER relies solely on gravity, a longer stopping distance, and thus a longer design length, is required to ensure the runaway vehicle comes to a complete stop. Even if the vehicle comes to a complete stop, it may roll backwards or jackknife, which can be dangerous. Furthermore, there may not be an adjacent side road to utilize as a TER. For these reasons, this design is the least preferred of the available TER design options. 


\subsubsection{Sand Pile}

As the name suggests, the basic design of a sand pile TER is piling loose, dry sand at the base of the TER. Since sand has very strong deceleration characteristics, this type of TER is typically 120 meters in length or shorter. As a result of this severe deceleration in combination with the fact that sand is strongly affected by weather elements, sand pile TERs are not very desirable in comparison to an arrestor bed. With that being said, a sand pile TER is a good alternative in situations where there is insufficient space available for a longer ramp. Sand pile TERs are also beneficial when used in conjunction with other TER designs at the terminal point, if adequate TER length using an alternate design cannot be achieved [3].

\subsubsection{Arrestor Bed - Horizontal Grade, Descending Grade, Ascending Grade}

An arrestor bed TER is the most commonly implemented TER design and slows down runaway vehicles by displacing arrestor bed aggregate. The arrestor bed material provides the rolling resistance against the runaway vehicle and permits controlled deceleration and thus a shorter stopping distance [7]. Arrestor beds can be designed and constructed on a horizontal grade, descending grade, or ascending grade. According to the TAC Guide, arrestor bed TERs use "a regulated depth of loose sized gravel contained in form" [3]. Using a loose material, such as loose gravel, increases the system's rolling resistance. This assists the deceleration and eventual halt of the runaway vehicle by dissipating the kinetic energy to the arrestor bed aggregate and overcoming the shear resistance [3]. Unlike the sand pile TER design, the loose material in the arrestor bed design prevents trucks on an ascending grade from rolling backwards. However, similar to a sand pile, the use of loose material in an arrestor bed makes it difficult to remove 
the runaway vehicle from the TER bed, and alternate means such as anchors are required for extraction [3]. A benefit of implementing an arrestor bed TER design in comparison to the aforementioned designs is that an arrestor bed TER can be implemented on any roadway grade (i.e. positive, negative, or horizontal grades) which gives the designer more options when selecting the TER location [3].

The most common and ideal type of arrestor bed is an ascending grade, as gravity in combination with rolling resistance allows this type of arrestor bed to be designed at the shortest lengths of all arrestor bed types [3]. This is beneficial in locations where space is limited. Next, the horizontal arrestor bed depends on rolling resistance alone, and must be longer than an ascending grade TER [3]. Lastly, the descending grade arrestor bed is the longest of the arrestor beds as gravity is working against the rolling resistance forces and hinders the speed reduction and eventual stopping of the runaway vehicle.

\subsection{Design Details}

\subsubsection{Forces Affecting Truck Speed}

According to the TAC Guide, there are three forces which affect truck speed. These include forces generated by the engine, braking, and tractive resistance. However, when designing truck escape ramps, only the tractive resistance force is considered as this is the worst case scenario in which the truck's brakes have failed and the truck is "out of gear", essentially in neutral. This is caused by a missed gear downshift and improperly adjusted brakes which impose a higher demand and heat buildup on the functioning brakes, causing the brakes to fade and fail [3]. 
The tractive resistance force can be broken down into four main forces: air resistance, inertial resistance, gradient resistance, and rolling resistance forces. The air resistance, positive gradient resistance, and rolling resistance forces impede the vehicle's motion. However, the inertial resistance and negative gradient resistance forces facilitate the truck's motion [3]. The tractive resistance forces are illustrated in Figure 4 below.

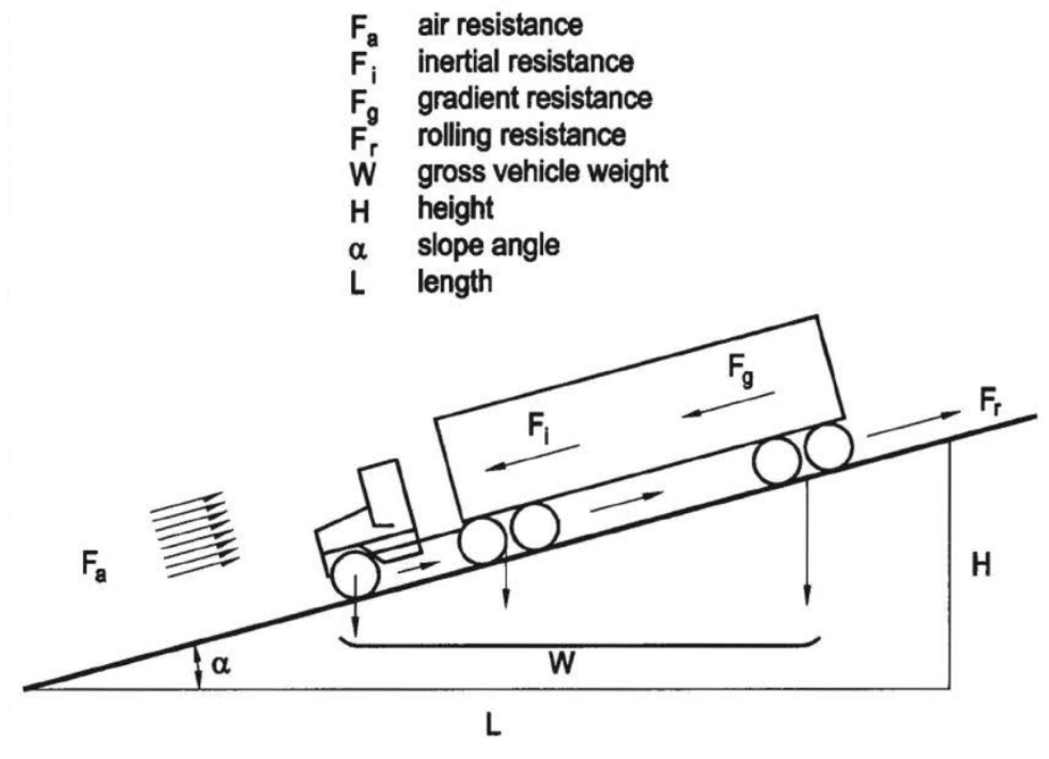

Figure 4 - Tractive Resistance Forces as Illustrated on a Truck in Motion (Reproduced with the express written authority of the Transportation Association of Canada (TAC). Excerpted from the TAC publication: Geometric Design Guide for Canadian Roads (1999)) [3]

Air resistance is negligible at vehicle speeds below $30 \mathrm{~km} / \mathrm{hr}$ yet causes a great amount of resistance at vehicle speeds over $80 \mathrm{~km} / \mathrm{hr}$, according to the TAC Guide [3]. However, the force induced by air resistance is ignored when calculating the required length of a truck escape ramp, as seen in Equation 1, which results in a smaller safety factor.

The force exerted by inertial resistance "resists movement of a vehicle at rest or maintains a vehicle in motion, unless the vehicle is acted on by some external force", according to the TAC Guide [3]. Positive gradient resistance and rolling resistance overcome inertial resistance [3]. 
Gradient resistance, either positive or negative, is due to gravity. A positive gradient (up-grade), creates a positive gradient resistance which slows down the vehicle in motion and is a beneficial force for a TER. However, a negative gradient (down-grade), creates a negative gradient resistance which reduces the forces which would otherwise stop or slow down the truck. The total gradient resistance is a function of the steepness of the grade and the truck mass. According to the TAC Guide, for every percent grade, the gradient resistance is 10 kilograms per 1000 kilograms of gross vehicle mass (GVM) [3].

Rolling resistance is only applicable to a vehicle in motion and is a force that resists movement between the roadway surface and the tires. Depending on the roadway surfacing material, such as sand or loose gravel, the rolling resistance will vary, as seen in Table 1, expressed in kilogram per 1000 kilogram of GVM [3].

Table 1 - Rolling Resistance Values [3]

\begin{tabular}{lcc}
\hline \multicolumn{1}{c}{ Surfacing Material } & $\begin{array}{c}\text { Rolling Resistance } \\
(\mathbf{k g} / \mathbf{1 0 0 0} \mathbf{~ k g ~ G V M})\end{array}$ & $\begin{array}{c}\text { Equivalent Grade } \\
(\%)^{\mathbf{a}}\end{array}$ \\
\hline Portland Cement Concrete & 10 & 1.0 \\
Asphalt Concrete & 12 & 1.2 \\
Gravel, Compacted & 15 & 1.5 \\
Earth, Sandy, Loose & 37 & 3.7 \\
Crushed Aggregate, Loose & 50 & 5.0 \\
Gravel, Loose & 100 & 10.0 \\
Sand & 150 & 15.0 \\
Pea Gravel & 250 & 25.0 \\
\hline
\end{tabular}

Note: ${ }^{a}$ Rolling resistance expressed as equivalent gradient. 


\subsubsection{Required Length of TER with One Grade}

The required length of a TER when dealing with one grade, or the first grade of a series of grades, can be calculated as follows:

$$
L_{i}=\frac{V_{i}^{2}}{254\left(R+G_{i}\right)}
$$

Where: $\quad L_{i}=$ required length of TER for segment $i(m)$,

$V_{i}=$ vehicle's speed entering segment $i(\mathrm{~km} / \mathrm{hr})$,

$R=$ rolling resistance as equivalent percentage gradient/100 (as seen in Table 1),

$G_{i}=$ percent grade of TER/100 for segment $i$, where $G$ is positive for an up-grade TER and negative for a down grade TER [3].

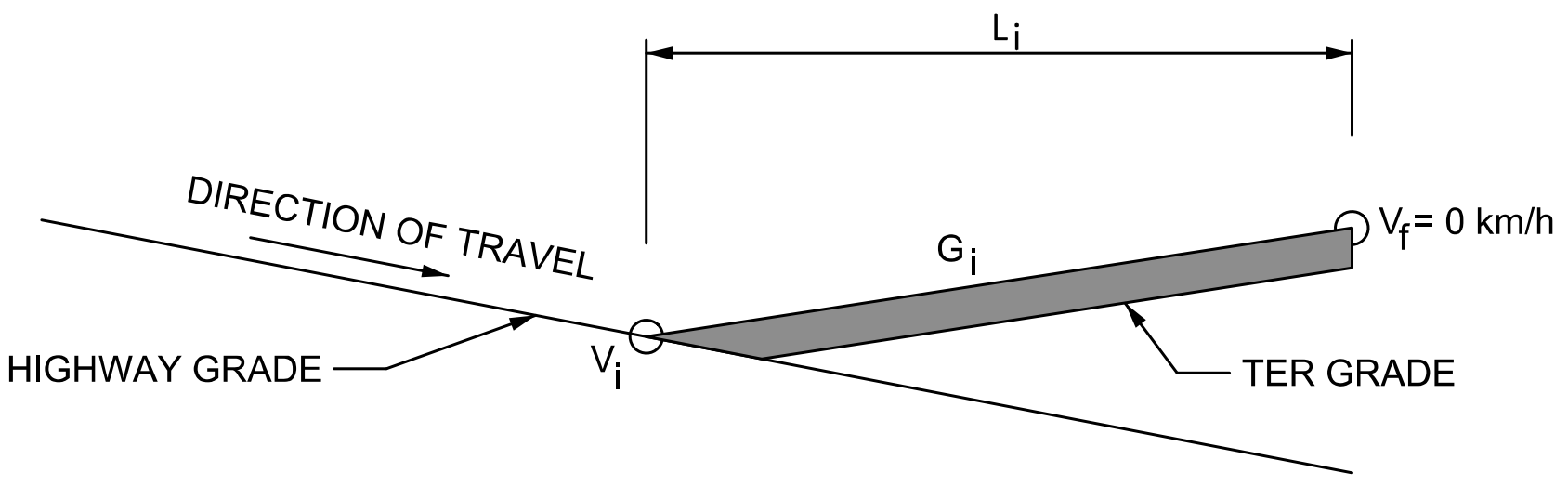

Figure 5 - Visual of TER with One Positive Grade, $G_{i}$ 


\subsubsection{Required Length of TER with More Than One Grade}

The required length of a TER with more than one grade can be calculated as follows:

Step 1: Determine the length of the first TER segment, $\mathrm{L}_{\mathrm{i}}$, using Equation 1.

Step 2: Calculate the speed of the vehicle at the end of the first TER grade segment, $V_{i+1}$ :

$$
V_{i+1}=\sqrt{V_{i}^{2}-254 * L_{i} *\left(R+G_{i}\right)}
$$

Where: $\quad V_{i}=$ vehicle's speed entering segment $\mathrm{i}(\mathrm{km} / \mathrm{hr})$,

$V_{i+1}=$ vehicle's speed at the end of the segment $\mathrm{i}$,

$L_{i}=$ required length of the TER grade segment $i(m)$,

$\mathrm{R}=$ rolling resistance of the TER grade segment as equivalent percentage gradient/100 (as seen in Table 1),

$G_{i}=$ percent grade of TER/100 for segment $i$, where $G$ is positive for an up-grade TER and negative for a down grade TER, for the TER grade segment [3].

Step 3: Use $V_{i+1}$ as the vehicle's speed entering the next TER grade segment, using Equation 1 to determine the length of the next TER segment. Then, calculate the speed of the vehicle at the end of this segment, $\mathrm{V}_{\mathrm{i}+2}$, using Equation 2 [3].

Step 4: Repeat Step 1 to Step 3 at each change in grade until an adequate TER length is achieved in order to stop the runaway vehicle, where $V_{f}=0 \mathrm{~km} / \mathrm{hr}[3]$. 


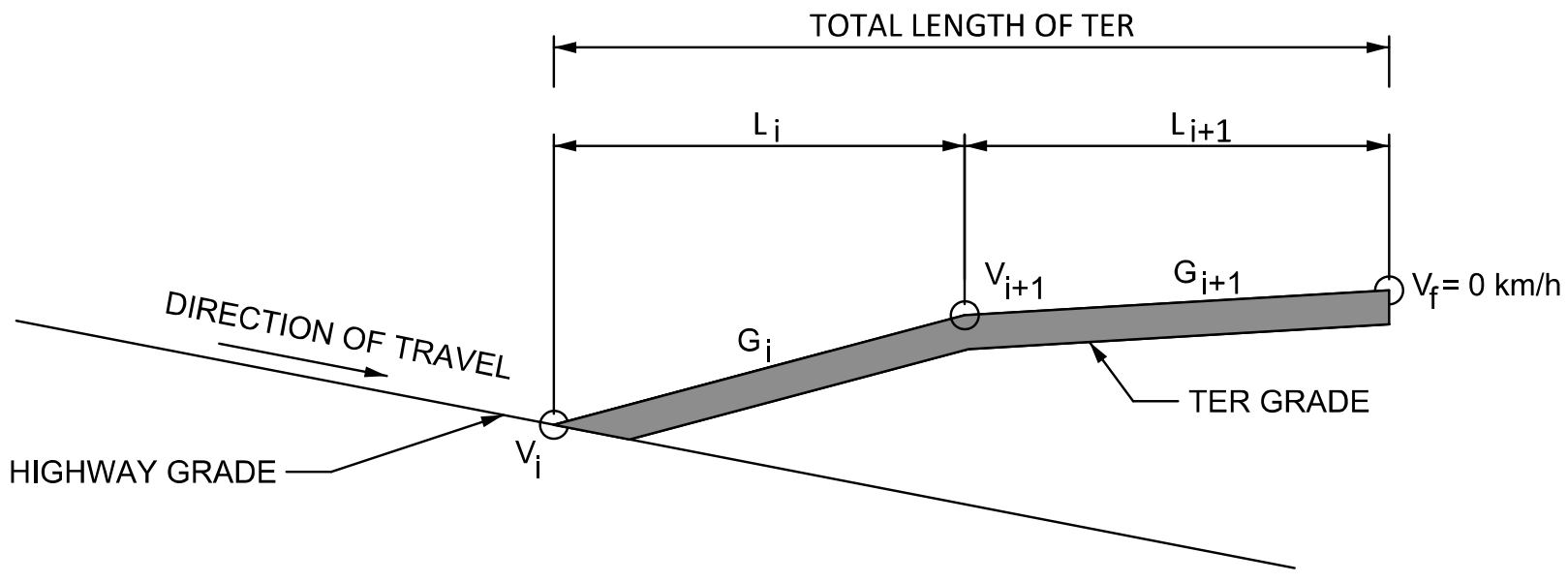

Figure 6 - Visual of TER with Two Positive Grades, $G_{i}$ and $G_{i+1}$

\subsubsection{If the Required Length of TER is Not Feasible}

If it is not possible to meet the TER design length requirement, positive attenuation devices can be placed at the end of the TER, such as an group of crash cushions in the form of barrels filled with bedding material, mounds of arrestor bed material, or a drag-net. It should be noted that positive attenuation devices should only be used if the effects of colliding with the device outweigh the effects of overrunning the TER, as these devices may in fact jeopardize the safety of the vehicle's occupant(s) rather than increase their safety [3].

\subsubsection{TER Layout}

A typical TER layout can be seen in Figure 7.

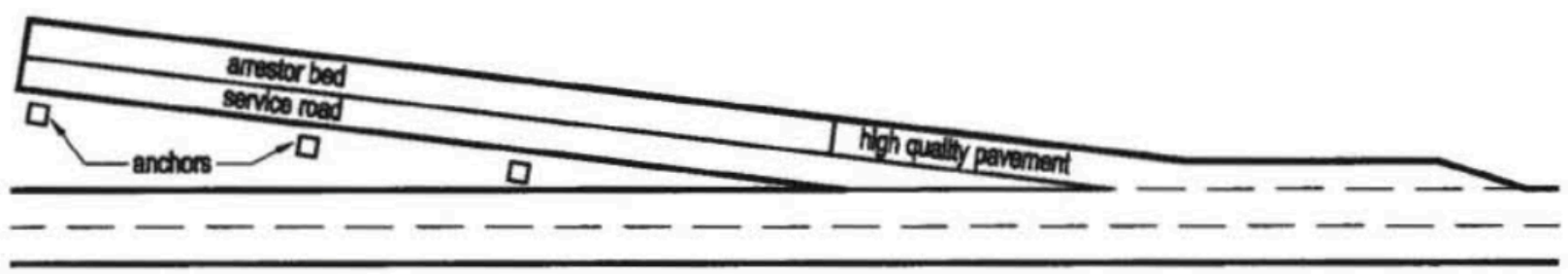

Figure 7 - Typical TER Layout (Reproduced with the express written authority of the Transportation Association of Canada (TAC). Excerpted from the TAC publication: Geometric Design Guide for Canadian Roads (1999)) [3] 
The layout of the TER lane should not include any changes in the horizontal alignment and should be straight. The TER should also be at a flush angle to the through roadway, approximately $5^{\circ}$ or less. This smooth transition from the through roadway to the TER is critical as the vehicle will be entering the TER at a very high speed and in most cases out of control. The user must feel also safe while navigating the TER, which is enhanced with a smooth transition. Furthermore, it is necessary that the user can see all or most of the TER in order to ensure safe navigation [3].

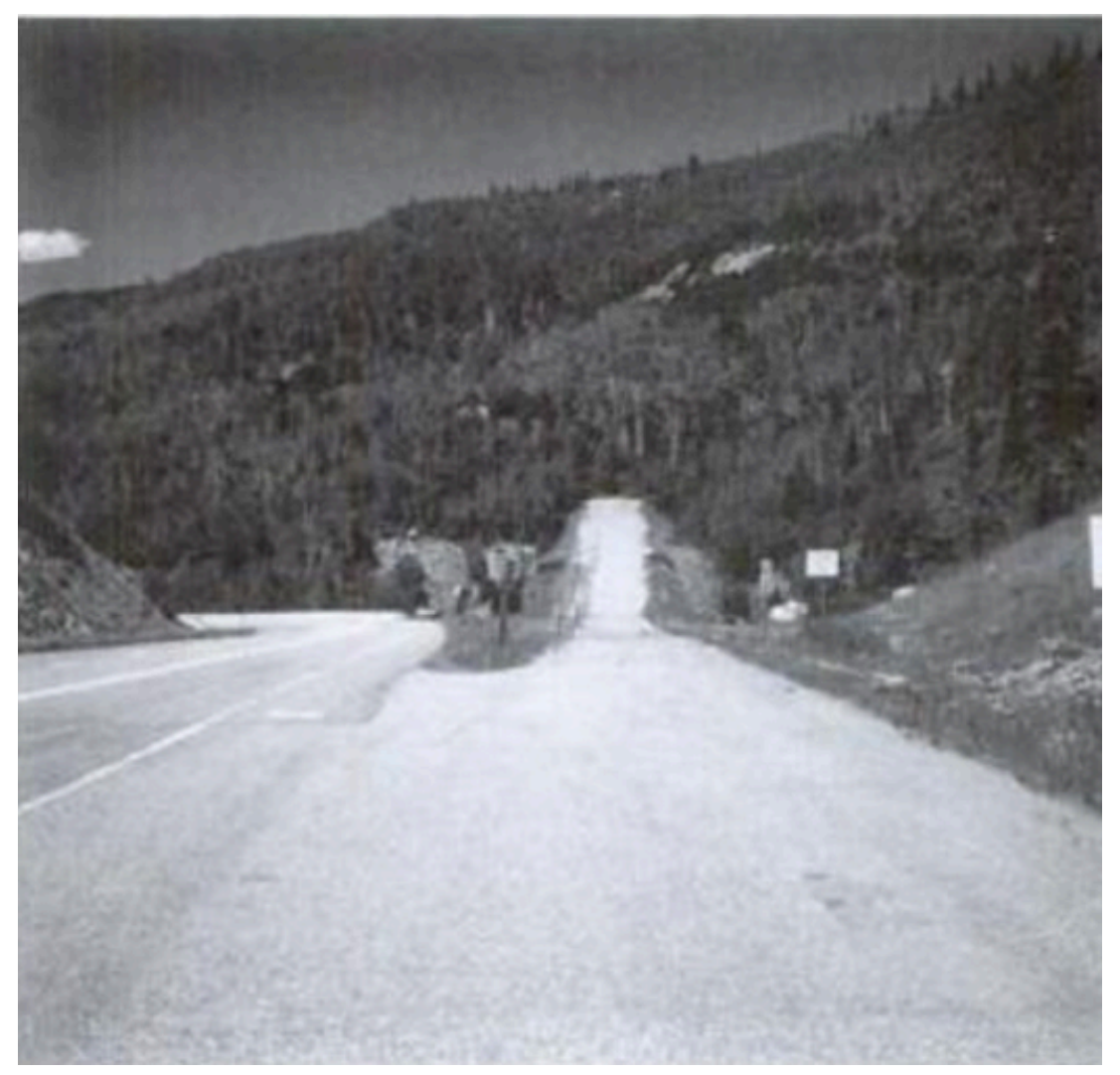

Figure 8 - TER Should Leave Through Roadway at the Smallest Angle Possible (Credit: Transportation Research Board) [4]

The TER lane width depends on how many vehicles the TER is designed to accommodate. According to the TAC Guide, a standard width for a TER designed to accommodate one runaway 
vehicle is $4 \mathrm{~m}$ for gravity ramps, and a minimum $5 \mathrm{~m}$ for all other types of TER. A $9 \mathrm{~m}$ to a maximum $12 \mathrm{~m}$ width is ideal for two lane TER operation [3].

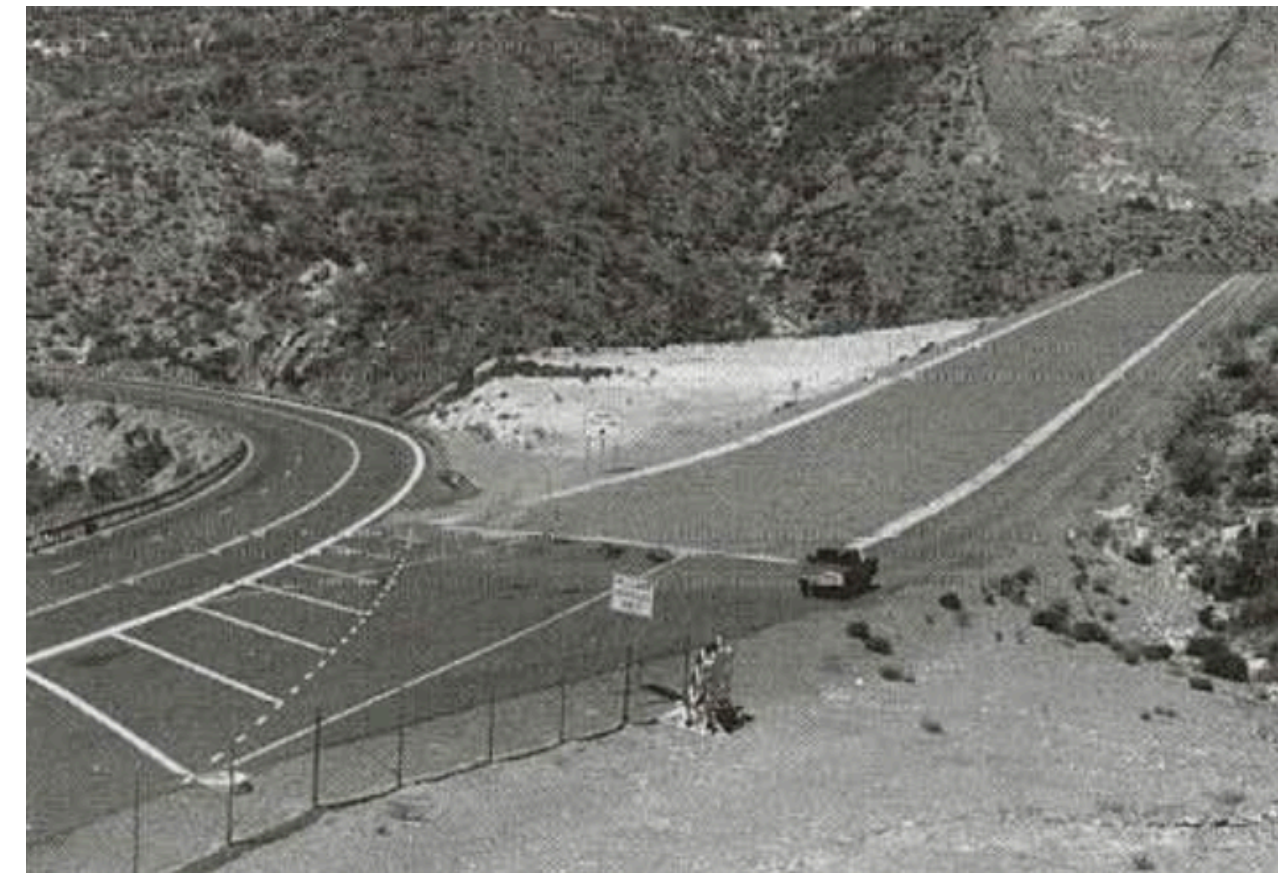

Figure 9 - Example of TER Which Can Accommodate More than One Runaway Vehicle (Credit: Transportation Research Board) [4]

Service lanes between $3.5 \mathrm{~m}$ to $4 \mathrm{~m}$ wide, either gravel or paved, and anchors should be included along the TER to facilitate vehicle extraction. In addition, a truck restraining barrier may be installed on the outside edge of the TER in cases where the out of control vehicle may exit through the side of the TER and impose a hazard to adjacent activity such as an urban or residential area [3].

\subsubsection{TER Arrestor Bed Details \& Design Elements}

The most common type of TER used in practice is the arrestor bed, and therefore requires more design consideration. 


\subsubsection{Arrestor Bed Cross Section}

Figure 10 shows typical arrestor bed TER cross section details.

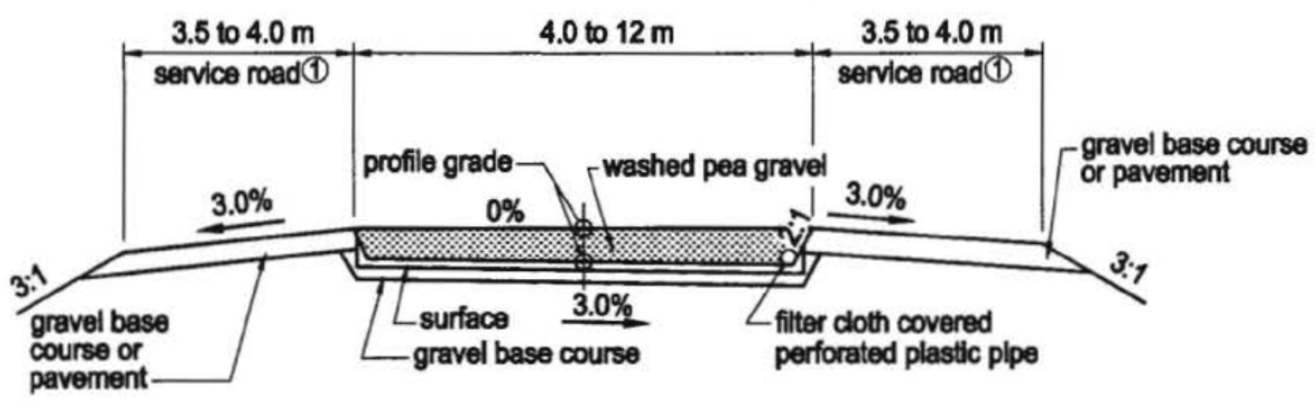

Note: 1. One service road minimum. Two service roads desirable.

Figure 10 - Typical TER Cross Section (Reproduced with the express written authority of the Transportation Association of Canada (TAC). Excerpted from the TAC publication: Geometric Design Guide for Canadian Roads (1999)) [3]

When a vehicle enters an arrestor bed, it will sink approximately $300 \mathrm{~mm}$ to $450 \mathrm{~mm}$. Therefore, in order to allow a steady deceleration, the bedding is tapered from roughly $75 \mathrm{~mm}$ to full bed depth in $30 \mathrm{~m}$ to $100 \mathrm{~m}$. The depth of the bedding material varies from $450 \mathrm{~mm}$ to $600 \mathrm{~mm}$ according to the Ontario Roadside Safety Manual [3].

The arrestor bed which holds the bedding material is trapezoidal and designed with a 2:1 side slope on each side. This controls the runaway vehicle's direction and stability within the arrestor bed and facilitates vehicle extraction [3].

\subsubsection{Arrestor Bed Materials}

In order to ensure proper functioning of the arrestor bed TER, the following guidelines should be followed, as per the TAC Guide:

1. Loose material should be clean, have a high coefficient of friction, and should not be easily compacted to allow the vehicle to sink into the aggregate upon entering the TER, 
2. Although smaller aggregate provides a quicker deceleration, large, predominant, singlesized aggregates reduce moisture retention and freeze-thaw issues associated with small-sized aggregate,

3. Avoid fractured angular aggregate which withstands the weight of the vehicle and thus decreases the rolling resistance,

4. Use uniformly graded and well-rounded aggregate which can displace easily and allow the runaway vehicle to sink into aggregate thus increasing rolling resistance and maximizing deceleration,

5. Use aggregate with high rolling resistance in order to allow shorter TER lengths which area also more economical,

6. Pea gravel is the most desirable material as it has a high rolling resistance, especially when installing a TER at locations where freezing is of concern, and

7. Particle size should range between $15 \mathrm{~mm}$ to $20 \mathrm{~mm}$, free of fines, and at a maximum 40 $\mathrm{mm}$, for best performance [3, 7].

\subsubsection{Arrestor Bed Drainage}

Proper drainage is critical to avoid freezing and ensure the TER is operable in the winter. Proper drainage also ensures contamination at the base of the arrestor bed is minimized. To ensure proper drainage, the base of the arrestor bed should be designed with a $3 \%$ cross slope and include sub drains and an open graded drainage layer [3]. 


\subsection{Variability in Design Variables and Their Effects}

As previously mentioned, arrestor beds displace the bedding material in order to slow down the runaway vehicle. This displacement in combination with nature's elements will not always yield the design specifications in practice. In other words, if the TER was designed with a rolling resistance equal to $0.25 \mathrm{~kg} / \mathrm{kg} \mathrm{GVM}$, in reality the rolling resistance may be higher or lower, which can alter the TER performance.

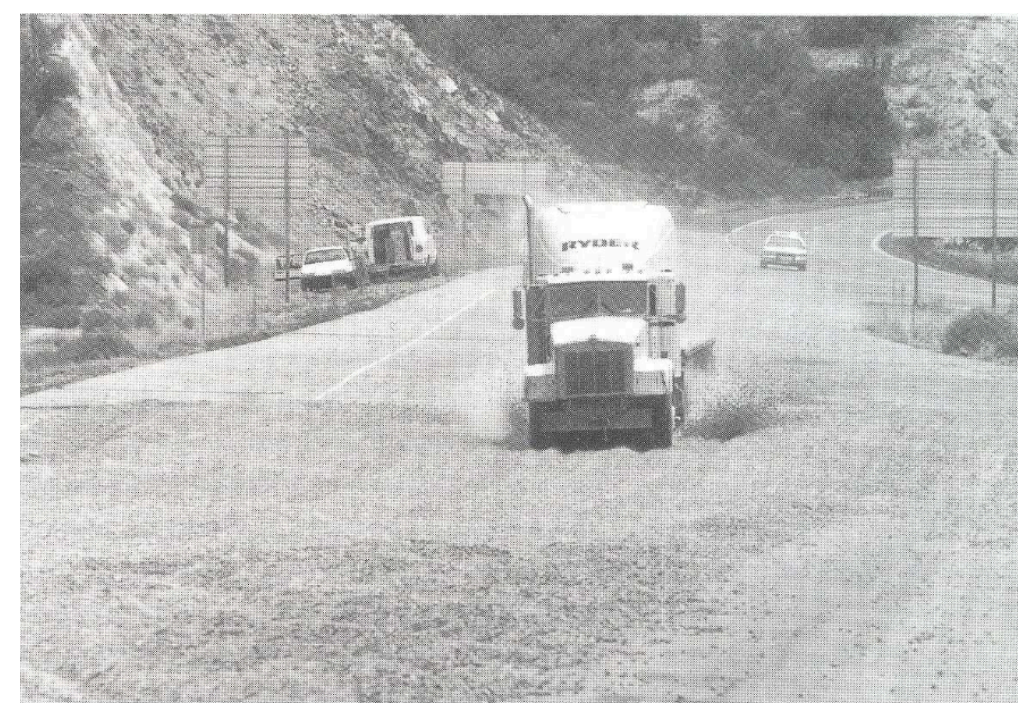

Figure 11 - Runaway Truck Entering TER (Credit: ADOT) [7]

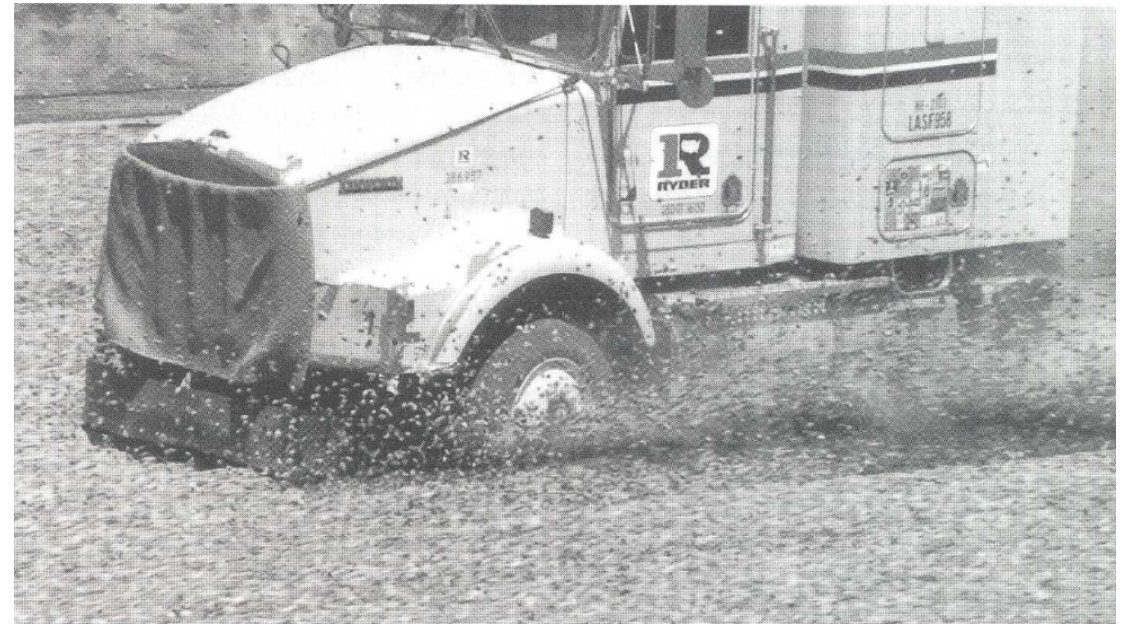

Figure 12 - Runaway Truck Displacing Arrestor Bed Aggregate (Credit: ADOT) [7] 
In fact, this variability in design variables can ultimately affect the supply length of the TER in practice. The performance of an arrestor bed TER depends primarily on the effects of nature's elements, proper maintenance, the geometry of the bed in terms of length and depth, and the characteristics of the bedding material in terms of gradation and shape [7].

In order to compare a TER design to the implemented TER in practice, the Arizona Department of Transportation (ADOT) conducted testing at four existing TER arrestor beds in Arizona: I-17 NB, I-17 SB, US 89, and SR 77. The main focus of the study was to analyze the rolling resistance of the arrestor bed aggregate while evaluating various maintenance methods [7].

In order to assess the rolling resistance of the in-place aggregate, 102 tests were conducted using an unloaded, 5-axle, single-trailer truck which entered the TER at approximately $70 \mathrm{~km} / \mathrm{hr}$ (45 $\mathrm{mph}$ ) and $105 \mathrm{~km} / \mathrm{hr}$ (65 mph) [7]. In order to back calculate the rolling resistance, radar was used to measure the difference in vehicle speed at $1 / 20$-second intervals [7]. The influence arrestor bed preparation has on the rolling resistance was also assessed using three different preparation techniques. Lastly, ADOT evaluated the stopping distance required for runaway vehicles that entered the arrestor bed TER in tracks left by a previous vehicle that used the TER [7]. The results of the analysis are displayed in Figure 13. 


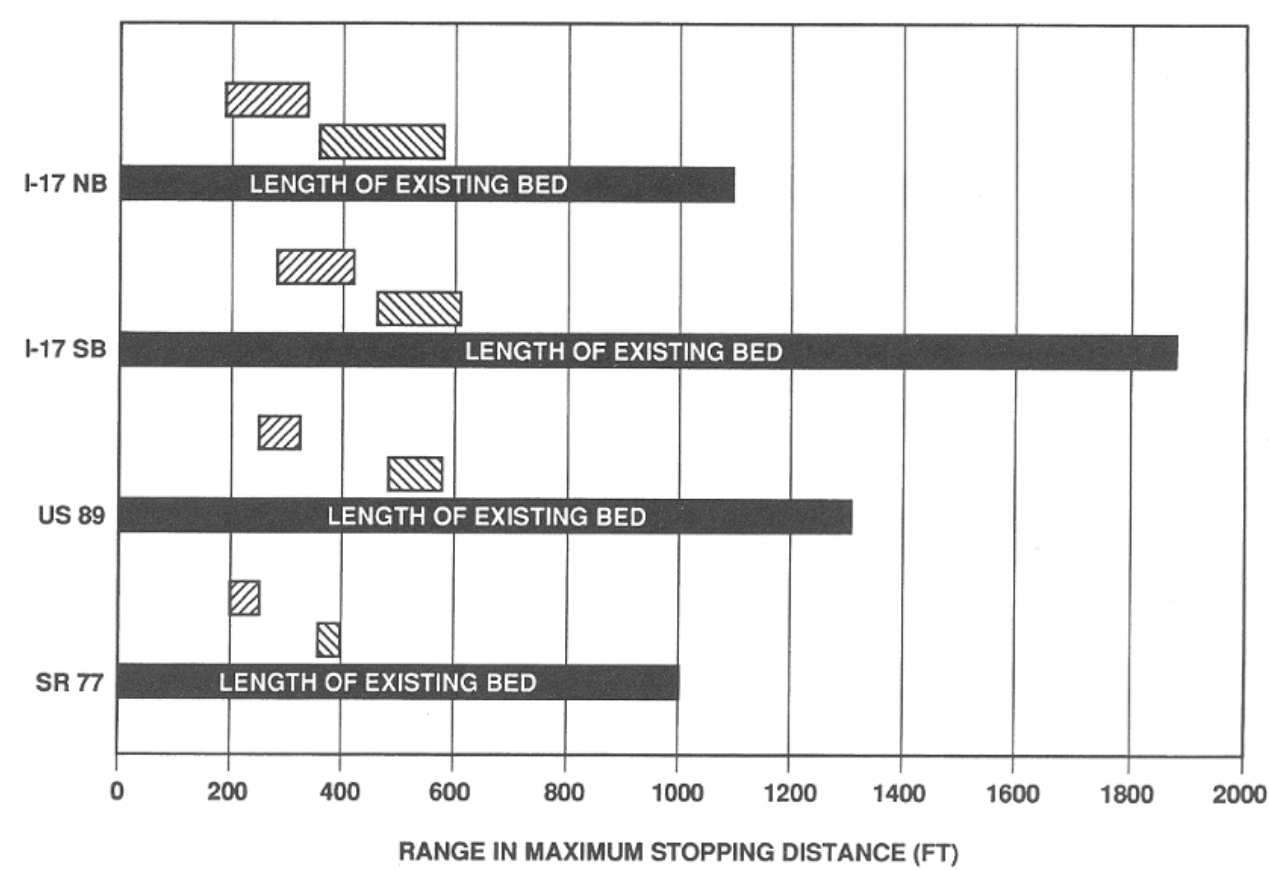

$\frac{\text { LEGEND }}{\text { QIIIIT }} 45 \mathrm{MPH}$

MIJIJ $65 \mathrm{MPH}$

Figure 13 - Ranges of Maximum Runaway Vehicle Stopping Distances at Four Arrestor Bed TER Locations Tested in Arizona (Credit: ADOT) [7]

In all cases, the supply length of the existing TER is longer than the required TER supply length demanded by the runaway vehicle using the TER. This means the existing rolling resistance supplied by the current TER exceeds the design rolling resistance. According to the study, this means the length of the TER can be reduced by approximately $55 \mathrm{~m}$, and the depth of the arrestor bed aggregate can be reduced by approximately $3.7 \mathrm{~m}$ [7]. It was also noted that when a runaway vehicle follows in the tracks of a previous runaway vehicle, the required stopping distance increases by almost $20 \%$ [7]. Therefore, the removal of theses tracks is critical in ensuring proper functioning of the TER.

These results indicate that runaway vehicle entering speed, bedding material preparation, and vehicle tracking all greatly affect the required stopping distance of a runaway vehicle and thus the distance travelled into the arrestor bed TER. 
Benefits associated to these findings include a more economical TER design as a shorter TER can be constructed, saving at least $\$ 30,000$ per site in Arizona, and hundreds of thousands of dollars in locations where large fill or cut requirements exist, such as mountainous regions [7]. Furthermore, the results show the age of the aggregate does not affect the performance as one TER arrestor bed in the study was of concern to ADOT due to its "old aggregate gradation" [7]. This means there is no need to replace this aggregate, further reducing anticipated maintenance and construction costs.

\subsection{TER Case Studies}

\subsubsection{TERs in Colorado}

A study was conducted on Colorado's TERs by the National Cooperative Highway Research Program in 1992 . This study reveals that $46 \%$ of TER usage was by runaway vehicles with a gross vehicle weight between 70,000 lbs and 80,000 lbs [4]. Furthermore, $38 \%$ of all TER entries occurred during the summer, $24 \%$ during the fall, $14 \%$ during the winter, and $24 \%$ during the spring [4]. Of the vehicles using the TER, $27 \%$ of the uses were due to failed brakes and $11 \%$ due to loss of air pressure [4]. Additionally, $47 \%$ of the runaway vehicles entered the TER at speeds ranging between $50 \mathrm{~km} / \mathrm{hr}$ and $100 \mathrm{~km} / \mathrm{hr}, 13 \%$ entered at speeds between $100 \mathrm{~km} / \mathrm{hr}$ to 130 $\mathrm{km} / \mathrm{hr}$, and $17 \%$ entered at speeds of $130 \mathrm{~km} / \mathrm{hr}$ or higher [4]. Lastly, $72 \%$ of all runaway vehicles stopped within $180 \mathrm{~m}$ [4].

The Colorado Interstate Highway 70 (I-70) in Mt. Vernon Canyon was studied in more detail. The $1-70$ is a negative grade arrestor bed with gravel type bedding material and a $5.2 \%$ downgrade [8]. Over three years, the TER stopped 53 runaway vehicles, with no injuries or fatal 
crashes reported [8]. In the same study period, 18 accidents were reported which involved runaway vehicles which did not use the TER, resulting in 24 injuries and 7 fatalities [8]. From these results it is clear that the implementation of a TER can significantly increase safety and reduce the number of fatal crashes.

\subsubsection{Drag Net TER Systems}

An alternate example of a TER design is a drag net system which includes additional elements and may reduce the required length of a TER. According to the Wyoming Department of Transportation (WYDOT), the Drag Net design is $100 \%$ successful when used by a runaway vehicle [9]. This system uses a sequence of nets which are installed along the TER and arranged in such a way as to stop the runaway vehicle within the length of the TER while diminishing deceleration forces [9]. The nets are made of aircraft cable and are connected to energy absorbers which are mounted to the TER concrete walls [9]. According to WYDOT, a 4,500 Ib runaway vehicle travelling at $100 \mathrm{~km} / \mathrm{hr}$ and intercepting a $9 \mathrm{~m}$ wide drag net will stop in approximately $25 \mathrm{~m}$ [9]. 


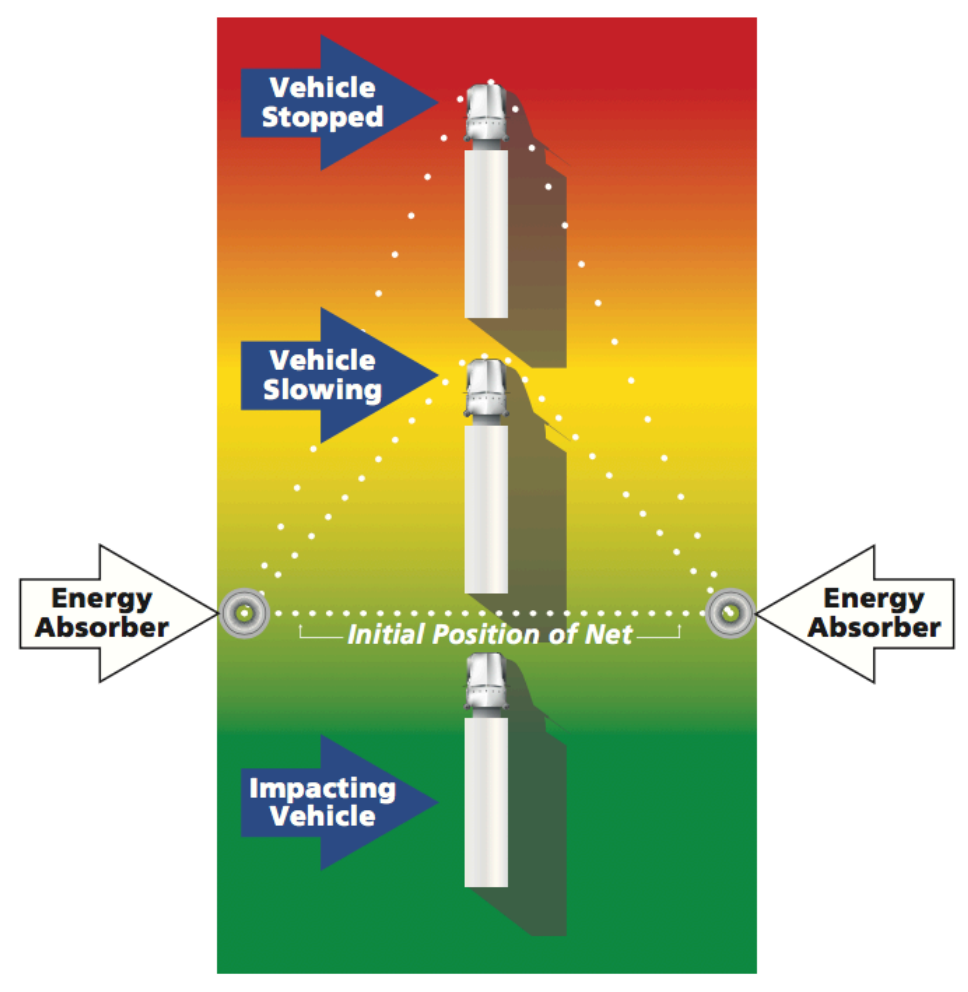

Figure 14 - Visual of Drag Net TER Design (Credit: WYDOT) [9]

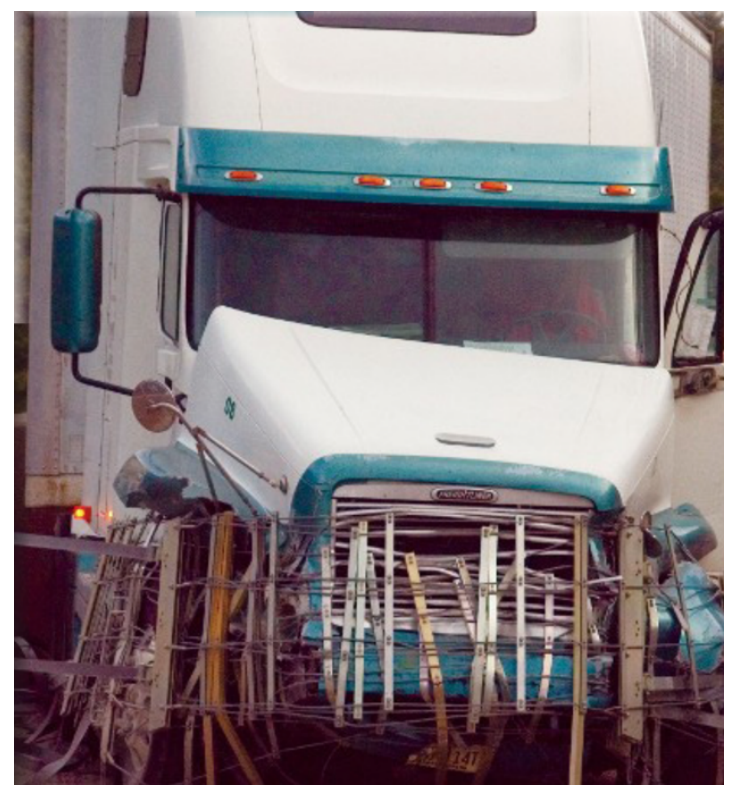

Figure 15 - Visual of Runaway Truck Using Drag Net TER Design (Credit: WYDOT) [9] 
Ten runaway vehicle cases were studied by WYDOT. In six cases, the runaway vehicle driver used the drag net TER system appropriately, resulting in no injuries and no fatalities [9]. On the other hand, in four cases, drivers bypassed the Drag Net TER system and resulted in one injury and 4 fatalities [9]. Statistics from some of these cases are shown in Table 2.

Table 2 - Drag Net TER System Statistics [9]

\begin{tabular}{|c|c|c|c|c|c|c|c|}
\hline & Date & Injuries & Fatalities & Damage & $\begin{array}{l}\text { Weight } \\
\text { of Truck } \\
\text { (lbs) }\end{array}$ & $\begin{array}{c}\text { Entering } \\
\text { Speed } \\
\text { (km/hr) }\end{array}$ & $\begin{array}{c}\text { Number } \\
\text { of Nets } \\
\text { Used }\end{array}$ \\
\hline \multirow{4}{*}{ TER USED } & $\begin{array}{c}\text { August 31, } \\
2007\end{array}$ & 0 & 0 & Minimal & 80,000 & 65 & 5 \\
\hline & $\begin{array}{c}\text { August 27, } \\
2008\end{array}$ & 0 & 0 & Minimal & 42,000 & 55 & 3 \\
\hline & $\begin{array}{c}\text { August 26, } \\
2010\end{array}$ & 0 & 0 & Minimal & 15,000 & 100 & 1 \\
\hline & $\begin{array}{c}\text { May 29, } \\
2012\end{array}$ & 0 & 0 & Minimal & 55,000 & 112 & 7 \\
\hline & $\begin{array}{c}\text { September } \\
23,2008\end{array}$ & \multicolumn{6}{|c|}{ Fatal Crash } \\
\hline TER & $\begin{array}{c}\text { April 4, } \\
2011\end{array}$ & \multicolumn{6}{|c|}{ Major Injuries } \\
\hline BYPASSED & $\begin{array}{c}\text { April 1, } \\
2012\end{array}$ & \multicolumn{6}{|c|}{ Fatal Crash } \\
\hline & $\begin{array}{c}\text { September } \\
4,2012\end{array}$ & \multicolumn{6}{|c|}{ Fatal Crash } \\
\hline
\end{tabular}

A drag net TER system has been implemented on Ontario's Highway 11 at Thibeault Hills, as seen in Figure 16 [6]. This drag net system 'catches' the runaway vehicle using seven metal nets attached to energy absorbers [6]. This design requires nominal maintenance, works very well in winter months, and only demands $140 \mathrm{~m}$ for the runaway vehicle to stop in comparison to a $370 \mathrm{~m}$ standard gravel bed [6]. 


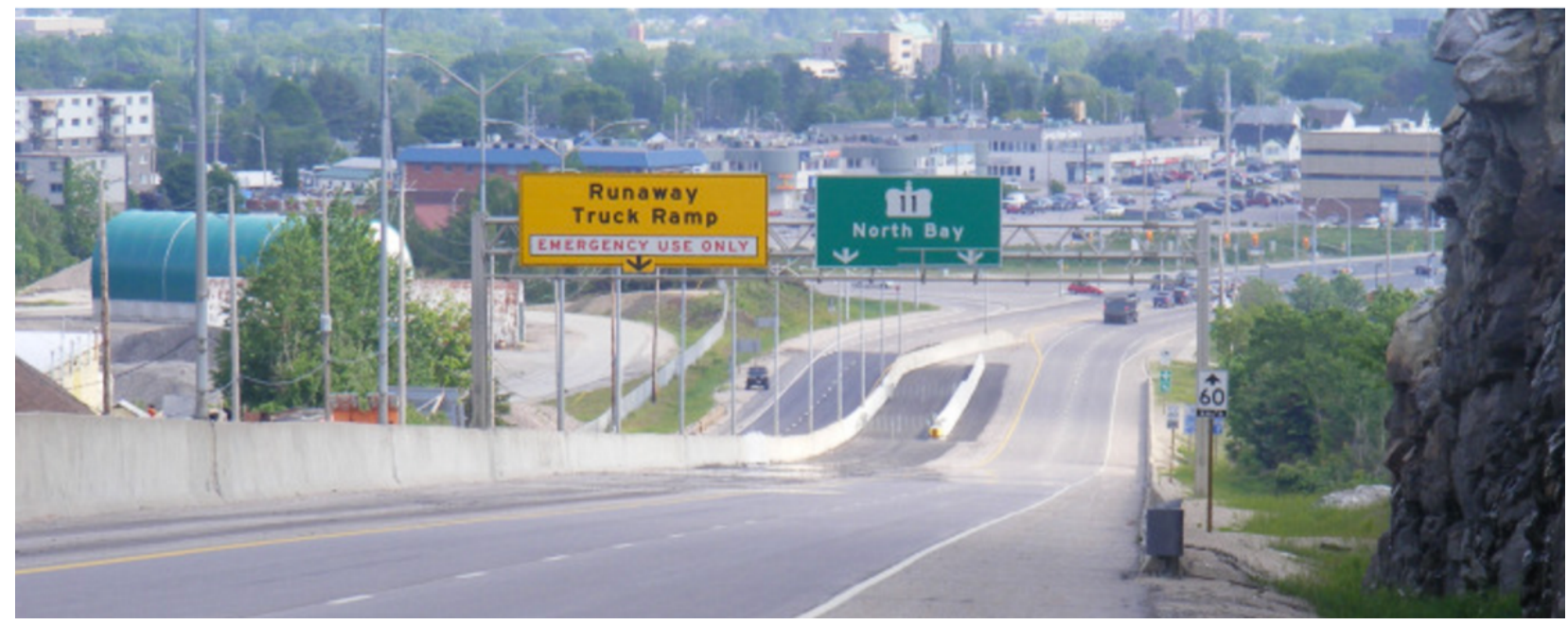

Figure 16 - Ontario's Highway 11 Drag Net TER (Credit: MTO) [6]

Since the runaway vehicle can stop in a shorter distance using a drag net system, this type of TER can be placed further down the through roadway which gives users an opportunity to determine whether or not their vehicle is experiencing brake issues prior to entering the TER [6]. 


\section{Literature Review - Reliability Models}

A reliability model is a statistical analysis tool used to limit the probability of failure of a particular engineering system of interest. In terms of reliability modelling, the term 'failure' is understood as the failure of the particular engineering system to fulfill a specific limit state criterion, which may or may not necessarily be definite system failure [10].

Reliability of an engineering system is defined as the engineering system's ability to meet the system performance requirements over a specified time period [11]. This 'ability' is measured using statistics and probability theory as the fundamental basis of analysis [10, 12]. Therefore, reliability can also be defined as the probability that failure will not ensue, and is equal to one minus the probability of failure $[10,12]$. For example, if the reliability of a system is $98 \%$, the probability of failure is equal to $2 \%$.

When analyzing the reliability of an engineering system, a performance function is established, equal to the system supply less system demand, where the failure state occurs when the performance function is negative [13]. In regards to this study, the reliability analysis attempts to eliminate the probability that the TER design length reaches failure state, where the runaway vehicle will demand a TER length that exceeds the supplied TER design length. With this in mind, designing a TER that guarantees $100 \%$ user safety is impractical, unrealistic, and extremely expensive. As a result, an acceptable probability of failure, or level of risk, must be agreed upon by the designer [14]. Once a suitable probability of failure is determined, a reliability analysis can provide information regarding the required TER design length. 
This report uses two methods of reliability analysis which limit the probability the TER design length will reach failure state. These two reliability analysis methods include the First Order Second Moment (FOSM) method and the Advanced First Order Second Moment (AFOSM) method. Each method simplifies the functional relationship of the engineering system design using a condensed Taylor series expansion where the inputs and outputs of the model are expressed as mean values with respective variance and standard deviation values [13].

The performance function of a reliability model is defined by random variables inputs, each with a respective mean value, variance, and standard deviation. The FOSM method is much simpler than the AFOSM method and expands the performance function at each random variable's mean value, whereas the AFOSM method is an iterative procedure which expands the performance function at a point on the failure boundary [13].

\subsection{Method 1 - FOSM Reliability Method}

The FOSM reliability model is so named since the analysis uses a Taylor series approximation of the first order, and only second moment information is considered regarding the random variables [15]. FOSM reliability model analysis approximates the mean value and variance of a random variable, which are also referred to as the "first two moments", where the random variable is a nonlinear function of some other random variables [13]. Assume a safety margin, $\mathrm{SM}$, is equal to a nonlinear performance function which is a function of many random variables, as displayed in Equation 3. If $\mathrm{SM}$ is equal to a negative value ( $\mathrm{SM}<0)$, then the performance function has reached a state of failure. If $S M$ is equal to $0(S M=0)$, then the performance 
function is at the limit state. If $S M$ is equal to a positive value $(S M>0)$, then the performance function is at a safe state. The goal of the reliability analysis is to avoid failure state.

$$
S M=f\left(X_{1}, X_{2}, \ldots, X_{n}\right)
$$

Using Taylor series expansion, the function $\mathrm{f}$ in Equation 3 can be expanded about the mean value of each random variable, as displayed in Equation 4 [13].

$$
S M=f\left(\mu_{X 1}, \mu_{X 2}, \ldots, \mu_{X n}\right)+\sum_{i=1}^{n}\left(X_{i}-\mu_{X i}\right)\left(\frac{\partial f}{\partial X_{i}}\right)+\epsilon
$$

Where: $\quad X_{i}=$ random variable $i$,

$$
\begin{aligned}
& \mu_{\mathrm{X}_{\mathrm{i}}}=\text { mean value of random variable } \mathrm{X} \text {, and } \\
& \epsilon=\text { error of truncating higher order terms [13]. }
\end{aligned}
$$

Next, the mean value and variance of random variable SM are given by E[SM] and $\operatorname{var}[S M]$, respectively, as follows [13]:

$$
\begin{gathered}
E[S M] \cong f\left(\mu_{X 1}, \mu_{X 2}, \ldots, \mu_{X n}\right) \\
\operatorname{var}[S M] \cong \sum_{i=1}^{n}\left(\frac{\partial f}{\partial X_{i}}\right)^{2} \sigma_{X i}^{2}+\sum_{i \neq}^{n} \sum_{j}^{n}\left(\frac{\partial f}{\partial X_{i}}\right)\left(\frac{\partial f}{\partial X_{j}}\right) \operatorname{cov}\left[X_{i}, X_{j}\right] \\
\operatorname{cov}\left[X_{i}, X_{j}\right]=\rho_{X i, X j} * \sigma_{X i} * \sigma_{X j}
\end{gathered}
$$


Where: $\quad \sigma_{x_{i}}{ }^{2}=$ variance of random variable $X_{i}$,

$$
\begin{aligned}
& \sigma_{X_{i}}=\text { standard deviation of random variable } X_{i} \text {, and } \\
& \rho_{X_{i}, x_{j}}=\text { Pearson's coefficient of correlation between } X_{i} \text { and } X_{j}[13] \text {. }
\end{aligned}
$$

Furthermore, the coefficient of variation, $\mathrm{CV}_{\mathrm{X}_{\mathrm{i}}}$, for a given random variable, $\mathrm{X}_{\mathrm{i}}$, is $\mathrm{a}$ dimensionless measure of the unpredictability, dispersion, and variability of the selected data [14]. The coefficient of variations is given by [13]:

$$
C V_{X i}=\frac{\sigma_{X i}}{\mu_{X i}}
$$

In terms of analyzing the TER length design, the probability of failure expresses the probability the supplied TER design length is shorter than the TER length demand dictated by a runaway vehicle. Consider the TER design length, $L_{\text {supply, }}$ and the distance required for a runaway vehicle to come to a complete stop given the conditions set out in the TER design, $L_{\text {demand. }}$ Since the value of $L_{\text {supply }}$ and the value of $L_{\text {demand }}$ is a function of random variables, consequently, $L_{\text {supply }}$ and $\mathrm{L}_{\text {demand }}$ are considered random variables with respective probability density functions (PDFs) [10]. Figure 17 shows the assumed PDFs for $L_{\text {supply }}$ and $L_{\text {demand }}$. The shaded area below the overlapping PDF curves indicates the failure region where $L_{\text {supply }}$ is less than $L_{\text {demand. }}$ If $L_{\text {supply }}$ is subtracted from $L_{\text {demand, }}$ the resulting value is equal to the safety margin, $S M$, and a probability curve is obtained, shown in Figure 18. The failure region, or probability of failure $\left(P_{f}\right)$, is equal to the area where SM is negative. 

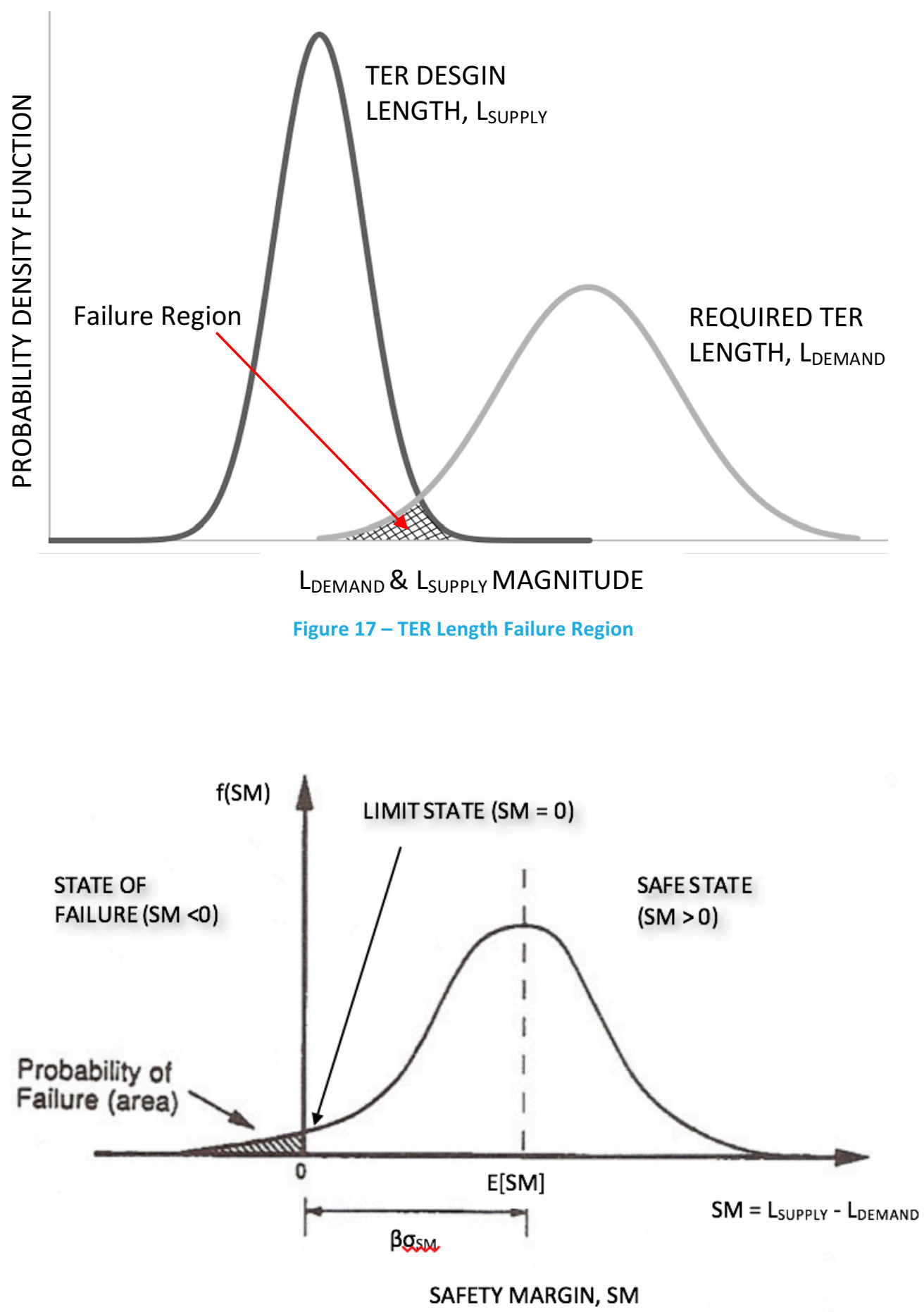

Figure 18 - Reliability Index and Probability of Failure [13]

The probability of failure is a function of a reliability index, $\beta$, which is a safety measure related to the probability that $L_{\text {demand }}$ is greater than $L_{\text {supply }}$ [14]. Alternatively, the reliability index can 
be described as a factor which expresses how reliable a system is to prevent failure [14]. Figure 18 can be used to determine a reliability index. The reliability index, $\beta$, defines the number of standard deviations between $\mu_{S M}$ and the limit state, $\mathrm{SM}=0$, where [13]:

$$
\beta=\frac{\mu_{S M}}{\sigma_{S M}}
$$

Where: $\quad \sigma_{\mathrm{SM}}=$ standard deviation of safety margin, SM.

The larger the reliability index value, the smaller the probability of failure. Assuming the safety margin, SM, has a normal distribution, and using standard normal variate tables, the probability of failure can be estimated as follows:

$$
P_{f}=\phi(-\beta)=1-\phi(\beta)
$$

Where: $\quad \Phi(-\beta)=$ area under standard normal variate PDF from $-\infty$ to $-\beta$, obtained using standard normal variate tables [13].

For a selected probability of failure, some examples of $\Phi(-\beta)$ are shown in Table 3.

Table 3 - $\beta$ Values for Respective Probability of Failure [16]

\begin{tabular}{|c|c|}
\hline $\begin{array}{c}\text { Probability } \\
\text { of Failure, Pf }\end{array}$ & Beta \\
\hline $\mathbf{1 \%}$ & 2.32 \\
\hline $\mathbf{2 \%}$ & 2.05 \\
\hline $\mathbf{3 \%}$ & 1.88 \\
\hline $\mathbf{4 \%}$ & 1.75 \\
\hline $\mathbf{5 \%}$ & 1.64 \\
\hline $\mathbf{6 \%}$ & 1.55 \\
\hline $\mathbf{7 \%}$ & 1.47 \\
\hline $\mathbf{8 \%}$ & 1.4 \\
\hline $\mathbf{9 \%}$ & 1.34 \\
\hline $\mathbf{1 0 \%}$ & 1.28 \\
\hline $\mathbf{1 5 \%}$ & 1.03 \\
\hline
\end{tabular}


Once an acceptable probability of failure is specified, meaning the TER length demand exceeds the supply length of the TER, a corresponding $\beta$ can be selected for analysis.

\subsection{Method 2-AFOSM Reliability Method}

Although the FOSM reliability method provides a rather simple reliability analysis, it suffers from the problem of invariance [15]. If the SM is linear, then the mean and standard deviation will be accurately assessed using the FOSM method, however, if the limit state function, SM, is non-linear, then the FOSM analysis uses first-order approximations and may introduce errors [15]. This means that depending on the way the same SM equation is expressed (i.e. $S M=3 y^{2}+$ $3 x y$ vs. SM $=3 y(y+x))$, different reliability index values would be produced [10]. Therefore, an invariant method, AFOSM, was developed. Based on the same principles outlined using the FOSM method, the AFOSM method uses an iterative procedure which expands SM at a point on the failure boundary, and ultimately yields a maximum probability of failure $[10,13]$. The following algorithm can be used to determine the reliability index after a number of iterations.

First, assume a safety margin, SM, equal to a nonlinear performance function which is a function of many random variables, as displayed in Equation 3. Determine an expression for a new function, $g\left(X_{i}\right)$, by replacing each random variable in the performance function with $X_{i}[10]$.

Next, substitute each $X_{i}$ using Equation 11, for all random variables to develop an expression for a new function, $h(y)[13]$.

$$
X_{i}=\sigma_{i} y_{i}+m_{i}
$$

Where: $\quad \sigma_{\mathrm{i}}=$ standard deviation of random variable $\mathrm{i}$,

$y_{i}=$ variable used for future iterations, 


$$
m_{i}=\text { mean value of random variable } i[10]
$$

Then, evolve an equation for each first derivative of $h(y), h_{i}{ }^{\prime}$.

To begin an iteration, assume values $y_{i}=0$, and $\beta=0$. Using these values, evaluate $h(y), h_{i}^{\prime}$, and $\sigma_{\mathrm{SM}}$, where the standard deviation of SM is calculated as follows [10]:

$$
\sigma_{S M}=\sqrt{\sum\left(h_{i}^{\prime}\right)^{2}}
$$

This concludes Iteration 1.

For the next iteration, calculate new values for $y_{i}$ given the following equation [10]:

$$
y_{i}=-\frac{h_{i}^{\prime}}{\sigma_{S M}}\left[\beta+\frac{h(y)}{\sigma_{S M}}\right]
$$

Finally, evaluate a new reliability index, $\beta$ using the following equation [10]:

$$
\beta=\sqrt{\sum\left(y_{i}\right)^{2}}
$$

This process is then repeated until the reliability index, $\beta$, converges. As previously mentioned, the larger the reliability index value, the smaller the probability of failure. 


\section{Development of Reliability Models for TERs}

The purpose of conducting a reliability analysis on TERs is that the existing design approach, as discussed in Section 2.5, is deterministic, and does not consider variations in the design variables or the probability that the design will fail [13].

Four cases were established for TER design analysis based on the existing design approach:

Case 1: FOSM Reliability Method - One TER Grade

Case 2: FOSM Reliability Method - Two TER Grades

Case 3: AFOSM Reliability Method - One TER Grade

Case 4: AFOSM Reliability Method - Two TER Grades

The methodology for each model is discussed in this section, along with sample calculations for each model. The results can be found in Appendix A through Appendix D.

\subsection{Case 1: FOSM Reliability Method-One TER Grade}

\subsubsection{Methodology}

The following steps were used to develop the FOSM Reliability Model for a TER with one grade.

\section{Step 1 - Define Safety Margin Equation}

The safety margin, SM, is defined as the excess length of the TER provided above and beyond the minimum design length as calculated in Equation 1. The equation is expressed as follows:

$$
S M=L_{\text {supply }}-L_{\text {demand }}
$$


Where: $\quad \mathrm{SM}=$ safety $\operatorname{margin}(\mathrm{m})$,

$$
\begin{aligned}
& L_{\text {supply }}=\text { length of TER to be supplied on the highway }(m) \text {, } \\
& L_{\text {demand }}=\text { required design length of TER as calculated using Equation } 1(\mathrm{~m}) \text {. }
\end{aligned}
$$

Rewriting Equation 15 by substituting Equation 1 for $L_{\text {demand }}$ gives:

$$
S M=L_{\text {supply }}-\frac{V_{1}^{2}}{254\left(R+G_{i}\right)}
$$

\section{Step 2 - Determine Random Variables}

Using this deterministic method, the variables include: supply length of TER $\left(L_{\text {supply }}\right)$, vehicle entering speed $\left(V_{1}\right)$, rolling resistance $(R)$, and percent grade $\left(G_{1}\right)$, all of which are random variables with the exception of $L_{\text {supply }}$ which is a deterministic variable. The random variables all have a known mean, coefficient of variation, and standard deviation, and are also not correlated.

\section{Step 3 - Set Coefficient of Variation, Mean Value, and Standard Deviation to Random}

\section{Variables}

A coefficient of variation, CV, must be set for all random variables. For the purpose of this study, the same coefficient of variation was set to all variables for each analysis. For a practical analysis, the CV value will range from $5 \%$ to $25 \%$ and analyzed at increments of $5 \%$.

Next, a mean value, $\mu_{\mathrm{i}}$, must be set to each random variable for design analysis. Firstly, for practicality purposes, the vehicle entering speed, $V_{1}$, was analyzed at mean values of $100 \mathrm{~km} / \mathrm{hr}$, 
$120 \mathrm{~km} / \mathrm{hr}$, and $140 \mathrm{~km} / \mathrm{hr}$. These speeds were selected since TER ramps are normally designed for trucks entering a TER at a speed of $130 \mathrm{~km} / \mathrm{hr}$ to $140 \mathrm{~km} / \mathrm{hr}$ [3]. However, in reality, trucks can enter a TER at lower speeds such as $100 \mathrm{~km} / \mathrm{hr}$ or $120 \mathrm{~km} / \mathrm{hr}$. Secondly, the rolling resistance, $R$, was analyzed at a mean value corresponding to pea gravel, $0.25 \mathrm{~kg} / \mathrm{kg} \mathrm{GVM}$, as selected from Table 1. This value was selected since the majority of TERs analyzed in Section 2.7 use pea gravel. Lastly, the percent grade, $G_{1}$, was analyzed at mean values ranging from $+10 \%$ to $-10 \%$ for practicality purposes.

The standard deviation, $\sigma$, must be calculated for each random variable using the following equation:

$$
\sigma_{i}=C V * \mu_{i}
$$

\section{Step 4 - Calculate Mean, Variance, and Standard Deviation of SM}

The mean of SM, $\mu_{S M}$, variance of SM, $\sigma_{S M}^{2}$, and standard deviation of $\mathrm{SM}, \sigma_{S M}$, are given by:

$$
\begin{gathered}
\mu_{S M}=L_{\text {supply }}-\frac{\mu_{V 1}{ }^{2}}{254\left(\mu_{R}+\mu_{G 1}\right)} \\
\sigma_{S M}^{2}=\left(\frac{\partial S M}{\partial V_{1}}\right)^{2} * \sigma_{V 1}^{2}+\left(\frac{\partial S M}{\partial R}\right)^{2} * \sigma_{R}^{2}+\left(\frac{\partial S M}{\partial G_{1}}\right)^{2} * \sigma_{G 1}^{2}
\end{gathered}
$$

Where:

$$
\frac{\partial S M}{\partial V_{1}}=\frac{2 * \mu_{V 1}}{254\left(\mu_{R}+\mu_{G 1}\right)}
$$




$$
\begin{aligned}
& \frac{\partial S M}{\partial R}=\frac{-254 * \mu_{V 1}^{2}}{\left(254\left(\mu_{R}+\mu_{G 1}\right)\right)^{2}} \\
& \frac{\partial S M}{\partial G_{1}}=\frac{-254 * \mu_{V 1}^{2}}{\left(254\left(\mu_{R}+\mu_{G 1}\right)\right)^{2}}
\end{aligned}
$$

And:

$$
\sigma_{S M}=\sqrt{\sigma_{S M}^{2}}
$$

The values selected in Step 3 are then substituted into Equation 18 through Equation 23 to generate an equation for the mean value of SM as a function of $L_{\text {supply }}$ and a value for the variance and standard deviation of SM.

\section{Step 5 - Define Desired Probability of Failure, $\mathbf{P}_{\mathrm{f}}$, and Reliability Index, $\beta$}

The desired probability of failure, $\mathrm{P}_{\mathrm{f}}$, must be selected by the user for the desired analysis. Typical and realistic $P_{f}$ values range from $1 \%$ to $5 \%$, however, $P_{f}$ values between $1 \%$ to $15 \%$ were selected for experimentation. For the purposes of this report, an accurate analysis was desired for a small probability of failure, therefore each percent value from $1 \%$ to $10 \%$ was analyzed in Case 1.

Based on normal distribution tables, the corresponding reliability index, $\beta$, is determined based on the desired $\mathrm{P}_{\mathrm{f}}$, as listed in Table 4. 
Table 4 - $\beta$ Values for Respective Probability of Failure [16]

\begin{tabular}{|c|c|}
\hline $\begin{array}{c}\text { Probability } \\
\text { of Failure, Pf }\end{array}$ & Beta \\
\hline $\mathbf{1 \%}$ & 2.32 \\
\hline $\mathbf{2 \%}$ & 2.05 \\
\hline $\mathbf{3 \%}$ & 1.88 \\
\hline $\mathbf{4 \%}$ & 1.75 \\
\hline $\mathbf{5 \%}$ & 1.64 \\
\hline $\mathbf{6 \%}$ & 1.55 \\
\hline $\mathbf{7 \%}$ & 1.47 \\
\hline $\mathbf{8 \%}$ & 1.4 \\
\hline $\mathbf{9 \%}$ & 1.34 \\
\hline $\mathbf{1 0 \%}$ & 1.28 \\
\hline $\mathbf{1 5 \%}$ & 1.03 \\
\hline
\end{tabular}

After defining the desired $P_{f}$ and obtaining a $\beta$ value, Equation 9 must be rearranged as follows:

$$
\mu_{S M}=\sigma_{S M} * \beta
$$

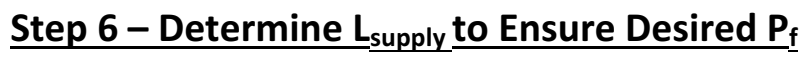

Rearranging Equation 18 and substituting Equation 24 gives:

$$
\begin{gathered}
L_{\text {supply }}=\mu_{S M}+\frac{\mu_{V 1}{ }^{2}}{254\left(\mu_{R}+\mu_{G 1}\right)} \\
L_{\text {supply }}=\sigma_{S M} * \beta+\frac{\mu_{V 1}{ }^{2}}{254\left(\mu_{R}+\mu_{G 1}\right)}
\end{gathered}
$$

Repeating Step 3 through Step 6, $L_{\text {supply }}$ is then calculated for each combination of CV and $P_{f}$, for a given combination of the random variables $V_{1}, G_{1}$, and $R$. 


\subsubsection{Sample Calculations and Results}

The FOSM Reliability Method was conducted for various TER design scenarios with a single grade using varying values for the TER grade and vehicle entering speed. For consistency, the TER design material, pea gravel, was held constant. Furthermore, the majority of the analysis was conducted using a design speed of $140 \mathrm{~km} / \mathrm{hr}$ in order to simulate a real life scenario where runaway trucks will be travelling at very high speeds, rather than speeds of $100 \mathrm{~km} / \mathrm{hr}$ or below.

The desired scenarios used for analysis are as follows:

Scenario 1: Grade $=+2 \%$, Speed $=140 \mathrm{~km} / \mathrm{hr}$, Rolling Resistance $($ Pea Gravel $)=0.25 \mathrm{~kg} / \mathrm{kgGVM}$

Scenario 2: Grade $=+2 \%$, Speed $=120 \mathrm{~km} / \mathrm{hr}$, Rolling Resistance $($ Pea Gravel $)=0.25 \mathrm{~kg} / \mathrm{kgGVM}$

Scenario 3: Grade $=+2 \%$, Speed $=100 \mathrm{~km} / \mathrm{hr}$, Rolling Resistance $($ Pea Gravel $)=0.25 \mathrm{~kg} / \mathrm{kgGVM}$

Scenario 4: Grade $=0 \%$, Speed $=140 \mathrm{~km} / \mathrm{hr}$, Rolling Resistance $($ Pea Gravel $)=0.25 \mathrm{~kg} / \mathrm{kgGVM}$

Scenario 5: Grade $=+4 \%$, Speed $=140 \mathrm{~km} / \mathrm{hr}$, Rolling Resistance $($ Pea Gravel $)=0.25 \mathrm{~kg} / \mathrm{kgGVM}$

Scenario 6: Grade $=+6 \%$, Speed $=140 \mathrm{~km} / \mathrm{hr}$, Rolling Resistance $($ Pea Gravel $)=0.25 \mathrm{~kg} / \mathrm{kgGVM}$

Scenario 7: Grade $=+8 \%$, Speed $=140 \mathrm{~km} / \mathrm{hr}$, Rolling Resistance $($ Pea Gravel $)=0.25 \mathrm{~kg} / \mathrm{kgGVM}$

Scenario 8: Grade $=+10 \%$, Speed $=140 \mathrm{~km} / \mathrm{hr}$, Rolling Resistance $($ Pea Gravel $)=0.25 \mathrm{~kg} / \mathrm{kgGVM}$

Scenario 9: Grade $=-2 \%$, Speed $=140 \mathrm{~km} / \mathrm{hr}$, Rolling Resistance $($ Pea Gravel $)=0.25 \mathrm{~kg} / \mathrm{kgGVM}$

Scenario 10: Grade $=-4 \%$, Speed $=140 \mathrm{~km} / \mathrm{hr}$, Rolling Resistance $($ Pea Gravel $)=0.25 \mathrm{~kg} / \mathrm{kgGVM}$

Scenario 11: Grade $=-6 \%$, Speed $=140 \mathrm{~km} / \mathrm{hr}$, Rolling Resistance $($ Pea Gravel $)=0.25 \mathrm{~kg} / \mathrm{kgGVM}$ 
Scenario 12: Grade $=-8 \%$, Speed $=140 \mathrm{~km} / \mathrm{hr}$, Rolling Resistance $($ Pea Gravel $)=0.25 \mathrm{~kg} / \mathrm{kgGVM}$

Scenario 13: Grade $=-10 \%$, Speed $=140 \mathrm{~km} / \mathrm{hr}$, Rolling Resistance $($ Pea Gravel $)=0.25 \mathrm{~kg} / \mathrm{kgGVM}$

Sample calculations and results regarding Scenario 1 are provided in this section. Step 3 through Step 6, as outlined in Section 4.1.1, are carried out in detail in order to develop sample calculations for Case 1, Scenario 1. Scenario 1 assumes a TER using pea gravel with a $2 \%$ upgrade and $140 \mathrm{~km} / \mathrm{hr}$ entering vehicle speed. A brief discussion of the results regarding Scenario 1 through Scenario 13 is also included in this section. The results and visuals regarding Scenario 2 through Scenario 13 can be found in Appendix A.

\section{Step 3 - Set Coefficient of Variation, Mean Value, and Standard Deviation to Random}

\section{Variables}

For a practical analysis, the selected CV values are:

\section{$5 \% \quad 10 \% \quad 15 \% \quad 20 \% \quad 25 \%$}

The following mean values were selected for each random variable:

Table 5 - Selected Mean Values for Each Random Variable

\begin{tabular}{|c|c|}
\hline Random Variable & Mean Value, $\boldsymbol{\mu}$ \\
\hline $\mathbf{V}_{\mathbf{1}}$ & $140 \mathrm{~km} / \mathrm{hr}$ \\
\hline $\mathbf{R}$ & $0.25 \mathrm{~kg} / \mathrm{kg} \mathrm{GVM}$ \\
\hline $\mathbf{G}_{1}$ & +0.02 \\
\hline
\end{tabular}


Using Equation 17, the standard deviation, $\sigma$, was calculated for each random variable at each selected $C V$ value. A sample calculation for random variable $V$ and $C V=5 \%$ is shown below. The results of this step are shown in Table 6.

$$
\sigma_{V}=C V * \mu_{V}=0.05 * 140 \mathrm{~km} / \mathrm{hr}=7 \mathrm{~km} / \mathrm{hr}
$$

Table 6 - Calculated Standard Deviation for each Random Variable at Varying CV Values

\begin{tabular}{|c|c|c|c|c|c|}
\hline & $C V=5 \%$ & $C V=10 \%$ & $C V=15 \%$ & $C V=20 \%$ & $C V=25 \%$ \\
\hline Standard Deviation of V & 7 & 14 & 21 & 28 & 35 \\
\hline Standard Deviation of $\mathbf{R}$ & 0.0125 & 0.025 & 0.0375 & 0.05 & 0.0625 \\
\hline Standard Deviation of G & 0.001 & 0.002 & 0.003 & 0.004 & 0.005 \\
\hline
\end{tabular}

\section{Step 4 - Calculate Mean, Variance, and Standard Deviation of SM}

The mean of SM, $\mu_{S M}$, variance of SM, $\sigma_{S M}^{2}$, and standard deviation of SM, $\sigma_{S M}$, were calculated using Equation 18 through Equation 23. First, the mean values of each random variable were substituted into Equation 18 , leaving the function in terms of $L_{\text {supply, }}$ as follows:

$$
\begin{gathered}
\mu_{S M}=L_{\text {supply }}-\frac{140^{2}}{254(0.25+0.02)} \\
\mu_{S M}=L_{\text {supply }}-285.798
\end{gathered}
$$

Next, Equation 19 was used to calculate the variance of the safety margin at each selected CV value by first substituting the mean values of each random variable into Equation 20 through Equation 22 as shown below:

$$
\frac{d S M}{d V_{1}}=\frac{2 * 140}{254 *(0.25+0.02)}=4.083
$$




$$
\begin{aligned}
& \frac{d S M}{d R}=\frac{-254 * 140^{2}}{(254 *(0.25+0.02))^{2}}=-1058.51 \\
& \frac{d S M}{d G_{1}}=\frac{-254 * 140^{2}}{(254 *(0.25+0.02))^{2}}=-1058.51
\end{aligned}
$$

A sample calculation for the variance and standard deviation of SM for a CV $=5 \%$ are shown below. The results of these steps are displayed in Table 7.

$$
\begin{gathered}
\sigma_{S M}^{2}=(4.083)^{2} * 7^{2}+(-1058.51)^{2} * 0.0125^{2}+(-1058.51)^{2} * 0.001^{2}=993 \\
\sigma_{S M}=\sqrt{993}=31.5
\end{gathered}
$$

Table 7 - Calculated Variance of SM and Standard Deviation of SM at Varying CV Values

\begin{tabular}{|c|c|c|c|c|c|}
\hline & CV $=5 \%$ & CV $=10 \%$ & CV $=15 \%$ & CV $=20 \%$ & CV $=25 \%$ \\
\hline Variance of SM & 993.0 & 3972.0 & 8936.9 & 15887.9 & 24824.8 \\
\hline Standard Deviation of SM & 31.5 & 63.0 & 94.5 & 126.0 & 157.6 \\
\hline
\end{tabular}

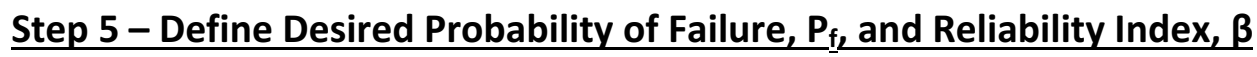

As previously mentioned in Section 4.1.1, the desired probability of failure, $P_{f}$, and corresponding reliability index, $\beta$, were selected as follows:

Table 8 - Selected $P_{f}$ and Corresponding $\beta$ Values [16]

\begin{tabular}{|c|c|c|c|}
$\begin{array}{c}\text { Probability } \\
\text { of Failure, } \\
\text { Pf }\end{array}$ & Beta & $\begin{array}{c}\text { Probability } \\
\text { of Failure, } \\
\text { Pf }\end{array}$ & Beta \\
\hline $\mathbf{1 \%}$ & 2.32 & $\mathbf{7 \%}$ & 1.47 \\
\hline $\mathbf{2 \%}$ & 2.05 & $\mathbf{8 \%}$ & 1.4 \\
\hline $\mathbf{3 \%}$ & 1.88 & $\mathbf{9 \%}$ & 1.34 \\
\hline $\mathbf{4 \%}$ & 1.75 & $\mathbf{1 0 \%}$ & 1.28 \\
\hline $\mathbf{5 \%}$ & 1.64 & $\mathbf{1 5 \%}$ & 1.03 \\
\hline $\mathbf{6 \%}$ & 1.55 & & \\
\hline
\end{tabular}




\section{$\underline{\text { Step } 6 \text { - Determine } L_{s u p p l y} \text { to Ensure Desired } P_{f}}$}

In order to determine $\mathrm{L}_{\text {supply }}$ for each selected $\mathrm{CV}$ value and desired $\mathrm{P}_{\mathrm{f}}$, Equation 25 was used.

The sample calculation is provided below for a $C V=5 \%, P_{f}=1 \%$, and $\beta=2.32$ :

$$
L_{\text {supply }}=31.5 * 2.32+\frac{140^{2}}{254(0.25+0.02)}=358.9 \mathrm{~m}
$$

Repeating Step 3 through Step 6, $L_{\text {supply }}$ is then calculated for each combination of CV and $\mathrm{P}_{\mathrm{f}}$.

The results for all $\mathrm{L}_{\text {supply }}$ values are displayed in Table 9 with a visual representation displayed in

Figure 19.

Table $9-L_{\text {supply }}$ Values at Corresponding $P_{f}$ and CV Values

\begin{tabular}{|c|c|c|c|c|c|}
\hline $\begin{array}{c}\text { Probability of } \\
\text { Failure, } P_{f}\end{array}$ & $\begin{array}{c}\mathrm{L}_{\text {supply }}(\mathrm{m}) \text {, } \\
\text { CV }=5 \%\end{array}$ & $\begin{array}{c}L_{\text {supply }}(m), \\
\text { CV }=10 \%\end{array}$ & $\begin{array}{c}L_{\text {supply }}(m), \\
C V=15 \%\end{array}$ & $\begin{array}{l}L_{\text {supply }}(\mathrm{m}), \\
\text { CV }=20 \%\end{array}$ & $\begin{array}{r}L_{\text {supply }}(\mathrm{m}) \\
\mathrm{CV}=25 \%\end{array}$ \\
\hline $1 \%$ & 358.9 & 432.0 & 505.1 & 578.2 & 651.3 \\
\hline $2 \%$ & 350.4 & 415.0 & 479.6 & 544.2 & 608.8 \\
\hline $3 \%$ & 345.0 & 404.3 & 463.5 & 522.8 & 582.0 \\
\hline $4 \%$ & 340.9 & 396.1 & 451.2 & 506.4 & 561.5 \\
\hline $5 \%$ & 337.5 & 389.2 & 440.8 & 492.5 & 544.2 \\
\hline $6 \%$ & 334.6 & 383.5 & 432.3 & 481.2 & 530.0 \\
\hline $7 \%$ & 332.1 & 378.4 & 424.8 & 471.1 & 517.4 \\
\hline $8 \%$ & 329.9 & 374.0 & 418.1 & 462.3 & 506.4 \\
\hline $9 \%$ & 328.0 & 370.2 & 412.5 & 454.7 & 496.9 \\
\hline $10 \%$ & 326.1 & 366.5 & 406.8 & 447.1 & 487.5 \\
\hline $15 \%$ & 318.3 & 350.7 & 383.2 & 415.6 & 448.1 \\
\hline
\end{tabular}


Supply Length of TER vs Probability of Failure

( $\mathrm{G}=+2 \%, \mathrm{~V}=140 \mathrm{~km} / \mathrm{hr}$ )

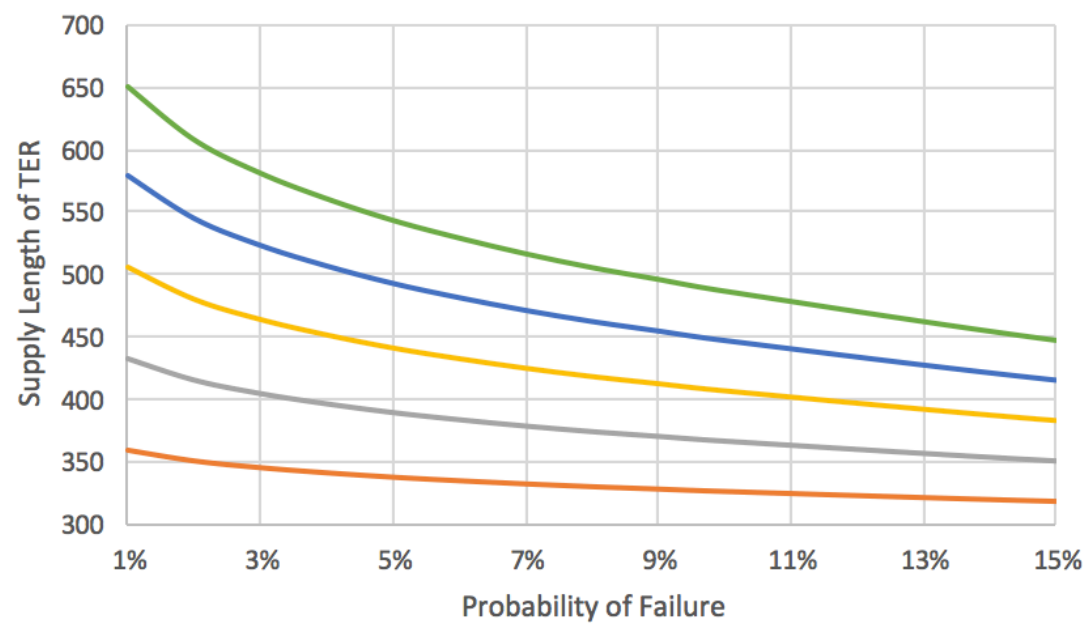

$-\mathrm{CV}=5 \%-\mathrm{CV}=10 \% \quad \mathrm{CV}=15 \% \quad \mathrm{CV}=20 \% \quad-\mathrm{CV}=25 \%$

Figure 19 - FOSM Visual Representation of $L_{\text {supply }}$ for a TER using G $=+2 \%, V=140 \mathrm{~km} / \mathrm{hr}$, and $R=0.25 \mathrm{~kg} / \mathrm{kgGVM}$

\subsection{Case 2: FOSM Reliability Method - Two TER Grades}

\subsubsection{Methodology}

The following steps were used in order to develop the FOSM Reliability Model for a TER with more than one grade. Since this case analyzes two grades, the problem must be split up into two segments, as shown in Figure 20.

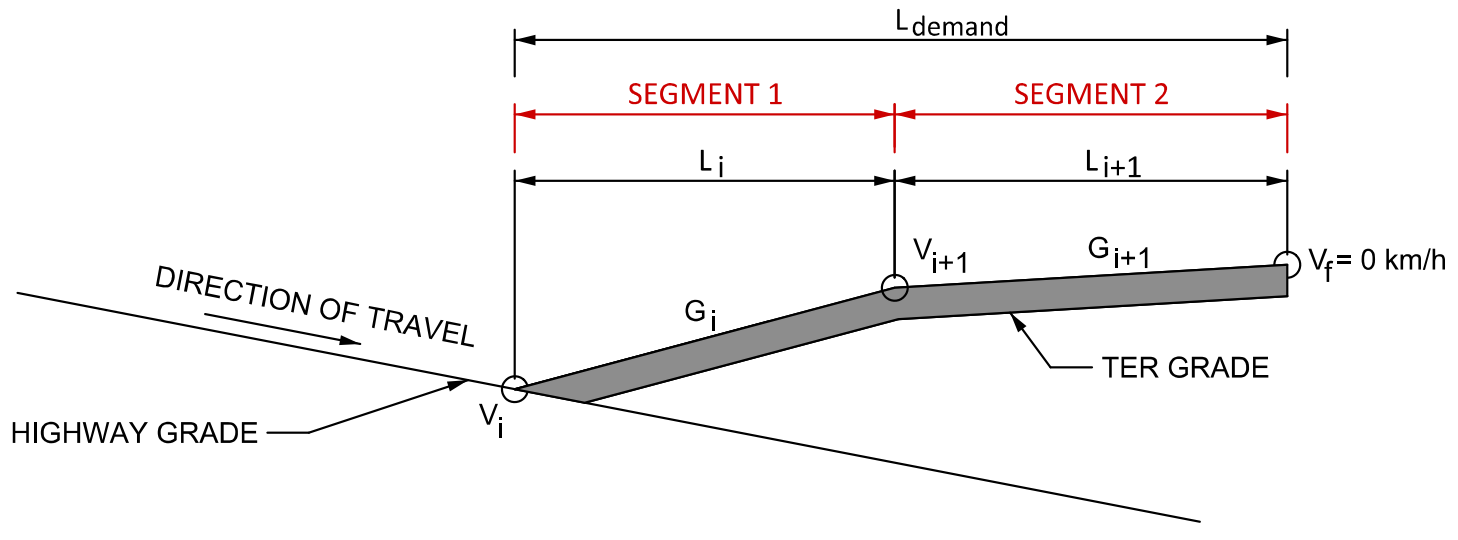

Figure 20 - Visual of TER Split into Segment 1 and Segment 2 


\section{Segment 1}

Segment 1 analyzes the first length of the TER, $L_{1}$, and the goal is to determine the mean value and standard deviation of the vehicle's speed exiting Segment 1 and entering Segment $2, V_{2}$.

\section{Step 1 - Define Length of Segment 1}

The length of Segment 1, $L_{1}$, must be predetermined for analysis. For the purpose of this study, $L_{1}=1 \mathrm{~m}$ was selected for all scenarios.

\section{Step 2 - Define Equation to Determine Segment 1 Exiting Speed, $\mathbf{V}_{2}$}

As established in Equation 2, $V_{2}$ is expressed as follows:

$$
V_{2}=\sqrt{V_{1}^{2}-254 * L_{1} *\left(R+G_{1}\right)}
$$

\section{Step 3 - Determine Random Variables}

Using this deterministic method, the exiting speed variables include: entering vehicle speed

$\left(V_{1}\right)$, rolling resistance $(R)$, percent grade of Segment $1\left(G_{1}\right)$, and length of TER Segment $1\left(L_{1}\right)$, all of which are random variables with the exception of $L_{1}$ which is a deterministic variable. These random variables all have a known mean, coefficient of variation, and standard deviation, and are also not correlated.

Step 4 - Set Coefficient of Variation, Mean Value, and Standard Deviation to Random

\section{Variables}

A coefficient of variation, $\mathrm{CV}$, must be set for all random variables. For the purpose of this study, the same coefficient of variation was set to all variables for each analysis. For a practical analysis, the CV value will range from $5 \%$ to $25 \%$ and analyzed at increments of $5 \%$. 
Next, a mean value, $\mu_{i}$, must be set to each random variable for design analysis. Firstly, for practicality and consistency purposes, the vehicle entering speed, $V_{1}$, was analyzed at mean values of $120 \mathrm{~km} / \mathrm{hr}$, and $140 \mathrm{~km} / \mathrm{hr}$. Secondly, the rolling resistance, $\mathrm{R}$, was analyzed at a mean value corresponding to pea gravel, $0.25 \mathrm{~kg} / \mathrm{kg}$ GVM, as selected from Table 1 . Lastly, the percent grade for Segment $1, G_{1}$, was analyzed at a mean value of $0 \%$.

The standard deviation, $\sigma$, must be calculated for each random variable using Equation 17 described in Section 4.1.1.

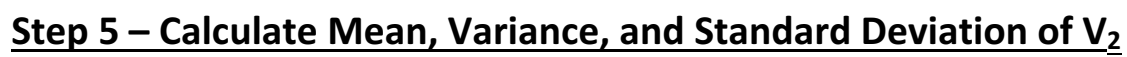

The mean of $\mathrm{V}_{2}, \mu_{V 2}$, variance of $\mathrm{V}_{2}, \sigma_{\mathrm{V} 2}^{2}$, and standard deviation of $\mathrm{V}_{2}, \sigma_{\mathrm{V} 2}$, are given by:

$$
\begin{gathered}
\mu_{\mathrm{V} 2}=\sqrt{\mu_{V 1}^{2}-254 * L_{1} *\left(\mu_{R}+\mu_{G 1}\right)} \\
\sigma_{V 2}^{2}=\left(\frac{\partial V_{2}}{\partial V_{1}}\right)^{2} * \sigma_{V 1}^{2}+\left(\frac{\partial V_{2}}{\partial R}\right)^{2} * \sigma_{R}^{2}+\left(\frac{\partial V_{2}}{\partial G_{1}}\right)^{2} * \sigma_{G 1}^{2}
\end{gathered}
$$

Where:

$$
\begin{gathered}
\frac{\partial V_{2}}{\partial V_{1}}=\mu_{V 1}\left(\mu_{V 1}^{2}-254 * L_{1} *\left(\mu_{R}+\mu_{G 1}\right)\right)^{-0.5} \\
\frac{\partial V_{2}}{\partial R}=-127 * L_{1} *\left(\mu_{V 1}^{2}-254 * L_{1} *\left(\mu_{R}+\mu_{G 1}\right)\right)^{-0.5} \\
\frac{\partial V_{2}}{\partial G_{1}}=-127 * L_{1} *\left(\mu_{V 1}^{2}-254 * L_{1} *\left(\mu_{R}+\mu_{G 1}\right)\right)^{-0.5}
\end{gathered}
$$


And:

$$
\sigma_{V 2}=\sqrt{\sigma_{V 2}^{2}}
$$

The values selected in Step 4 are then substituted into Equation 27 through Equation 32 to generate a value for the mean, variance, and standard deviation of $V_{2}$. The mean value and standard deviation of $\mathrm{V}_{2}$ calculated in Segment 1 will then be used in Segment 2.

\section{Segment 2}

\section{Step 1 - Define Safety Margin Equation}

As established in Equation 15 of Case 1, the safety margin, SM, is defined as the excess length of the TER provided above and beyond the minimum design length.

$$
S M=L_{\text {supply }}-L_{\text {demand }}
$$

Where:

$$
\begin{gathered}
L_{\text {demand }}=L_{1}+L_{2} \\
L_{\text {demand }}=1 m+\frac{V_{2}^{2}}{254\left(R+G_{2}\right)}
\end{gathered}
$$

Substituting Equation 33 into Equation 15 gives:

$$
S M=L_{\text {supply }}-1 m-\frac{V_{2}^{2}}{254\left(R+G_{2}\right)}
$$




\section{Step 2 - Determine Random Variables}

Using this deterministic method, the variables include: supply length of TER $\left(L_{\text {supply }}\right)$, vehicle entering speed $\left(V_{2}\right)$, rolling resistance $(R)$, and percent grade of Segment $2\left(G_{2}\right)$, all of which are random variables with the exception of $L_{\text {supply }}$ which is a deterministic variable. The random variables all have a known mean, coefficient of variation, and standard deviation, and are also not correlated.

\section{Step 3 - Set Coefficient of Variation, Mean Value, and Standard Deviation to Random}

\section{$\underline{\text { Variables }}$}

A coefficient of variation, CV, must be set for all random variables. For consistency, the same coefficient of variation set for each analysis in Segment 1 was set to all variables in Segment 2.

Next, a mean value, $\mu_{i}$, must be set to each random variable for design analysis, however, the vehicle entering speed, $V_{2}$, will take the mean value calculated in Segment 1 . Secondly, the rolling resistance, $\mathrm{R}=0.25 \mathrm{~kg} / \mathrm{kg} \mathrm{GVM}$, will remain constant as selected in Segment 1 . Lastly, the percent grade for Segment $2, G_{2}$, is analyzed at mean values ranging from $+1 \%$ to $+4 \%$ for practicality purposes.

The standard deviation, $\sigma$, must be calculated for each random variable using Equation 17 described in Section 4.1.1, with the exception of $V_{2}$ which was calculated in Segment 1. 


\section{Step 4 - Calculate Mean, Variance, and Standard Deviation of SM}

The mean of SM, $\mu_{S M}$, variance of $\mathrm{SM}, \sigma_{S M}^{2}$, and standard deviation of $\mathrm{SM}, \sigma_{S M}$, are given by:

$$
\begin{gathered}
\mu_{S M}=L_{\text {supply }}-1 m-\frac{\mu_{V 2}{ }^{2}}{254\left(\mu_{R}+\mu_{G 2}\right)} \\
\sigma_{S M}^{2}=\left(\frac{\partial S M}{\partial V_{2}}\right)^{2} * \sigma_{V 2}^{2}+\left(\frac{\partial S M}{\partial R}\right)^{2} * \sigma_{R}^{2}+\left(\frac{\partial S M}{\partial G_{2}}\right)^{2} * \sigma_{G 2}^{2}
\end{gathered}
$$

Where:

$$
\begin{aligned}
& \frac{\partial S M}{\partial V_{2}}=\frac{-\mu_{V 2}}{127 *\left(\mu_{R}+\mu_{G 2}\right)} \\
& \frac{\partial S M}{\partial R}=\frac{\mu_{V 2}^{2}}{254 *\left(\mu_{R}+\mu_{G 2}\right)^{2}} \\
& \frac{\partial S M}{\partial G_{2}}=\frac{\mu_{V 2}^{2}}{254 *\left(\mu_{R}+\mu_{G 2}\right)^{2}}
\end{aligned}
$$

And:

$$
\sigma_{S M}=\sqrt{\sigma_{S M}^{2}}
$$

The values selected in Step 3 are then substituted into Equation 35 through Equation 40 to generate a value for the variance and standard deviation of SM as well as an equation for the mean value of $S M$ as a function of $L_{\text {supply. }}$ 


\section{Step 5 - Define Desired Probability of Failure, $P_{f}$ and Reliability Index, $\beta$}

The desired probability of failure, $P_{f}$, must be selected by the user for the desired analysis. Typical and realistic $P_{f}$ values range from $1 \%$ to $5 \%$, however, $P_{f}$ values between $1 \%$ to $15 \%$ were selected for experimentation. For the purposes of this report, an accurate analysis was desired for a small probability of failure, therefore each percent value from $1 \%$ to $10 \%$ was analyzed in Case 2. Based on normal distribution tables, the corresponding reliability index, $\beta$, is determined based on the desired $P_{f}$, as listed in Table 4. After defining the desired $P_{f}$ and obtaining a $\beta$ value, Equation 9 must be rearranged as follows:

$$
\mu_{S M}=\sigma_{S M} * \beta
$$

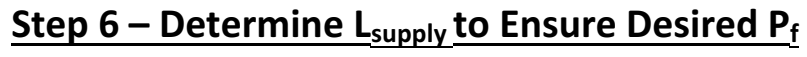

Rearranging Equation 18 and substituting Equation 41 gives:

$$
\begin{gathered}
L_{\text {supply }}=\mu_{S M}+1 m+\frac{\mu_{V 2}{ }^{2}}{254\left(\mu_{R}+\mu_{G 2}\right)} \\
L_{\text {supply }}=\sigma_{S M} * \beta+1 m+\frac{\mu_{V 2}{ }^{2}}{254\left(\mu_{R}+\mu_{G 2}\right)}
\end{gathered}
$$

Repeating Step 3 through Step 6, $L_{\text {supply }}$ is then calculated for each combination of $C V$ and $P_{f}$, for a given combination of the random variables $V_{1}, G_{2}$, and $R$.

\subsubsection{Sample Calculations and Results}

The FOSM Reliability Method was also conducted for various TER design scenarios with two grades using varying values for the TER grade and vehicle entering speed. For consistency, the 
TER design material, pea gravel, was held constant. Furthermore, the majority of the analysis was conducted using a design speed of $140 \mathrm{~km} / \mathrm{hr}$ in order to simulate a real life scenario where runaway trucks will be travelling at very high speeds.

The desired scenarios used for analysis are as follows:

Scenario 1: Grade $1=0 \%$, Grade $2=+4 \%$, Speed $=140 \mathrm{~km} / \mathrm{hr}$, Rolling Resistance (Pea Gravel) $=$ $0.25 \mathrm{~kg} / \mathrm{kgGVM}$

Scenario 2: Grade $1=0 \%$, Grade $2=+4 \%$, Speed $=120 \mathrm{~km} / \mathrm{hr}$, Rolling Resistance (Pea Gravel) $=$ $0.25 \mathrm{~kg} / \mathrm{kgGVM}$

Scenario 3: Grade $1=0 \%$, Grade $2=+3 \%$, Speed $=140 \mathrm{~km} / \mathrm{hr}$, Rolling Resistance (Pea Gravel) $=$ $0.25 \mathrm{~kg} / \mathrm{kgGVM}$

Scenario 4: Grade $1=0 \%$, Grade $2=+2 \%$, Speed $=140 \mathrm{~km} / \mathrm{hr}$, Rolling Resistance (Pea Gravel) $=$ $0.25 \mathrm{~kg} / \mathrm{kgGVM}$

Scenario 5: Grade $1=0 \%$, Grade $2=+1 \%$, Speed $=140 \mathrm{~km} / \mathrm{hr}$, Rolling Resistance (Pea Gravel) $=$ $0.25 \mathrm{~kg} / \mathrm{kgGVM}$

Sample calculations and results regarding Scenario 1 are provided in this section. The steps regarding Segment 1 and Segment 2, as outlined in Section 4.2.1, are carried out in detail in this section in order to develop sample calculations for Case 2, Scenario 1. Scenario 1 assumes a TER using pea gravel with a $0 \%$ grade for Segment 1, a $4 \%$ upgrade for Segment 2, and 140km/hr entering vehicle speed. A brief discussion of the results regarding Scenario 1 through Scenario 5 
is also included in this section. The results and visuals regarding Scenario 2 through Scenario 5 can be found in Appendix B.

\section{Segment 1}

Step 4 and Step 5, as outlined in Segment 1 of Section 4.2.1, are described in detail below.

Step 4 - Set Coefficient of Variation, Mean Value, and Standard Deviation to Random

\section{$\underline{\text { Variables }}$}

For a practical analysis, the selected CV values are:

\section{$5 \% \quad 10 \% \quad 15 \% \quad 20 \% \quad 25 \%$}

The following mean values were selected for each random variable:

Table 10 - Selected Mean Values for Each Random Variable

\begin{tabular}{|c|c|}
\hline Random Variable & Mean Value, $\boldsymbol{\mu}$ \\
\hline $\mathbf{V}_{\mathbf{1}}$ & $140 \mathrm{~km} / \mathrm{hr}$ \\
\hline $\mathbf{R}$ & $0.25 \mathrm{~kg} / \mathrm{kg} \mathrm{GVM}$ \\
\hline $\mathbf{G}_{1}$ & 0.00 \\
\hline
\end{tabular}

Using Equation 17, the standard deviation, $\sigma$, was calculated for each random variable at each selected $\mathrm{CV}$ value. A sample calculation for random variable $\mathrm{V}_{1}$ and $\mathrm{CV}=5 \%$ is shown below. The results of this step are shown in Table 11.

$$
\sigma_{V 1}=C V * \mu_{V 1}=0.05 * 140 \mathrm{~km} / \mathrm{hr}=7 \mathrm{~km} / \mathrm{hr}
$$

Table 11 - Calculated Standard Deviation for each Random Variable at Varying CV Values

\begin{tabular}{|c|c|c|c|c|c|}
\hline & CV $=5 \%$ & CV $=10 \%$ & CV $=15 \%$ & CV = 20\% & CV $=25 \%$ \\
\hline Standard Deviation of $\mathbf{V}_{1}$ & 7 & 14 & 21 & 28 & 35 \\
\hline Standard Deviation of $\mathbf{R}$ & 0.0125 & 0.025 & 0.0375 & 0.05 & 0.0625 \\
\hline Standard Deviation of $\mathrm{G}_{1}$ & 0 & 0 & 0 & 0 & 0 \\
\hline
\end{tabular}




\section{$\underline{\text { Step } 5 \text { - Calculate Mean, Variance, and Standard Deviation of } \mathbf{V}_{2}}$}

The mean of $\mathrm{V}_{2}, \mu_{\mathrm{V} 2}$, variance of $\mathrm{V}_{2}, \sigma_{\mathrm{V} 2}^{2}$, and standard deviation of $\mathrm{V}_{2}, \sigma_{\mathrm{V} 2}$, were calculated using Equation 27 through Equation 32. First, the mean values of each random variable were substituted into Equation 27 as follows:

$$
\mu_{\mathrm{V} 2}=\sqrt{140^{2}-254 * 1 *(0.25+0.00)}=140 \mathrm{~km} / \mathrm{hr}
$$

Next, Equation 28 was used to calculate the variance of $V_{2}$ at each selected CV value by first substituting the mean values of each random variable into Equation 29 through Equation 31, as shown below:

$$
\begin{gathered}
\frac{d V_{2}}{d V_{1}}=140 *\left(140^{2}-254 * 1 *(0.25+0.00)\right)^{-0.5}=1.002 \\
\frac{d V_{2}}{d R}=-127 * 1 *\left(140^{2}-254 * 1 *(0.25+0.00)\right)^{-0.5}=-0.909 \\
\frac{d V_{2}}{d G_{1}}=-127 * 1 *\left(140^{2}-254 * 1 *(0.25+0.00)\right)^{-0.5}=-0.909
\end{gathered}
$$

A sample calculation for the variance and standard deviation of $\mathrm{V}_{2}$ for a $\mathrm{CV}=5 \%$ are shown below. The results of these steps are displayed in Table 12.

$$
\begin{gathered}
\sigma_{V 2}^{2}=(1.002)^{2} * 7^{2}+(-0.909)^{2} * 0.0125^{2}+(-0.909)^{2} * 0.00^{2}=49.2 \\
\sigma_{V 2}=\sqrt{49.2}=7.0
\end{gathered}
$$

Table 12 - Calculated Variance of $V_{2}$ and Standard Deviation of $V_{2}$ at Varying CV Values

\begin{tabular}{|c|c|c|c|c|c|}
\hline & CV $=5 \%$ & CV $=10 \%$ & CV $=15 \%$ & CV $=20 \%$ & \multicolumn{2}{c|}{ CV $=25 \%$} \\
\hline Variance of $\mathrm{V}_{2}$ & 49.2 & 196.6 & 442.4 & 786.6 & 1229.0 \\
\hline Standard Deviation of $\mathrm{V}_{2}$ & 7.0 & 14.0 & 21.0 & 28.0 & 35.1 \\
\hline
\end{tabular}


The mean and standard deviation of $\mathrm{V}_{2}$ will be used as inputs for the mean value and standard deviation of $V_{2}$ in Segment 2.

\section{Segment 2}

Step 3 through Step 6, as outlined in Segment 2 of Section 4.2.1, are described in detail below.

Step 3 - Set Coefficient of Variation, Mean Value, and Standard Deviation to Random

\section{Variables}

For consistency, the same coefficient of variation set for each analysis in Segment 1 was set to all variables in Segment 2:

\section{$5 \% \quad 10 \% \quad 15 \% \quad 20 \% \quad 25 \%$}

The following mean values were set for each random variable:

Table 13 - Selected Mean Values for Each Random Variable

\begin{tabular}{|c|c|}
\hline Random Variable & Mean Value, $\boldsymbol{\mu}$ \\
\hline $\mathbf{V}_{\mathbf{2}}$ & $140 \mathrm{~km} / \mathrm{hr}$ \\
\hline $\mathbf{R}$ & $0.25 \mathrm{~kg} / \mathrm{kg} \mathrm{GVM}$ \\
\hline $\mathbf{G}_{\mathbf{2}}$ & +0.04 \\
\hline
\end{tabular}

The mean value and standard deviation for the random variable $V_{2}$ were previously calculated in Segment 1 and are used for Segment 2. Therefore, using Equation 17, the standard deviation, $\sigma$, was only calculated for the random variables $G_{2}$ and $R$ at each selected $C V$ value. A sample calculation for random variable $\mathrm{G}_{2}$ and $\mathrm{CV}=5 \%$ is shown below. The results of this step are shown in Table 14.

$$
\sigma_{V}=C V * \mu_{G 2}=0.05 * 0.04=0.002
$$




\begin{tabular}{|c|c|c|c|c|c|}
\hline & CV $=5 \%$ & CV $=10 \%$ & CV $=15 \%$ & CV $=20 \%$ & CV $=25 \%$ \\
\hline Standard Deviation of $\mathbf{V}_{2}$ & 7.0 & 14.0 & 21.0 & 28.0 & 35.1 \\
\hline Standard Deviation of $\mathbf{R}$ & 0.0125 & 0.025 & 0.0375 & 0.05 & 0.0625 \\
\hline Standard Deviation of $\mathrm{G}_{2}$ & 0.002 & 0.004 & 0.006 & 0.008 & 0.01 \\
\hline
\end{tabular}

\section{Step 4-Calculate Mean, Variance, and Standard Deviation of SM}

The mean of $\mathrm{SM}, \mu_{S M}$, variance of $\mathrm{SM}, \sigma_{S M}^{2}$, and standard deviation of $\mathrm{SM}, \sigma_{S M}$, were calculated using Equation 35 through Equation 40.

First, the mean values of each random variable were substituted into Equation 35, leaving the function in terms of $L_{\text {supply, }}$ as follows:

$$
\begin{gathered}
\mu_{S M}=L_{\text {supply }}-1 m-\frac{140^{2}}{254(0.25+0.04)} \\
\mu_{S M}=L_{\text {supply }}-267.09
\end{gathered}
$$

Next, Equation 36 was used to calculate the variance of the safety margin at each selected CV value by first substituting the mean values of each random variable into Equation 37 through Equation 39 as shown below:

$$
\begin{aligned}
& \frac{d S M}{d V_{2}}=\frac{-140}{127 *(0.25+0.04)}=-3.801 \\
& \frac{d S M}{d R}=\frac{140^{2}}{254 *(0.25+0.04)^{2}}=917.5 \\
& \frac{d S M}{d G_{2}}=\frac{140^{2}}{254 *(0.25+0.04)^{2}}=917.5
\end{aligned}
$$


A sample calculation for the variance and standard deviation of SM for a CV $=5 \%$ are shown below. The results of these steps are displayed in Table 15.

$$
\begin{gathered}
\sigma_{S M}^{2}=(-3.801)^{2} * 7.0^{2}+(917.5)^{2} * 0.0125^{2}+(917.5)^{2} * 0.002^{2}=842.8 \\
\sigma_{S M}=\sqrt{842.8}=29.0
\end{gathered}
$$

Table 15 - Calculated Variance of SM and Standard Deviation of SM at Varying CV Values

\begin{tabular}{|c|c|c|c|c|c|}
\hline & CV $=5 \%$ & CV $=10 \%$ & CV $=15 \%$ & CV $=20 \%$ & CV $=25 \%$ \\
\hline Variance of SM & 842.1 & 3368.3 & 7578.6 & 13473.1 & 21051.7 \\
\hline Standard Deviation of SM & 29.0 & 58.0 & 87.1 & 116.1 & 145.1 \\
\hline
\end{tabular}

\section{Step 5 - Define Desired Probability of Failure, $P_{f}$, and Reliability Index, $\beta$}

As previously mentioned in Section 4.2.1, the desired probability of failure, $P_{f}$, and corresponding reliability index, $\beta$, were selected as follows:

Table 16 - Selected $P_{f}$ and Corresponding $\beta$ Values [16]

\begin{tabular}{|c|c|c|c|}
\hline $\begin{array}{c}\text { Probability } \\
\text { of Failure, } \\
\text { Pf }\end{array}$ & Beta & $\begin{array}{c}\text { Probability } \\
\text { of Failure, } \\
\text { Pf }\end{array}$ & Beta \\
\hline $\mathbf{1 \%}$ & 2.32 & $\mathbf{7 \%}$ & 1.47 \\
\hline $\mathbf{2 \%}$ & 2.05 & $\mathbf{8 \%}$ & 1.4 \\
\hline $\mathbf{3 \%}$ & 1.88 & $\mathbf{9 \%}$ & 1.34 \\
\hline $\mathbf{4 \%}$ & 1.75 & $\mathbf{1 0 \%}$ & 1.28 \\
\hline $\mathbf{5 \%}$ & 1.64 & $\mathbf{1 5 \%}$ & 1.03 \\
\hline $\mathbf{6 \%}$ & 1.55 & & \\
\hline
\end{tabular}

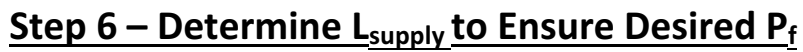

In order to determine $L_{\text {supply }}$ for each selected $C V$ value and desired $P_{f}$, Equation 42 was used.

The sample calculation is provided below for a $C V=5 \%, P_{f}=1 \%$, and $\beta=2.32$ :

$$
L_{\text {supply }}=29.0 * 2.32+1 \mathrm{~m}+\frac{140^{2}}{254(0.25+0.04)}=333.5 \mathrm{~m}
$$


Repeating Step 3 through Step 6, $L_{\text {supply }}$ is then calculated for each combination of CV and $P_{f}$. The results for all $L_{\text {supply }}$ values are displayed in Table 17 with a visual representation displayed in Figure 21.

Table $17-L_{\text {supply }}$ Values at Corresponding $P_{f}$ and CV Values

\begin{tabular}{|c|c|c|c|c|c|}
\hline $\begin{array}{c}\text { Probability of } \\
\text { Failure, } P_{f}\end{array}$ & $\begin{array}{l}\mathrm{L}_{\text {supply }}(\mathrm{m}) \\
\mathrm{CV}=5 \%\end{array}$ & $\begin{array}{l}L_{\text {supply }}(m) \\
C V=10 \%\end{array}$ & $\begin{array}{l}L_{\text {supply }}(m) \\
C V=15 \%\end{array}$ & $\begin{array}{l}L_{\text {supply }}(m) \\
C V=20 \%\end{array}$ & $\begin{array}{c}L_{\text {supply }}(m), \\
\text { CV }=25 \%\end{array}$ \\
\hline $1 \%$ & 333.5 & 400.9 & 468.2 & 535.5 & 602.8 \\
\hline $2 \%$ & 325.7 & 385.2 & 444.7 & 504.2 & 563.7 \\
\hline $3 \%$ & 320.8 & 375.3 & 429.9 & 484.4 & 539.0 \\
\hline $4 \%$ & 317.0 & 367.8 & 418.6 & 469.4 & 520.1 \\
\hline $5 \%$ & 313.8 & 361.4 & 409.0 & 456.6 & 504.2 \\
\hline $6 \%$ & 311.2 & 356.2 & 401.2 & 446.1 & 491.1 \\
\hline $7 \%$ & 308.9 & 351.5 & 394.2 & 436.9 & 479.5 \\
\hline $8 \%$ & 306.9 & 347.5 & 388.1 & 428.7 & 469.4 \\
\hline $9 \%$ & 305.1 & 344.0 & 382.9 & 421.8 & 460.6 \\
\hline $10 \%$ & 303.4 & 340.5 & 377.7 & 414.8 & 451.9 \\
\hline $15 \%$ & 296.1 & 326.0 & 355.9 & 385.8 & 415.7 \\
\hline
\end{tabular}

Supply Length of TER vs Probability of Failure $\left(G_{1}=0 \%, G_{2}=+4 \%, V=140 \mathrm{~km} / \mathrm{hr}\right)$

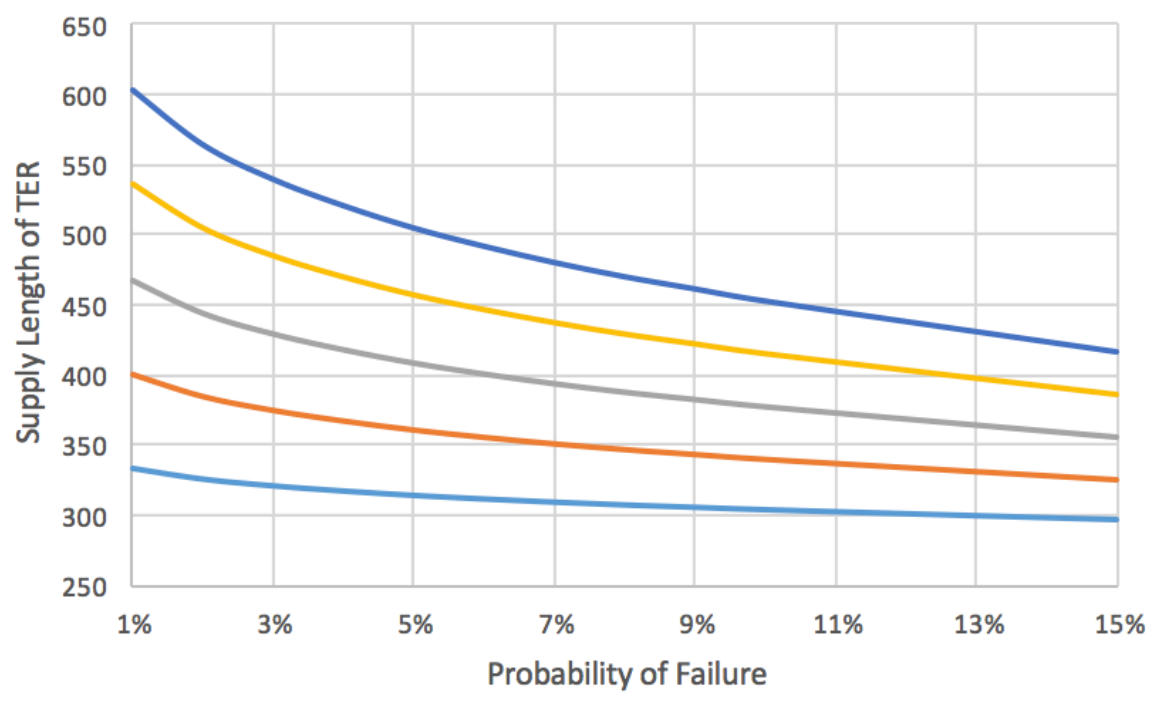

$\longrightarrow \mathrm{CV}=5 \%-\mathrm{CV}=10 \%-\mathrm{CV}=15 \% \quad \mathrm{CV}=20 \% \quad-\mathrm{CV}=25 \%$

Figure 21 - FOSM Visual Representation of $L_{\text {supply }}$ for a TER using $G_{1}=0 \%, G_{2}=+4 \%, V=140 \mathrm{~km} / \mathrm{hr}$, and $R=0.25 \mathrm{~kg} / \mathrm{kgGVM}$ 


\subsection{Case 3: AFOSM Reliability Method - One TER Grade}

\subsubsection{Methodology}

The following steps were used in order to develop the AFOSM Reliability Model for a TER with one grade.

\section{Step 1 - Define Safety Margin Equation, Determine an Expression for $\mathrm{g}(\mathrm{X})$}

As established in Equation 16 of Case 1, the safety margin, SM, for a TER with one grade is expressed as follows:

$$
S M=L_{\text {supply }}-\frac{V_{1}^{2}}{254\left(R+G_{i}\right)}
$$

The random variables $V_{1}, R$, and $G_{1}$ are then replaced with $X_{1}, X_{2}$, and $X_{3}$, respectively. The equation is then rewritten as:

$$
S M=g(X)=L_{\text {supply }}-\frac{X_{1}^{2}}{254\left(X_{2}+X_{3}\right)}
$$

\section{Step 2 - Evolve Equation for $h(y)$}

Since:

$$
X_{1}=\sigma_{1} y_{1}+m_{1} \quad X_{2}=\sigma_{2} y_{2}+m_{2} \quad X_{3}=\sigma_{3} y_{3}+m_{3}
$$

Thus:

$$
S M=h(y)=L_{\text {supply }}-\frac{\left(\sigma_{1} y_{1}+m_{1}\right)^{2}}{254\left(\sigma_{2} y_{2}+m_{2}+\sigma_{3} y_{3}+m_{3}\right)}
$$




\section{Step 3 - Define Equation for All First Derivative of $h(y), h^{\prime}$}

The first derivatives of $h(y)$ are as follows:

$$
\begin{aligned}
& h_{1}^{\prime}=-\frac{2 * \sigma_{1} *\left(\sigma_{1} y_{1}+m_{1}\right)}{254 *\left(\sigma_{2} y_{2}+m_{2}+\sigma_{3} y_{3}+m_{3}\right)} \\
& h_{2}^{\prime}=\frac{254 * \sigma_{2} *\left(\sigma_{1} y_{1}+m_{1}\right)^{2}}{\left[254 *\left(\sigma_{2} y_{2}+m_{2}+\sigma_{3} y_{3}+m_{3}\right)\right]^{2}} \\
& h_{2}^{\prime}=\frac{254 * \sigma_{3} *\left(\sigma_{1} y_{1}+m_{1}\right)^{2}}{\left[254 *\left(\sigma_{2} y_{2}+m_{2}+\sigma_{3} y_{3}+m_{3}\right)\right]^{2}}
\end{aligned}
$$

Step 4 - Set Coefficient of Variation, Mean Value, and Standard Deviation to Random

\section{Variables}

A coefficient of variation, CV, must be set for all random variables. For the purpose of this study, the same coefficient of variation was set to all variables for each analysis. For a practical analysis, the CV value will range from $5 \%$ to $25 \%$ and analyzed at increments of $5 \%$.

Next, a mean value, $m_{i}$, must be set to each random variable for design analysis. Firstly, for practicality and consistency purposes, the vehicle entering speed, $\mathrm{V}$, was analyzed at mean values of $100 \mathrm{~km} / \mathrm{hr}, 120 \mathrm{~km} / \mathrm{hr}$, and $140 \mathrm{~km} / \mathrm{hr}$. Secondly, the rolling resistance, R, was analyzed at a mean value corresponding to pea gravel, $0.25 \mathrm{~kg} / \mathrm{kg} \mathrm{GVM}$, as selected from Table 1 . Lastly, the percent grade, $\mathrm{G}$, was analyzed at mean values ranging from $+10 \%$ to $-10 \%$ for practicality purposes.

The standard deviation, $\sigma_{i}$, must be calculated for each random variable using Equation 17 described in Section 4.1.1. 
Step 5 - Set all $y_{i}=0, \beta=0$

Once a mean value and standard deviation are set to the random variables, $\beta=y_{1}=y_{2}=y_{3}=0$ for the first iteration.

\section{Step 6 through Step 9 - Solve $h(y), h_{1}{ }^{\prime}, h_{2}{ }^{\prime}, h_{3}{ }^{\prime}, \sigma_{S M}, y_{i}$ and $\beta$}

The values of $h(y), h_{1}{ }^{\prime}, h_{2}{ }^{\prime}, h_{3}{ }^{\prime}$ are obtained by plugging in $\beta=y_{1}=y_{2}=y_{3}=0, m_{i}$ selected in Step 4 , and $\sigma_{i}$ calculated in Step 4 for Iteration 1 . Since $L_{\text {supply }}$ is unknown, a reasonable value is assumed for future use of Excel Solver. Next, Equation 12 through Equation 14, discussed in Section 3.2, are used to calculate $\sigma_{S M}$ and new values for, $y_{1}, y_{2}, y_{3}$, and $\beta$ which will be used in the next iteration.

\section{$\underline{\text { Step } 10 \text { - Iterate }}$}

Step 6 through Step 9 are repeated until $\beta$ converges.

\section{Step 11 - Define Desired Probability of Failure, $P_{f}$, and Reliability Index, $\beta$}

The desired probability of failure, $P_{f}$, must be selected by the user for the desired analysis. Typical and realistic $P_{f}$ values range from $1 \%$ to $5 \%$, however, $P_{f}$ values between $1 \%$ to $15 \%$ were selected for experimentation. Due to the iterative nature of this method, only $P_{f}=1 \%, 5 \%$, $10 \%$, and $15 \%$ were analyzed in Case 3.

Based on normal distribution tables, the corresponding reliability index, $\beta$, is determined based on the desired $\mathrm{P}_{\mathrm{f}}$, as listed in Table 18. 
Table 18 - $\beta$ Values for Respective Probability of Failure [16]

\begin{tabular}{|c|c|}
\hline $\begin{array}{c}\text { Probability } \\
\text { of Failure, Pf }\end{array}$ & Beta \\
\hline $\mathbf{1 \%}$ & 2.32 \\
\hline $\mathbf{5 \%}$ & 1.64 \\
\hline $\mathbf{1 0 \%}$ & 1.28 \\
\hline $\mathbf{1 5 \%}$ & 1.03 \\
\hline
\end{tabular}

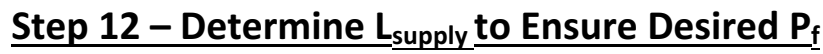

Once the desired $\beta$ values are specified, Excel Solver is used to optimize $L_{\text {supply }}$ so that the model converges to the desired $\beta$ value.

This process is repeated until $L_{\text {supply }}$ is calculated for each desired combination of CV and $P_{f}$.

\subsubsection{Sample Calculations and Results}

The AFOSM Reliability Method was conducted for various TER design scenarios with a single grade using varying values for the TER grade and vehicle entering speed. For consistency, the TER design material, pea gravel, was held constant. Furthermore, the majority of the analysis was conducted using a design speed of $140 \mathrm{~km} / \mathrm{hr}$ in order to simulate a real life scenario where runaway trucks will be travelling at very high speeds, rather than speeds of $100 \mathrm{~km} / \mathrm{hr}$ or below.

The desired scenarios used for analysis are identical to those analyzed in Case 1, as follows:

Scenario 1: Grade $=+2 \%$, Speed $=140 \mathrm{~km} / \mathrm{hr}$, Rolling Resistance $($ Pea Gravel) $=0.25 \mathrm{~kg} / \mathrm{kgGVM}$

Scenario 2: Grade $=+2 \%$, Speed $=120 \mathrm{~km} / \mathrm{hr}$, Rolling Resistance $($ Pea Gravel $)=0.25 \mathrm{~kg} / \mathrm{kgGVM}$

Scenario 3: Grade $=+2 \%$, Speed $=100 \mathrm{~km} / \mathrm{hr}$, Rolling Resistance $($ Pea Gravel) $=0.25 \mathrm{~kg} / \mathrm{kgGVM}$

Scenario 4: Grade $=0 \%$, Speed $=140 \mathrm{~km} / \mathrm{hr}$, Rolling Resistance $($ Pea Gravel $)=0.25 \mathrm{~kg} / \mathrm{kgGVM}$ 
Scenario 5: Grade $=+4 \%$, Speed $=140 \mathrm{~km} / \mathrm{hr}$, Rolling Resistance $($ Pea Gravel) $=0.25 \mathrm{~kg} / \mathrm{kgGVM}$

Scenario 6: Grade $=+6 \%$, Speed $=140 \mathrm{~km} / \mathrm{hr}$, Rolling Resistance $($ Pea Gravel) $=0.25 \mathrm{~kg} / \mathrm{kgGVM}$

Scenario 7: Grade $=+8 \%$, Speed $=140 \mathrm{~km} / \mathrm{hr}$, Rolling Resistance $($ Pea Gravel $)=0.25 \mathrm{~kg} / \mathrm{kgGVM}$

Scenario 8: Grade $=+10 \%$, Speed $=140 \mathrm{~km} / \mathrm{hr}$, Rolling Resistance (Pea Gravel) $=0.25 \mathrm{~kg} / \mathrm{kgGVM}$

Scenario 9: Grade $=-2 \%$, Speed $=140 \mathrm{~km} / \mathrm{hr}$, Rolling Resistance $($ Pea Gravel $)=0.25 \mathrm{~kg} / \mathrm{kgGVM}$

Scenario 10: Grade $=-4 \%$, Speed $=140 \mathrm{~km} / \mathrm{hr}$, Rolling Resistance $($ Pea Gravel $)=0.25 \mathrm{~kg} / \mathrm{kgGVM}$

Scenario 11: Grade $=-6 \%$, Speed $=140 \mathrm{~km} / \mathrm{hr}$, Rolling Resistance $($ Pea Gravel $)=0.25 \mathrm{~kg} / \mathrm{kgGVM}$

Scenario 12: Grade $=-8 \%$, Speed $=140 \mathrm{~km} / \mathrm{hr}$, Rolling Resistance $($ Pea Gravel $)=0.25 \mathrm{~kg} / \mathrm{kgGVM}$

Scenario 13: Grade $=-10 \%$, Speed $=140 \mathrm{~km} / \mathrm{hr}$, Rolling Resistance $($ Pea Gravel $)=0.25 \mathrm{~kg} / \mathrm{kgGVM}$

Sample calculations and results regarding Scenario 1 are provided in this section. Step 4 through Step 12, as outlined in Section 4.3.1, are carried out in detail in order to develop sample calculations for Case 3, Scenario 1 . Scenario 1 assumes a TER using pea gravel with a $2 \%$ upgrade and $140 \mathrm{~km} / \mathrm{hr}$ entering vehicle speed. A brief discussion of the results regarding Scenario 1 through Scenario 13 is also included in this section. The results and visuals regarding Scenario 2 through Scenario 13 can be found in Appendix C. 
Step 4 - Set Coefficient of Variation, Mean Value, and Standard Deviation to Random

Variables

For a practical analysis, the selected CV values are:

$$
5 \% \quad 10 \% \quad 15 \% \quad 20 \% \quad 25 \%
$$

The following mean values were selected for each random variable:

Table 19 - Selected Mean Values for Each Random Variable

\begin{tabular}{|c|c|}
\hline \multirow{2}{*}{ Random Variable } & Mean Value, $\boldsymbol{\mu}$ \\
\hline $\mathbf{V}_{\mathbf{1}}$ & $140 \mathrm{~km} / \mathrm{hr}$ \\
\hline $\mathbf{R}$ & $0.25 \mathrm{~kg} / \mathrm{kg} \mathrm{GVM}$ \\
\hline $\mathbf{G}_{1}$ & +0.02 \\
\hline
\end{tabular}

Using Equation 17, the standard deviation, $\sigma$, was calculated for each random variable at each selected $C V$ value. A sample calculation for random variable $V$ and $C V=5 \%$ is shown below. The results of this step are shown in Table 20.

$$
\sigma_{V}=C V * \mu_{V}=0.05 * 140 \mathrm{~km} / \mathrm{hr}=7 \mathrm{~km} / \mathrm{hr}
$$

Table 20 - Calculated Standard Deviation for each Random Variable at Varying CV Values

\begin{tabular}{|l|c|c|c|c|c|}
\hline & CV $=5 \%$ & CV $=10 \%$ & CV =15\% & CV = 20\% & CV $=25 \%$ \\
\hline Standard Deviation of V & 7 & 14 & 21 & 28 & 35 \\
\hline Standard Deviation of R & 0.0125 & 0.025 & 0.0375 & 0.05 & 0.0625 \\
\hline Standard Deviation of G & 0.001 & 0.002 & 0.003 & 0.004 & 0.005 \\
\hline
\end{tabular}

Step 5 - Set all $\mathrm{y}_{\mathrm{i}}=0, \beta=0$

Once mean value and standard deviation values are determined, $y_{1}, y_{2}, y_{3}$, and $\beta$ are set to equal 0 for the first iteration. 
Step 6 - Solve $h(y), h_{1}{ }^{\prime}, h_{2}{ }^{\prime}, h_{3}{ }^{\prime}$

The sample calculation provided below uses Equation 44 through Equation 47 and is for a $\mathrm{CV}=$ $5 \%$, and estimated $\mathrm{L}_{\text {supply }}=350 \mathrm{~m}$ :

$$
\begin{gathered}
h(y)=350 m-\frac{(7 * 0+140)^{2}}{254(0.0125 * 0+0.25+0.001 * 0+0.02)}=64.2 \\
h_{1}^{\prime}=-\frac{2 * 7 *(7 * 0+140)}{254 *(0.0125 * 0+0.25+0.001 * 0+0.02)}=-28.579 \\
h_{2}^{\prime}=\frac{254 * 0.0125 *(7 * 0+140)^{2}}{[254 *(0.0125 * 0+0.25+0.001 * 0+0.02)]^{2}}=13.231 \\
h_{3}^{\prime}=\frac{254 * 0.001 *(7 * 0+140)^{2}}{[254 *(0.0125 * 0+0.25+0.001 * 0+0.02)]^{2}}=1.058
\end{gathered}
$$

\section{$\underline{\text { Step } 7-\text { Solve } \sigma_{S M}}$}

Next, Equation 12 is used to calculate $\sigma_{S M}$.

$$
\sigma_{S M}=\sqrt{(-28.579)^{2}+(13.231)^{2}+(1.058)^{2}}=31.512
$$

\section{Step 8 - Solve all $\mathbf{y}_{\mathbf{i}}$ for Next Iteration}

Next, Equation 13 is used to calculate new values for, $y_{1}, y_{2}, y_{3}$, which will be used in iteration 2 .

$$
\begin{aligned}
& y_{1}=-\frac{-28.579}{31.512}\left[0+\frac{64.2}{31.512}\right]=1.847 \\
& y_{2}=-\frac{13.231}{31.512}\left[0+\frac{64.2}{31.512}\right]=-0.855 \\
& y_{3}=-\frac{1.058}{31.512}\left[0+\frac{64.2}{31.512}\right]=-0.068
\end{aligned}
$$




\section{Step 9 - Solve $\beta$ for Next Iteration}

Next, Equation 14 is used to calculate a new value for $\beta$ which will be used in iteration 2 .

$$
\beta=\sqrt{(1.847)^{2}+(-0.855)^{2}+(-0.068)^{2}}=2.036
$$

\section{Step 10 - Iterate}

The first 5 iterations are shown in Table 21 below. Note this model converges at $\beta=1.89$ for an estimated $\mathrm{L}_{\text {supply }}=350 \mathrm{~m}$.

Table 21 - Case 3 Iterations for Estimated $L_{\text {supply }}=350 \mathrm{~m}$

\begin{tabular}{|c|c|c|c|c|c|c|c|c|c|}
\hline Iteration \# & $y_{1}$ & $y_{2}$ & $y_{3}$ & $\boldsymbol{\beta}$ & $h(y)$ & $h_{1}^{\prime}$ & $h_{2}^{\prime}$ & $h_{3}^{\prime}$ & $\sigma_{S M}$ \\
\hline 1 & 0 & 0 & 0 & 0 & 64.202 & -28.580 & 13.231 & 1.059 & 31.512 \\
\hline 2 & 1.8478 & -0.8555 & -0.0684 & 2.04 & -5.206 & -32.516 & 17.127 & 1.370 & 36.777 \\
\hline 3 & 1.6762 & -0.8829 & -0.0706 & 1.90 & -0.114 & -32.304 & 16.904 & 1.352 & 36.485 \\
\hline 4 & 1.6758 & -0.8770 & -0.0702 & 1.89 & 0.000 & -32.294 & 16.894 & 1.352 & 36.471 \\
\hline 5 & 1.6759 & -0.8767 & -0.0701 & 1.89 & 0.000 & -32.294 & 16.894 & 1.352 & 36.471 \\
\hline
\end{tabular}

Step 11 - Define Desired Probability of Failure, $\mathrm{P}_{\mathrm{f}}$, and Reliability Index, $\beta$

As previously mentioned in Section 4.3.1, the desired probability of failure, $P_{f}$, and corresponding reliability index, $\beta$, were selected as follows:

Table 22 - $\beta$ Values for Respective Probability of Failure [16]

\begin{tabular}{|c|c|}
\hline $\begin{array}{c}\text { Probability } \\
\text { of Failure, Pf }\end{array}$ & Beta \\
\hline $\mathbf{1 \%}$ & 2.32 \\
\hline $\mathbf{5 \%}$ & 1.64 \\
\hline $\mathbf{1 0 \%}$ & 1.28 \\
\hline $\mathbf{1 5 \%}$ & 1.03 \\
\hline
\end{tabular}




\section{$\underline{\text { Step } 12 \text { - Determine } L_{\text {supply }} \text { to Ensure Desired } P_{f}}$}

Since the desired $\beta$ value was not achieved with the estimated $L_{\text {supply }}=350 \mathrm{~m}$ value, Excel Solver was used to optimize $L_{\text {supply }}$ so that the model would converge to the desired $\beta$ value. The objective of the sample calculation shown in Table 23 is to use Excel Solver to set the objective $\beta$ value equal to $2.32\left(P_{f}=1 \%\right)$ by changing variable $L_{\text {supply. }}$ In this case, Excel Solver found a solution for $L_{\text {supply }}=365.8 \mathrm{~m}$ which allows the model to converge at $\beta=2.32$.

Table 23 - Case 3 Iterations for Estimated $\mathrm{L}_{\text {supply }}$ Using Excel Solver

\begin{tabular}{|c|c|c|c|c|c|c|c|c|c|}
\hline Iteration \# & $\mathrm{y}_{1}$ & $\mathrm{y}_{2}$ & $\mathrm{y}_{\mathbf{3}}$ & $\boldsymbol{\beta}$ & $\mathrm{h}(\mathrm{y})$ & $\mathrm{h}_{1}{ }^{\prime}$ & $\mathrm{h}_{2}{ }^{\prime}$ & $\mathrm{h}_{\mathbf{3}}{ }^{\prime}$ & $\sigma_{\text {SM }}$ \\
\hline 1 & 0 & 0 & 0 & 0 & 80.002 & -28.580 & 13.231 & 1.059 & 31.512 \\
\hline $\mathbf{2}$ & 2.3026 & -1.0660 & -0.0853 & 2.54 & -8.167 & -33.536 & 18.218 & 1.457 & 38.193 \\
\hline 3 & 2.0415 & -1.1090 & -0.0887 & 2.32 & -0.234 & -33.213 & 17.869 & 1.430 & 37.742 \\
\hline 4 & 2.0405 & -1.0978 & -0.0878 & 2.32 & -0.001 & -33.194 & 17.848 & 1.428 & 37.715 \\
\hline 5 & 2.0408 & -1.0973 & -0.0878 & 2.32 & 0.000 & -33.193 & 17.848 & 1.428 & 37.714 \\
\hline
\end{tabular}

This process was repeated until $\mathrm{L}_{\text {supply }}$ is calculated for each desired combination of $\mathrm{CV}$ and $\mathrm{P}_{\mathrm{f}}$.

The results for all $\mathrm{L}_{\text {supply }}$ values are displayed in Table 24 with a visual representation displayed in Figure 22.

Table $24-L_{\text {supply }}$ Values at Corresponding $P_{f}$ and CV Values

\begin{tabular}{|c|c|c|c|c|c|}
\hline $\begin{array}{c}\text { Probability of } \\
\text { Failure, } P_{f}\end{array}$ & $\begin{array}{l}\mathrm{L}_{\text {supply }}(\mathrm{m}) \\
\mathrm{CV}=5 \%\end{array}$ & $\begin{array}{l}L_{\text {supply }}(m), \\
C V=10 \%\end{array}$ & $\begin{array}{l}L_{\text {supply }}(m), \\
C V=15 \%\end{array}$ & $\begin{array}{l}L_{\text {supply }}(m), \\
C V=20 \%\end{array}$ & $\begin{array}{l}L_{\text {supply }}(m) \text {, } \\
C V=25 \%\end{array}$ \\
\hline $1 \%$ & 365.8 & 462.1 & 579.5 & 726.4 & 918.4 \\
\hline $5 \%$ & 340.9 & 403.5 & 475.0 & 557.4 & 653.6 \\
\hline $10 \%$ & 328.2 & 375.0 & 426.8 & 484.4 & 548.8 \\
\hline $15 \%$ & 319.6 & 356.1 & 395.8 & 438.9 & 485.9 \\
\hline
\end{tabular}


Supply Length of TER vs Probability of Failure

( $\mathrm{G}=+2 \%, \mathrm{~V}=140 \mathrm{~km} / \mathrm{hr}$ )

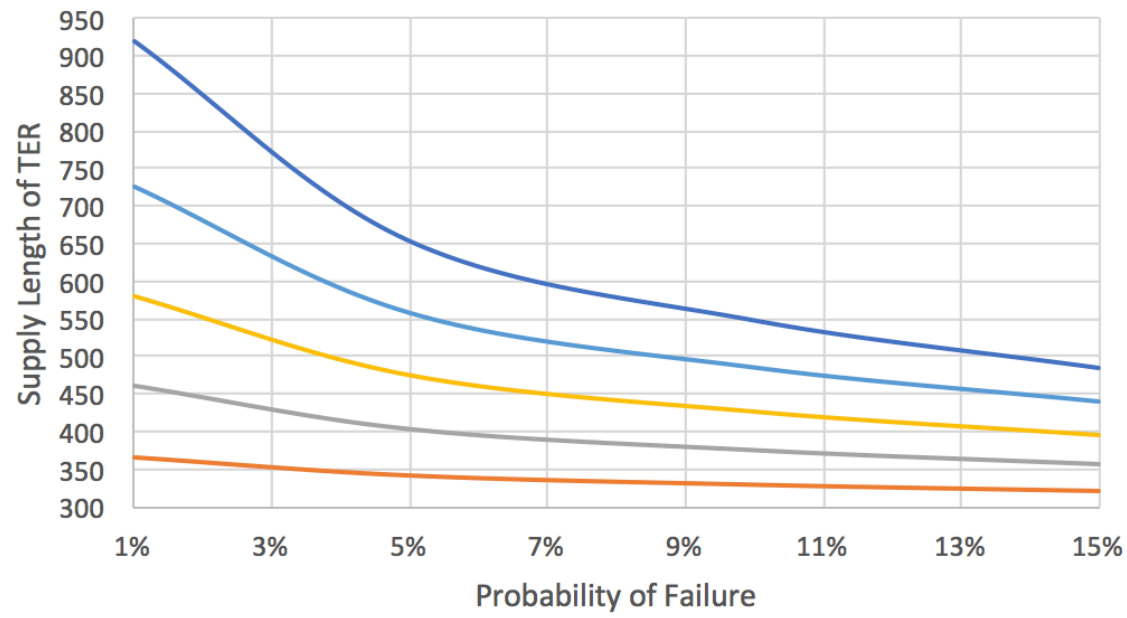

$\longrightarrow \mathrm{CV}=5 \%-\mathrm{CV}=10 \%-\mathrm{CV}=15 \%-\mathrm{CV}=20 \%-\mathrm{CV}=25 \%$

Figure 22 - AFOSM Visual Representation of $L_{\text {supply }}$ for a TER using $G=+2 \%, V=140 \mathrm{~km} / \mathrm{hr}$, and $R=0.25 \mathrm{~kg} / \mathrm{kgGVM}$

\subsection{Case 4: AFOSM Reliability Method - Two TER Grades}

\subsubsection{Methodology}

The following steps were used in order to develop the AFOSM Reliability Model for a TER with more than one grade. Case 4 analyzes two grades and therefore must be split up into two segments, as seen in Case 2 analysis.

\section{Segment 1}

To begin the AFOSM analysis, the steps pertaining to Case 2 - Segment 1 may be repeated in order to determine the mean value and standard deviation of $\mathrm{V}_{2}$.

\section{Segment 2}

\section{Step 1 - Define Safety Margin Equation, Determine an Expression for $g(X)$}

As established in Equation 34 of Case 2, the safety margin, SM, for a TER with two grades is expressed as follows: 


$$
S M=L_{\text {supply }}-1 m-\frac{V_{2}^{2}}{254\left(R+G_{2}\right)}
$$

The random variables $V_{2}, R$, and $G_{2}$ are then replaced with $X_{1}, X_{2}$, and $X_{3}$, respectively. The equation is then rewritten as:

$$
S M=g(X)=L_{\text {supply }}-1 m-\frac{X_{1}^{2}}{254\left(X_{2}+X_{3}\right)}
$$

\section{Step 2 - Evolve Equation for $\mathrm{h}(\mathrm{y})$}

Since:

$$
X_{1}=\sigma_{1} y_{1}+m_{1} \quad X_{2}=\sigma_{2} y_{2}+m_{2} \quad X_{3}=\sigma_{3} y_{3}+m_{3}
$$

Thus:

$$
S M=h(y)=L_{\text {supply }}-1 m-\frac{\left(\sigma_{1} y_{1}+m_{1}\right)^{2}}{254\left(\sigma_{2} y_{2}+m_{2}+\sigma_{3} y_{3}+m_{3}\right)}
$$

\section{Step 3 - Define Equation for All First Derivative of $h(y), h^{\prime}$}

The first derivatives of $h(y)$ are as follows:

$$
\begin{aligned}
& h_{1}^{\prime}=-\frac{2 * \sigma_{1} *\left(\sigma_{1} y_{1}+m_{1}\right)}{254 *\left(\sigma_{2} y_{2}+m_{2}+\sigma_{3} y_{3}+m_{3}\right)} \\
& h_{2}^{\prime}=\frac{254 * \sigma_{2} *\left(\sigma_{1} y_{1}+m_{1}\right)^{2}}{\left[254 *\left(\sigma_{2} y_{2}+m_{2}+\sigma_{3} y_{3}+m_{3}\right)\right]^{2}} \\
& h_{2}^{\prime}=\frac{254 * \sigma_{3} *\left(\sigma_{1} y_{1}+m_{1}\right)^{2}}{\left[254 *\left(\sigma_{2} y_{2}+m_{2}+\sigma_{3} y_{3}+m_{3}\right)\right]^{2}}
\end{aligned}
$$


Step 4 - Set Coefficient of Variation, Mean Value, and Standard Deviation to Random Variables

A coefficient of variation, CV, must be set for all random variables. For the purpose of this study, the same coefficient of variation was set to all variables for each analysis. For a practical analysis, the CV value will range from $5 \%$ to $25 \%$ and analyzed at increments of $5 \%$.

Next, a mean value, $m_{i}$, must be set to each random variable for design analysis. Firstly, for practicality and consistency purposes, the vehicle entering speed, $\mathrm{V}$, was analyzed at mean values of $120 \mathrm{~km} / \mathrm{hr}$, and $140 \mathrm{~km} / \mathrm{hr}$. Secondly, the rolling resistance, $\mathrm{R}$, was analyzed at a mean value corresponding to pea gravel, $0.25 \mathrm{~kg} / \mathrm{kg}$ GVM, as selected from Table 1 . Lastly, the percent grade for Segment $2, G_{2}$, was analyzed at mean values ranging from $+1 \%$ to $+4 \%$ for practicality purposes.

The standard deviation, $\sigma_{i}$, must be calculated for each random variable using Equation 17 described in Section 4.1.1.

Step 5 - Set all $y_{i}=0, \beta=0$

Once mean values and standard deviation values are set to the random variables, $y_{1}, y_{2}, y_{3}$, and $\beta$ are set to equal 0 for the first iteration.

Step 6 through Step $9-$ Solve $h(y), h_{1}{ }^{\prime}, h_{2}{ }^{\prime}, h_{3}{ }^{\prime}, \sigma_{S M}, y_{i}$, and $\beta$

The values of $h(y), h_{1}{ }^{\prime}, h_{2}{ }^{\prime}, h_{3}{ }^{\prime}$ are obtained by plugging in $\beta=y_{1}=y_{2}=y_{3}=0, m_{i}$ selected in Step 4 , and $\sigma_{i}$ calculated in Step 4 for Iteration 1 . Since $L_{\text {supply }}$ is unknown, a reasonable value is assumed for future use of Excel Solver. Next, Equation 12, Equation 13, and Equation 14 
discussed in Section 3.2, are used to calculate $\sigma_{S M}$ and new values for, $y_{1}, y_{2}, y_{3}$, and $\beta$ which will be used in the next iteration.

\section{Step 10 - Iterate}

Step 6 through Step 9 are repeated until values converge.

\section{Step 11 - Define Desired Probability of Failure, $P_{f}$, and Reliability Index, $\beta$}

The desired probability of failure, $\mathrm{P}_{\mathrm{f}}$, must be selected by the user for the desired analysis. Typical and realistic $P_{f}$ values range from $1 \%$ to $5 \%$, however, $P_{f}$ values between $1 \%$ to $15 \%$ were selected for experimentation. Due to the iterative nature of this method, only $P_{f}=1 \%, 5 \%$, $10 \%$, and $15 \%$ were analyzed in Case 4.

Based on normal distribution tables, the corresponding reliability index, $\beta$, is determined based on the desired $\mathrm{P}_{\mathrm{f}}$, as listed in Table 18.

\section{Step 12 - Determine $L_{\text {supply }} \underline{\text { to Ensure Desired } \mathbf{P}_{\mathbf{f}}}$}

Once the desired $\beta$ values are specified, Excel Solver is used to optimize $L_{\text {supply }}$ so that the model converges to the desired $\beta$ value.

This process is repeated until $L_{\text {supply }}$ is calculated for each desired combination of CV and $P_{f}$.

\subsubsection{Sample Calculations and Results}

The AFOSM Reliability Method was also conducted for various TER design scenarios with two grades using varying values for the TER grade and vehicle entering speed. For consistency, the TER design material, pea gravel, was held constant. Furthermore, the majority of the analysis 
was conducted using a design speed of $140 \mathrm{~km} / \mathrm{hr}$ in order to simulate a real life scenario where runaway trucks will be travelling at very high speeds.

The desired scenarios used for analysis are identical to those analyzed in Case 2, as follows:

Scenario 1: Grade $1=0 \%$, Grade $2=+4 \%$, Speed $=140 \mathrm{~km} / \mathrm{hr}$, Rolling Resistance (Pea Gravel) $=$ $0.25 \mathrm{~kg} / \mathrm{kgGVM}$

Scenario 2: Grade $1=0 \%$, Grade $2=+4 \%$, Speed $=120 \mathrm{~km} / \mathrm{hr}$, Rolling Resistance (Pea Gravel) $=$ $0.25 \mathrm{~kg} / \mathrm{kgGVM}$

Scenario 3: Grade $1=0 \%$, Grade $2=+3 \%$, Speed $=140 \mathrm{~km} / \mathrm{hr}$, Rolling Resistance (Pea Gravel) $=$ $0.25 \mathrm{~kg} / \mathrm{kgGVM}$

Scenario 4: Grade $1=0 \%$, Grade $2=+2 \%$, Speed $=140 \mathrm{~km} / \mathrm{hr}$, Rolling Resistance (Pea Gravel) $=$ $0.25 \mathrm{~kg} / \mathrm{kgGVM}$

Scenario 5: Grade $1=0 \%$, Grade $2=+1 \%$, Speed $=140 \mathrm{~km} / \mathrm{hr}$, Rolling Resistance (Pea Gravel) $=$ $0.25 \mathrm{~kg} / \mathrm{kgGVM}$

Sample calculations and results regarding Scenario 1 are provided in this section. The steps regarding Segment 1 and Segment 2, as outlined in Section 4.4.1, are carried out in detail in this section in order to develop sample calculations for Case 4, Scenario 1. Scenario 1 assumes a TER using pea gravel with a $0 \%$ grade for Segment 1, a $4 \%$ upgrade for Segment 2, and $140 \mathrm{~km} / \mathrm{hr}$ entering vehicle speed. A brief discussion of the results regarding Scenario 1 through Scenario 5 is also included in this section. The results and visuals regarding Scenario 2 through Scenario 5 can be found in Appendix D. 


\section{Segment 1}

To begin the AFOSM analysis, the steps pertaining to Case 2 - Segment 1 are repeated in order to determine the mean value and standard deviation of $V_{2}$ as displayed in Table 25.

Table 25 - Calculated Variance of $\mathrm{V}_{\mathbf{2}}$ and Standard Deviation of $\mathrm{V}_{\mathbf{2}}$ at Varying CV Values

\begin{tabular}{|c|c|c|c|c|c|}
\hline & CV $=5 \%$ & CV $=10 \%$ & CV $=15 \%$ & CV $=20 \%$ & CV $=25 \%$ \\
\hline Mean Value of $\mathrm{V}_{2}(\mathrm{~km} / \mathrm{hr})$ & 140 & 140 & 140 & 140 & 140 \\
\hline Standard Deviation of $\mathrm{V}_{2}$ & 7.0 & 14.0 & 21.0 & 28.0 & 35.1 \\
\hline
\end{tabular}

The mean and standard deviation of $V_{2}$ will be used as inputs for the mean value and standard deviation of $V_{2}$ in Segment 2.

\section{Segment 2}

Step 4 through Step 12, as outlined in Segment 2 of Section 4.4.1, are described in detail below.

\section{Step 4 - Set Coefficient of Variation, Mean Value, and Standard Deviation to Random}

\section{Variables}

For consistency, the same coefficient of variation set for each analysis in Segment 1 was set to all variables in Segment 2:

\section{$5 \% \quad 10 \% \quad 15 \% \quad 20 \% \quad 25 \%$}

The following mean values were set for each random variable:

Table 26 - Selected Mean Values for Each Random Variable

\begin{tabular}{|c|c|}
\hline Random Variable & Mean Value, $\boldsymbol{\mu}$ \\
\hline $\mathbf{V}_{\mathbf{2}}$ & $140 \mathrm{~km} / \mathrm{hr}$ \\
\hline $\mathbf{R}$ & $0.25 \mathrm{~kg} / \mathrm{kg} \mathrm{GVM}$ \\
\hline $\mathbf{G}_{\mathbf{2}}$ & +0.04 \\
\hline
\end{tabular}


The mean value and standard deviation for the random variable $V_{2}$ were previously calculated in Segment 1 and are used for Segment 2. Therefore, using Equation 17, the standard deviation, $\sigma$, was only calculated for the random variables $G_{2}$ and $R$ at each selected $C V$ value. A sample calculation for random variable $G_{2}$ and $C V=5 \%$ is shown below. The results of this step are shown in Table 27.

$$
\sigma_{V}=C V * \mu_{G 2}=0.05 * 0.04=0.002
$$

Table 27 - Calculated Standard Deviation for each Random Variable at Varying CV Values

\begin{tabular}{|c|c|c|c|c|c|}
\hline & CV $=5 \%$ & CV $=10 \%$ & CV $=15 \%$ & CV = 20\% & CV $=25 \%$ \\
\hline Standard Deviation of $V_{2}$ & 7.0 & 14.0 & 21.0 & 28.0 & 35.1 \\
\hline Standard Deviation of $\mathbf{R}$ & 0.0125 & 0.025 & 0.0375 & 0.05 & 0.0625 \\
\hline Standard Deviation of $\mathrm{G}_{2}$ & 0.002 & 0.004 & 0.006 & 0.008 & 0.01 \\
\hline
\end{tabular}

Step 5 - Set all $\mathrm{y}_{\mathrm{i}}=0, \beta=0$

Once mean values and standard deviation values are determined, $y_{1}, y_{2}, y_{3}$, and $\beta$ are set to equal 0 for the first iteration.

\section{Step 6 - Solve $h(y), h_{1}^{\prime}, h_{2}^{\prime}, h_{3}^{\prime}$}

The sample calculation provided below uses Equation 49 through Equation 52 and is for a CV = $5 \%$ and estimated $\mathrm{L}_{\text {supply }}=300 \mathrm{~m}$ :

$$
\begin{gathered}
h(y)=300 m-1 m-\frac{(7.0 * 0+140)^{2}}{254(0.0125 * 0+0.25+0.002 * 0+0.04)}=33.775 \\
h_{1}^{\prime}=-\frac{2 * 7.0 *(7.0 * 0+140)}{254 *(0.0125 * 0+0.25+0.002 * 0+0.04)}=-26.609
\end{gathered}
$$




$$
\begin{gathered}
h_{2}^{\prime}=\frac{254 * 0.0125 *(7.0 * 0+140)^{2}}{[254 *(0.0125 * 0+0.25+0.002 * 0+0.04)]^{2}}=11.432 \\
h_{3}^{\prime}=\frac{254 * 0.002 *(7.0 * 0+140)^{2}}{[254 *(0.0125 * 0+0.25+0.002 * 0+0.04)]^{2}}=1.829
\end{gathered}
$$

\section{$\underline{\text { Step } 7-\text { Solve } \sigma_{S M}}$}

Next, Equation 12 is used to calculate $\sigma_{S M}$.

$$
\sigma_{S M}=\sqrt{(-26.609)^{2}+(11.432)^{2}+(1.829)^{2}}=29.018
$$

\section{Step 8 - Solve all $y_{i}$ for Next Iteration}

Next, Equation 13 is used to calculate new values for, $\mathrm{y}_{1}, \mathrm{y}_{2}, \mathrm{y}_{3}$, which will be used in iteration 2 .

$$
\begin{aligned}
& y_{1}=-\frac{-26.609}{29.018}\left[0+\frac{33.775}{29.018}\right]=1.067 \\
& y_{2}=-\frac{11.432}{29.018}\left[0+\frac{33.775}{29.018}\right]=-0.459 \\
& y_{3}=-\frac{1.829}{29.018}\left[0+\frac{33.775}{29.018}\right]=-0.073
\end{aligned}
$$

\section{Step 9 - Solve $\beta$ for Next Iteration}

Next, Equation 14 is used to calculate a new value for $\beta$ which will be used in iteration 2 .

$$
\beta=\sqrt{(1.067)^{2}+(-0.459)^{2}+(-0.073)^{2}}=1.164
$$

\section{Step 10 - Iterate}

The first 5 iterations are shown in Table 28 below. Note this model converges at $\beta=1.12$ for an estimated $\mathrm{L}_{\text {supply }}=300 \mathrm{~m}$. 
Table 28 - Case 4 Iterations for Estimated $\mathrm{L}_{\text {supply }}=\mathbf{3 0 0 ~} \mathrm{m}$

\begin{tabular}{|c|c|c|c|c|c|c|c|c|c|}
\hline Iteration \# & $\mathrm{y}_{1}$ & $\mathrm{y}_{\mathbf{2}}$ & $\mathrm{y}_{\mathbf{3}}$ & $\boldsymbol{\beta}$ & $\mathrm{h}(\mathrm{y})$ & $\boldsymbol{h}_{1}{ }^{\prime}$ & $\boldsymbol{h}_{2}{ }^{\prime}$ & $\boldsymbol{h}_{\mathbf{3}}{ }^{\prime}$ & $\sigma_{\text {SM }}$ \\
\hline 1 & 0 & 0 & 0 & 0 & 33.775 & -26.609 & 11.432 & 1.829 & 29.018 \\
\hline 2 & 1.0673 & -0.4585 & -0.0734 & 1.16 & -1.475 & -28.613 & 13.219 & 2.115 & 31.590 \\
\hline 3 & 1.0119 & -0.4675 & -0.0748 & 1.12 & -0.015 & -28.550 & 13.161 & 2.106 & 31.507 \\
\hline 4 & 1.0119 & -0.4665 & -0.0746 & 1.12 & 0.000 & -28.548 & 13.159 & 2.105 & 31.505 \\
\hline 5 & 1.0119 & -0.4664 & -0.0746 & 1.12 & 0.000 & -28.548 & 13.159 & 2.105 & 31.505 \\
\hline
\end{tabular}

\section{Step 11 - Define Desired Probability of Failure, $\mathbf{P}_{\underline{f}}$ and Reliability Index, $\beta$}

As previously mentioned in Section 4.3.1, the desired probability of failure, $P_{f}$, and corresponding reliability index, $\beta$, were selected as follows:

Table 29 - $\beta$ Values for Respective Probability of Failure [16]

\begin{tabular}{|c|c|}
\hline $\begin{array}{c}\text { Probability } \\
\text { of Failure, Pf }\end{array}$ & Beta \\
\hline $\mathbf{1 \%}$ & 2.32 \\
\hline $\mathbf{5 \%}$ & 1.64 \\
\hline $\mathbf{1 0 \%}$ & 1.28 \\
\hline $\mathbf{1 5 \%}$ & 1.03 \\
\hline
\end{tabular}

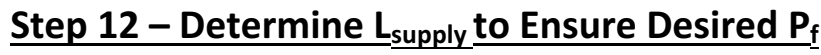

Since the desired $\beta$ value was not achieved with the estimated $L_{\text {supply }}=300 \mathrm{~m}$ value, Excel Solver was used to optimize $L_{\text {supply }}$ so that the model converges to the desired $\beta$ value. The objective of sample calculation shown in Table 30 is to use Excel Solver to set the objective $\beta$ value equal to $2.32\left(P_{f}=1 \%\right)$ by changing variable $L_{\text {supply. }}$ In this case, Excel Solver found a solution for $L_{\text {supply }}=$ 339.7 $\mathrm{m}$ which allows the model to converge at $\beta=2.32$.

Table 30 - Case 3 Iterations for Estimated $\mathrm{L}_{\text {supply }}$ Using Excel Solver

\begin{tabular}{|c|c|c|c|c|c|c|c|c|c|}
\hline Iteration \# & $\mathrm{y}_{1}$ & $\mathrm{y}_{\mathbf{2}}$ & $\mathrm{y}_{\mathbf{3}}$ & $\boldsymbol{\beta}$ & $\mathrm{h}(\mathrm{y})$ & $\boldsymbol{h}_{1}{ }^{\prime}$ & $\boldsymbol{h}_{2}{ }^{\prime}$ & $\boldsymbol{h}_{\mathbf{3}}{ }^{\prime}$ & $\sigma_{\text {SM }}$ \\
\hline 1 & 0 & 0 & 0 & 0 & 73.475 & -26.609 & 11.432 & 1.829 & 29.018 \\
\hline 2 & 2.3218 & -0.9975 & -0.1596 & 2.53 & -7.153 & -31.078 & 15.595 & 2.495 & 34.861 \\
\hline 3 & 2.0743 & -1.0409 & -0.1665 & 2.33 & -0.186 & -30.795 & 15.312 & 2.450 & 34.478 \\
\hline 4 & 2.0734 & -1.0309 & -0.1649 & 2.32 & -0.001 & -30.779 & 15.296 & 2.447 & 34.457 \\
\hline 5 & 2.0736 & -1.0305 & -0.1649 & 2.32 & 0.000 & -30.779 & 15.296 & 2.447 & 34.457 \\
\hline
\end{tabular}


This process was repeated until $L_{\text {supply }}$ is calculated for each desired combination of CV and $P_{f}$. The results for all $L_{\text {supply }}$ values are displayed in Table 31 with a visual representation displayed in Figure 23.

Table $31-L_{\text {supply }}$ Values at Corresponding $P_{f}$ and CV Values

\begin{tabular}{|c|c|c|c|c|c|}
\hline $\begin{array}{c}\text { Probability of } \\
\text { Failure, } P_{f}\end{array}$ & $\begin{array}{c}L_{\text {supply }}(m) \\
C V=5 \%\end{array}$ & $\begin{array}{l}L_{\text {supply }}(m), \\
C V=10 \%\end{array}$ & $\begin{array}{l}L_{\text {supply }}(m), \\
C V=15 \%\end{array}$ & $\begin{array}{l}L_{\text {supply }}(m) \text {, } \\
C V=20 \%\end{array}$ & $\begin{array}{l}L_{\text {supply }}(m) \text {, } \\
C V=25 \%\end{array}$ \\
\hline $1 \%$ & 339.7 & 427.1 & 532.2 & 661.1 & 824.4 \\
\hline $5 \%$ & 316.8 & 374.0 & 438.7 & 512.6 & 597.7 \\
\hline $10 \%$ & 305.2 & 348.0 & 395.2 & 447.2 & 505.0 \\
\hline $15 \%$ & 297.3 & 330.8 & 367.0 & 406.1 & 448.5 \\
\hline
\end{tabular}

Supply Length of TER vs Probability of Failure $\left(G_{1}=0 \%, G_{2}=+4 \%, V=140 \mathrm{~km} / \mathrm{hr}\right)$

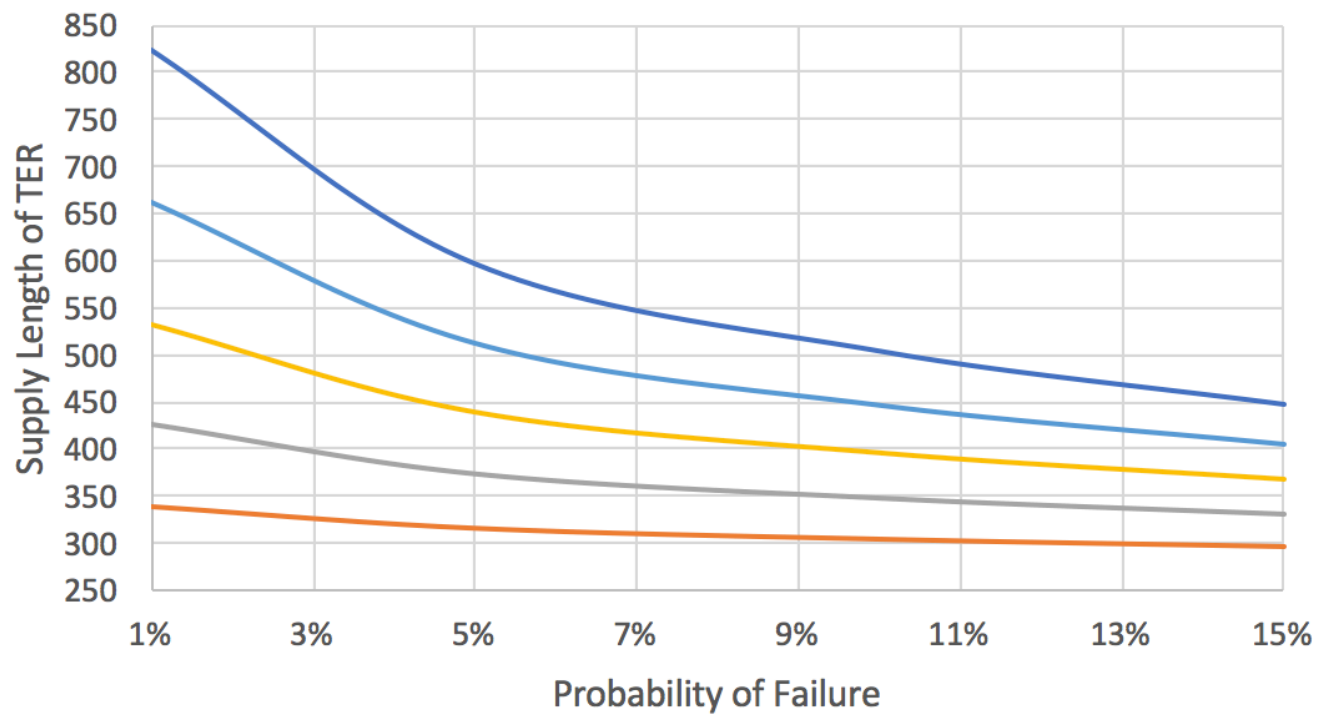

$\longrightarrow C V=5 \%-C V=10 \% \quad C V=15 \% \quad C V=20 \% \quad-C V=25 \%$ 


\section{Analysis of Results}

\subsection{General Observations}

After analyzing the results of all four cases, some general observations can be made regarding the study as a whole.

To begin, each case follows the same downward trend; a large TER supply length is required for a low probability of failure and a shorter TER supply length is required for a higher probability of failure. Furthermore, in each case, the TER supply length tapers off once the probability of failure exceeds 5\%. Intuitively this makes sense as a longer TER offers the runaway vehicle a longer stopping distance than is required and therefore a lower probability the TER design will fail, whereas a shorter TER, although more economical, may not provide enough stopping distance for the runaway vehicle, and thus a higher probability the TER design could fail.

When designing a TER, particular attention should be paid to the critical design area, between $1 \%$ to $5 \%$, where the TER supply length increases rapidly as the probability of failure is reduced. This observation was noted for all four cases. For example, in Case 1, Scenario 1, CV $=25 \%$ (FOSM Reliability Analysis, $\mathrm{G}_{1}=+2 \%, \mathrm{~V}_{1}=140 \mathrm{~km} / \mathrm{hr}, \mathrm{R}=0.25 \mathrm{~kg} / \mathrm{kgGVM}$ ), the required TER supply length increased by up to $20 \%$. As a result, it is highly recommended to design a TER using a probability of failure below $5 \%$ or as small as possible, as this significant change in length can severely affect the reliability of the design.

It was also noted that the coefficient of variation strongly affected the supply length of the TER. For a larger coefficient of variation, which accounts for more variation in the design variables, a longer TER supply length is required. For a smaller coefficient of variation, which accounts for less variation in the design variables and is less accurate, a shorter TER supply length is 
required. As a result, the change in the TER supply length over a range of probability of failure is minimal for smaller CV values and larger for larger CV values. For example, in Case 1, Scenario 1, the TER supply length for $\mathrm{CV}=25 \%$ is $292.4 \mathrm{~m}$ greater than $\mathrm{CV}=1 \%$, which is a $81.5 \%$ difference. Furthermore, in Case 1, Scenario 1, the change in TER supply length over a range of $P_{f}=1 \%$ to $P_{f}=15 \%$ is a $12.8 \%$ difference for $C V=5 \%$ and a $45.3 \%$ difference for a $C V=25 \%$. This range in values is significant, and designers should perform a benefit cost analysis to determine a CV value that will optimize safety while creating an economical design.

\subsection{Effect of Changes in Speed}

In order to analyze the effects of speed on the TER supply length, Case 1, Scenario 1, where V = $140 \mathrm{~km} / \mathrm{hr}$ and Case 1, Scenario 3 where $\mathrm{V}=100 \mathrm{~km} / \mathrm{hr}$, were analyzed and plotted on the graph in Figure 24. All other variables in Case 1, Scenario 1 and Scenario 3 were identical (i.e. FOSM Reliability Analysis, $\left.\mathrm{G}_{1}=+2 \%, \mathrm{R}=0.25 \mathrm{~kg} / \mathrm{kgGVM}\right)$.

Figure 24 makes it clear that increased vehicle speed strongly affects the supply length of the TER. For a larger speed, a longer TER supply length is required. For a smaller speed, a shorter TER supply length is required. These results reflect intuition as vehicles travelling at higher speeds require a longer distance to come to a complete stop. For example, for a CV $=25 \%$, the TER supply length is $319 \mathrm{~m}$ longer, or a 96\% difference, for a vehicle travelling $140 \mathrm{~km} / \mathrm{hr}$ (Case 1, Scenario 1) in comparison to a vehicle travelling $100 \mathrm{~km} / \mathrm{hr}$ (Case 1, Scenario 3). This range in values is very significant, and designers should perform a benefit cost analysis to determine a design speed that will optimize safety while creating an economical design. 


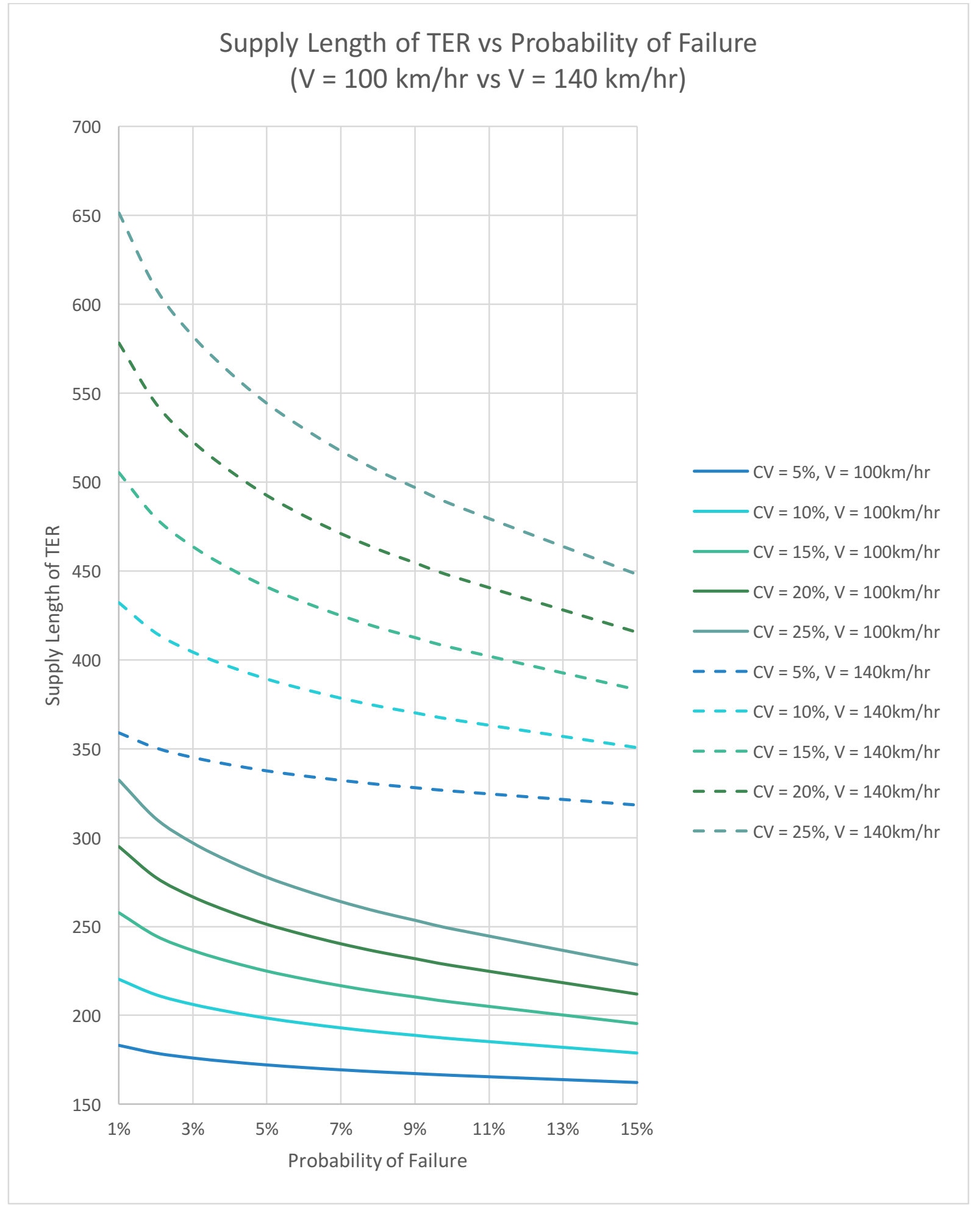

Figure 24 - Effect of Varying Vehicle Speed on TER $L_{\text {supply }}$ (using $G_{1}=+2 \%, R=0.25 \mathrm{~kg} / \mathrm{kgGVM}$ ) 


\subsection{Effect of Changes in Grade}

In order to analyze the effect grade has on the TER supply length, Case 1, Scenario 1 , where $G=$ $+2 \%$ and Case 1, Scenario 9 where $\mathrm{G}=-2 \%$, were analyzed and plotted on the graph in Figure 25. All other variables in Case 1, Scenario 1 and Scenario 9 were identical (i.e. FOSM Reliability Analysis, $\left.\mathrm{V}_{1}=140 \mathrm{~km} / \mathrm{hr}, \mathrm{R}=0.25 \mathrm{~kg} / \mathrm{kgGVM}\right)$.

Figure 25 makes it clear that the TER grade slightly affects the supply length of the TER. For a negative grade, a longer TER supply length is required. For a positive grade, a shorter TER supply length is required. These results reflect intuition as vehicles travelling downgrade require a longer distance to come to a complete stop due to the failed brake system in combination with the force of gravity. For example, for a $C V=25 \%$, the TER supply length is $127.5 \mathrm{~m}$ longer, or $19.6 \%$ greater, for a vehicle travelling downgrade at $\mathrm{G}=-2 \%$ (Case 1 , Scenario 9) in comparison to a vehicle travelling upgrade at $G=+2 \%$ (Case 1, Scenario 1). Although this difference is smaller than the change in speed, this range in values is still significant, and designers should perform a benefit cost analysis to determine a TER grade that will optimize safety while creating an economical design. 
Supply Length of TER vs Probability of Failure ( $G=+2 \%$ vs $G=-2 \%$ )

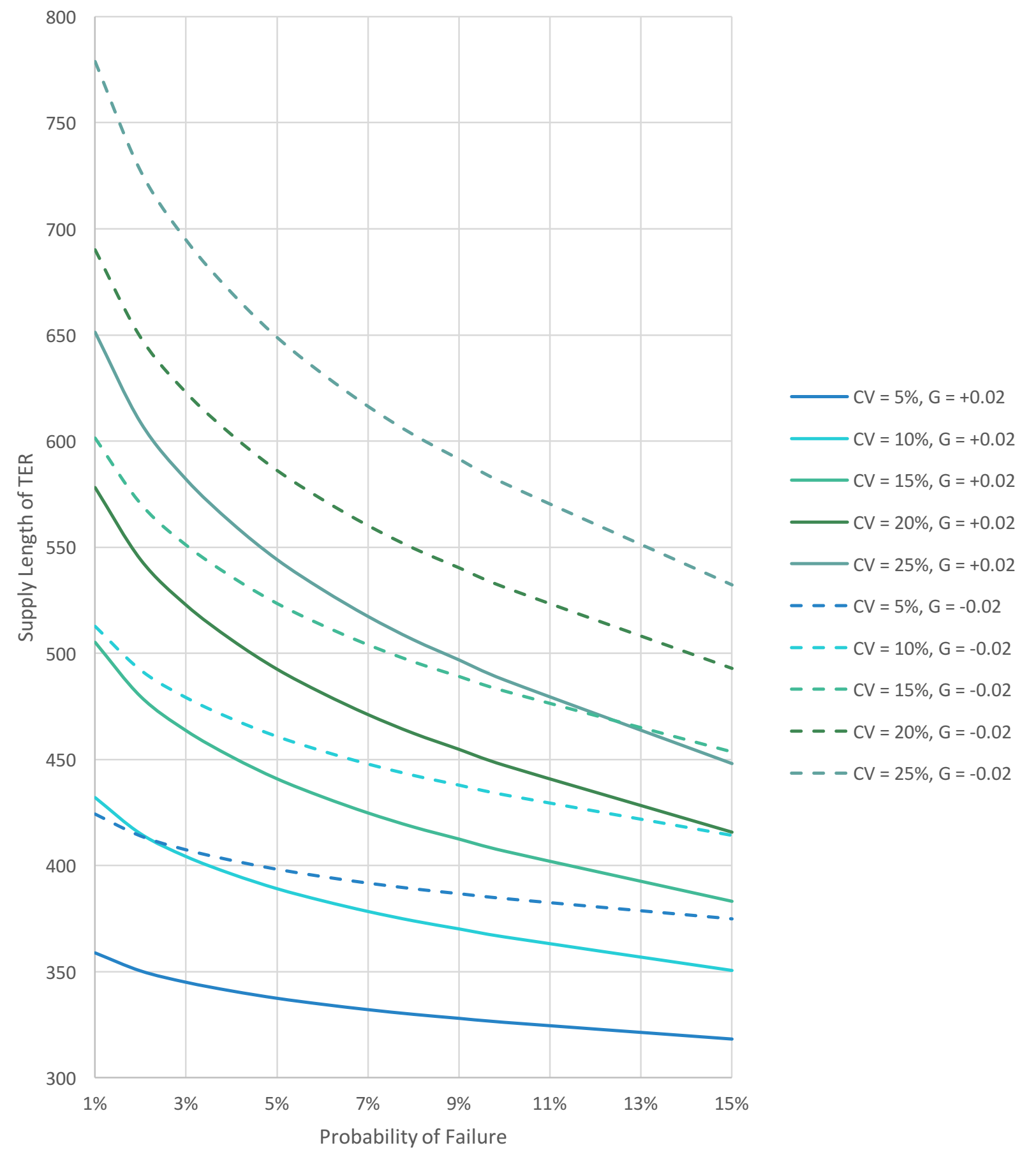

Figure 25 - Effect of Varying Grade on TER $L_{\text {supply }}$ (using V = $140 \mathrm{~km} / \mathrm{hr}, \mathrm{R}=0.25 \mathrm{~kg} / \mathrm{kgGVM}$ ) 


\subsection{Effect of Reliability Method (FOSM vs AFOSM)}

Since two reliability methods were used to assess identical TER designs, the results from each method were compared. First one TER grade was analyzed using Case 1, Scenario 1 (FOSM) versus Case 3, Scenario 1 (AFOSM) where $G_{1}=+2 \%, V_{1}=140 \mathrm{~km} / \mathrm{hr}$, and $\mathrm{R}=0.25 \mathrm{~kg} / \mathrm{kgGVM}$ for both cases. Secondly, two TER grades were analyzed using Case 2, Scenario 1 (FOSM) versus Case 4, Scenario 1 (AFOSM) where $\mathrm{G}_{1}=0 \%, \mathrm{G}_{2}=+4 \%, \mathrm{~V}_{1}=140 \mathrm{~km} / \mathrm{hr}$, and $\mathrm{R}=0.25 \mathrm{~kg} / \mathrm{kgGVM}$ for both cases. The comparisons are plotted on the graphs in Figure 26 and Figure 27.

Figure 26 and Figure 27 makes it evident that the method used to assess a TER design significantly affects the supply length of the TER. The FOSM analysis produces a shorter TER design supply length in comparison to the AFOSM analysis. This is because the AFOSM analysis is a more accurate reliability method and uses iterations to reduce error created in the FOSM model. For example, for a CV $=25 \%$ for Case 1 , Scenario 1 versus Case 3 , Scenario 1 , the TER supply length is $267.1 \mathrm{~m}$ longer, or $41 \%$ greater using the AFOSM analysis in comparison to the FOSM analysis.

To further compare the FOSM and AFOSM models, the AFOSM model was tested using the $\mathrm{P}_{f}$ and $\mathrm{L}_{\text {supply }}$ values obtained in the FOSM reliability analysis. For all cases, the AFOSM model yielded an identical response to that obtained using the FOSM model after one iteration. However, upon further iteration, the probability of failure increased for the same $L_{\text {supply, }}$ implying that the initial value obtained from the FOSM model has a higher probability of failure than initially assumed. 
As a result, the AFOSM method is highly recommended for a more accurate design. However, space constraints may be of concern and designers should perform a benefit cost analysis to determine how accurate of an analysis is required in order to optimize safety while creating an economical design.

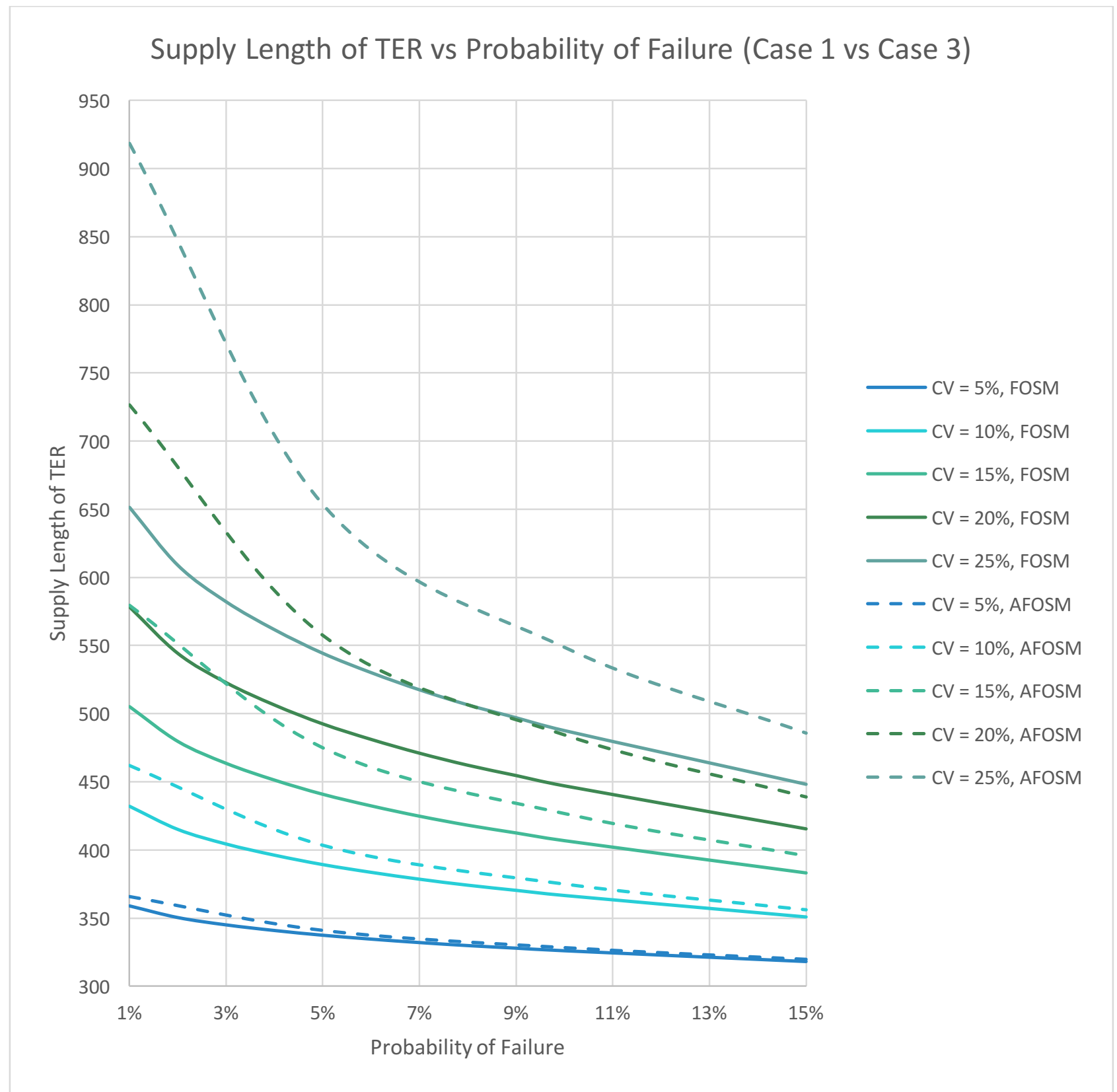

Figure 26 - Effect of Varying Reliability Method on TER $\mathrm{L}_{\text {supply }}$ for One TER Grade (using Case 1 FOSM Reliability Method vs Case 3 AFOSM Reliability Method; G = +2\%, V = $140 \mathrm{~km} / \mathrm{hr}, \mathrm{R}=0.25 \mathrm{~kg} / \mathrm{kgGVM}$ ) 


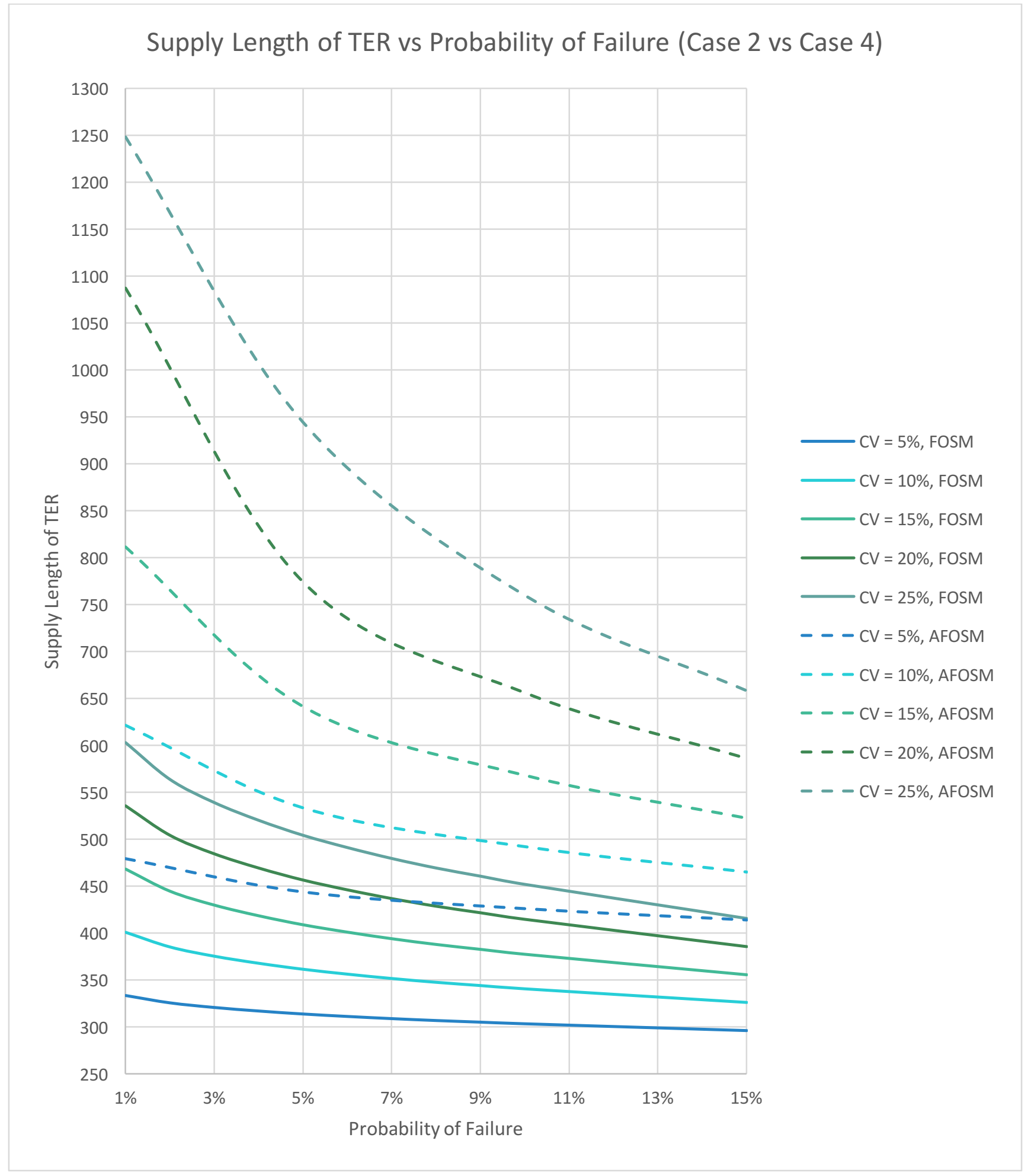

Figure 27 - Effect of Varying Reliability Method on TER $L_{\text {supply }}$ for Two TER Grades (using Case 2 FOSM Reliability Method vs Case 4 AFOSM Reliability Method; $G_{1}=0 \%, G_{2}=+4 \%, V=140 \mathrm{~km} / \mathrm{hr}, R=0.25 \mathrm{~kg} / \mathrm{kgGVM}$ ) 


\section{Application}

Since a FOSM and AFOSM reliability analysis has never been performed for the design of TERs, the models developed in this study were applied to existing one grade and two grade TERs in order to assess the reliability of existing TERs in practice.

\subsection{Arrestor Bed Single Ascending Grade: I-17 NB}

A single ascending grade arrestor bed TER exists on Arizona's Interstate 17 NB (I-17 NB). The present conditions of this TER include pea gravel bedding material with a $2 \%$ upgrade [17]. The I-17 NB TER consists of a $445 \mathrm{~m}$ exit ramp terminal and a $335 \mathrm{~m}$ of arrestor bed, for a total TER length of $780 \mathrm{~m}$ [17]. Between 1986 through 2001, this TER has been used 51 times [17].

The FOSM and AFOSM reliability analyses were applied to Arizona's I-17. This application is identical to the analysis completed in Case 1, Scenario 1, and Case 3, Scenario 1. Since a design speed was not provided, $140 \mathrm{~km} / \mathrm{hr}$ was assumed for this analysis. When comparing the results from the existing I-17 NB TER design to the FOSM and AFOSM reliability analyses, the probability of failure for all CV values is smaller than $1 \%$, with the exception of the AFOSM analysis when $\mathrm{CV}=25 \%$, in which case, the probability of failure is roughly $2.5 \%$. For higher CV values, the probability of failure will increase, and for lower CV values, the probability of failure will decrease. Overall this TER design has a low probability of failure.

\subsection{Arrestor Bed Multiple Descending Grades: KY 118}

A two grade descending arrestor bed TER exists on Kentucky's Route 118 (KY 118) located in Leslie County. The present conditions of this TER include pea gravel bedding material with a $-8 \%$ downgrade followed by a $4 \%$ downgrade [18]. The total length of the I-17 NB TER is $275 \mathrm{~m}$ long 
and consists of $117 \mathrm{~m}$ paved section followed by $158 \mathrm{~m}$ of arrestor bed [18]. Between 1980 through 1985, this TER has been used 4 times in emergency situations, resulting in little damage to the vehicle and no reported injury [18].

\subsubsection{FOSM Results}

Based on the inputs described above, the FOSM Reliability analysis was completed, as shown in Table 32 and Figure 28. Since a design speed was not provided, $140 \mathrm{~km} / \mathrm{hr}$ was assumed for this analysis.

Table $32-L_{\text {supply }}$ Values at Corresponding $P_{f}$ and CV Values

\begin{tabular}{|c|c|c|c|c|c|}
\hline $\begin{array}{c}\text { Probability of } \\
\text { Failure, } P_{f}\end{array}$ & $\begin{array}{l}L_{\text {supply }}(m), \\
\text { CV }=5 \%\end{array}$ & $\begin{array}{l}L_{\text {supply }}(m), \\
C V=10 \%\end{array}$ & $\begin{array}{l}L_{\text {supply }}(\mathrm{m}) \\
\mathrm{CV}=15 \%\end{array}$ & $\begin{array}{l}L_{\text {supply }}(\mathrm{m}) \text {, } \\
\text { CV }=20 \%\end{array}$ & $\begin{array}{l}L_{\text {supply }}(m) \text {, } \\
\text { CV }=25 \%\end{array}$ \\
\hline $1 \%$ & 467.1 & 566.6 & 666.1 & 765.6 & 865.1 \\
\hline $2 \%$ & 455.5 & 543.5 & 631.4 & 719.3 & 807.2 \\
\hline $3 \%$ & 448.3 & 528.9 & 609.5 & 690.1 & 770.7 \\
\hline $4 \%$ & 442.7 & 517.7 & 592.8 & 667.8 & 742.8 \\
\hline $5 \%$ & 438.0 & 508.3 & 578.6 & 648.9 & 719.3 \\
\hline $6 \%$ & 434.1 & 500.6 & 567.0 & 633.5 & 700.0 \\
\hline $7 \%$ & 430.7 & 493.7 & 556.7 & 619.8 & 682.8 \\
\hline $8 \%$ & 427.7 & 487.7 & 547.7 & 607.8 & 667.8 \\
\hline $9 \%$ & 425.1 & 482.6 & 540.0 & 597.5 & 654.9 \\
\hline $10 \%$ & 422.5 & 477.4 & 532.3 & 587.2 & 642.1 \\
\hline $15 \%$ & 411.8 & 456.0 & 500.1 & 544.3 & 588.5 \\
\hline
\end{tabular}




\section{Supply Length of TER vs Probability of Failure}

$$
\left(G_{1}=-8 \%, G_{2}=-4 \%, V=140 \mathrm{~km} / \mathrm{hr}\right)
$$

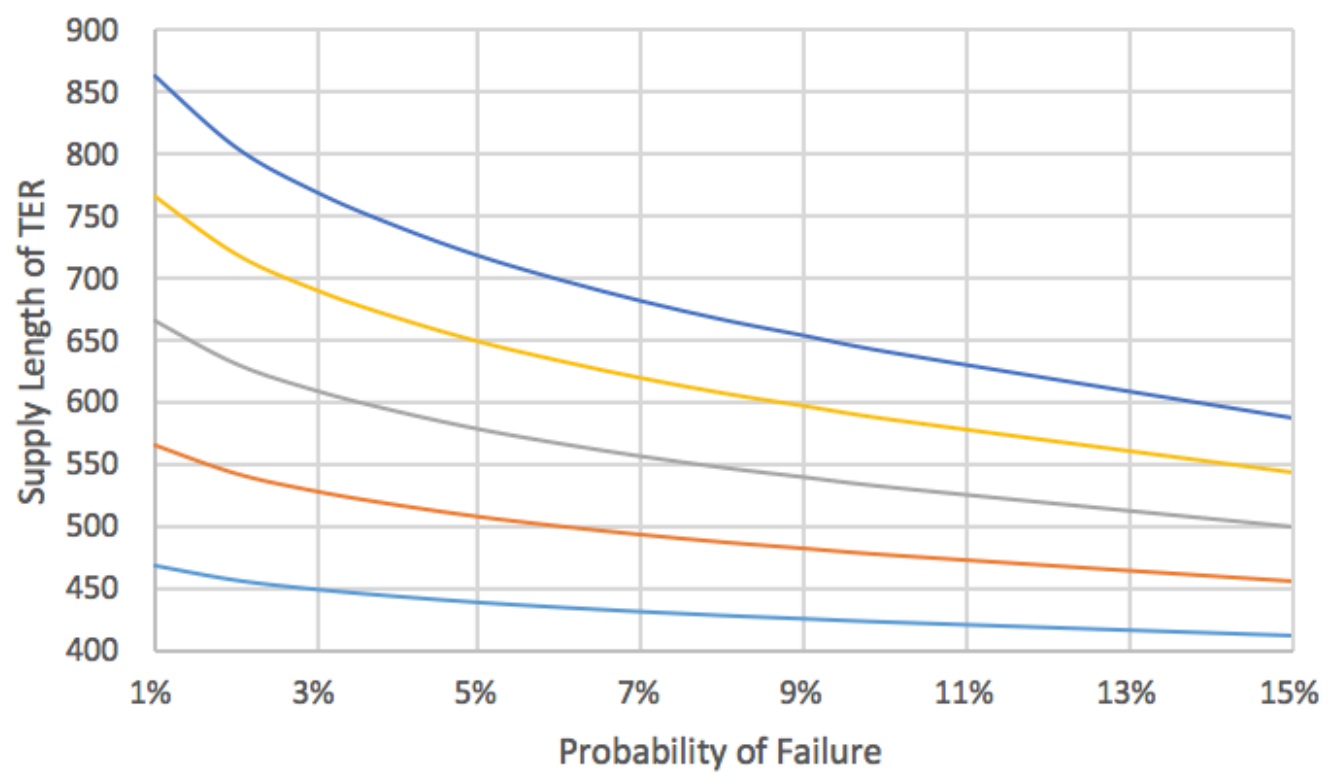

$-C V=5 \% \quad C V=10 \% \quad-C V=15 \% \quad-C V=20 \% \quad-C V=25 \%$

\subsubsection{AFOSM Results}

Based on the inputs described above, the FOSM Reliability analysis was completed, as shown in Table 32 and Figure 29. Since a design speed was not provided, $140 \mathrm{~km} / \mathrm{hr}$ was assumed for this analysis.

Table $33-L_{\text {supply }}$ Values at Corresponding $P_{f}$ and CV Values

\begin{tabular}{|c|c|c|c|c|c|}
\hline $\begin{array}{c}\text { Probability of } \\
\text { Failure, } P_{f}\end{array}$ & $\begin{array}{c}L_{\text {supply }}(m), \\
\text { CV = 5\% }\end{array}$ & $\begin{array}{c}\mathrm{L}_{\text {supply }}(\mathrm{m}), \\
\mathrm{CV}=10 \%\end{array}$ & $\begin{array}{c}\mathrm{L}_{\text {supply }}(\mathrm{m}), \\
\mathrm{CV}=15 \%\end{array}$ & $\begin{array}{c}\mathrm{L}_{\text {supply }}(\mathrm{m}), \\
\mathrm{CV}=\mathbf{2 0 \%}\end{array}$ & $\begin{array}{c}\mathrm{L}_{\text {supply }}(\mathrm{m}), \\
\mathrm{CV}=\mathbf{2 5 \%}\end{array}$ \\
\hline $1 \%$ & 479.2 & 621.5 & 811.5 & 1087.0 & 1247.9 \\
\hline $\mathbf{5 \%}$ & 443.8 & 533.6 & 641.4 & 774.1 & 944.1 \\
\hline $10 \%$ & 426.0 & 492.3 & 568.1 & 656.1 & 759.8 \\
\hline $15 \%$ & 414.0 & 465.3 & 522.4 & 586.2 & 658.3 \\
\hline
\end{tabular}




\section{Supply Length of TER vs Probability of Failure}

$$
\left(G_{1}=-8 \%, G_{2}=-4 \%, V=140 \mathrm{~km} / \mathrm{hr}\right)
$$
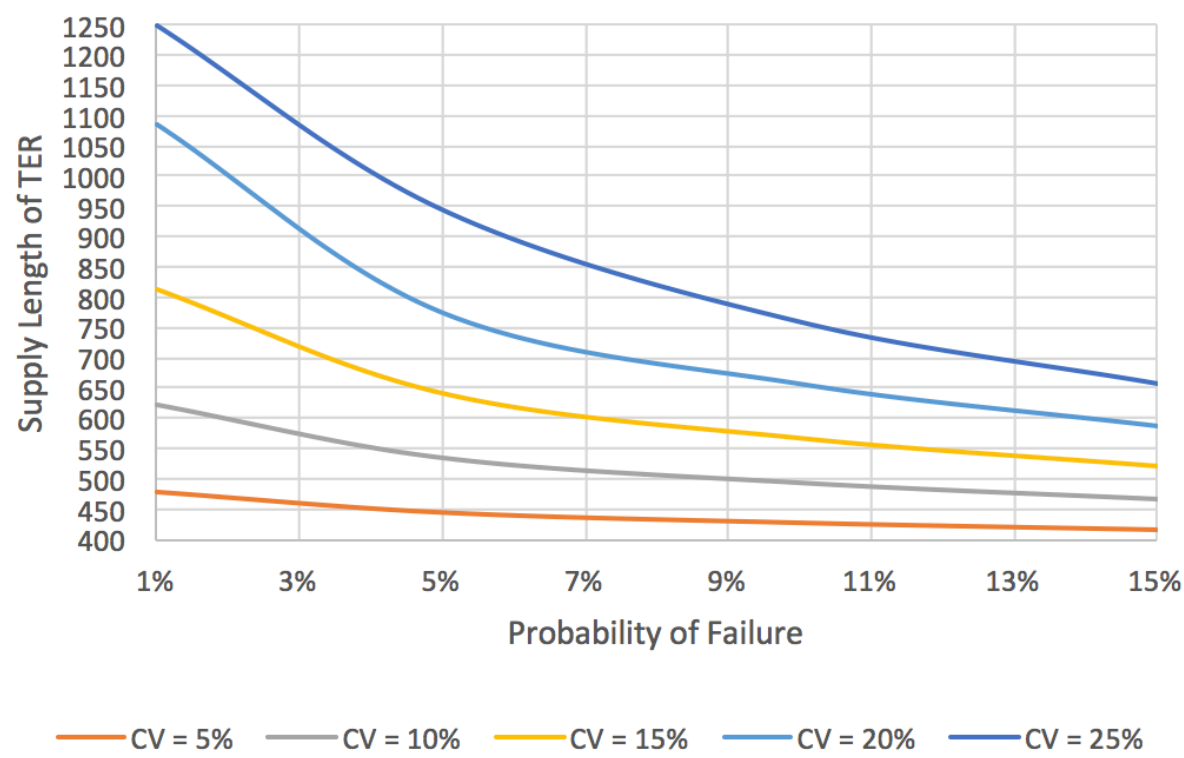

Figure 29 - Visual Representation of $L_{\text {supply }}$ for a TER using $G_{1}=-8 \%, G_{2}=-4 \%, V=140 \mathrm{~km} / \mathrm{hr}$, and $R=0.25 \mathrm{~kg} / \mathrm{kgGVM}$

\subsubsection{FOSM \& AFOSM Discussion}

When comparing the results from the existing design to the FOSM and AFOSM reliability analyses, the length of the existing KY 118 TER does not meet acceptable criteria as the probability of failure exceeds $15 \%$ for all CV. Furthermore, the supplied TER length does not meet the design standard described in Section 2.5. This may be due to the fact that the TER was installed in 1980 and could have used less conservative standards or an alternate method to determine the required TER design length. In addition, a smaller design speed, higher rolling resistance, or a combination of both, may have been used, resulting in a shorter required stopping distance. Overall according to the FOSM and AFOSM reliability methods discussed in this paper, this design is considered unreliable until more information is obtained regarding the exact design details. 


\section{Conclusions}

The results of this study demonstrate that many factors can affect the design and reliability of a TER. Varying conditions such as a change in grade, entering vehicle speed, and rolling resistance all contribute to the final design length for a given TER.

In regards to the reliability analysis, it is clear that shorter TERs yield a higher probability of failure as the runaway vehicle does not have as much available distance to safely stop. In particular, attention should be paid to the critical design area, between $1 \%$ to $5 \%$, since the TER supply length decreases and tapers off once the probability of failure exceeds $5 \%$. For example, in Case 1, Scenario 1, CV $=25 \%$ (FOSM Reliability Analysis, $\mathrm{G}_{1}=+2 \%, \mathrm{~V}_{1}=140 \mathrm{~km} / \mathrm{hr}, \mathrm{R}=$ $0.25 \mathrm{~kg} / \mathrm{kgGVM})$, the required TER supply length increased by up to $20 \%$.

The variation of the design variables also affects the TER supply length where a larger coefficient of variation requires a larger TER supply length. For example, in Case 1, Scenario 1, the TER supply length for CV $=25 \%$ is $81.5 \%$ greater than CV $=1 \%$. Furthermore, in Case 1 , Scenario 1 , the change in TER supply length over a range of $P_{f}=1 \%$ to $P_{f}=15 \%$ is a $12.8 \%$ difference for $\mathrm{CV}=5 \%$ and a $45.3 \%$ difference for a $\mathrm{CV}=25 \%$.

Furthermore, the higher the speed of a runaway vehicle entering the TER, the longer the required TER supply length. For example, for a $C V=25 \%$, the TER supply length increases by $96 \%$, for a vehicle travelling $140 \mathrm{~km} / \mathrm{hr}$ (Case 1, Scenario 1) in comparison to a vehicle travelling $100 \mathrm{~km} / \mathrm{hr}$ (Case 1, Scenario 3).

Similarly, a negative grade yields a higher probability of failure as gravity is working with the runaway vehicle, prohibiting the vehicle from safely stopping in a shorter distance. For example, for a $C V=25 \%$, the TER supply length is $127.5 \mathrm{~m}$ longer, or $19.6 \%$ greater, for a 
vehicle travelling downgrade at $G=-2 \%$ (Case 1 , Scenario 9) in comparison to a vehicle travelling upgrade at $\mathrm{G}=+2 \%$ (Case 1 , Scenario 1 ).

Lastly, it is clear that the AFOSM reliability method is more accurate than the FOSM reliability method and yields a larger TER length for all cases. This is because the AFOSM analysis is a more accurate reliability method due to the nature of the methodology which considers analysis at design points. The AFOSM reliability method provides the designer with a more conservative value for the design length of a TER which is useful to ensure safety and a low probability of failure. For example, for a CV $=25 \%$ for Case 1, Scenario 1 versus Case 3, Scenario 1 , the TER supply length is $41 \%$ greater using the AFOSM analysis in comparison to the FOSM analysis.

In conclusion, the range in values is significant for all factors affecting the required TER supply length. The design variables should be optimized in order to produce a cost effective design while ensuring user safety as a top priority. 


\section{Appendix A - Case 1 Analysis Results}

Scenario $2-$ FOSM, G $=+2 \%, V=120 \mathrm{~km} / \mathrm{hr}$

Table $34-L_{\text {supply }}$ Values at Corresponding $P_{f}$ and $C V$ Values

\begin{tabular}{|c|c|c|c|c|c|}
\hline $\begin{array}{c}\text { Probability of } \\
\text { Failure, } P_{f}\end{array}$ & $\begin{array}{c}L_{\text {supply }}(m) \\
\text { CV }=5 \%\end{array}$ & $\begin{array}{l}L_{\text {supply }}(m), \\
C V=10 \%\end{array}$ & $\begin{array}{l}L_{\text {supply }}(m) \\
C V=15 \%\end{array}$ & $\begin{array}{l}L_{\text {supply }}(m), \\
C V=20 \%\end{array}$ & $\begin{array}{c}L_{\text {supply }}(m), \\
C V=25 \%\end{array}$ \\
\hline $1 \%$ & 263.7 & 317.4 & 371.1 & 424.8 & 478.5 \\
\hline $2 \%$ & 257.4 & 304.9 & 352.4 & 399.8 & 447.3 \\
\hline $3 \%$ & 253.5 & 297.0 & 340.5 & 384.1 & 427.6 \\
\hline $4 \%$ & 250.5 & 291.0 & 331.5 & 372.0 & 412.5 \\
\hline $5 \%$ & 247.9 & 285.9 & 323.9 & 361.8 & 399.8 \\
\hline $6 \%$ & 245.9 & 281.7 & 317.6 & 353.5 & 389.4 \\
\hline $7 \%$ & 244.0 & 278.0 & 312.1 & 346.1 & 380.1 \\
\hline $8 \%$ & 242.4 & 274.8 & 307.2 & 339.6 & 372.0 \\
\hline $9 \%$ & 241.0 & 272.0 & 303.0 & 334.1 & 365.1 \\
\hline $10 \%$ & 239.6 & 269.2 & 298.9 & 328.5 & 358.1 \\
\hline $15 \%$ & 233.8 & 257.7 & 281.5 & 305.4 & 329.2 \\
\hline
\end{tabular}

Supply Length of TER vs Probability of Failure

$$
(\mathrm{G}=+2 \%, \mathrm{~V}=120 \mathrm{~km} / \mathrm{hr})
$$

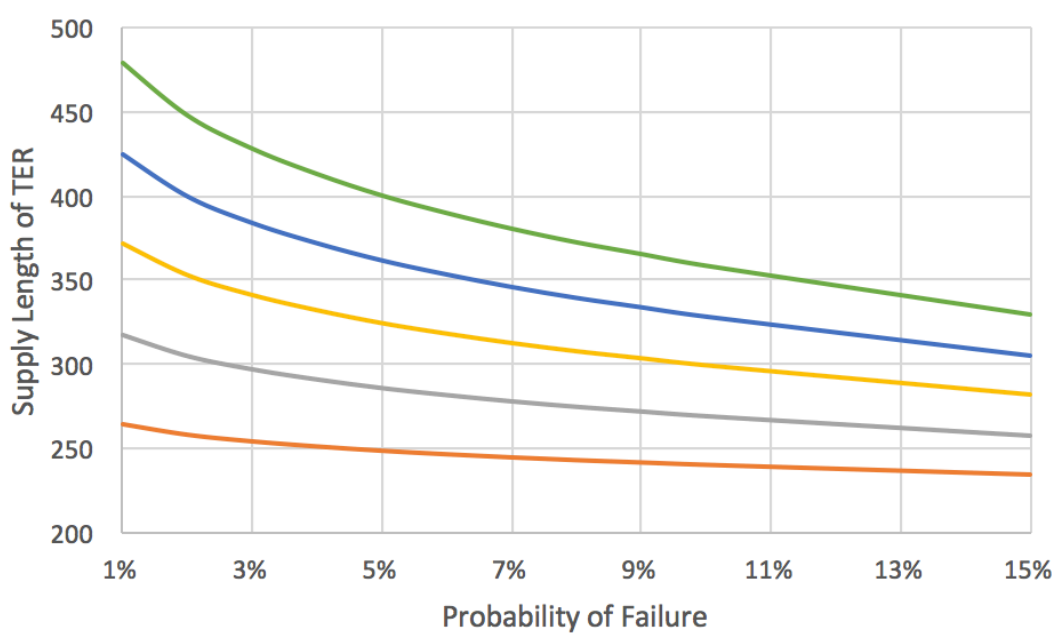

$\longrightarrow \mathrm{CV}=5 \%-\mathrm{CV}=10 \%-\mathrm{CV}=15 \%-\mathrm{CV}=20 \%-\mathrm{CV}=25 \%$ 
Scenario $3-$ FOSM, G $=+2 \%, V=100 \mathrm{~km} / \mathrm{hr}$

Table $35-L_{\text {supply }}$ Values at Corresponding $P_{f}$ and CV Values

\begin{tabular}{|c|c|c|c|c|c|}
\hline $\begin{array}{c}\text { Probability of } \\
\text { Failure, } P_{f}\end{array}$ & $\begin{array}{c}\mathrm{L}_{\text {supply }}(\mathrm{m}) \text {, } \\
\mathrm{CV}=5 \%\end{array}$ & $\begin{array}{c}L_{\text {supply }}(m), \\
C V=10 \%\end{array}$ & $\begin{array}{c}L_{\text {supply }}(m), \\
C V=15 \%\end{array}$ & $\begin{array}{l}L_{\text {supply }}(m), \\
C V=20 \%\end{array}$ & $\begin{array}{l}\mathrm{L}_{\text {supply }}(\mathrm{m}) \\
\mathrm{CV}=25 \%\end{array}$ \\
\hline $1 \%$ & 183.1 & 220.4 & 257.7 & 295.0 & 332.3 \\
\hline $2 \%$ & 178.8 & 211.7 & 244.7 & 277.7 & 310.6 \\
\hline $3 \%$ & 176.0 & 206.3 & 236.5 & 266.7 & 296.9 \\
\hline $4 \%$ & 174.0 & 202.1 & 230.2 & 258.4 & 286.5 \\
\hline $5 \%$ & 172.2 & 198.5 & 224.9 & 251.3 & 277.7 \\
\hline $6 \%$ & 170.7 & 195.7 & 220.6 & 245.5 & 270.4 \\
\hline $7 \%$ & 169.4 & 193.1 & 216.7 & 240.4 & 264.0 \\
\hline $8 \%$ & 168.3 & 190.8 & 213.3 & 235.8 & 258.4 \\
\hline $9 \%$ & 167.4 & 188.9 & 210.4 & 232.0 & 253.5 \\
\hline $10 \%$ & 166.4 & 187.0 & 207.6 & 228.1 & 248.7 \\
\hline $15 \%$ & 162.4 & 178.9 & 195.5 & 212.1 & 228.6 \\
\hline
\end{tabular}

Supply Length of TER vs Probability of Failure

( $\mathrm{G}=+2 \%, V=100 \mathrm{~km} / \mathrm{hr}$ )

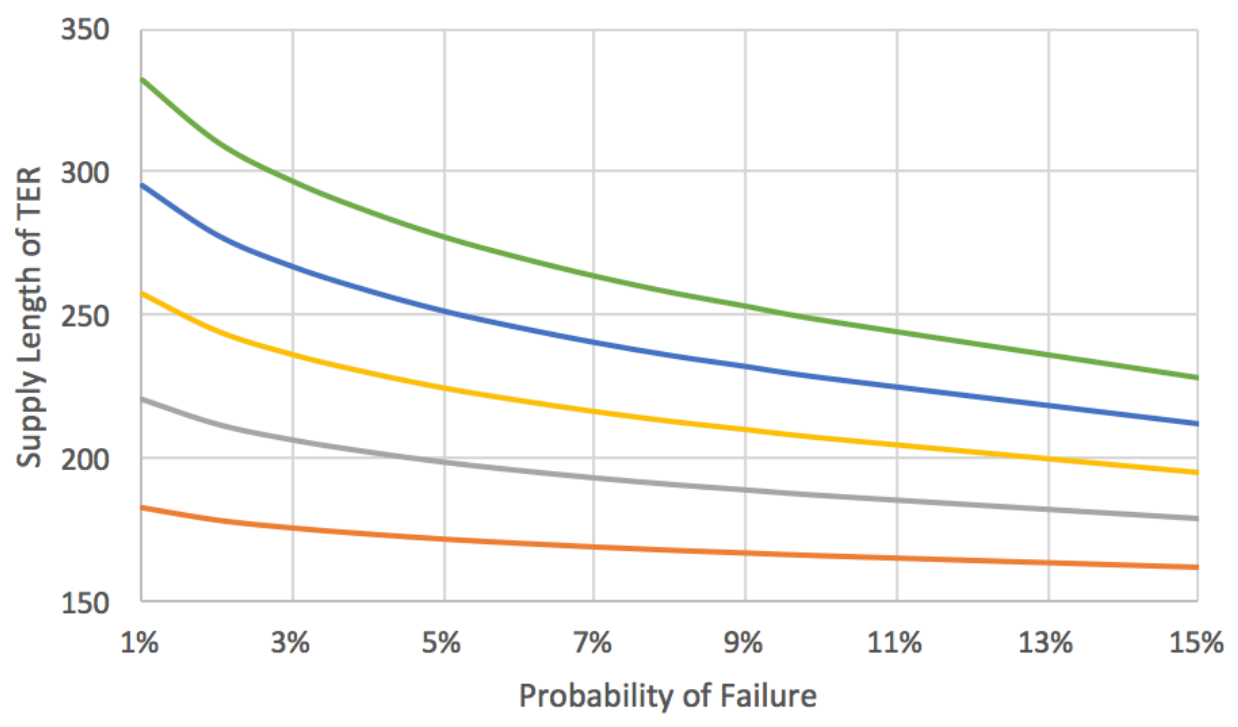

$\longrightarrow C V=5 \% \quad C V=10 \% \quad C V=15 \% \quad-C V=20 \% \quad-C V=25 \%$

Figure 31 - FOSM Visual Representation of $L_{\text {supply }}$ for a TER using $G=+2 \%, V=100 \mathrm{~km} / \mathrm{hr}$, and R= $0.25 \mathrm{~kg} / \mathrm{kgGVM}$ 
Scenario 4 - FOSM, G = 0\%, V = $140 \mathrm{~km} / \mathrm{hr}$

Table $36-L_{\text {supply }}$ Values at Corresponding $P_{f}$ and CV Values

\begin{tabular}{|c|c|c|c|c|c|}
\hline $\begin{array}{c}\text { Probability of } \\
\text { Failure, } P_{f}\end{array}$ & $\begin{array}{c}\mathrm{L}_{\text {supply }}(\mathrm{m}) \\
\mathrm{CV}=5 \%\end{array}$ & $\begin{array}{l}L_{\text {supply }}(m), \\
C V=10 \%\end{array}$ & $\begin{array}{c}\mathrm{L}_{\text {supply }}(\mathrm{m}) \\
\mathrm{CV}=15 \%\end{array}$ & $\begin{array}{l}L_{\text {supply }}(m) \text {, } \\
C V=20 \%\end{array}$ & $\begin{array}{l}L_{\text {supply }}(\mathrm{m}) \\
\mathrm{CV}=25 \%\end{array}$ \\
\hline $1 \%$ & 388.7 & 468.8 & 548.8 & 628.9 & 709.0 \\
\hline $2 \%$ & 379.4 & 450.1 & 520.9 & 591.6 & 662.4 \\
\hline $3 \%$ & 373.5 & 438.4 & 503.3 & 568.2 & 633.0 \\
\hline $4 \%$ & 369.1 & 429.4 & 489.8 & 550.2 & 610.6 \\
\hline $5 \%$ & 365.3 & 421.9 & 478.4 & 535.0 & 591.6 \\
\hline $6 \%$ & 362.2 & 415.6 & 469.1 & 522.6 & 576.1 \\
\hline $7 \%$ & 359.4 & 410.1 & 460.8 & 511.6 & 562.3 \\
\hline $8 \%$ & 357.0 & 405.3 & 453.6 & 501.9 & 550.2 \\
\hline $9 \%$ & 354.9 & 401.1 & 447.4 & 493.6 & 539.9 \\
\hline $10 \%$ & 352.8 & 397.0 & 441.2 & 485.3 & 529.5 \\
\hline $15 \%$ & 344.2 & 379.8 & 415.3 & 450.8 & 486.4 \\
\hline
\end{tabular}

Supply Length of TER vs Probability of Failure

( $\mathrm{G}=0 \%, \mathrm{~V}=140 \mathrm{~km} / \mathrm{hr}$ )

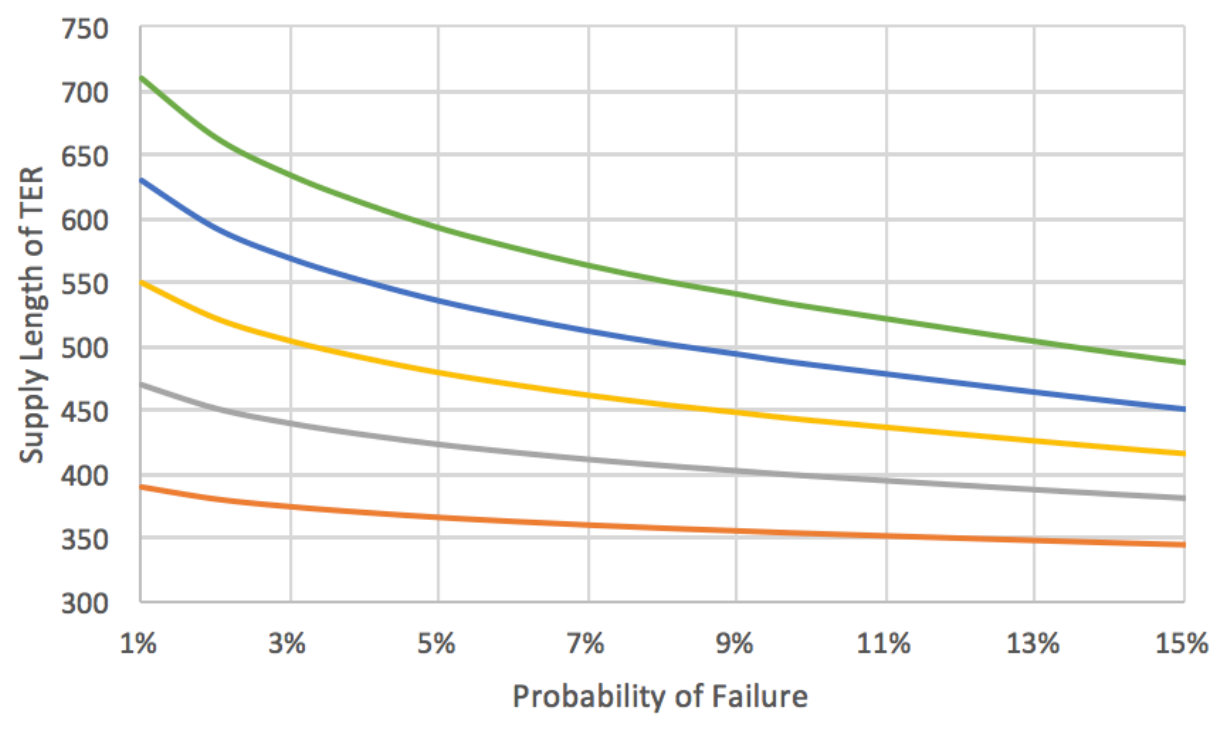

$\longrightarrow \mathrm{CV}=5 \%-\mathrm{CV}=10 \%-\mathrm{CV}=15 \% \quad-\mathrm{CV}=20 \% \quad-\mathrm{CV}=25 \%$ 
Scenario 5 - FOSM, G = +4\%, V = $140 \mathrm{~km} / \mathrm{hr}$

Table $37-L_{\text {supply }}$ Values at Corresponding $P_{f}$ and CV Values

\begin{tabular}{|c|c|c|c|c|c|}
\hline $\begin{array}{l}\text { Probability of } \\
\text { Failure, } P_{f}\end{array}$ & $\begin{array}{l}\mathrm{L}_{\text {supply }}(\mathrm{m}) \\
\mathrm{CV}=5 \%\end{array}$ & $\begin{array}{l}L_{\text {supply }}(m) \\
\text { CV }=10 \%\end{array}$ & $\begin{array}{l}L_{\text {supply }}(m) \\
C V=15 \%\end{array}$ & $\begin{array}{l}L_{\text {supply }}(m) \\
C V=20 \%\end{array}$ & $\begin{array}{l}L_{\text {supply }}(m) \text {, } \\
C V=25 \%\end{array}$ \\
\hline $1 \%$ & 333.4 & 400.8 & 468.2 & 535.5 & 602.9 \\
\hline $2 \%$ & 325.6 & 385.1 & 444.6 & 504.2 & 563.7 \\
\hline $3 \%$ & 320.7 & 375.3 & 429.8 & 484.4 & 539.0 \\
\hline $4 \%$ & 316.9 & 367.7 & 418.5 & 469.3 & 520.1 \\
\hline $5 \%$ & 313.7 & 361.3 & 408.9 & 456.5 & 504.2 \\
\hline $6 \%$ & 311.1 & 356.1 & 401.1 & 446.1 & 491.1 \\
\hline $7 \%$ & 308.8 & 351.4 & 394.1 & 436.8 & 479.5 \\
\hline $8 \%$ & 306.7 & 347.4 & 388.0 & 428.7 & 469.3 \\
\hline $9 \%$ & 305.0 & 343.9 & 382.8 & 421.7 & 460.6 \\
\hline $10 \%$ & 303.3 & 340.4 & 377.6 & 414.7 & 451.9 \\
\hline $15 \%$ & 296.0 & 325.9 & 355.8 & 385.7 & 415.6 \\
\hline
\end{tabular}

Supply Length of TER vs Probability of Failure

( $G=+4 \%, V=140 \mathrm{~km} / \mathrm{hr}$ )

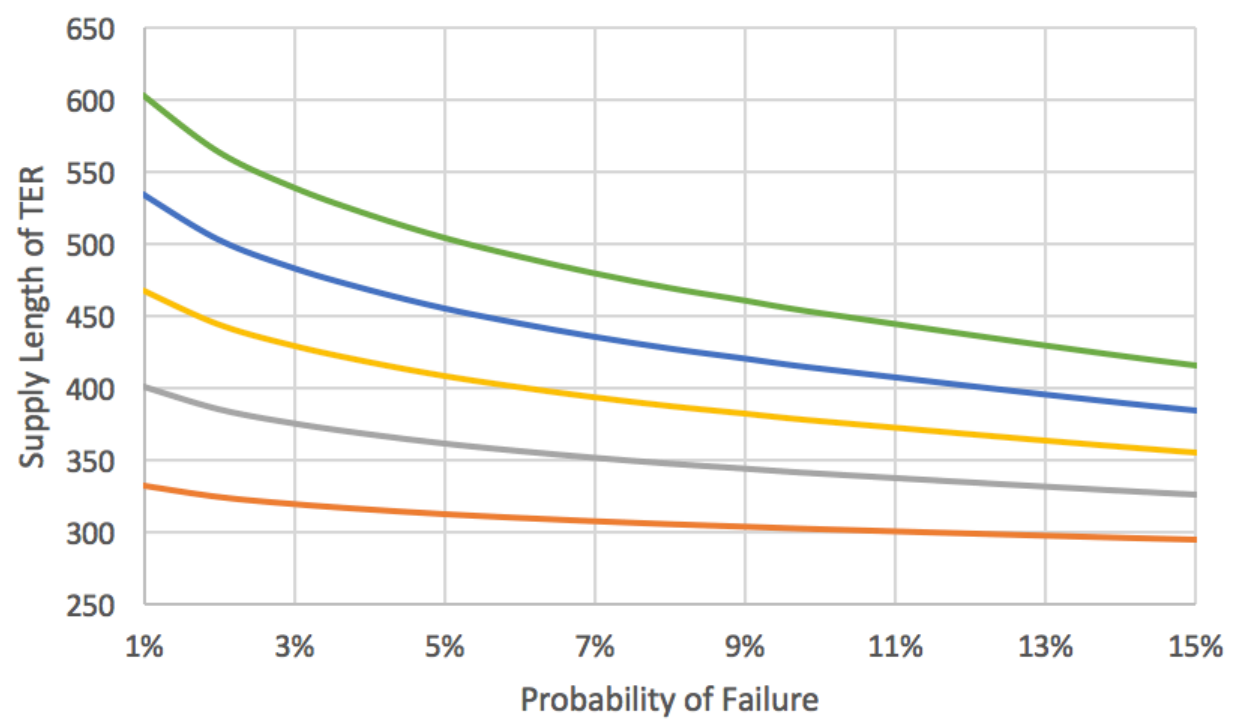

$\longrightarrow \mathrm{CV}=5 \%-\mathrm{CV}=10 \%-\mathrm{CV}=15 \% \quad-\mathrm{CV}=20 \% \quad-\mathrm{CV}=25 \%$ 
Scenario 6 - FOSM, G = +6\%, V = $140 \mathrm{~km} / \mathrm{hr}$

Table $38-L_{\text {supply }}$ Values at Corresponding $P_{f}$ and CV Values

\begin{tabular}{|c|c|c|c|c|c|}
\hline $\begin{array}{c}\text { Probability of } \\
\text { Failure, } P_{f}\end{array}$ & $\begin{array}{c}\mathrm{L}_{\text {supply }}(\mathrm{m}) \text {, } \\
\mathrm{CV}=5 \%\end{array}$ & $\begin{array}{c}L_{\text {supply }}(m), \\
C V=10 \%\end{array}$ & $\begin{array}{c}L_{\text {supply }}(m), \\
C V=15 \%\end{array}$ & $\begin{array}{l}L_{\text {supply }}(m), \\
C V=20 \%\end{array}$ & $\begin{array}{l}\mathrm{L}_{\text {supply }}(\mathrm{m}) \\
\mathrm{CV}=25 \%\end{array}$ \\
\hline $1 \%$ & 311.4 & 374.0 & 436.5 & 499.0 & 561.5 \\
\hline $2 \%$ & 304.2 & 359.4 & 414.6 & 469.9 & 525.1 \\
\hline $3 \%$ & 299.6 & 350.2 & 400.9 & 451.6 & 502.2 \\
\hline $4 \%$ & 296.1 & 343.2 & 390.4 & 437.6 & 484.7 \\
\hline $5 \%$ & 293.1 & 337.3 & 381.5 & 425.7 & 469.9 \\
\hline $6 \%$ & 290.7 & 332.5 & 374.2 & 416.0 & 457.8 \\
\hline $7 \%$ & 288.5 & 328.1 & 367.8 & 407.4 & 447.0 \\
\hline $8 \%$ & 286.6 & 324.4 & 362.1 & 399.8 & 437.6 \\
\hline $9 \%$ & 285.0 & 321.1 & 357.2 & 393.4 & 429.5 \\
\hline $10 \%$ & 283.4 & 317.9 & 352.4 & 386.9 & 421.4 \\
\hline $15 \%$ & 276.7 & 304.4 & 332.2 & 359.9 & 387.7 \\
\hline
\end{tabular}

Supply Length of TER vs Probability of Failure

( $\mathrm{G}=+6 \%, V=140 \mathrm{~km} / \mathrm{hr}$ )

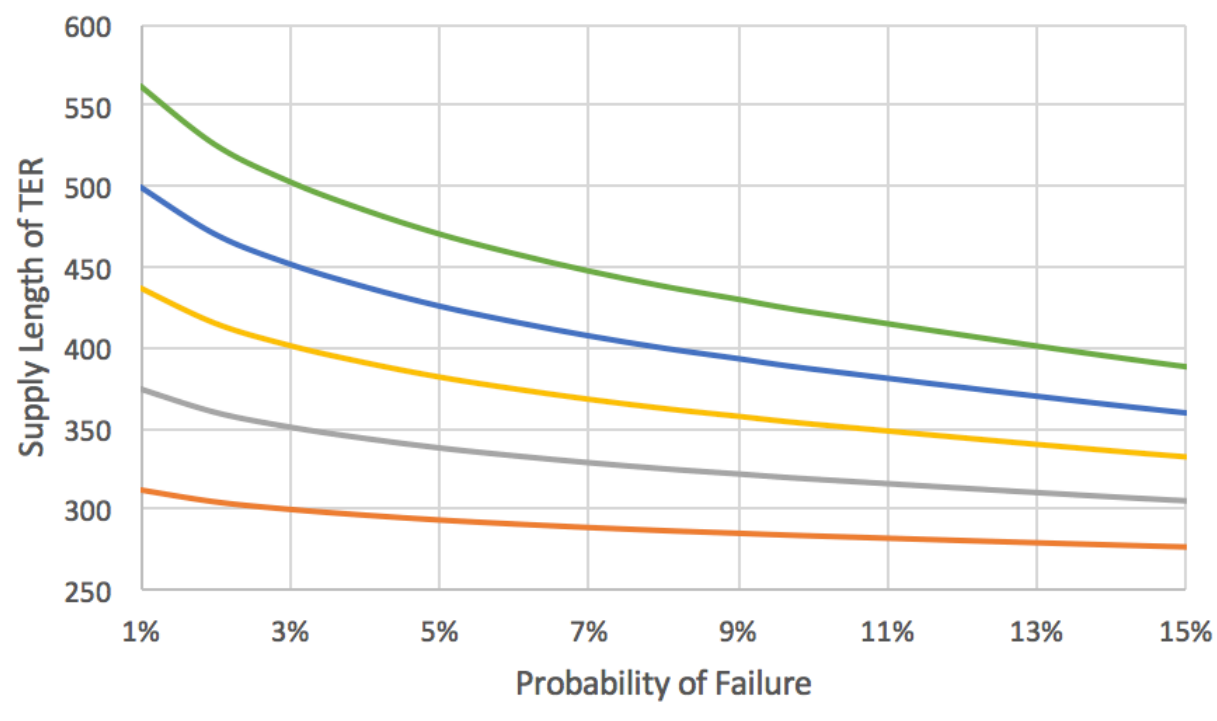

$\longrightarrow C V=5 \%-C V=10 \%-C V=15 \%-C V=20 \%-C V=25 \%$

Figure 34 - FOSM Visual Representation of $L_{\text {supply }}$ for a TER using G = +6\%, V = $140 \mathrm{~km} / \mathrm{hr}$, and $R=0.25 \mathrm{~kg} / \mathrm{kgGVM}$ 
Scenario 7 - FOSM, G = +8\%, V = $140 \mathrm{~km} / \mathrm{hr}$

Table $39-L_{\text {supply }}$ Values at Corresponding $P_{f}$ and CV Values

\begin{tabular}{|c|c|c|c|c|c|}
\hline $\begin{array}{l}\text { Probability of } \\
\text { Failure, } P_{f}\end{array}$ & $\begin{array}{l}\mathrm{L}_{\text {supply }}(\mathrm{m}) \\
\mathrm{CV}=5 \%\end{array}$ & $\begin{array}{l}L_{\text {supply }}(m) \\
\text { CV }=10 \%\end{array}$ & $\begin{array}{l}L_{\text {supply }}(m) \\
C V=15 \%\end{array}$ & $\begin{array}{l}L_{\text {supply }}(m) \\
C V=20 \%\end{array}$ & $\begin{array}{l}L_{\text {supply }}(m) \text {, } \\
C V=25 \%\end{array}$ \\
\hline $1 \%$ & 292.2 & 350.6 & 409.0 & 467.4 & 525.7 \\
\hline $2 \%$ & 285.4 & 337.0 & 388.6 & 440.2 & 491.8 \\
\hline $3 \%$ & 281.1 & 328.5 & 375.8 & 423.1 & 470.4 \\
\hline $4 \%$ & 277.9 & 321.9 & 366.0 & 410.0 & 454.0 \\
\hline $5 \%$ & 275.1 & 316.4 & 357.6 & 398.9 & 440.2 \\
\hline $6 \%$ & 272.8 & 311.8 & 350.9 & 389.9 & 428.9 \\
\hline $7 \%$ & 270.8 & 307.8 & 344.8 & 381.8 & 418.8 \\
\hline $8 \%$ & 269.1 & 304.3 & 339.5 & 374.8 & 410.0 \\
\hline $9 \%$ & 267.6 & 301.3 & 335.0 & 368.7 & 402.4 \\
\hline $10 \%$ & 266.0 & 298.3 & 330.5 & 362.7 & 394.9 \\
\hline $15 \%$ & 259.8 & 285.7 & 311.6 & 337.5 & 363.4 \\
\hline
\end{tabular}

Supply Length of TER vs Probability of Failure

( $\mathrm{G}=+8 \%, \mathrm{~V}=140 \mathrm{~km} / \mathrm{hr}$ )

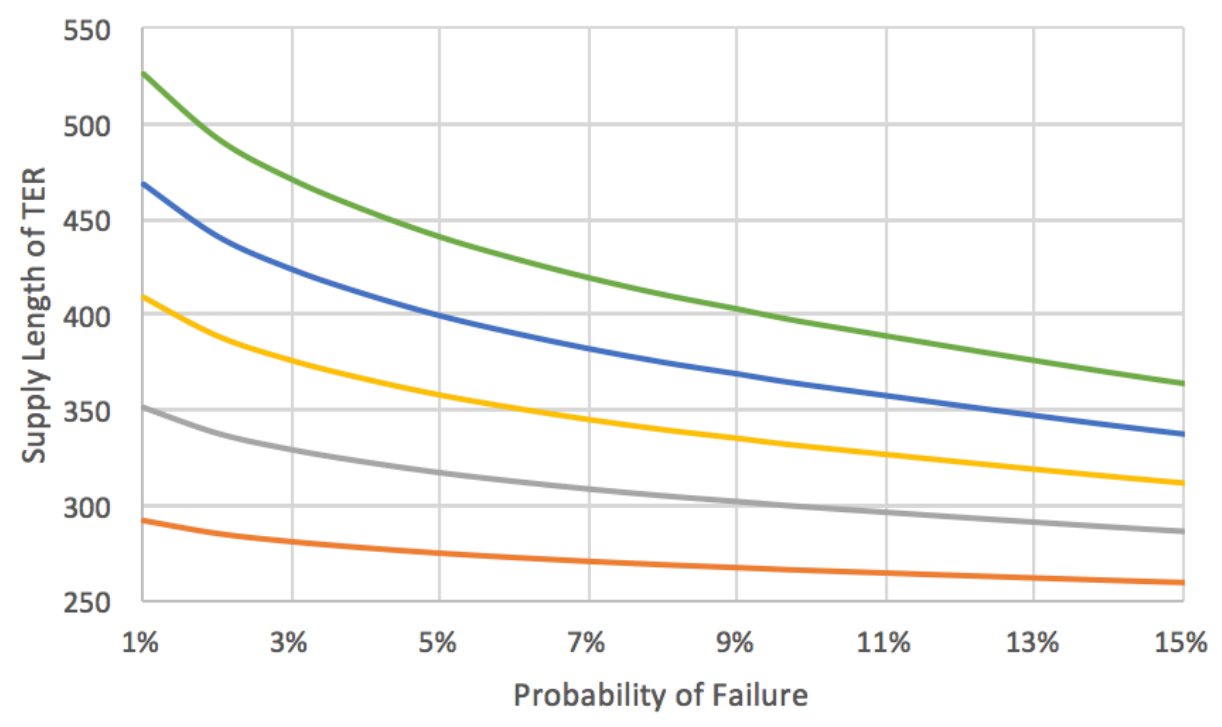

$\longrightarrow \mathrm{CV}=5 \%-\mathrm{CV}=10 \%-\mathrm{CV}=15 \%-\mathrm{CV}=20 \% \quad-\mathrm{CV}=25 \%$

Figure 35 - FOSM Visual Representation of $L_{\text {supply }}$ for a TER using $G=+8 \%, V=140 \mathrm{~km} / \mathrm{hr}$, and $R=0.25 \mathrm{~kg} / \mathrm{kgGVM}$ 
Scenario 8 - FOSM, G $=+10 \%, V=140 \mathrm{~km} / \mathrm{hr}$

Table $40-L_{\text {supply }}$ Values at Corresponding $P_{f}$ and CV Values

\begin{tabular}{|c|c|c|c|c|c|}
\hline $\begin{array}{l}\text { Probability of } \\
\text { Failure, } P_{f}\end{array}$ & $\begin{array}{l}\mathrm{L}_{\text {supply }}(\mathrm{m}) \\
\mathrm{CV}=5 \%\end{array}$ & $\begin{array}{l}L_{\text {supply }}(m) \\
\text { CV }=10 \%\end{array}$ & $\begin{array}{l}L_{\text {supply }}(m) \\
C V=15 \%\end{array}$ & $\begin{array}{l}L_{\text {supply }}(m) \\
C V=20 \%\end{array}$ & $\begin{array}{l}L_{\text {supply }}(m) \text {, } \\
C V=25 \%\end{array}$ \\
\hline $1 \%$ & 275.3 & 330.1 & 384.9 & 439.7 & 494.5 \\
\hline $2 \%$ & 268.9 & 317.3 & 365.7 & 414.2 & 462.6 \\
\hline $3 \%$ & 264.9 & 309.3 & 353.7 & 398.1 & 442.5 \\
\hline $4 \%$ & 261.8 & 303.1 & 344.5 & 385.8 & 427.2 \\
\hline $5 \%$ & 259.2 & 298.0 & 336.7 & 375.4 & 414.2 \\
\hline $6 \%$ & 257.1 & 293.7 & 330.3 & 366.9 & 403.5 \\
\hline $7 \%$ & 255.2 & 289.9 & 324.6 & 359.4 & 394.1 \\
\hline $8 \%$ & 253.5 & 286.6 & 319.7 & 352.8 & 385.8 \\
\hline $9 \%$ & 252.1 & 283.8 & 315.4 & 347.1 & 378.7 \\
\hline $10 \%$ & 250.7 & 280.9 & 311.2 & 341.4 & 371.7 \\
\hline $15 \%$ & 244.8 & 269.1 & 293.5 & 317.8 & 342.1 \\
\hline
\end{tabular}

Supply Length of TER vs Probability of Failure ( $G=+10 \%, V=140 \mathrm{~km} / \mathrm{hr}$ )

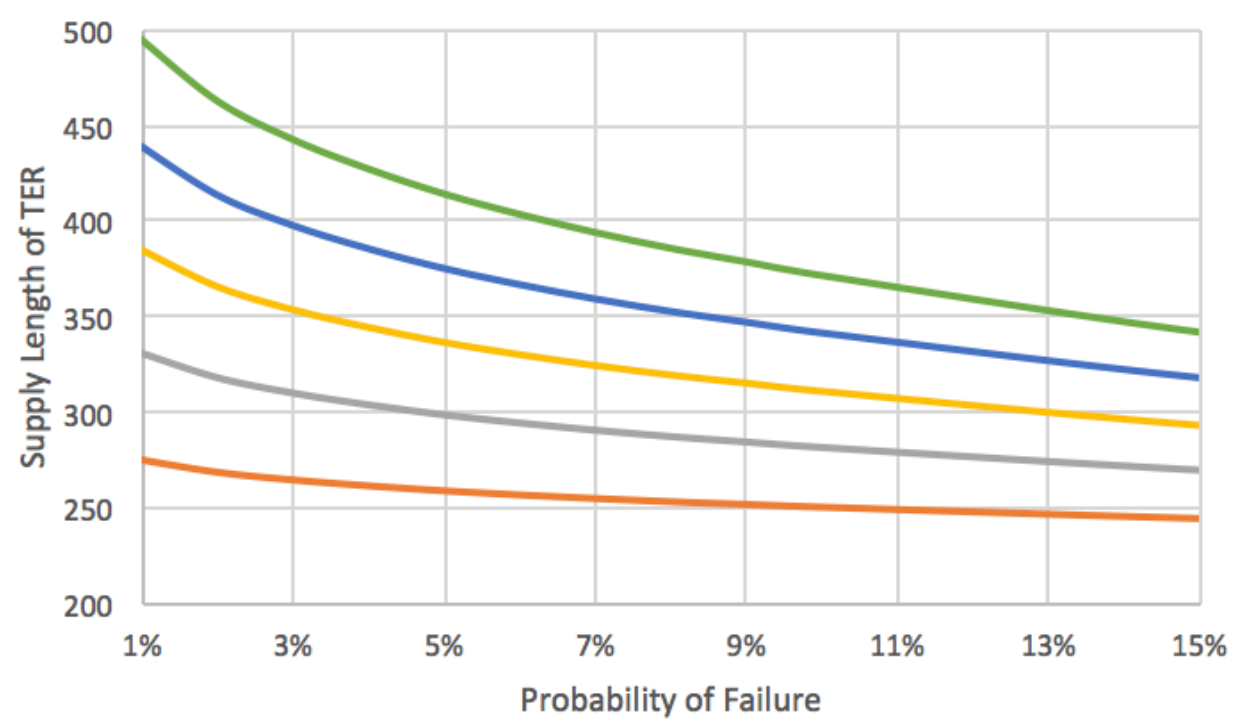

$\longrightarrow \mathrm{CV}=5 \%-\mathrm{CV}=10 \%-\mathrm{CV}=15 \%-\mathrm{CV}=20 \% \quad \mathrm{CV}=\mathbf{2 5} \%$ 
Scenario 9 - FOSM, G = -2\%, V = $140 \mathrm{~km} / \mathrm{hr}$

Table $41-L_{\text {supply }}$ Values at Corresponding $P_{f}$ and CV Values

\begin{tabular}{|c|c|c|c|c|c|}
\hline $\begin{array}{c}\text { Probability of } \\
\text { Failure, } P_{f}\end{array}$ & $\begin{array}{c}\mathrm{L}_{\text {supply }}(\mathrm{m}) \text {, } \\
\mathrm{CV}=5 \%\end{array}$ & $\begin{array}{c}L_{\text {supply }}(m), \\
C V=10 \%\end{array}$ & $\begin{array}{c}L_{\text {supply }}(m), \\
C V=15 \%\end{array}$ & $\begin{array}{l}L_{\text {supply }}(m), \\
C V=20 \%\end{array}$ & $\begin{array}{l}\mathrm{L}_{\text {supply }}(\mathrm{m}) \\
\mathrm{CV}=25 \%\end{array}$ \\
\hline $1 \%$ & 424.2 & 512.8 & 601.5 & 690.1 & 778.8 \\
\hline $2 \%$ & 413.8 & 492.2 & 570.5 & 648.8 & 727.2 \\
\hline $3 \%$ & 407.3 & 479.2 & 551.0 & 622.9 & 694.7 \\
\hline $4 \%$ & 402.4 & 469.2 & 536.1 & 603.0 & 669.9 \\
\hline $5 \%$ & 398.2 & 460.8 & 523.5 & 586.2 & 648.8 \\
\hline $6 \%$ & 394.7 & 454.0 & 513.2 & 572.4 & 631.7 \\
\hline $7 \%$ & 391.7 & 447.8 & 504.0 & 560.2 & 616.4 \\
\hline $8 \%$ & 389.0 & 442.5 & 496.0 & 549.5 & 603.0 \\
\hline $9 \%$ & 386.7 & 437.9 & 489.1 & 540.3 & 591.5 \\
\hline $10 \%$ & 384.4 & 433.3 & 482.2 & 531.2 & 580.1 \\
\hline $15 \%$ & 374.9 & 414.2 & 453.6 & 492.9 & 532.3 \\
\hline
\end{tabular}

Supply Length of TER vs Probability of Failure

( $\mathrm{G}=-2 \%, \mathrm{~V}=140 \mathrm{~km} / \mathrm{hr})$

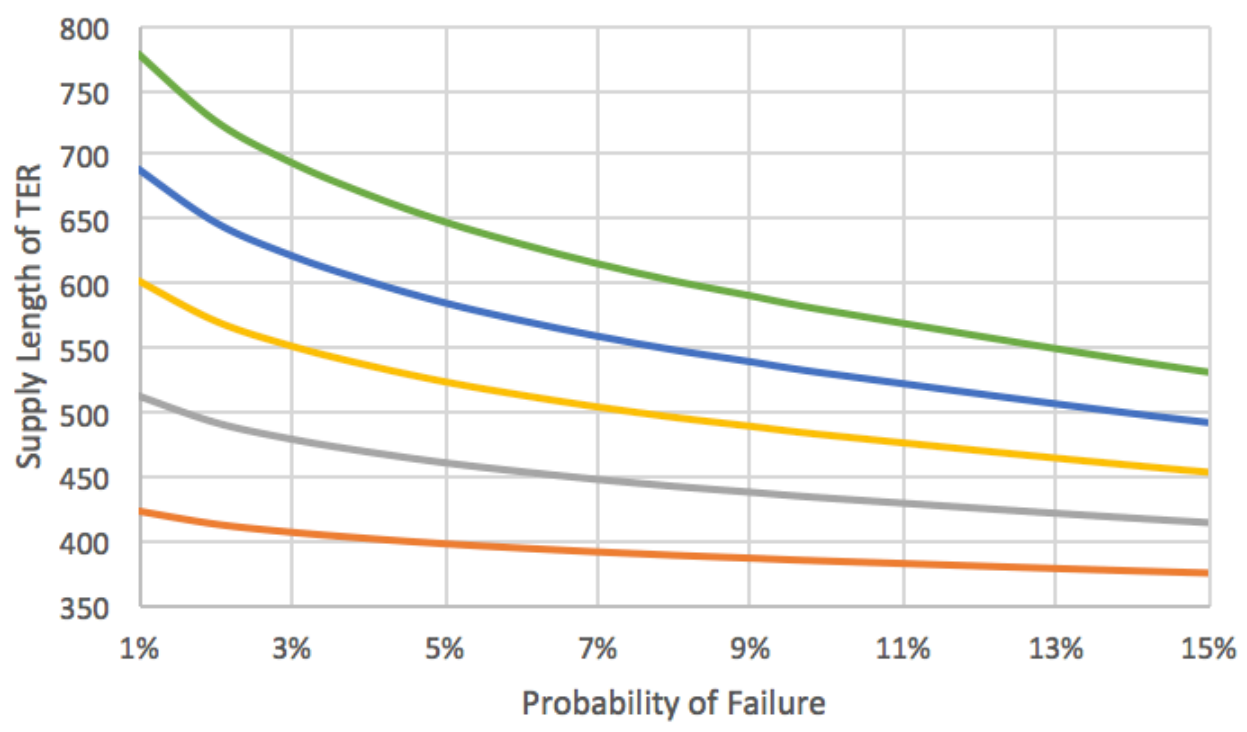

$\longrightarrow C V=5 \%-C V=10 \%-C V=15 \%-C V=20 \%-C V=25 \%$

Figure 37 - FOSM Visual Representation of $L_{\text {supply }}$ for a TER using G = -2\%, V = $140 \mathrm{~km} / \mathrm{hr}$, and $R=0.25 \mathrm{~kg} / \mathrm{kgGVM}$ 
Scenario $10-F O S M, G=-4 \%, V=140 \mathrm{~km} / \mathrm{hr}$

Table $42-L_{\text {supply }}$ Values at Corresponding $P_{f}$ and CV Values

\begin{tabular}{|c|c|c|c|c|c|}
\hline $\begin{array}{c}\text { Probability of } \\
\text { Failure, } P_{f}\end{array}$ & $\begin{array}{c}\mathrm{L}_{\text {supply }}(\mathrm{m}) \text {, } \\
\mathrm{CV}=5 \%\end{array}$ & $\begin{array}{c}L_{\text {supply }}(m), \\
C V=10 \%\end{array}$ & $\begin{array}{c}L_{\text {supply }}(m), \\
C V=15 \%\end{array}$ & $\begin{array}{l}L_{\text {supply }}(m), \\
C V=20 \%\end{array}$ & $\begin{array}{l}\mathrm{L}_{\text {supply }}(\mathrm{m}) \\
\mathrm{CV}=25 \%\end{array}$ \\
\hline $1 \%$ & 467.0 & 566.5 & 666.1 & 765.6 & 865.2 \\
\hline $2 \%$ & 455.4 & 543.4 & 631.3 & 719.3 & 807.2 \\
\hline $3 \%$ & 448.1 & 528.8 & 609.4 & 690.1 & 770.8 \\
\hline $4 \%$ & 442.5 & 517.6 & 592.7 & 667.8 & 742.9 \\
\hline $5 \%$ & 437.8 & 508.2 & 578.5 & 648.9 & 719.3 \\
\hline $6 \%$ & 434.0 & 500.5 & 567.0 & 633.5 & 700.0 \\
\hline $7 \%$ & 430.5 & 493.6 & 556.7 & 619.7 & 682.8 \\
\hline $8 \%$ & 427.5 & 487.6 & 547.7 & 607.7 & 667.8 \\
\hline $9 \%$ & 424.9 & 482.4 & 539.9 & 597.4 & 654.9 \\
\hline $10 \%$ & 422.4 & 477.3 & 532.2 & 587.1 & 642.0 \\
\hline $15 \%$ & 411.6 & 455.8 & 500.0 & 544.2 & 588.4 \\
\hline
\end{tabular}

Supply Length of TER vs Probability of Failure

( $G=-4 \%, V=140 \mathrm{~km} / \mathrm{hr}$ )

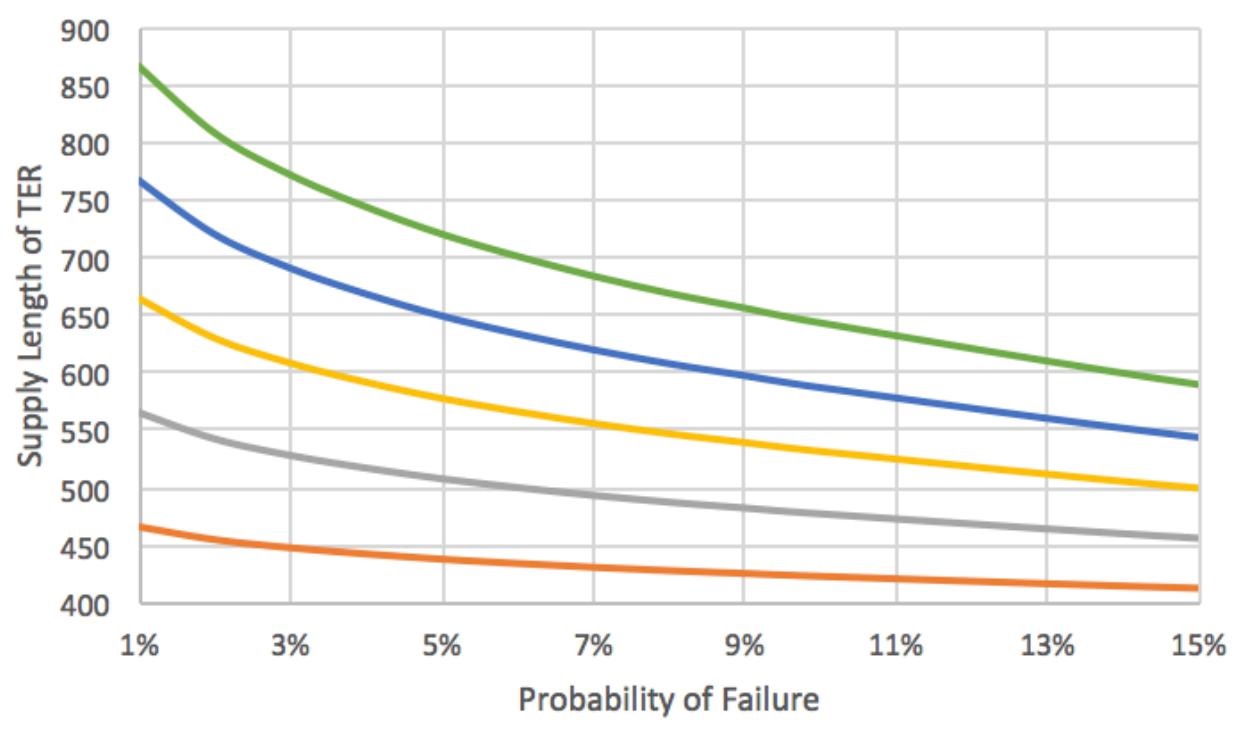

$\longrightarrow \mathrm{CV}=5 \%-\mathrm{CV}=10 \%-\mathrm{CV}=15 \%-\mathrm{CV}=20 \% \quad \mathrm{CV}=25 \%$ 
Scenario $11-F O S M, G=-6 \%, V=140 \mathrm{~km} / \mathrm{hr}$

Table $43-L_{\text {supply }}$ Values at Corresponding $P_{f}$ and CV Values

\begin{tabular}{|c|c|c|c|c|c|}
\hline $\begin{array}{c}\text { Probability of } \\
\text { Failure, } P_{f}\end{array}$ & $\begin{array}{c}\mathrm{L}_{\text {supply }}(\mathrm{m}) \\
\mathrm{CV}=5 \%\end{array}$ & $\begin{array}{l}L_{\text {supply }}(m), \\
C V=10 \%\end{array}$ & $\begin{array}{c}\mathrm{L}_{\text {supply }}(\mathrm{m}) \\
\mathrm{CV}=15 \%\end{array}$ & $\begin{array}{l}L_{\text {supply }}(m) \text {, } \\
C V=20 \%\end{array}$ & $\begin{array}{l}L_{\text {supply }}(\mathrm{m}) \\
\mathrm{CV}=25 \%\end{array}$ \\
\hline $1 \%$ & 519.9 & 633.7 & 747.4 & 861.2 & 974.9 \\
\hline $2 \%$ & 506.7 & 607.2 & 707.7 & 808.2 & 908.7 \\
\hline $3 \%$ & 498.3 & 590.5 & 682.7 & 774.9 & 867.1 \\
\hline $4 \%$ & 491.9 & 577.8 & 663.6 & 749.4 & 835.2 \\
\hline $5 \%$ & 486.6 & 567.0 & 647.4 & 727.8 & 808.2 \\
\hline $6 \%$ & 482.1 & 558.1 & 634.1 & 710.2 & 786.2 \\
\hline $7 \%$ & 478.2 & 550.3 & 622.4 & 694.5 & 766.5 \\
\hline $8 \%$ & 474.8 & 543.4 & 612.1 & 680.7 & 749.4 \\
\hline $9 \%$ & 471.8 & 537.5 & 603.3 & 669.0 & 734.7 \\
\hline $10 \%$ & 468.9 & 531.7 & 594.4 & 657.2 & 720.0 \\
\hline $15 \%$ & 456.6 & 507.1 & 557.7 & 608.2 & 658.7 \\
\hline
\end{tabular}

Supply Length of TER vs Probability of Failure ( $G=-6 \%, V=140 \mathrm{~km} / \mathrm{hr}$ )

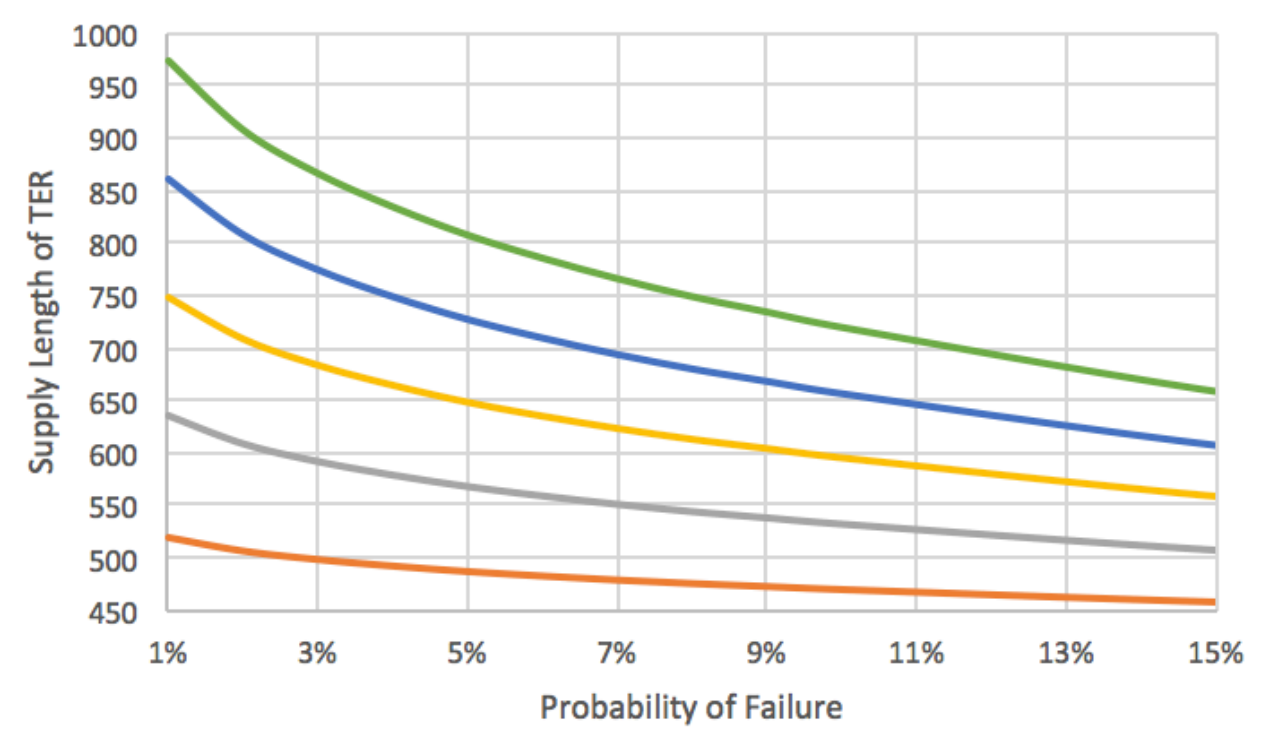

$\longrightarrow \mathrm{CV}=5 \%-\mathrm{CV}=10 \%-\mathrm{CV}=15 \%-\mathrm{CV}=20 \% \quad \mathrm{CV}=\mathbf{2 5} \%$ 
Scenario 12 - FOSM, G = -8\%, V = $140 \mathrm{~km} / \mathrm{hr}$

Table $44-L_{\text {supply }}$ Values at Corresponding $P_{f}$ and CV Values

\begin{tabular}{|c|c|c|c|c|c|}
\hline $\begin{array}{c}\text { Probability of } \\
\text { Failure, } P_{f}\end{array}$ & $\begin{array}{c}\mathrm{L}_{\text {supply }}(\mathrm{m}) \text {, } \\
\mathrm{CV}=5 \%\end{array}$ & $\begin{array}{c}L_{\text {supply }}(m), \\
C V=10 \%\end{array}$ & $\begin{array}{c}L_{\text {supply }}(m), \\
C V=15 \%\end{array}$ & $\begin{array}{l}L_{\text {supply }}(m), \\
C V=20 \%\end{array}$ & $\begin{array}{l}\mathrm{L}_{\text {supply }}(\mathrm{m}) \\
\mathrm{CV}=25 \%\end{array}$ \\
\hline $1 \%$ & 587.0 & 720.0 & 853.0 & 986.1 & 1119.1 \\
\hline $2 \%$ & 571.5 & 689.0 & 806.6 & 924.1 & 1041.7 \\
\hline $3 \%$ & 561.7 & 669.5 & 777.3 & 885.1 & 993.0 \\
\hline $4 \%$ & 554.3 & 654.6 & 755.0 & 855.3 & 955.7 \\
\hline $5 \%$ & 548.0 & 642.0 & 736.0 & 830.1 & 924.1 \\
\hline $6 \%$ & 542.8 & 631.7 & 720.6 & 809.5 & 898.3 \\
\hline $7 \%$ & 538.2 & 622.5 & 706.8 & 791.1 & 875.4 \\
\hline $8 \%$ & 534.2 & 614.5 & 694.8 & 775.0 & 855.3 \\
\hline $9 \%$ & 530.8 & 607.6 & 684.4 & 761.3 & 838.1 \\
\hline $10 \%$ & 527.3 & 600.7 & 674.1 & 747.5 & 820.9 \\
\hline $15 \%$ & 513.0 & 572.0 & 631.1 & 690.2 & 749.2 \\
\hline
\end{tabular}

Supply Length of TER vs Probability of Failure

( $G=-8 \%, V=140 \mathrm{~km} / \mathrm{hr}$ )

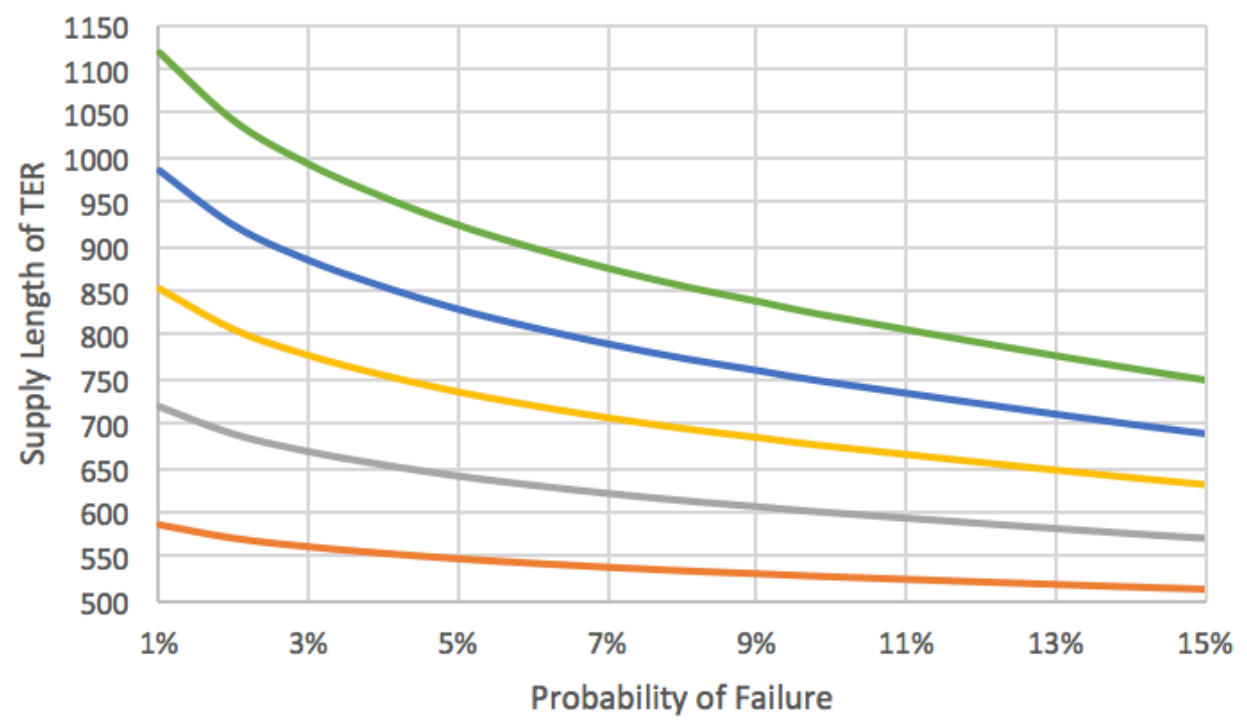

$\longrightarrow \mathrm{CV}=5 \%-\mathrm{CV}=10 \%-\mathrm{CV}=15 \%-\mathrm{CV}=20 \% \quad-\mathrm{CV}=25 \%$

Figure 40 - FOSM Visual Representation of $L_{\text {supply }}$ for a TER using $G=-8 \%, V=140 \mathrm{~km} / \mathrm{hr}$, and $R=0.25 \mathrm{~kg} / \mathrm{kgGVM}$ 
Scenario 13 - FOSM, G = -10\%, V = $140 \mathrm{~km} / \mathrm{hr}$

Table $45-L_{\text {supply }}$ Values at Corresponding $P_{f}$ and CV Values

\begin{tabular}{|c|c|c|c|c|c|}
\hline $\begin{array}{c}\text { Probability of } \\
\text { Failure, } P_{f}\end{array}$ & $\begin{array}{c}\mathrm{L}_{\text {supply }}(\mathrm{m}) \text {, } \\
\mathrm{CV}=5 \%\end{array}$ & $\begin{array}{c}L_{\text {supply }}(m), \\
C V=10 \%\end{array}$ & $\begin{array}{c}L_{\text {supply }}(m), \\
C V=15 \%\end{array}$ & $\begin{array}{l}L_{\text {supply }}(m), \\
C V=20 \%\end{array}$ & $\begin{array}{l}\mathrm{L}_{\text {supply }}(\mathrm{m}) \\
\mathrm{CV}=25 \%\end{array}$ \\
\hline $1 \%$ & 674.8 & 835.2 & 995.5 & 1155.9 & 1316.3 \\
\hline $2 \%$ & 656.1 & 797.8 & 939.6 & 1081.3 & 1223.0 \\
\hline $3 \%$ & 644.4 & 774.3 & 904.3 & 1034.3 & 1164.2 \\
\hline $4 \%$ & 635.4 & 756.4 & 877.3 & 998.3 & 1119.3 \\
\hline $5 \%$ & 627.8 & 741.2 & 854.5 & 967.9 & 1081.3 \\
\hline $6 \%$ & 621.6 & 728.7 & 835.9 & 943.0 & 1050.2 \\
\hline $7 \%$ & 616.0 & 717.7 & 819.3 & 920.9 & 1022.5 \\
\hline $8 \%$ & 611.2 & 708.0 & 804.8 & 901.5 & 998.3 \\
\hline $9 \%$ & 607.1 & 699.7 & 792.3 & 884.9 & 977.6 \\
\hline $10 \%$ & 602.9 & 691.4 & 779.9 & 868.4 & 956.8 \\
\hline $15 \%$ & 585.6 & 656.8 & 728.0 & 799.2 & 870.4 \\
\hline
\end{tabular}

Supply Length of TER vs Probability of Failure

$$
\text { ( } G=-10 \%, V=140 \mathrm{~km} / \mathrm{hr} \text { ) }
$$

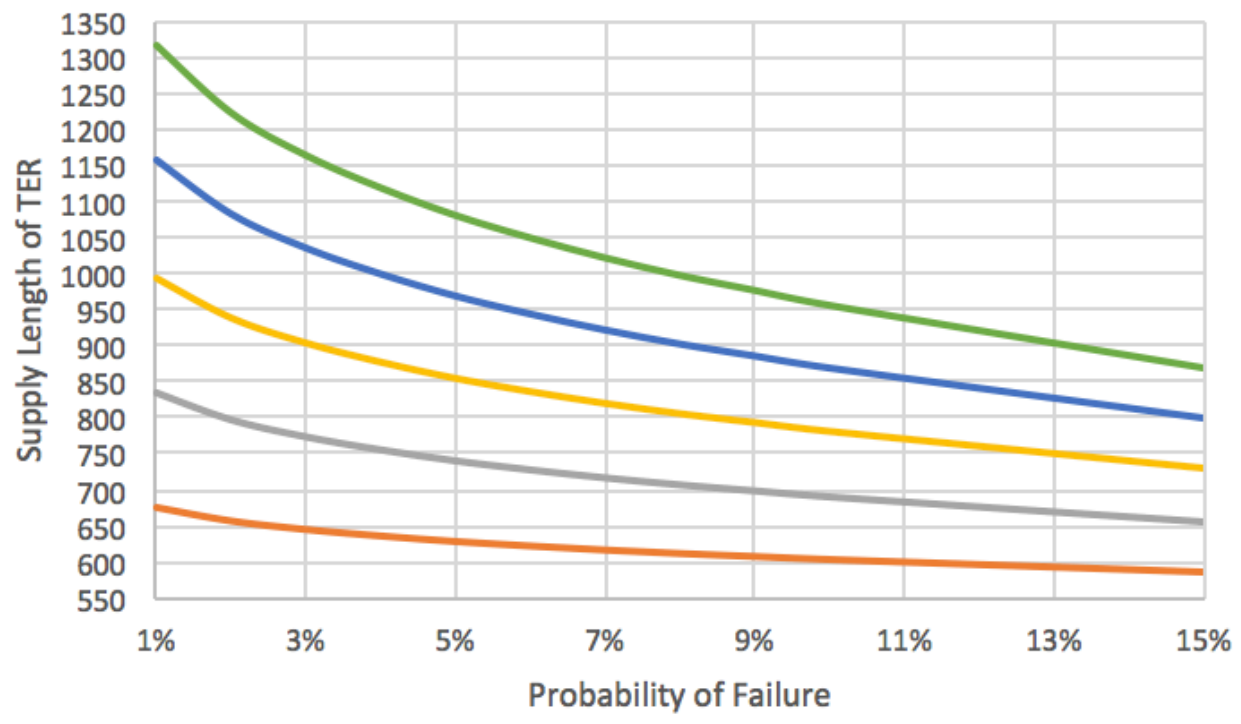

$\longrightarrow C V=5 \%-C V=10 \%-C V=15 \%-C V=20 \%-C V=25 \%$ 


\section{Appendix B - Case 2 Analysis Results}

Scenario 2 - FOSM, $\mathrm{G}_{1}=0 \%, \mathrm{G}_{2}=+4 \%, \mathrm{~V}=120 \mathrm{~km} / \mathrm{hr}$

Table $46-L_{\text {supply }}$ Values at Corresponding $P_{f}$ and $C V$ Values

\begin{tabular}{|c|c|c|c|c|c|}
\hline $\begin{array}{c}\text { Probability of } \\
\text { Failure, } P_{f}\end{array}$ & $\begin{array}{c}L_{\text {supply }}(m) \\
\text { CV }=5 \%\end{array}$ & $\begin{array}{l}L_{\text {supply }}(m), \\
C V=10 \%\end{array}$ & $\begin{array}{l}L_{\text {supply }}(m) \\
C V=15 \%\end{array}$ & $\begin{array}{l}L_{\text {supply }}(m), \\
C V=20 \%\end{array}$ & $\begin{array}{c}L_{\text {supply }}(m), \\
C V=25 \%\end{array}$ \\
\hline $1 \%$ & 245.1 & 294.5 & 344.0 & 393.4 & 442.9 \\
\hline $2 \%$ & 239.3 & 283.0 & 326.7 & 370.4 & 414.1 \\
\hline $3 \%$ & 235.7 & 275.8 & 315.9 & 355.9 & 396.0 \\
\hline $4 \%$ & 232.9 & 270.2 & 307.5 & 344.8 & 382.1 \\
\hline $5 \%$ & 230.6 & 265.5 & 300.5 & 335.5 & 370.4 \\
\hline $6 \%$ & 228.7 & 261.7 & 294.7 & 327.8 & 360.8 \\
\hline $7 \%$ & 227.0 & 258.3 & 289.6 & 321.0 & 352.3 \\
\hline $8 \%$ & 225.5 & 255.3 & 285.2 & 315.0 & 344.8 \\
\hline $9 \%$ & 224.2 & 252.8 & 281.3 & 309.9 & 338.4 \\
\hline $10 \%$ & 222.9 & 250.2 & 277.5 & 304.8 & 332.1 \\
\hline $15 \%$ & 217.6 & 239.5 & 261.5 & 283.5 & 305.4 \\
\hline
\end{tabular}

Supply Length of TER vs Probability of Failure $\left(G_{1}=0 \%, G_{2}=+4 \%, V=120 \mathrm{~km} / \mathrm{hr}\right)$

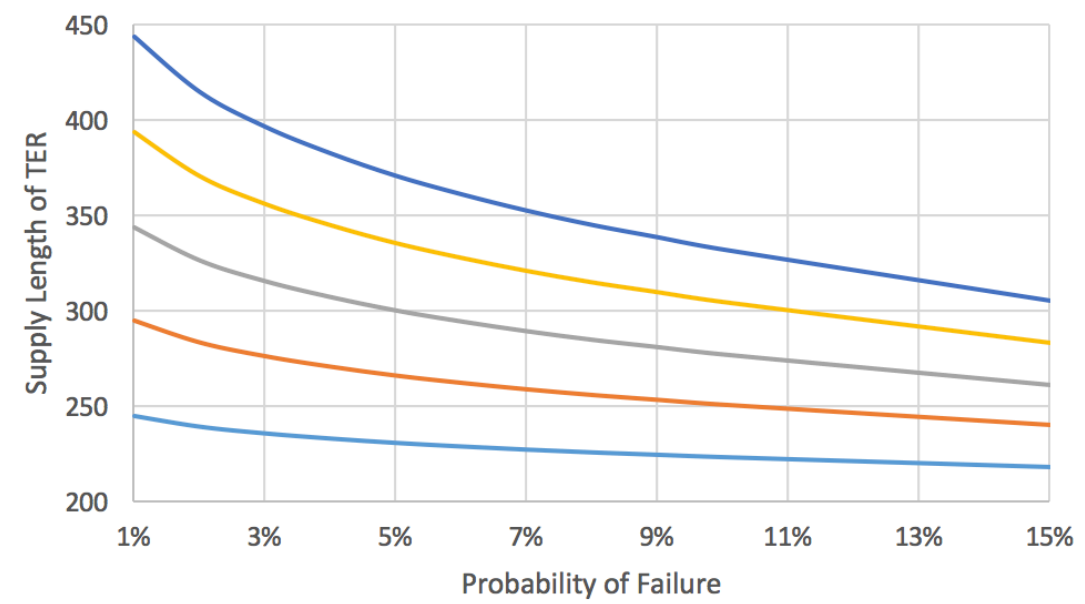

$-\mathrm{CV}=5 \%-\mathrm{CV}=10 \% \quad \mathrm{CV}=15 \% \quad \mathrm{CV}=20 \% \quad-\mathrm{CV}=25 \%$ 
Scenario 3 - FOSM, $\mathrm{G}_{1}=0 \%, \mathrm{G}_{2}=+3 \%, \mathrm{~V}=140 \mathrm{~km} / \mathrm{hr}$

Table $47-L_{\text {supply }}$ Values at Corresponding $P_{f}$ and CV Values

\begin{tabular}{|c|c|c|c|c|c|}
\hline $\begin{array}{l}\text { Probability of } \\
\text { Failure, } P_{f}\end{array}$ & $\begin{array}{l}\mathrm{L}_{\text {supply }}(\mathrm{m}) \\
\mathrm{CV}=5 \%\end{array}$ & $\begin{array}{l}L_{\text {supply }}(m) \\
\text { CV }=10 \%\end{array}$ & $\begin{array}{l}L_{\text {supply }}(m) \\
C V=15 \%\end{array}$ & $\begin{array}{l}L_{\text {supply }}(m) \\
C V=20 \%\end{array}$ & $\begin{array}{l}L_{\text {supply }}(m) \text {, } \\
C V=25 \%\end{array}$ \\
\hline $1 \%$ & 345.8 & 415.8 & 485.9 & 556.0 & 626.0 \\
\hline $2 \%$ & 337.6 & 399.5 & 461.4 & 523.3 & 585.3 \\
\hline $3 \%$ & 332.5 & 389.3 & 446.0 & 502.8 & 559.6 \\
\hline $4 \%$ & 328.5 & 381.4 & 434.2 & 487.1 & 540.0 \\
\hline $5 \%$ & 325.2 & 374.8 & 424.3 & 473.8 & 523.3 \\
\hline $6 \%$ & 322.5 & 369.3 & 416.1 & 462.9 & 509.7 \\
\hline $7 \%$ & 320.1 & 364.5 & 408.9 & 453.3 & 497.7 \\
\hline $8 \%$ & 318.0 & 360.3 & 402.5 & 444.8 & 487.1 \\
\hline $9 \%$ & 316.2 & 356.6 & 397.1 & 437.6 & 478.0 \\
\hline $10 \%$ & 314.4 & 353.0 & 391.7 & 430.3 & 469.0 \\
\hline $15 \%$ & 306.8 & 337.9 & 369.0 & 400.1 & 431.2 \\
\hline
\end{tabular}

Supply Length of TER vs Probability of Failure

$\left(G_{1}=0 \%, G_{2}=+3 \%, V=140 \mathrm{~km} / \mathrm{hr}\right)$

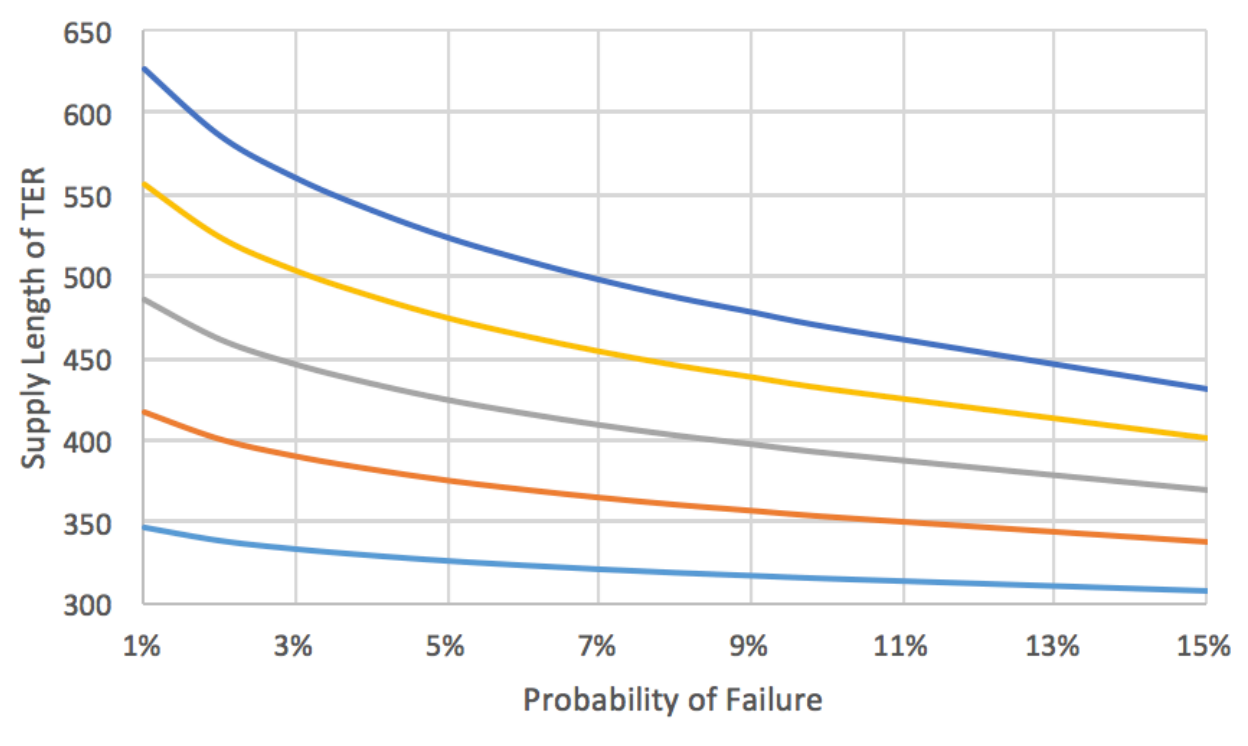

$\longrightarrow \mathrm{CV}=5 \%-\mathrm{CV}=10 \% \quad \mathrm{CV}=15 \% \quad \mathrm{CV}=20 \% \quad-\mathrm{CV}=25 \%$ 
Scenario 4 - FOSM, $\mathrm{G}_{1}=0 \%, \mathrm{G}_{2}=+2 \%, \mathrm{~V}=140 \mathrm{~km} / \mathrm{hr}$

Table $48-L_{\text {supply }}$ Values at Corresponding $P_{f}$ and CV Values

\begin{tabular}{|c|c|c|c|c|c|}
\hline $\begin{array}{c}\text { Probability of } \\
\text { Failure, } P_{f}\end{array}$ & $\begin{array}{c}\mathrm{L}_{\text {supply }}(\mathrm{m}) \text {, } \\
\mathrm{CV}=5 \%\end{array}$ & $\begin{array}{c}L_{\text {supply }}(m), \\
C V=10 \%\end{array}$ & $\begin{array}{c}L_{\text {supply }}(m), \\
C V=15 \%\end{array}$ & $\begin{array}{l}L_{\text {supply }}(m), \\
C V=20 \%\end{array}$ & $\begin{array}{l}\mathrm{L}_{\text {supply }}(\mathrm{m}) \\
\mathrm{CV}=25 \%\end{array}$ \\
\hline $1 \%$ & 358.9 & 432.0 & 505.1 & 578.1 & 651.2 \\
\hline $2 \%$ & 350.4 & 415.0 & 479.6 & 544.1 & 608.7 \\
\hline $3 \%$ & 345.1 & 404.3 & 463.5 & 522.7 & 581.9 \\
\hline $4 \%$ & 341.0 & 396.1 & 451.2 & 506.3 & 561.4 \\
\hline $5 \%$ & 337.5 & 389.2 & 440.8 & 492.5 & 544.1 \\
\hline $6 \%$ & 334.7 & 383.5 & 432.3 & 481.1 & 529.9 \\
\hline $7 \%$ & 332.2 & 378.5 & 424.8 & 471.1 & 517.4 \\
\hline $8 \%$ & 330.0 & 374.1 & 418.1 & 462.2 & 506.3 \\
\hline $9 \%$ & 328.1 & 370.3 & 412.5 & 454.7 & 496.9 \\
\hline $10 \%$ & 326.2 & 366.5 & 406.8 & 447.1 & 487.4 \\
\hline $15 \%$ & 318.3 & 350.7 & 383.2 & 415.6 & 448.1 \\
\hline
\end{tabular}

Supply Length of TER vs Probability of Failure

$\left(G_{1}=0 \%, G_{2}=+2 \%, V=140 \mathrm{~km} / \mathrm{hr}\right.$ )

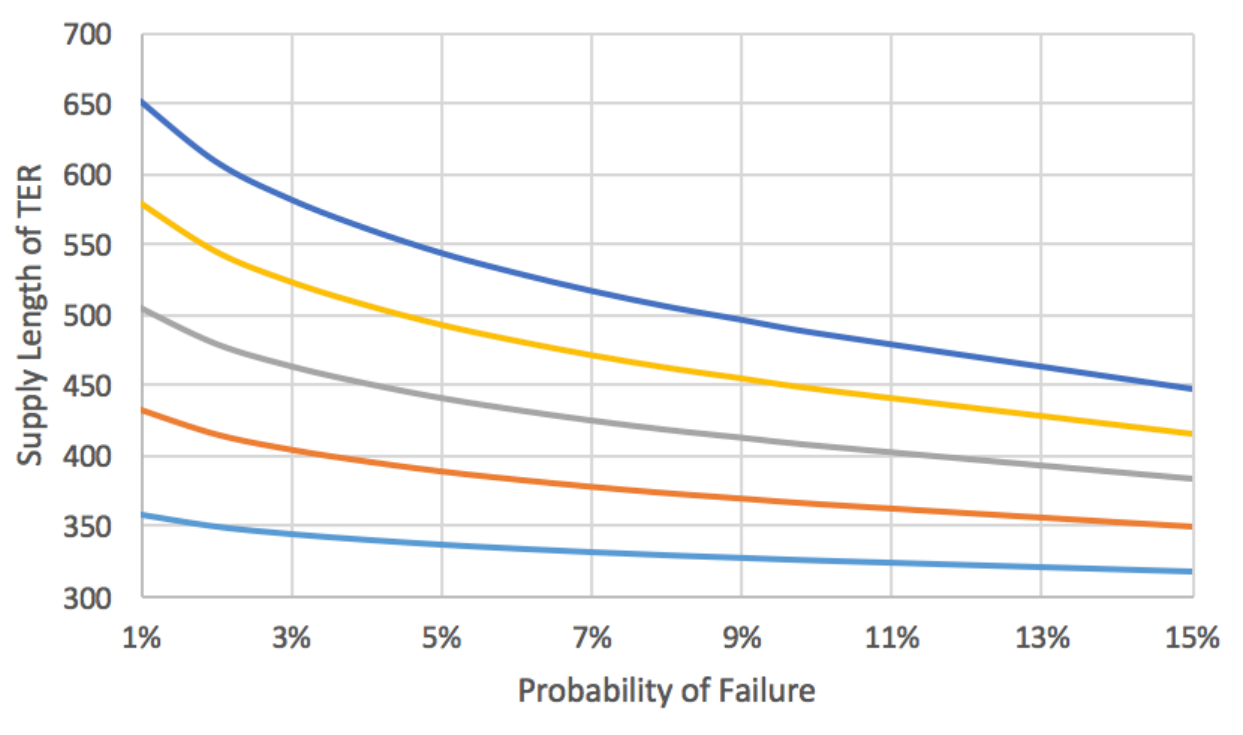

$-\mathrm{CV}=5 \%-\mathrm{CV}=10 \% \quad \mathrm{CV}=15 \% \quad \mathrm{CV}=20 \% \quad-\mathrm{CV}=25 \%$ 
Scenario 5 - FOSM, $\mathrm{G}_{1}=0 \%, \mathrm{G}_{2}=+1 \%, \mathrm{~V}=140 \mathrm{~km} / \mathrm{hr}$

Table $49-L_{\text {supply }}$ Values at Corresponding $P_{f}$ and CV Values

\begin{tabular}{|c|c|c|c|c|c|}
\hline $\begin{array}{c}\text { Probability of } \\
\text { Failure, } P_{f}\end{array}$ & $\begin{array}{c}\mathrm{L}_{\text {supply }}(\mathrm{m}) \text {, } \\
\mathrm{CV}=5 \%\end{array}$ & $\begin{array}{c}L_{\text {supply }}(m), \\
C V=10 \%\end{array}$ & $\begin{array}{c}L_{\text {supply }}(m), \\
C V=15 \%\end{array}$ & $\begin{array}{l}L_{\text {supply }}(m), \\
C V=20 \%\end{array}$ & $\begin{array}{l}\mathrm{L}_{\text {supply }}(\mathrm{m}) \\
\mathrm{CV}=25 \%\end{array}$ \\
\hline $1 \%$ & 373.2 & 449.6 & 525.9 & 602.3 & 678.7 \\
\hline $2 \%$ & 364.3 & 431.8 & 499.3 & 566.7 & 634.2 \\
\hline $3 \%$ & 358.7 & 420.6 & 482.5 & 544.4 & 606.2 \\
\hline $4 \%$ & 354.4 & 412.0 & 469.6 & 527.2 & 584.8 \\
\hline $5 \%$ & 350.8 & 404.8 & 458.8 & 512.8 & 566.7 \\
\hline $6 \%$ & 347.8 & 398.9 & 449.9 & 500.9 & 551.9 \\
\hline $7 \%$ & 345.2 & 393.6 & 442.0 & 490.4 & 538.8 \\
\hline $8 \%$ & 342.9 & 389.0 & 435.1 & 481.2 & 527.2 \\
\hline $9 \%$ & 340.9 & 385.0 & 429.1 & 473.3 & 517.4 \\
\hline $10 \%$ & 339.0 & 381.1 & 423.2 & 465.4 & 507.5 \\
\hline $15 \%$ & 330.7 & 364.6 & 398.5 & 432.4 & 466.3 \\
\hline
\end{tabular}

Supply Length of TER vs Probability of Failure

$\left(G_{1}=0 \%, G_{2}=+1 \%, V=140 \mathrm{~km} / \mathrm{hr}\right.$ )

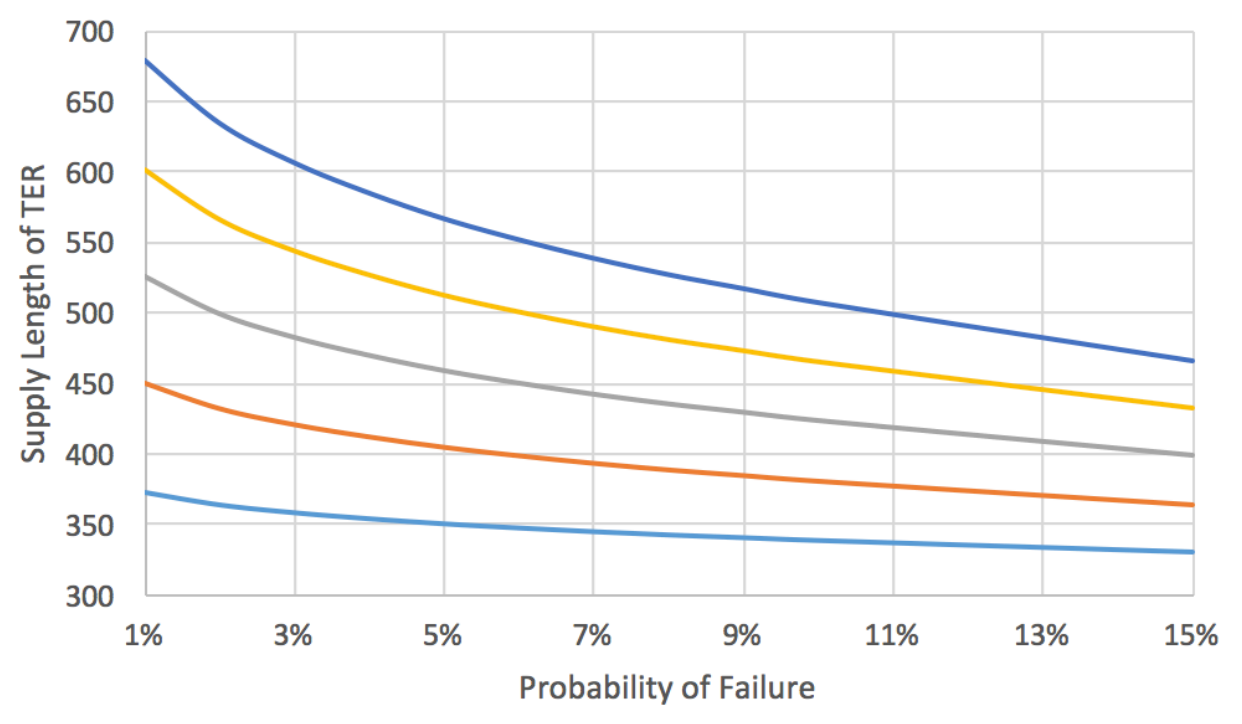

$\longrightarrow \mathrm{CV}=5 \%-\mathrm{CV}=10 \% \quad \mathrm{CV}=15 \% \quad \mathrm{CV}=\mathbf{2 0} \quad-\mathrm{CV}=\mathbf{2 5 \%}$

Figure 45 - FOSM Visual Representation of $L_{\text {supply }}$ for a TER using $G_{1}=0 \%, G_{2}=+1 \%, V=140 \mathrm{~km} / \mathrm{hr}$, and $R=0.25 \mathrm{~kg} / \mathrm{kgGVM}$ 


\section{Appendix C-Case 3 Analysis Results}

Scenario 2 - AFOSM, G = +2\%, V= $120 \mathrm{~km} / \mathrm{hr}$

Table $50-L_{\text {supply }}$ Values at Corresponding $P_{f}$ and CV Values

\begin{tabular}{|c|c|c|c|c|c|}
\hline $\begin{array}{l}\text { Probability of } \\
\text { Failure, } P_{f}\end{array}$ & $\begin{array}{c}L_{\text {supply }}(m) \\
\text { CV }=5 \%\end{array}$ & $\begin{array}{l}L_{\text {supply }}(\mathrm{m}) \\
\mathrm{CV}=10 \%\end{array}$ & $\begin{array}{l}L_{\text {supply }}(\mathrm{m}) \\
\text { CV }=15 \%\end{array}$ & $\begin{array}{l}L_{\text {supply }}(\mathrm{m}) \\
C V=20 \%\end{array}$ & $\begin{array}{l}L_{\text {supply }}(m), \\
C V=25 \%\end{array}$ \\
\hline $1 \%$ & 268.8 & 339.5 & 425.7 & 533.7 & 674.8 \\
\hline $5 \%$ & 250.4 & 296.4 & 349.0 & 409.5 & 480.2 \\
\hline $10 \%$ & 241.1 & 275.5 & 313.6 & 355.9 & 403.2 \\
\hline $15 \%$ & 234.8 & 261.7 & 290.8 & 322.5 & 357.0 \\
\hline
\end{tabular}

Supply Length of TER vs Probability of Failure

$$
\text { ( } G=+2 \%, V=120 \mathrm{~km} / \mathrm{hr} \text { ) }
$$

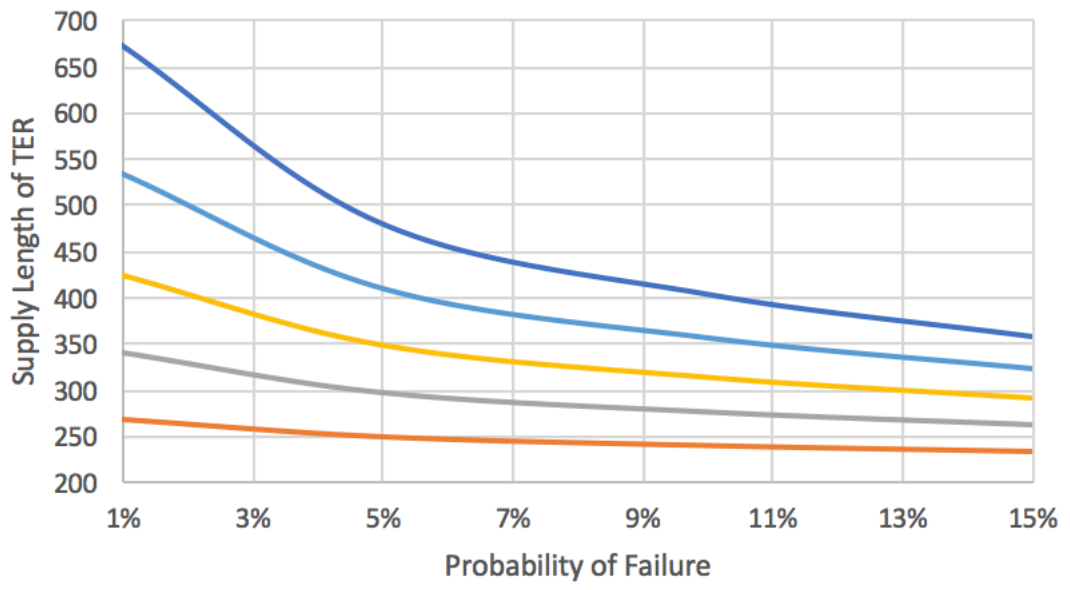

$-\mathrm{CV}=5 \%-\mathrm{CV}=10 \%-\mathrm{CV}=15 \%-\mathrm{CV}=20 \%-\mathrm{CV}=25 \%$

Figure 46 - AFOSM Visual Representation of $L_{\text {supply }}$ for a TER using G $=+2 \%, V=120 \mathrm{~km} / \mathrm{hr}$, and $R=0.25 \mathrm{~kg} / \mathrm{kgGVM}$ 
Scenario 3 - AFOSM, G = +2\%, V = $100 \mathrm{~km} / \mathrm{hr}$

Table $51-L_{\text {supply }}$ Values at Corresponding $P_{f}$ and CV Values

\begin{tabular}{|c|c|c|c|c|c|}
\hline $\begin{array}{c}\text { Probability of } \\
\text { Failure, } P_{f}\end{array}$ & $\begin{array}{l}\mathrm{L}_{\text {supply }}(\mathrm{m}) \\
\mathrm{CV}=5 \%\end{array}$ & $\begin{array}{l}L_{\text {supply }}(m), \\
C V=10 \%\end{array}$ & $\begin{array}{l}L_{\text {supply }}(m), \\
C V=15 \%\end{array}$ & $\begin{array}{l}L_{\text {supply }}(m) \\
C V=20 \%\end{array}$ & $\begin{array}{l}L_{\text {supply }}(\mathrm{m}) \\
\mathrm{CV}=25 \%\end{array}$ \\
\hline $1 \%$ & 186.7 & 235.8 & 295.7 & 370.6 & 468.6 \\
\hline $5 \%$ & 173.9 & 205.9 & 242.4 & 284.4 & 333.5 \\
\hline $10 \%$ & 167.4 & 191.3 & 217.8 & 247.2 & 280.0 \\
\hline $15 \%$ & 163.0 & 181.7 & 201.9 & 223.9 & 247.9 \\
\hline
\end{tabular}

Supply Length of TER vs Probability of Failure ( $\mathrm{G}=+2 \%, \mathrm{~V}=100 \mathrm{~km} / \mathrm{hr}$ )

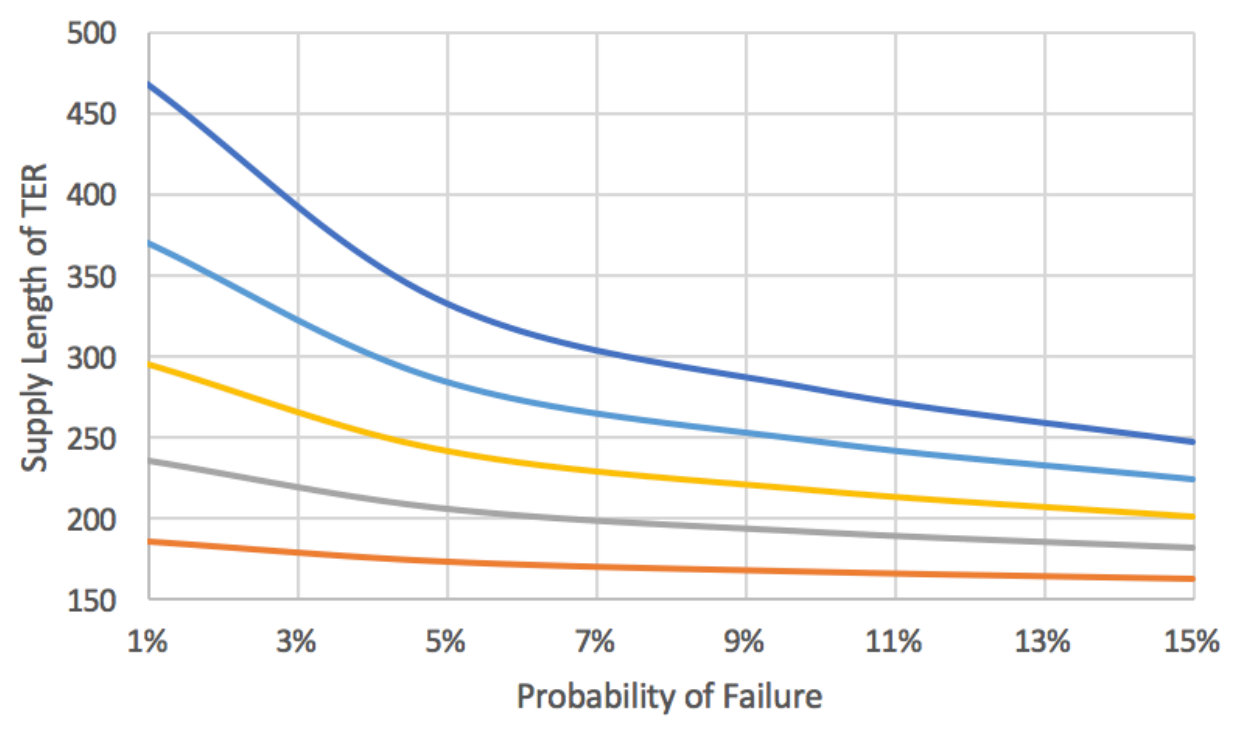

$\longrightarrow \mathrm{CV}=5 \%-\mathrm{CV}=10 \%-\mathrm{CV}=15 \%-\mathrm{CV}=20 \% \quad-\mathrm{CV}=25 \%$

Figure 47 - AFOSM Visual Representation of $L_{\text {supply }}$ for a TER using G $=+2 \%, V=100 \mathrm{~km} / \mathrm{hr}$, and $R=0.25 \mathrm{~kg} / \mathrm{kgGVM}$ 
Scenario 4 - AFOSM, G = 0\%, V = $140 \mathrm{~km} / \mathrm{hr}$

Table $52-L_{\text {supply }}$ Values at Corresponding $P_{f}$ and CV Values

\begin{tabular}{|c|c|c|c|c|c|}
\hline $\begin{array}{c}\text { Probability of } \\
\text { Failure, } P_{f}\end{array}$ & $\begin{array}{c}L_{\text {supply }}(\mathrm{m}), \\
\mathrm{CV}=5 \%\end{array}$ & $\begin{array}{c}\mathrm{L}_{\text {supply }}(\mathrm{m}), \\
\mathrm{CV}=10 \%\end{array}$ & $\begin{array}{c}\mathrm{L}_{\text {supply }}(\mathrm{m}), \\
\mathrm{CV}=15 \%\end{array}$ & $\begin{array}{c}\mathrm{L}_{\text {supply }}(\mathrm{m}), \\
\mathrm{CV}=\mathbf{2 0 \%}\end{array}$ & $\begin{array}{c}\mathrm{L}_{\text {supply }}(\mathrm{m}), \\
\mathrm{CV}=\mathbf{2 5 \%}\end{array}$ \\
\hline $1 \%$ & 396.8 & 504.2 & 637.9 & 810.3 & 1044.7 \\
\hline $5 \%$ & 369.2 & 438.6 & 518.8 & 612.5 & 724.0 \\
\hline $10 \%$ & 355.2 & 406.9 & 464.7 & 529.4 & 602.7 \\
\hline $15 \%$ & 345.7 & 386.1 & 430.1 & 478.2 & 531.0 \\
\hline
\end{tabular}

Supply Length of TER vs Probability of Failure

( $\mathrm{G}=0 \%, \mathrm{~V}=140 \mathrm{~km} / \mathrm{hr}$ )

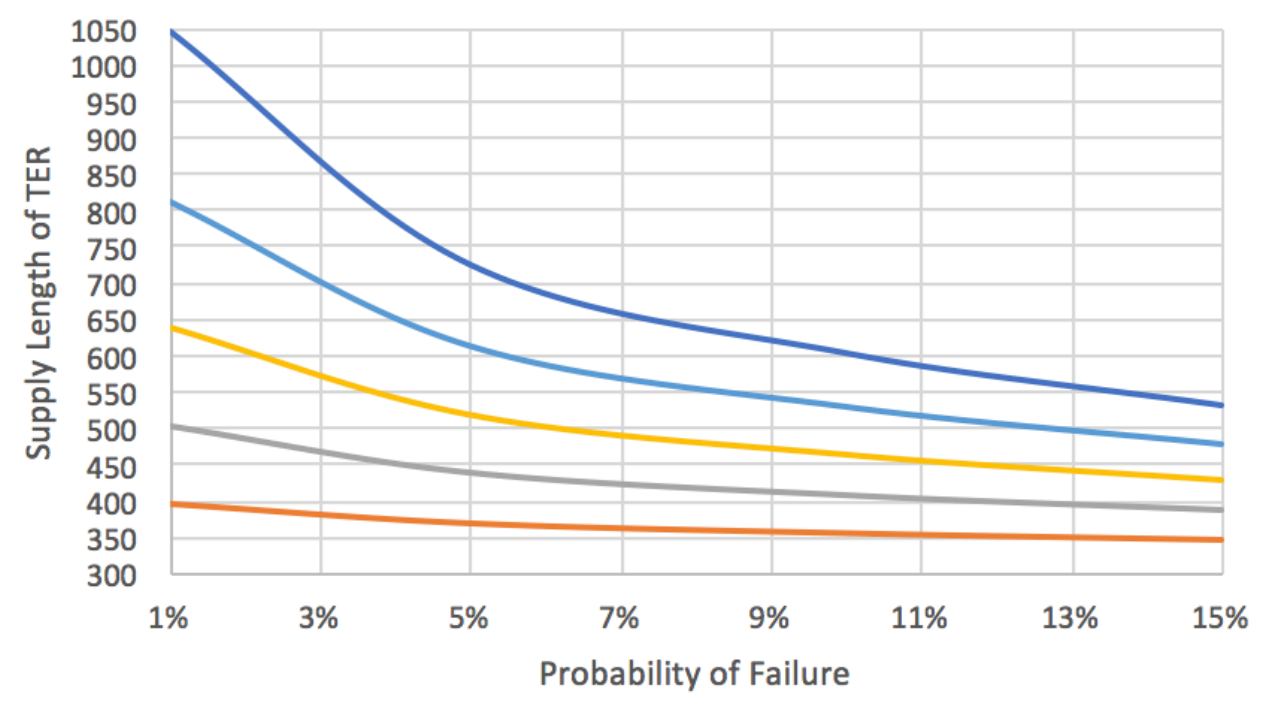

$-C V=5 \%-C V=10 \%-C V=15 \%-C V=20 \% \quad-C V=25 \%$

Figure 48 - AFOSM Visual Representation of $L_{\text {supply }}$ for a TER using $G=0 \%, V=140 \mathrm{~km} / \mathrm{hr}$, and $R=0.25 \mathrm{~kg} / \mathrm{kgGVM}$ 
Scenario 5 - AFOSM, G = +4\%, V= $140 \mathrm{~km} / \mathrm{hr}$

Table $53-L_{\text {supply }}$ Values at Corresponding $P_{f}$ and CV Values

\begin{tabular}{|c|c|c|c|c|c|}
\hline $\begin{array}{c}\text { Probability of } \\
\text { Failure, } P_{f}\end{array}$ & $\begin{array}{c}L_{\text {supply }}(m) \\
\text { CV }=5 \%\end{array}$ & $\begin{array}{l}L_{\text {supply }}(m) \\
C V=10 \%\end{array}$ & $\begin{array}{l}L_{\text {supply }}(m), \\
C V=15 \%\end{array}$ & $\begin{array}{l}L_{\text {supply }}(m), \\
\text { CV }=20 \%\end{array}$ & $\begin{array}{c}L_{\text {supply }}(m) \text {, } \\
C V=25 \%\end{array}$ \\
\hline $1 \%$ & 339.5 & 427.0 & 532.2 & 661.1 & 824.4 \\
\hline $5 \%$ & 316.7 & 373.9 & 438.7 & 512.6 & 597.6 \\
\hline $10 \%$ & 305.1 & 347.9 & 395.1 & 447.1 & 504.9 \\
\hline $15 \%$ & 297.2 & 330.7 & 366.9 & 406.0 & 448.4 \\
\hline
\end{tabular}

Supply Length of TER vs Probability of Failure ( $\mathrm{G}=+4 \%, V=140 \mathrm{~km} / \mathrm{hr}$ )

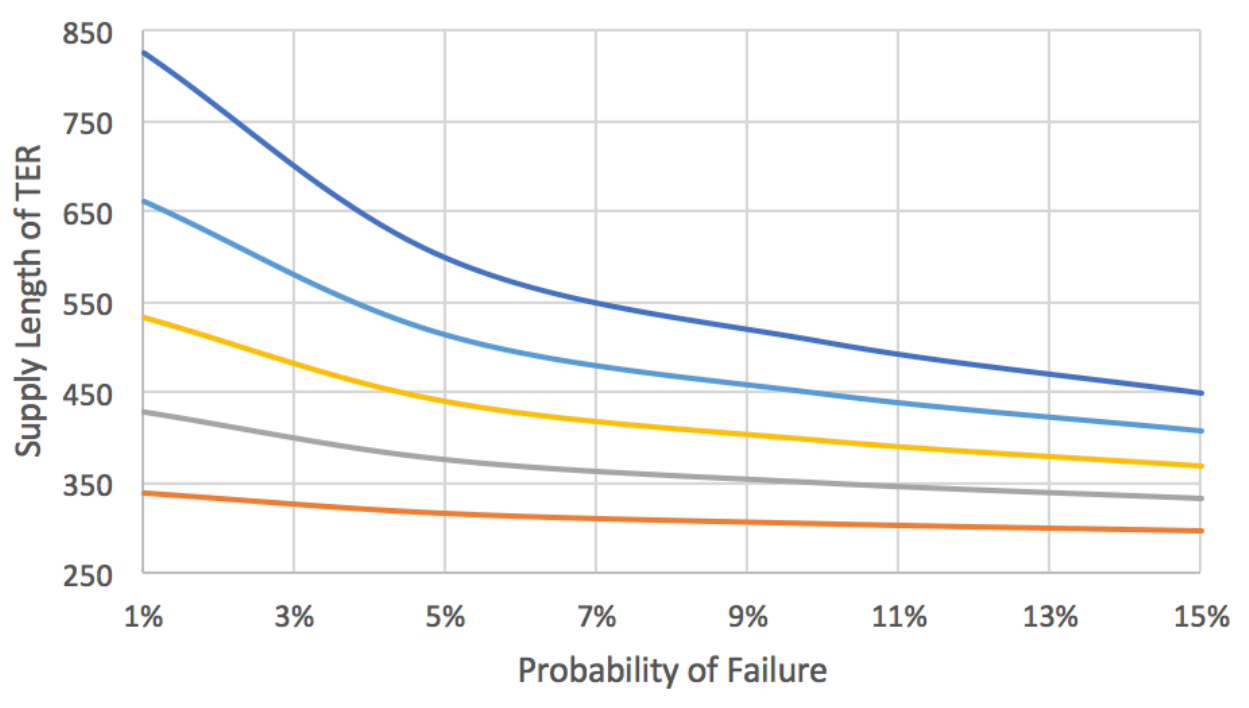

$\longrightarrow \mathrm{CV}=5 \%-\mathrm{CV}=10 \% \quad \mathrm{CV}=15 \% \quad-\mathrm{CV}=20 \% \quad-\mathrm{CV}=25 \%$ 
Scenario 6 - AFOSM, G = +6\%, V = $140 \mathrm{~km} / \mathrm{hr}$

Table $54-L_{\text {supply }}$ Values at Corresponding $P_{f}$ and CV Values

\begin{tabular}{|c|c|c|c|c|c|}
\hline $\begin{array}{c}\text { Probability of } \\
\text { Failure, } P_{f}\end{array}$ & $\begin{array}{c}L_{\text {supply }}(\mathrm{m}), \\
\mathrm{CV}=5 \%\end{array}$ & $\begin{array}{c}\mathrm{L}_{\text {supply }}(\mathrm{m}), \\
\mathrm{CV}=10 \%\end{array}$ & $\begin{array}{c}\mathrm{L}_{\text {supply }}(\mathrm{m}), \\
\mathrm{CV}=15 \%\end{array}$ & $\begin{array}{c}\mathrm{L}_{\text {supply }}(\mathrm{m}), \\
\mathrm{CV}=\mathbf{2 0 \%}\end{array}$ & $\begin{array}{c}\mathrm{L}_{\text {supply }}(\mathrm{m}), \\
\mathrm{CV}=\mathbf{2 5 \%}\end{array}$ \\
\hline $1 \%$ & 316.9 & 397.2 & 492.9 & 608.5 & 751.8 \\
\hline $5 \%$ & 295.8 & 348.5 & 407.9 & 475.2 & 551.8 \\
\hline $10 \%$ & 285.0 & 324.6 & 368.0 & 415.7 & 468.2 \\
\hline $15 \%$ & 277.7 & 308.7 & 342.1 & 378.0 & 416.8 \\
\hline
\end{tabular}

Supply Length of TER vs Probability of Failure ( $G=+6 \%, V=140 \mathrm{~km} / \mathrm{hr}$ )

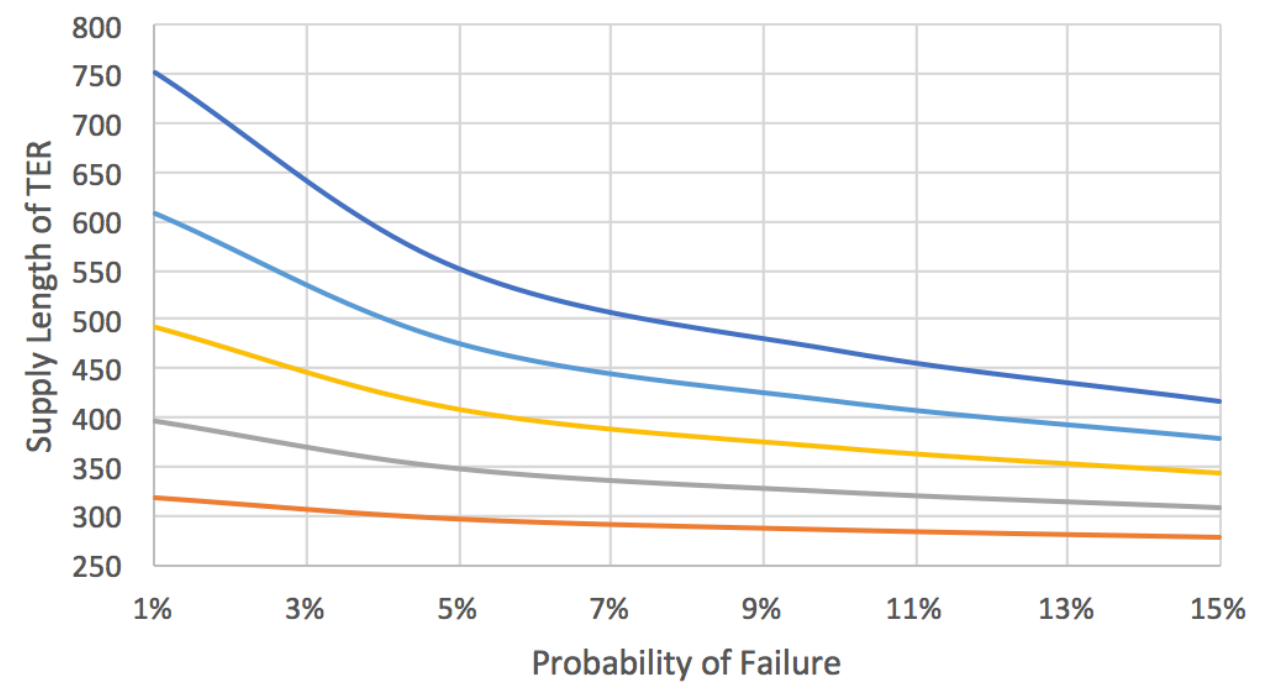

$\longrightarrow C V=5 \% \quad C V=10 \%-C V=15 \% \quad-C V=20 \% \quad-C V=25 \%$

Figure 50 - AFOSM Visual Representation of $L_{\text {supply }}$ for a TER using $G=+6 \%, V=140 \mathrm{~km} / \mathrm{hr}$, and $R=0.25 \mathrm{~kg} / \mathrm{kgGVM}$ 
Scenario 7 - AFOSM, G $=+8 \%, V=140 \mathrm{~km} / \mathrm{hr}$

Table $55-L_{\text {supply }}$ Values at Corresponding $P_{f}$ and CV Values

\begin{tabular}{|c|c|c|c|c|c|}
\hline $\begin{array}{l}\text { Probability of } \\
\text { Failure, } P_{f}\end{array}$ & $\begin{array}{c}\mathrm{L}_{\text {supply }}(\mathrm{m}) \\
\mathrm{CV}=5 \%\end{array}$ & $\begin{array}{l}L_{\text {supply }}(m) \\
C V=10 \%\end{array}$ & $\begin{array}{l}\mathrm{L}_{\text {supply }}(\mathrm{m}) \\
\mathrm{CV}=15 \%\end{array}$ & $\begin{array}{l}L_{\text {supply }}(m) \text {, } \\
C V=20 \%\end{array}$ & $\begin{array}{c}\mathrm{L}_{\text {supply }}(\mathrm{m}) \\
\mathrm{CV}=\mathbf{2 5} \%\end{array}$ \\
\hline $1 \%$ & 297.2 & 371.6 & 459.7 & 565.0 & 693.5 \\
\hline $5 \%$ & 277.5 & 326.5 & 381.5 & 443.4 & 513.5 \\
\hline $10 \%$ & 267.5 & 304.3 & 344.6 & 388.6 & 437.0 \\
\hline $15 \%$ & 260.7 & 289.6 & 320.6 & 353.9 & 389.7 \\
\hline
\end{tabular}

Supply Length of TER vs Probability of Failure

( $G=+8 \%, V=140 \mathrm{~km} / \mathrm{hr}$ )

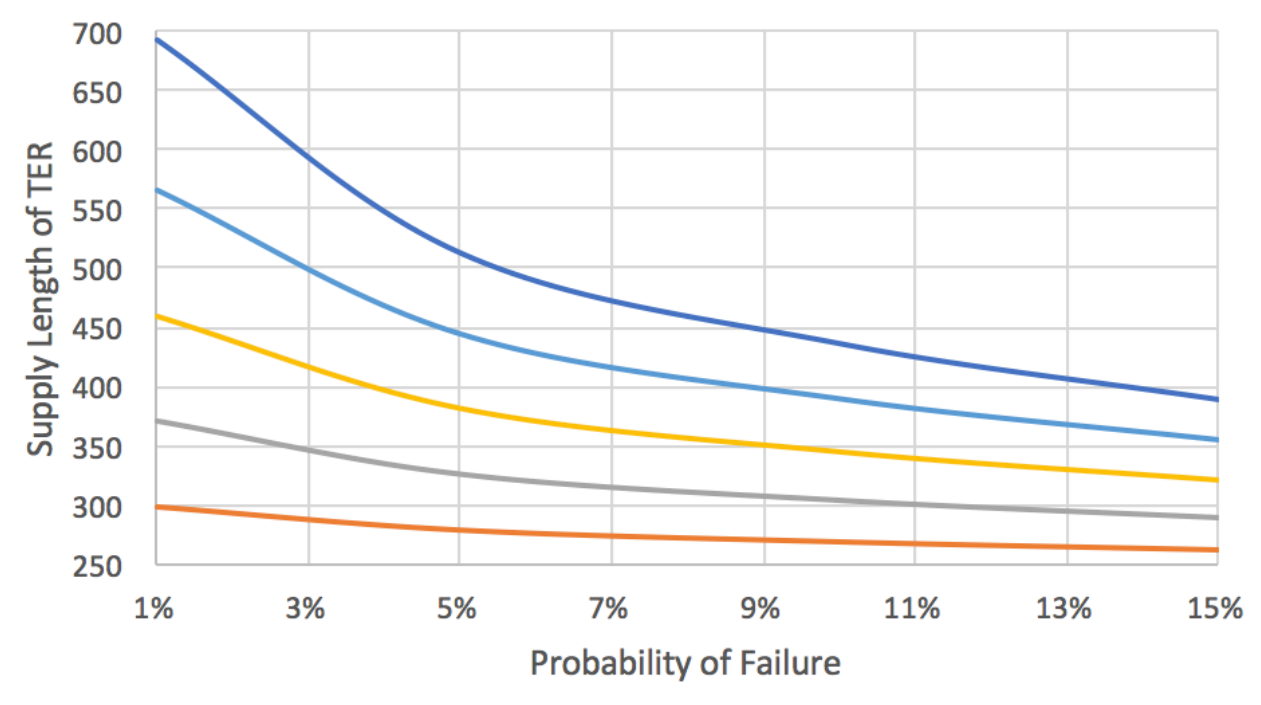

$\longrightarrow C V=5 \%-C V=10 \%-C V=15 \% \quad C V=20 \% \quad-C V=25 \%$

Figure 51 - AFOSM Visual Representation of $L_{\text {supply }}$ for a TER using $G=+8 \%, V=140 \mathrm{~km} / \mathrm{hr}$, and $R=0.25 \mathrm{~kg} / \mathrm{kgGVM}$ 
Scenario 8 - AFOSM, G $=+10 \%, V=140 \mathrm{~km} / \mathrm{hr}$

Table $56-L_{\text {supply }}$ Values at Corresponding $P_{f}$ and CV Values

\begin{tabular}{|c|c|c|c|c|c|}
\hline $\begin{array}{c}\text { Probability of } \\
\text { Failure, } P_{f}\end{array}$ & $\begin{array}{l}\mathrm{L}_{\text {supply }}(\mathrm{m}) \\
\mathrm{CV}=5 \%\end{array}$ & $\begin{array}{l}L_{\text {supply }}(m) \\
C V=10 \%\end{array}$ & $\begin{array}{l}L_{\text {supply }}(m) \\
C V=15 \%\end{array}$ & $\begin{array}{l}L_{\text {supply }}(m) \text {, } \\
C V=20 \%\end{array}$ & $\begin{array}{l}L_{\text {supply }}(m) \text {, } \\
C V=25 \%\end{array}$ \\
\hline $1 \%$ & 279.8 & 349.4 & 431.1 & 528.1 & 645.3 \\
\hline $5 \%$ & 261.5 & 307.3 & 358.5 & 416.0 & 480.8 \\
\hline $10 \%$ & 252.1 & 286.5 & 324.1 & 365.2 & 410.1 \\
\hline $15 \%$ & 245.7 & 272.7 & 301.7 & 332.8 & 366.2 \\
\hline
\end{tabular}

Supply Length of TER vs Probability of Failure ( $\mathrm{G}=+10 \%, \mathrm{~V}=140 \mathrm{~km} / \mathrm{hr}$ )

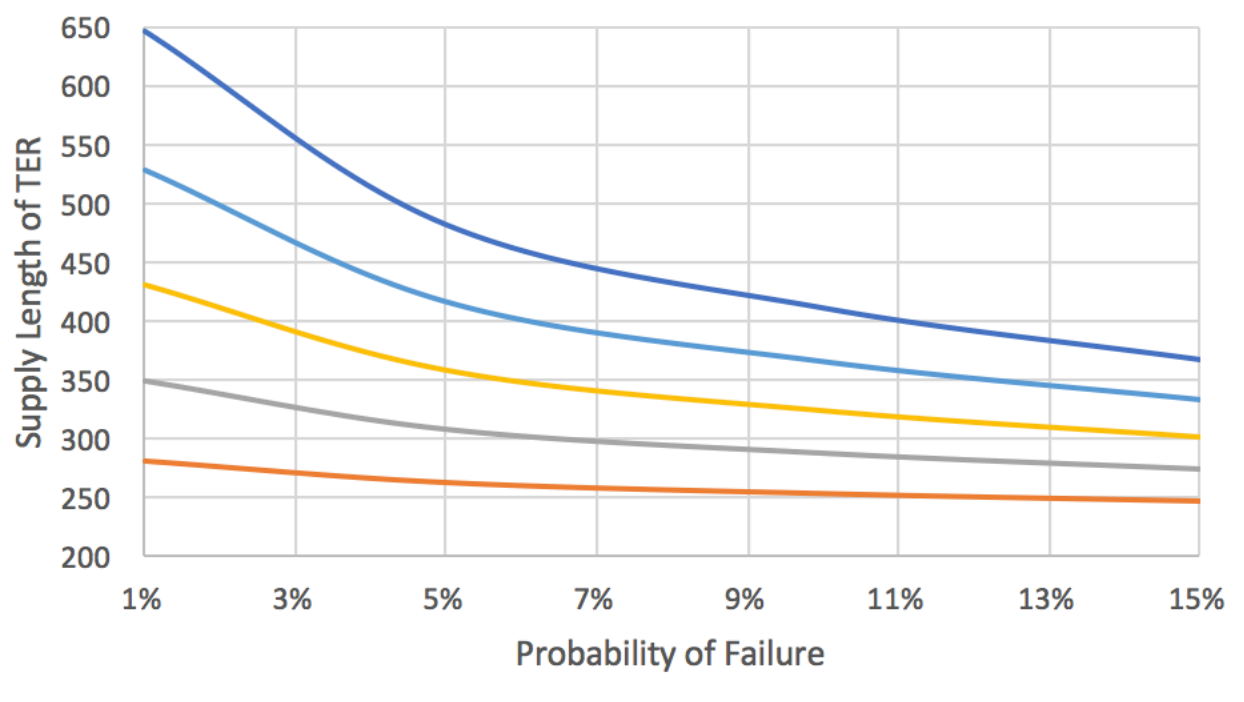

$\longrightarrow \mathrm{CV}=5 \%-\mathrm{CV}=10 \%-\mathrm{CV}=15 \% \quad \mathrm{CV}=20 \%-\mathrm{CV}=25 \%$

Figure 52 - AFOSM Visual Representation of $L_{\text {supply }}$ for a TER using $G=+10 \%, V=140 \mathrm{~km} / \mathrm{hr}$, and $R=0.25 \mathrm{~kg} / \mathrm{kgGVM}$ 
Scenario 9 - AFOSM, G = -2\%, V = $140 \mathrm{~km} / \mathrm{hr}$

Table $57-L_{\text {supply }}$ Values at Corresponding $P_{f}$ and CV Values

\begin{tabular}{|c|c|c|c|c|c|}
$\begin{array}{c}\text { Probability of } \\
\text { Failure, } P_{f}\end{array}$ & $\begin{array}{c}L_{\text {supply }}(\mathrm{m}), \\
\mathrm{CV}=\mathbf{5 \%}\end{array}$ & $\begin{array}{c}\mathrm{L}_{\text {supply }}(\mathrm{m}), \\
\mathrm{CV}=10 \%\end{array}$ & $\begin{array}{c}\mathrm{L}_{\text {supply }}(\mathrm{m}), \\
\mathrm{CV}=15 \%\end{array}$ & $\begin{array}{c}\mathrm{L}_{\text {supply }}(\mathrm{m}), \\
\mathrm{CV}=\mathbf{2 0 \%}\end{array}$ & $\begin{array}{c}\mathrm{L}_{\text {supply }}(\mathrm{m}), \\
\mathrm{CV}=\mathbf{2 5 \%}\end{array}$ \\
\hline $1 \%$ & 433.8 & 556.0 & 712.4 & 923.5 & 1169.8 \\
\hline $5 \%$ & 402.9 & 481.0 & 572.8 & 682.3 & 816.4 \\
\hline $10 \%$ & 387.2 & 445.2 & 510.7 & 585.0 & 670.7 \\
\hline $15 \%$ & 376.7 & 421.8 & 471.4 & 526.1 & 586.9 \\
\hline
\end{tabular}

Supply Length of TER vs Probability of Failure

( $G=-2 \%, V=140 \mathrm{~km} / \mathrm{hr}$ )

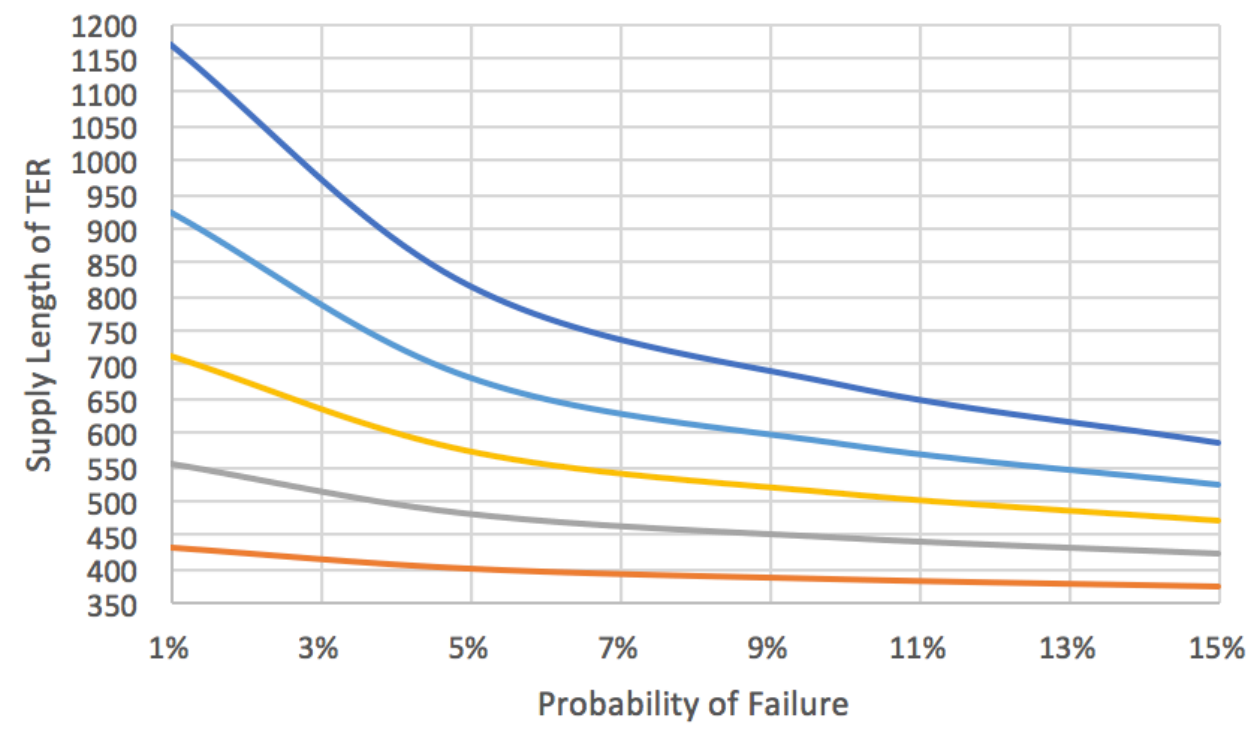

$\longrightarrow \mathrm{CV}=5 \%-\mathrm{CV}=10 \%-\mathrm{CV}=15 \%-\mathrm{CV}=20 \%-\mathrm{CV}=25 \%$

Figure 53 - AFOSM Visual Representation of $L_{\text {supply }}$ for a TER using $G=-2 \%, V=140 \mathrm{~km} / \mathrm{hr}$, and $R=0.25 \mathrm{~kg} / \mathrm{kgGVM}$ 
Scenario $10-A F O S M, G=-4 \%, V=140 \mathrm{~km} / \mathrm{hr}$

Table $58-L_{\text {supply }}$ Values at Corresponding $P_{f}$ and CV Values

\begin{tabular}{|c|c|c|c|c|c|}
\hline $\begin{array}{c}\text { Probability of } \\
\text { Failure, } P_{f}\end{array}$ & $\begin{array}{c}L_{\text {supply }}(\mathrm{m}), \\
\mathrm{CV}=5 \%\end{array}$ & $\begin{array}{c}\mathrm{L}_{\text {supply }}(\mathrm{m}), \\
\mathrm{CV}=10 \%\end{array}$ & $\begin{array}{c}\mathrm{L}_{\text {supply }}(\mathrm{m}), \\
\mathrm{CV}=15 \%\end{array}$ & $\begin{array}{c}\mathrm{L}_{\text {supply }}(\mathrm{m}), \\
\mathrm{CV}=20 \%\end{array}$ & $\begin{array}{c}\mathrm{L}_{\text {supply }}(\mathrm{m}), \\
\mathrm{CV}=25 \%\end{array}$ \\
\hline $1 \%$ & 479.0 & 621.4 & 811.6 & 1086.1 & 1229.4 \\
\hline $5 \%$ & 443.6 & 533.5 & 641.4 & 774.2 & 944.3 \\
\hline $10 \%$ & 425.9 & 492.1 & 568.0 & 656.1 & 759.9 \\
\hline $15 \%$ & 413.9 & 465.2 & 522.3 & 586.2 & 658.3 \\
\hline
\end{tabular}

Supply Length of TER vs Probability of Failure

( $G=-4 \%, V=140 \mathrm{~km} / \mathrm{hr}$ )

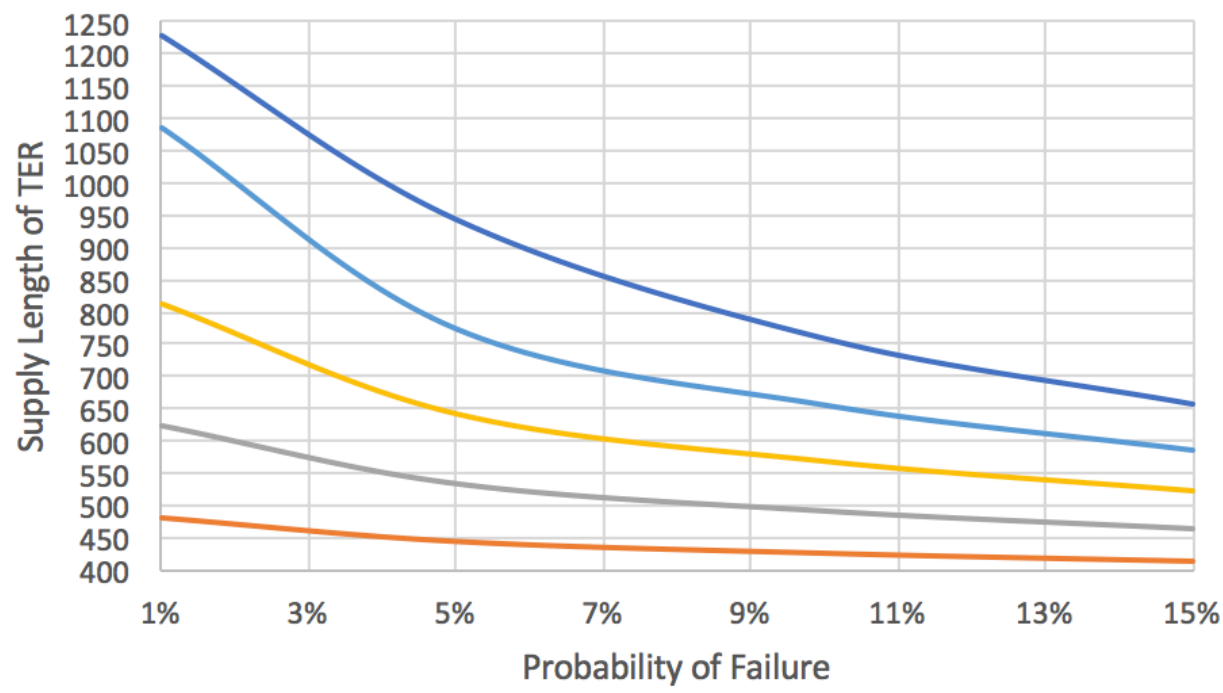

$\longrightarrow C V=5 \%-C V=10 \%-C V=15 \%-C V=20 \%-C V=25 \%$

Figure 54 - AFOSM Visual Representation of $L_{\text {supply }}$ for a TER using $\mathrm{G}=-4 \%, \mathrm{~V}=140 \mathrm{~km} / \mathrm{hr}$, and $R=0.25 \mathrm{~kg} / \mathrm{kgGVM}$ 
Scenario $11-A F O S M, G=-6 \%, V=140 \mathrm{~km} / \mathrm{hr}$

Table $59-L_{\text {supply }}$ Values at Corresponding $P_{f}$ and CV Values

\begin{tabular}{|c|c|c|c|c|c|}
\hline $\begin{array}{c}\text { Probability of } \\
\text { Failure, } P_{f}\end{array}$ & $\begin{array}{l}\mathrm{L}_{\text {supply }}(\mathrm{m}) \\
\mathrm{CV}=5 \%\end{array}$ & $\begin{array}{l}L_{\text {supply }}(m) \\
C V=10 \%\end{array}$ & $\begin{array}{l}L_{\text {supply }}(m), \\
C V=15 \%\end{array}$ & $\begin{array}{l}L_{\text {supply }}(m), \\
C V=20 \%\end{array}$ & $\begin{array}{c}\mathrm{L}_{\text {supply }}(\mathrm{m}) \text {, } \\
\mathrm{CV}=25 \%\end{array}$ \\
\hline $1 \%$ & 535.6 & 707.3 & 952.1 & 1246.8 & 1278.9 \\
\hline $5 \%$ & 494.1 & 600.3 & 732.1 & 902.4 & 1135.1 \\
\hline $10 \%$ & 473.4 & 551.0 & 641.9 & 750.5 & 883.5 \\
\hline $15 \%$ & 459.5 & 519.3 & 586.9 & 664.0 & 753.3 \\
\hline
\end{tabular}

Supply Length of TER vs Probability of Failure ( $G=-6 \%, V=140 \mathrm{~km} / \mathrm{hr}$ )

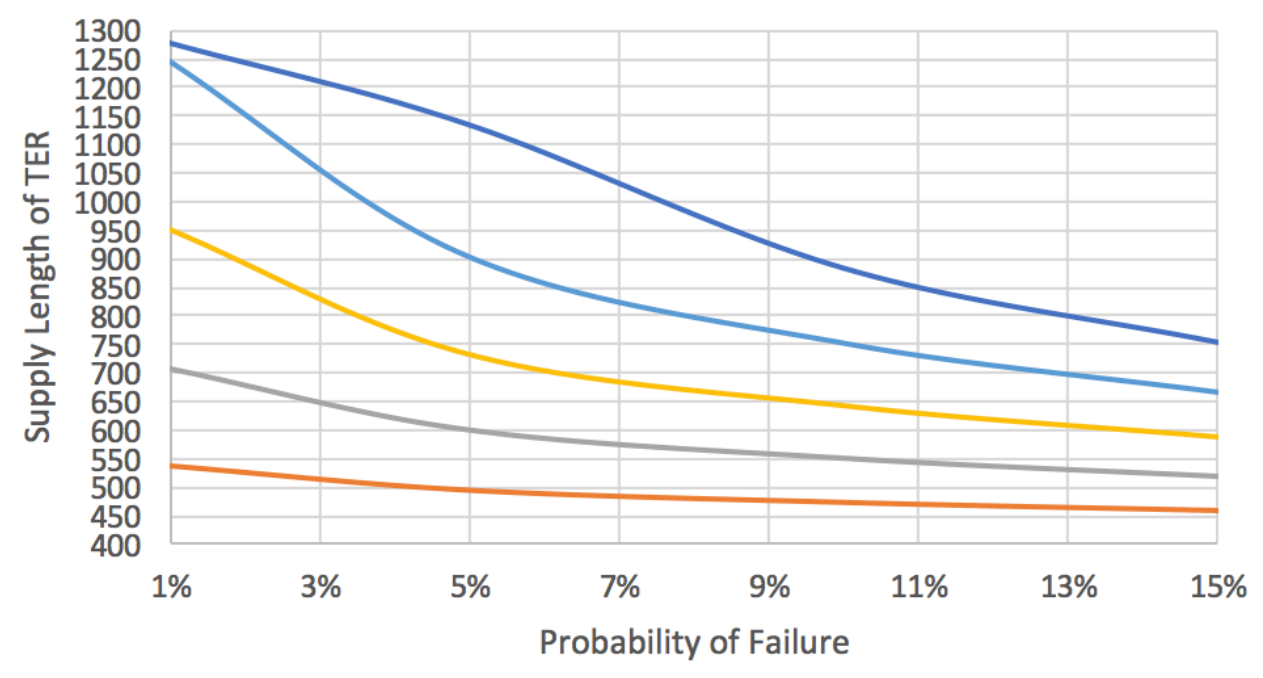

$\longrightarrow C V=5 \%-C V=10 \%-C V=15 \% \quad C V=20 \% \quad-C V=25 \%$

Figure 55 - AFOSM Visual Representation of $L_{\text {supply }}$ for a TER using $G=-6 \%, V=140 \mathrm{~km} / \mathrm{hr}$, and $R=0.25 \mathrm{~kg} / \mathrm{kgGVM}$ 
Scenario 12 - AFOSM, G = -8\%, V = $140 \mathrm{~km} / \mathrm{hr}$

Table $60-L_{\text {supply }}$ Values at Corresponding $P_{f}$ and CV Values

\begin{tabular}{|c|c|c|c|c|c|}
\hline $\begin{array}{c}\text { Probability of } \\
\text { Failure, } P_{f}\end{array}$ & $\begin{array}{c}L_{\text {supply }}(\mathrm{m}), \\
\mathrm{CV}=5 \%\end{array}$ & $\begin{array}{c}\mathrm{L}_{\text {supply }}(\mathrm{m}), \\
\mathrm{CV}=10 \%\end{array}$ & $\begin{array}{c}\mathrm{L}_{\text {supply }}(\mathrm{m}), \\
\mathrm{CV}=15 \%\end{array}$ & $\begin{array}{c}\mathrm{L}_{\text {supply }}(\mathrm{m}), \\
\mathrm{CV}=\mathbf{2 0 \%}\end{array}$ & $\begin{array}{c}\mathrm{L}_{\text {supply }}(\mathrm{m}), \\
\mathrm{CV}=\mathbf{2 5 \%}\end{array}$ \\
\hline $1 \%$ & 608.5 & 826.1 & 1169.4 & 1321.9 & 1336.4 \\
\hline $5 \%$ & 558.2 & 688.7 & 858.9 & 1096.2 & 1304.2 \\
\hline $10 \%$ & 533.4 & 627.5 & 741.4 & 883.5 & 1068.8 \\
\hline $15 \%$ & 516.9 & 588.7 & 671.9 & 769.7 & 887.2 \\
\hline
\end{tabular}

Supply Length of TER vs Probability of Failure ( $\mathrm{G}=-8 \%, \mathrm{~V}=140 \mathrm{~km} / \mathrm{hr}$ )

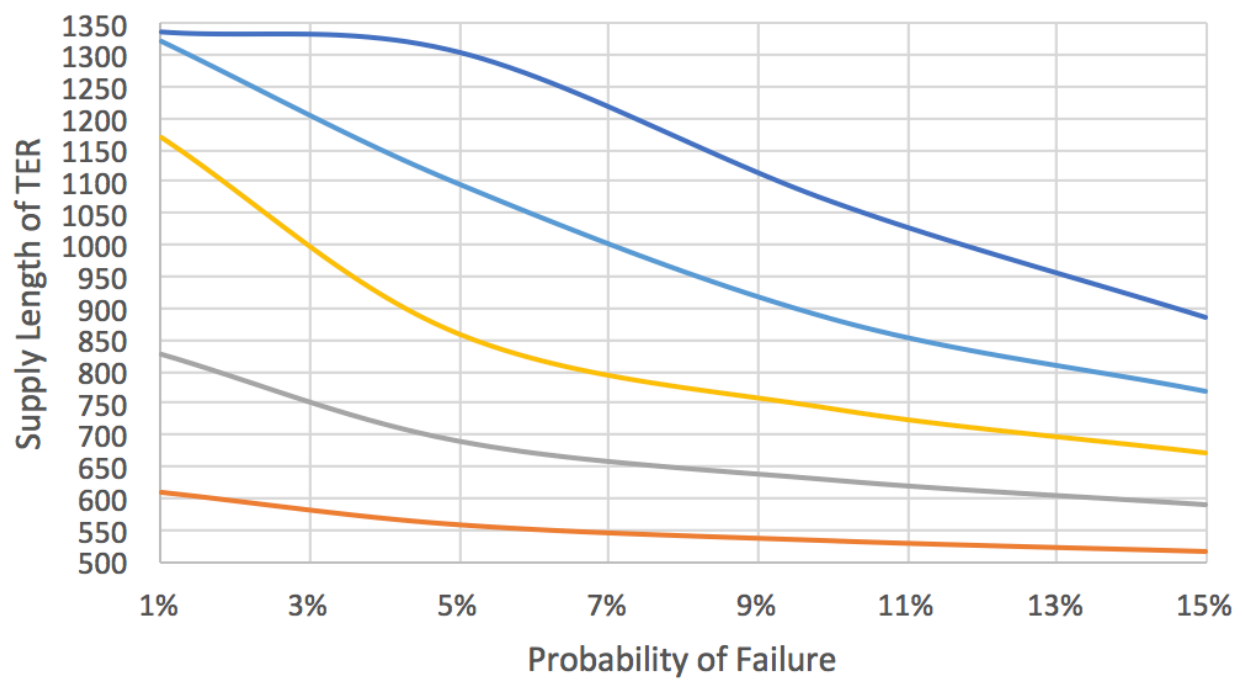

$\longrightarrow C V=5 \%-C V=10 \%-C V=15 \%-C V=20 \%-C V=25 \%$

Figure 56 - AFOSM Visual Representation of $L_{\text {supply }}$ for a TER using $G=-8 \%, V=140 \mathrm{~km} / \mathrm{hr}$, and $R=0.25 \mathrm{~kg} / \mathrm{kgGVM}$ 
Scenario 13 - AFOSM, G = -10\%, V= $140 \mathrm{~km} / \mathrm{hr}$

Table $61-L_{\text {supply }}$ Values at Corresponding $P_{f}$ and CV Values

\begin{tabular}{|c|c|c|c|c|c|}
\hline $\begin{array}{c}\text { Probability of } \\
\text { Failure, } P_{f}\end{array}$ & $\begin{array}{c}\mathrm{L}_{\text {supply }}(\mathrm{m}) \\
\mathrm{CV}=5 \%\end{array}$ & $\begin{array}{l}L_{\text {supply }}(m), \\
C V=10 \%\end{array}$ & $\begin{array}{l}L_{\text {supply }}(m), \\
C V=15 \%\end{array}$ & $\begin{array}{l}L_{\text {supply }}(m), \\
C V=20 \%\end{array}$ & $\begin{array}{c}\mathrm{L}_{\text {supply }}(\mathrm{m}) \text {, } \\
\mathrm{CV}=25 \%\end{array}$ \\
\hline $1 \%$ & 706.8 & 1003.0 & 1376.7 & 1403.7 & 1413.2 \\
\hline $5 \%$ & 642.8 & 811.9 & 1050.8 & 1359.9 & 1396.0 \\
\hline $10 \%$ & 611.8 & 731.3 & 883.4 & 1087.3 & 1346.8 \\
\hline $15 \%$ & 591.2 & 681.4 & 789.5 & 922.7 & 1093.0 \\
\hline
\end{tabular}

Supply Length of TER vs Probability of Failure

( $G=-10 \%, V=140 \mathrm{~km} / \mathrm{hr}$ )

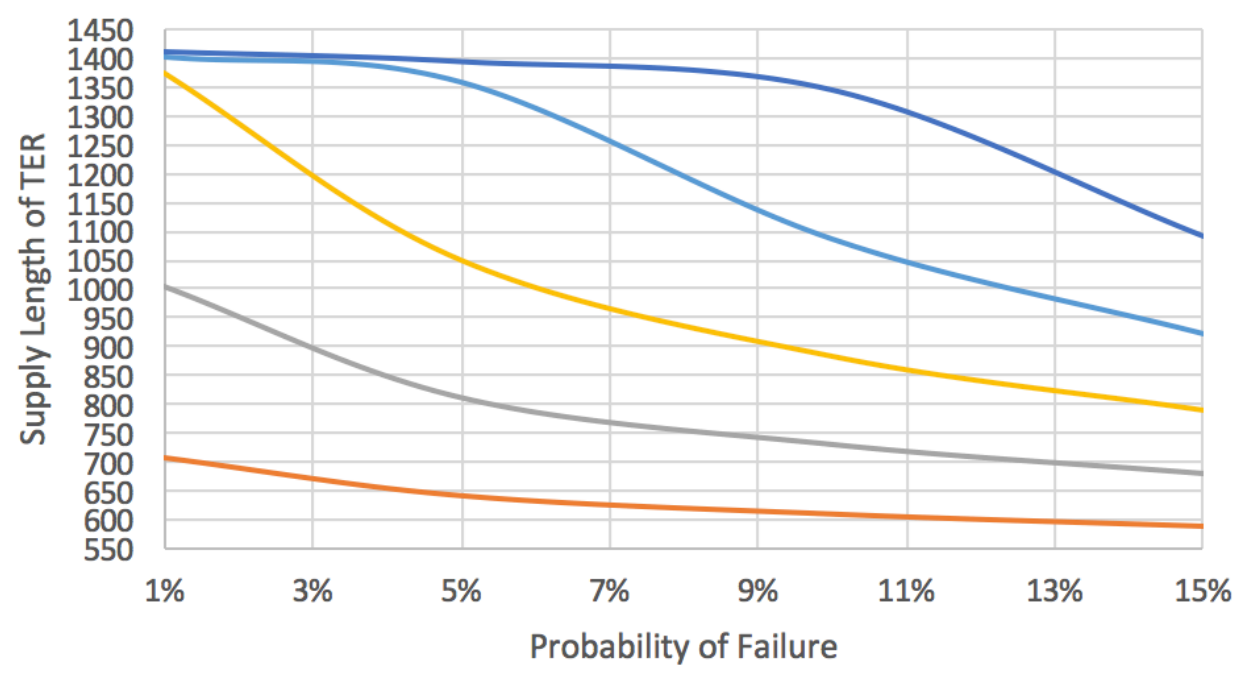

$-C V=5 \%-C V=10 \%-C V=15 \%-C V=20 \%-C V=25 \%$

Figure 57 - AFOSM Visual Representation of $\mathrm{L}_{\text {supply }}$ for a TER using $\mathrm{G}=-10 \%, \mathrm{~V}=140 \mathrm{~km} / \mathrm{hr}$, and R= $0.25 \mathrm{~kg} / \mathrm{kgGVM}$ 


\section{Appendix D-Case 4 Analysis Results}

Scenario 2 - AFOSM, $\mathrm{G}_{1}=0 \%, \mathrm{G}_{2}=+4 \%, \mathrm{~V}=120 \mathrm{~km} / \mathrm{hr}$

Table $62-L_{\text {supply }}$ Values at Corresponding $P_{f}$ and CV Values

\begin{tabular}{|c|c|c|c|c|c|}
\hline $\begin{array}{l}\text { Probability of } \\
\text { Failure, } P_{f}\end{array}$ & $\begin{array}{c}L_{\text {supply }}(m) \\
\text { CV }=5 \%\end{array}$ & $\begin{array}{l}L_{\text {supply }}(\mathrm{m}) \\
\mathrm{CV}=10 \%\end{array}$ & $\begin{array}{l}L_{\text {supply }}(\mathrm{m}) \\
\text { CV }=15 \%\end{array}$ & $\begin{array}{l}L_{\text {supply }}(\mathrm{m}) \\
C V=20 \%\end{array}$ & $\begin{array}{l}L_{\text {supply }}(m), \\
C V=25 \%\end{array}$ \\
\hline $1 \%$ & 249.6 & 313.8 & 391.0 & 485.7 & 605.6 \\
\hline $5 \%$ & 232.8 & 274.8 & 322.4 & 376.6 & 439.1 \\
\hline $10 \%$ & 224.2 & 255.7 & 290.3 & 328.6 & 371.0 \\
\hline $15 \%$ & 218.4 & 243.1 & 269.6 & 298.4 & 329.5 \\
\hline
\end{tabular}

Supply Length of TER vs Probability of Failure

$\left(G_{1}=0 \%, G_{2}=+4 \%, V=120 \mathrm{~km} / \mathrm{hr}\right)$

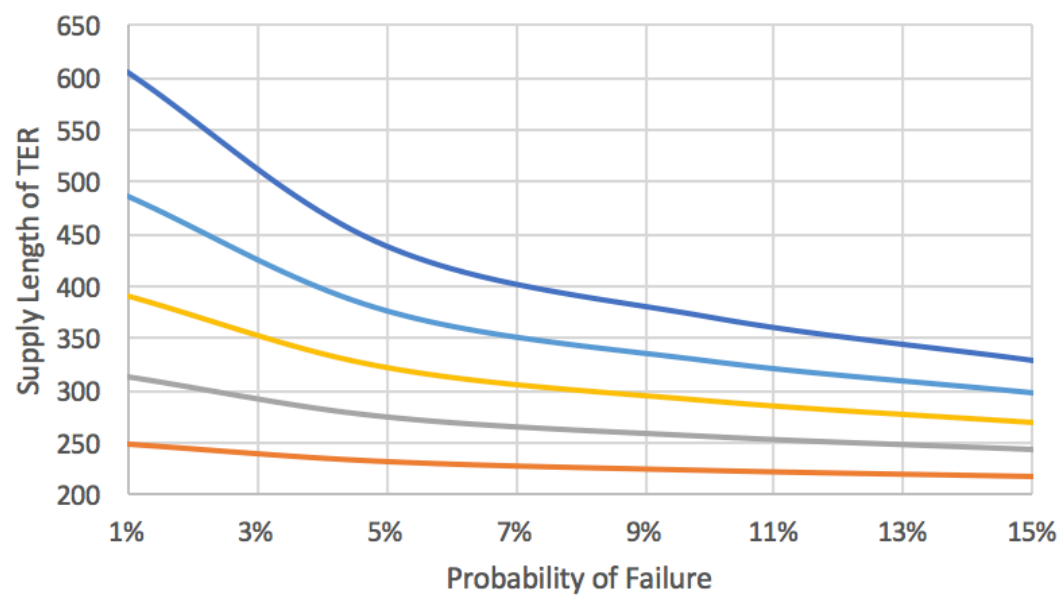

$-C V=5 \%-C V=10 \%-C V=15 \%-C V=20 \%-C V=25 \%$

Figure 58 - AFOSM Visual Representation of $L_{\text {supply }}$ for a TER using $G_{1}=0 \%, G_{2}=+4 \%, V=120 \mathrm{~km} / \mathrm{hr}$, and $R=0.25 \mathrm{~kg} / \mathrm{kgGVM}$ 
Scenario $3-A F O S M, G_{1}=0 \%, G_{2}=+3 \%, V=140 \mathrm{~km} / \mathrm{hr}$

Table $63-L_{\text {supply }}$ Values at Corresponding $P_{f}$ and CV Values

\begin{tabular}{|c|c|c|c|c|c|}
\hline $\begin{array}{c}\text { Probability of } \\
\text { Failure, } P_{f}\end{array}$ & $\begin{array}{c}L_{\text {supply }}(\mathrm{m}), \\
\mathrm{CV}=5 \%\end{array}$ & $\begin{array}{c}\mathrm{L}_{\text {supply }}(\mathrm{m}), \\
\mathrm{CV}=10 \%\end{array}$ & $\begin{array}{c}\mathrm{L}_{\text {supply }}(\mathrm{m}), \\
\mathrm{CV}=15 \%\end{array}$ & $\begin{array}{c}\mathrm{L}_{\text {supply }}(\mathrm{m}), \\
\mathrm{CV}=20 \%\end{array}$ & $\begin{array}{c}\mathrm{L}_{\text {supply }}(\mathrm{m}), \\
\mathrm{CV}=\mathbf{2 5 \%}\end{array}$ \\
\hline $1 \%$ & 352.3 & 443.8 & 554.7 & 691.8 & 868.0 \\
\hline $5 \%$ & 328.4 & 388.1 & 456.1 & 533.9 & 624.1 \\
\hline $10 \%$ & 316.3 & 361.0 & 410.3 & 465.0 & 525.9 \\
\hline $15 \%$ & 308.0 & 343.0 & 380.8 & 421.8 & 466.3 \\
\hline
\end{tabular}

Supply Length of TER vs Probability of Failure

$\left(G_{1}=0 \%, G_{2}=+3 \%, V=140 \mathrm{~km} / \mathrm{hr}\right)$

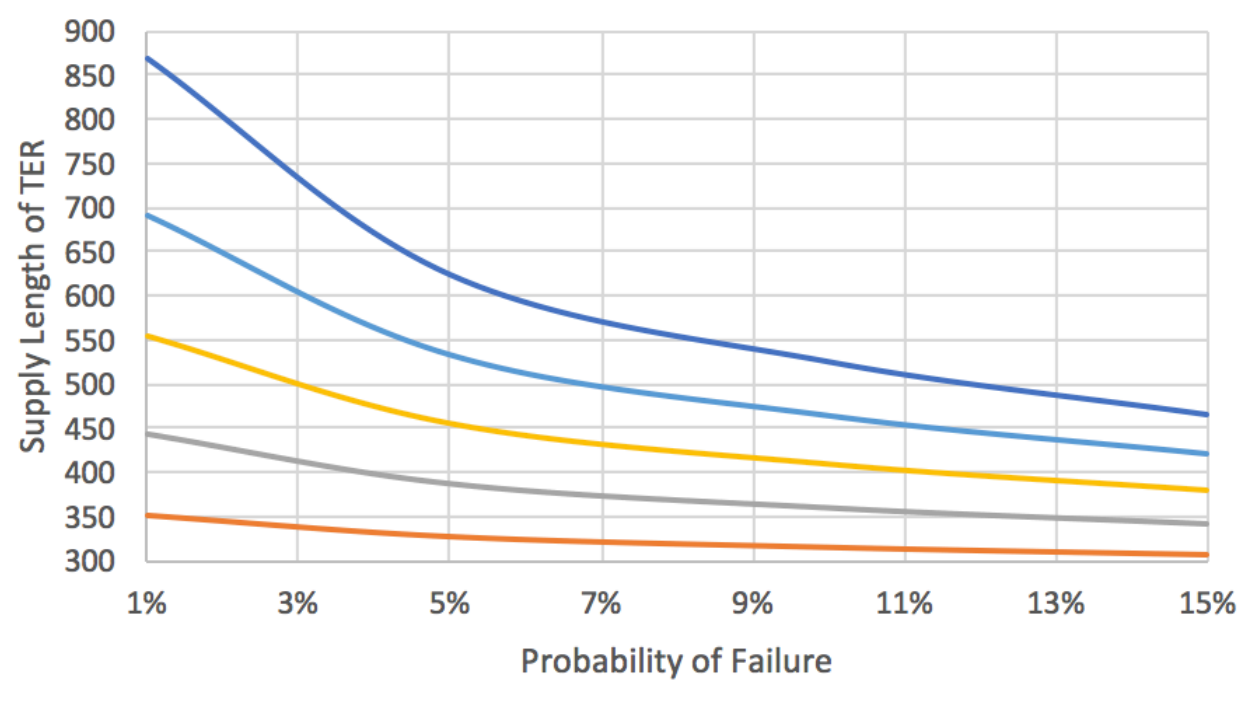

$\longrightarrow C V=5 \%-C V=10 \%-C V=15 \%-C V=20 \%-C V$

Figure 59 - AFOSM Visual Representation of $L_{\text {supply }}$ for a TER using $G_{1}=0 \%, G_{2}=+3 \%, V=140 \mathrm{~km} / \mathrm{hr}$, and $R=0.25 \mathrm{~kg} / \mathrm{kgGVM}$ 
Scenario 4 - AFOSM, $\mathrm{G}_{1}=0 \%, \mathrm{G}_{2}=+2 \%, \mathrm{~V}=140 \mathrm{~km} / \mathrm{hr}$

Table $64-L_{\text {supply }}$ Values at Corresponding $P_{f}$ and CV Values

\begin{tabular}{|c|c|c|c|c|c|}
\hline $\begin{array}{c}\text { Probability of } \\
\text { Failure, } P_{f}\end{array}$ & $\begin{array}{c}L_{\text {supply }}(m) \\
C V=5 \%\end{array}$ & $\begin{array}{l}L_{\text {supply }}(m) \\
C V=10 \%\end{array}$ & $\begin{array}{l}L_{\text {supply }}(m) \\
C V=15 \%\end{array}$ & $\begin{array}{l}L_{\text {supply }}(m), \\
C V=20 \%\end{array}$ & $\begin{array}{l}L_{\text {supply }}(m) \text {, } \\
C V=25 \%\end{array}$ \\
\hline $1 \%$ & 365.9 & 462.1 & 579.4 & 726.3 & 918.3 \\
\hline $5 \%$ & 340.9 & 403.5 & 475.0 & 557.4 & 653.5 \\
\hline $10 \%$ & 328.2 & 375.0 & 426.8 & 484.4 & 548.8 \\
\hline $15 \%$ & 319.6 & 356.2 & 395.8 & 438.9 & 485.8 \\
\hline
\end{tabular}

Supply Length of TER vs Probability of Failure

$\left(G_{1}=0 \%, G_{2}=+2 \%, V=140 \mathrm{~km} / \mathrm{hr}\right)$

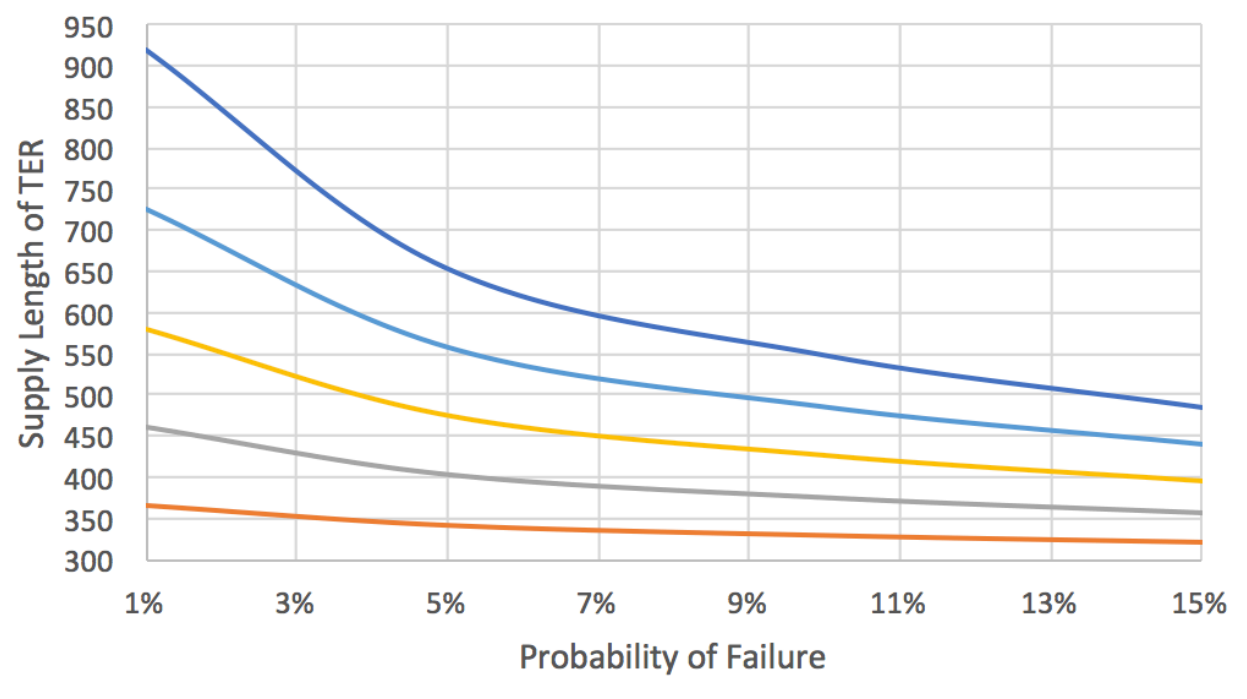

$-\mathrm{CV}=5 \%-\mathrm{CV}=10 \% \quad \mathrm{CV}=15 \% \quad \mathrm{CV}=20 \% \quad-\mathrm{CV}=25 \%$

Figure 60 - AFOSM Visual Representation of $L_{\text {supply }}$ for a TER using $G_{1}=0 \%, G_{2}=+2 \%, V=140 \mathrm{~km} / \mathrm{hr}$, and $R=0.25 \mathrm{~kg} / \mathrm{kgGVM}$ 
Scenario 5 - AFOSM, $\mathrm{G}_{1}=0 \%, \mathrm{G}_{2}=+1 \%, \mathrm{~V}=140 \mathrm{~km} / \mathrm{hr}$

Table $65-L_{\text {supply }}$ Values at Corresponding $P_{f}$ and CV Values

\begin{tabular}{|c|c|c|c|c|c|}
\hline $\begin{array}{c}\text { Probability of } \\
\text { Failure, } P_{f}\end{array}$ & $\begin{array}{c}L_{\text {supply }}(\mathrm{m}), \\
\mathrm{CV}=5 \%\end{array}$ & $\begin{array}{c}\mathrm{L}_{\text {supply }}(\mathrm{m}), \\
\mathrm{CV}=10 \%\end{array}$ & $\begin{array}{c}\mathrm{L}_{\text {supply }}(\mathrm{m}), \\
\mathrm{CV}=15 \%\end{array}$ & $\begin{array}{c}\mathrm{L}_{\text {supply }}(\mathrm{m}), \\
\mathrm{CV}=20 \%\end{array}$ & $\begin{array}{c}\mathrm{L}_{\text {supply }}(\mathrm{m}), \\
\mathrm{CV}=\mathbf{2 5 \%}\end{array}$ \\
\hline $1 \%$ & 380.7 & 482.1 & 606.9 & 765.3 & 976.9 \\
\hline $5 \%$ & 354.5 & 420.2 & 495.8 & 583.4 & 686.5 \\
\hline $10 \%$ & 341.2 & 390.3 & 444.8 & 505.8 & 574.2 \\
\hline $15 \%$ & 332.1 & 370.5 & 412.1 & 457.6 & 507.3 \\
\hline
\end{tabular}

Supply Length of TER vs Probability of Failure

$\left(G_{1}=0 \%, G_{2}=+1 \%, V=140 \mathrm{~km} / \mathrm{hr}\right)$

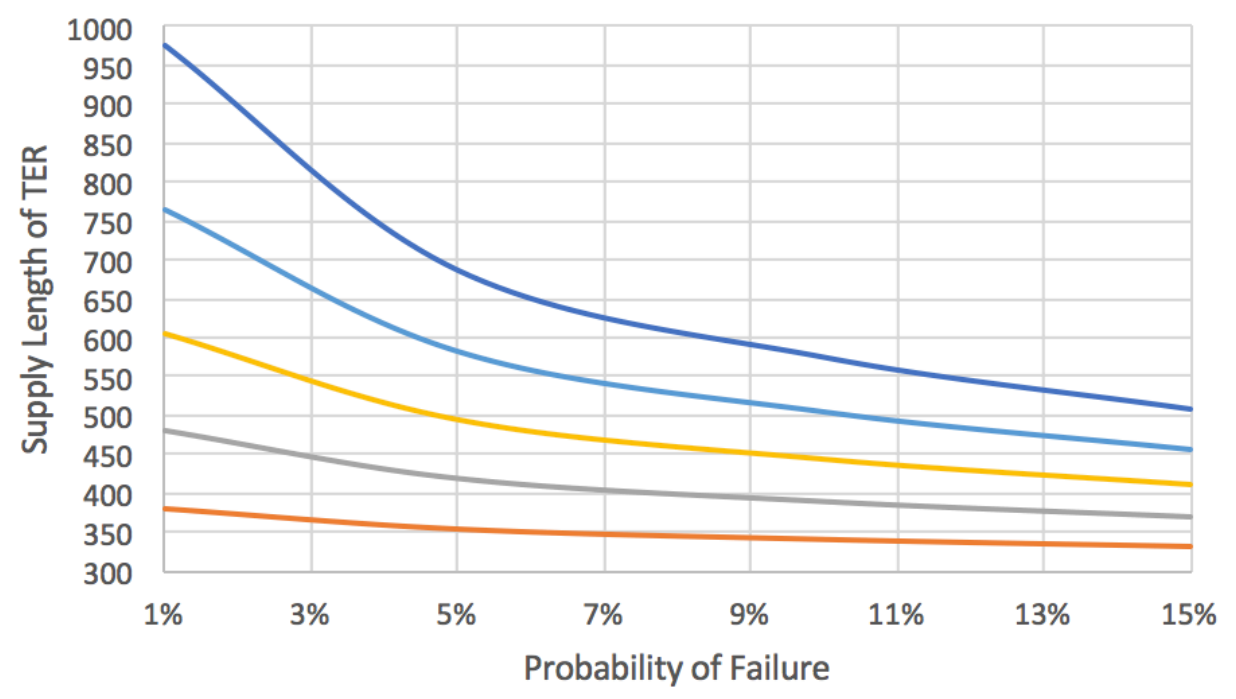

$\longrightarrow C V=5 \%-C V=10 \%-C V=15 \%-C V=20 \%-C V=25 \%$

Figure 61 - AFOSM Visual Representation of $L_{\text {supply }}$ for a TER using $G_{1}=0 \%, G_{2}=+1 \%, V=140 \mathrm{~km} / \mathrm{hr}$, and $R=0.25 \mathrm{~kg} / \mathrm{kgGVM}$ 


\section{References}

[1] Washington State Department of Transportation, "WSDOT Design Manual M 22-01.12," Washington State Department of Transportation, Olympia, 2015.

[2] R. Hanley, "Connecticut Department of Transportation's Truck Escape Ramp (TER) - Avon, CT," Connecticut Department of Transportation, Rocky Hill.

[3] Transportation Association of Canada, Geometric Design Guide for Canadian Roads, Ottawa: Transportation Association of Canada, 1999.

[4] D.K. Witheford, "NCHRP Synthesis 178: Truck Escape Ramps, A Synthesis of Highway Practice," Transportation Research Board, National Research Council, Washington, D.C., 1992.

[5] E. Tye, "Design Gude for Truck Escape Ramps," State of California Department of Transportation, 1986.

[6] Ministry of Transportation Ontario, "Highway 11 Runaway Truck Ramp Now Open," Government of Ontario, 25 June 2009. [Online]. Available: https://news.ontario.ca/mto/en/2009/06/highway-11-runaway-truck-rampnow-open.html. [Accessed 20 July 2016].

[7] State of Arizona Department of Transportation, "Full-Scale Arrester Bed Testing Leads to More Cost-Effective Design," TR News, no. 166, pp. 20-21, May-June 1993.

[8] R. Hayden, "Mt. Vernon Canyon Runaway Truck Escape Ramp," Colorado Department of Highways, December 1982. [Online]. Available: https://trid.trb.org/view.aspx?id=194035. [Accessed 23 July 2016].

[9] Wyoming Department of Transportation, "Catch Net System for Runaway Trucks," WYDOT, [Online]. Available: http://www.wyoroad.info/Highway/RunawayTruckRampInfo2013.pdf. [Accessed 16 July 2016 ]. 
[10] G. N. Smith, Probability and Statistics in Civil Engineering: An Introduction, New York: Nichols Pub. Co., 1986.

[11] University of Maryland, "Risk Analysis in Engineering and Economics," [Online]. Available: http://www.assakkaf.com/Courses/ENCE620/Lectures/Chapter4a.pdf. [Accessed 20 July 2016].

[12] R. Patev, "Introduction to Engineering Reliability," [Online]. Available: https://www.palisade.com/downloads/pdf/EngineeringReliabilityConcepts.pdf. [Accessed 26 July 2016 ].

[13] S. Easa, "Reliability Approach to Intersection Sight Distance Design," Transportation Research Record Journal of the Transportation Research Board, January 2000.

[14] E. Villegas, "Development of LRFD Driven Pile Resistance Factor by First Order Second Moment Method in Alabama Soils," University of South Alabama, 2015.

[15] Terje Haukaas, "Mean-value First-order Second-moment Method (MVFOSM)," University of British Columbia, Vancouver, 2014.

[16] The University of Arizona, "Standard Normal Distribution," [Online]. Available: http://math.arizona.edu/ rsims/ma464/standardnormaltable.pdf. [Accessed 16 July 2016].

[17] HDR Engineering, "Truck Escape Ramp Study," Arizona Department of Transportation, 2003.

[18] K. A. J Pigman, "Evaluation of Truck Escape Ramps," Kentucky Transportation Cabinet, 1985.

[19] Washington State Department of Transportation, "Design Manual, M 22-01.12," WSDOT, 2015.

[20] Ministry of Transportation Ontario, "Highway 11 Runaway Truck Ramp Now Open," MTO, 25 June 2009. [Online]. Available: https://news.ontario.ca/mto/en/2009/06/highway-11-runaway-truck-ramp-nowopen.html. [Accessed 24 July 2016]. 